\title{
Expedition 342 summary ${ }^{1}$
}

R.D. Norris, P.A. Wilson, P. Blum, A. Fehr, C. Agnini, A. Bornemann, S. Boulila, P.R. Bown, C. Cournede, O. Friedrich, A.K. Ghosh, C.J. Hollis, P.M. Hull, K. Jo, C.K. Junium, M. Kaneko, D. Liebrand, P.C. Lippert, Z. Liu, H. Matsui, K. Moriya, H. Nishi, B.N. Opdyke, D. Penman, B. Romans, H.D. Scher, P. Sexton, H. Takagi, S.K. Turner, J.H. Whiteside, T. Yamaguchi, and Y. Yamamoto ${ }^{2}$

\section{Chapter contents}

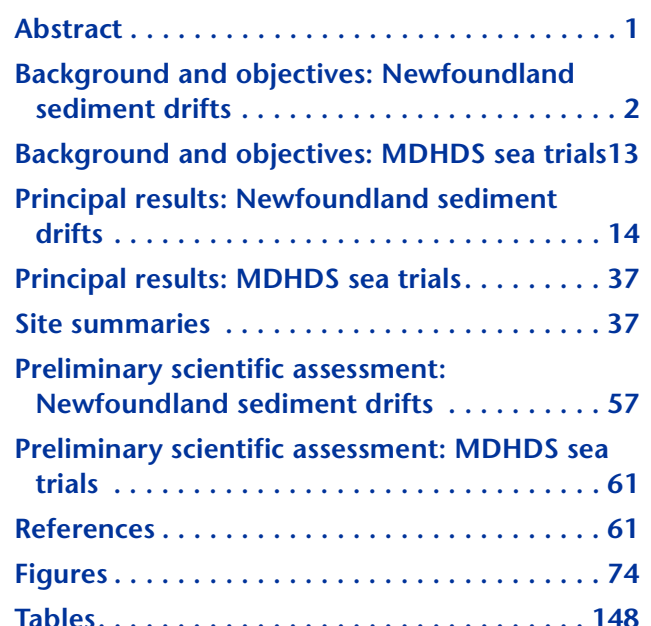

${ }^{1}$ Norris, R.D., Wilson, P.A., Blum, P., Fehr, A., Agnini, C., Bornemann, A., Boulila, S., Bown, P.R., Cournede, C., Friedrich, O., Ghosh, A.K., Hollis, C.J., Hull, P.M., Jo, K., Junium, C.K., Kaneko, M., Liebrand, D., Lippert, P.C., Liu, Z., Matsui, H., Moriya, K., Nishi, H., Opdyke, B.N., Penman, D., Romans, B., Scher, H.D., Sexton, P., Takagi, H., Turner, S.K., Whiteside, J.H., Yamaguchi, T., and Yamamoto, Y., 2014. Expedition 342 summary. In Norris, R.D., Wilson, P.A., Blum, P., and the Expedition 342 Scientists, Proc. IODP, 342: College Station, TX (Integrated Ocean Drilling Program). doi:10.2204/iodp.proc.342.101.2014

${ }^{2}$ Expedition 342 Scientists' addresses.

\section{Abstract}

Integrated Ocean Drilling Program Expedition 342 was designed to recover Paleogene sedimentary sequences with unusually high deposition rates across a wide range of water depths (Sites U1403U1411). The drilling area is positioned to capture sedimentary and geochemical records of ocean chemistry and overturning circulation beneath the flow of the Deep Western Boundary Current in the northwest Atlantic Ocean. In addition, two operational days were dedicated to a sea trial of the Motion Decoupled Hydraulic Delivery System (MDHDS) developmental tool (Site U1402).

The expedition was primarily targeted at reconstructing the Paleogene carbonate compensation depth (CCD) in the North Atlantic for reference to recently obtained high-fidelity records of the CCD in the equatorial Pacific. The site in the deepest water (Site U1403) was at a paleodepth of $\sim 4.5 \mathrm{~km} 50 \mathrm{~m}$.y. ago, whereas the site in the shallowest water (Site U1408) can be backtracked to a paleodepth of $2.5 \mathrm{~km}$ at the same time. The combination of sites yields a record of the history of CCD change over a $2 \mathrm{~km}$ depth range from the ocean abyss to middle-range water depths. Notable findings include the discovery of intermittent calcareous sediments in the Cretaceous, Paleocene, and early to middle Eocene at $4.5 \mathrm{~km}$ paleodepth, suggesting a deep Atlantic CCD during these times. We find evidence of carbonate deposition events following the Cretaceous/Paleogene $(\mathrm{K} / \mathrm{Pg})$ boundary mass extinction, the Paleocene/Eocene Thermal Maximum, and the EoceneOligocene transition (EOT). These deposition events may reflect the rebalancing of ocean alkalinity after mass extinctions or abrupt global climate change. Intervals during which the CCD appears to have been markedly shallow in the North Atlantic include the Early Eocene Climatic Optimum, the late Eocene, and the middle Oligocene.

A second major objective of Expedition 342 was to recover clayrich sequences with well-preserved microfossils and high rates of accumulation in comparison to the modest rates of accumulation $(\sim 0.5-1 \mathrm{~cm} / \mathrm{k} . \mathrm{y}$. in the Paleogene) typically encountered at pelagic sites. As anticipated, Expedition 342 recovered sequences with sedimentation rates as high as $10 \mathrm{~cm} / \mathrm{k} . \mathrm{y}$.- - high enough to enable studies of the dynamics of past abrupt climate change, including both transitions into "greenhouse" and "icehouse" climate states, the full magnitudes of hyperthermal events, and rates of change 
in the CCD. We find that the thickest central parts of the various sediment drifts typically record similar depositional packages to those recovered in the thin "noses" and "tails" of these drifts, but these central parts are often massively expanded with clay, especially near the CCD. Times of rapid accumulation of drift deposits include the early to late middle Eocene, the late Eocene to early Oligocene, the late Oligocene and early Miocene, the later Miocene to probably late Pliocene, and the Pleistocene. Widespread hiatuses are present near the Paleocene/Eocene boundary into the middle early Eocene and the middle Oligocene. The EOT interval features comparatively modest accumulation rates typical of pelagic deep-sea sedimentation at most Expedition 342 sites but is expanded at Site U1411. A marked change in the geometry of drift formation is observed in the ?late Pliocene, as has been observed in drift deposits elsewhere. Seismic stratigraphy on Southeast Newfoundland Ridge is consistent with a massive increase in sedimentation rates in the later Neogene that dwarf the "high deposition" records of the Eocene and Oligocene sediment drifts drilled during Expedition 342.

An unexpected finding was the recovery of a number of Cretaceous "critical boundaries." These include the K/Pg boundary, the Campanian-Coniacian interval, the Cenomanian/Turonian boundary and Oceanic Anoxic Event (OAE) 2, and the Albian/Cenomanian boundary OAE $1 \mathrm{~d}$. These intervals were drilled opportunistically when they were encountered near or above our target depth for a given site. The K/Pg boundary was recovered at Site U1403, where it proved to have a well-preserved, normally graded spherule bed and unusually well preserved earliest Danian planktonic foraminifer community. The Campanian-Coniacian interval was cored at Site U1407 and is unusual mainly for the relative biostratigraphic completeness of a sequence that elsewhere commonly shows hiatuses in the early Campanian. The Cenomanian-Turonian transition was also cored at Site U1407 and consists of a series of organic black shales in nannofossil chalk with as much as $11 \mathrm{wt} \%$ total organic carbon (TOC). The Cenomanian-Turonian sequence at Site U1407 is broadly similar in biostratigraphy, sequence of black shales, and sediment color to classic Italian and northern German outcrop sections. Finally, coring at Site U1407 also recovered a lower Cenomanian nannofossil chalk and nannofossil claystone record that extends into the biozones associated with OAE 1d. The Albian-Cenomanian sequence is notable for the generally high quality of microfossil preservation and its gradational contact with underlying Albian shallowmarine carbonate grainstones and packstones.
We created high-quality spliced records of most of the sites on Southeast Newfoundland Ridge that penetrate sequences with carbonate-rich lithologies. As anticipated, the task of creating spliced records in the more clay rich lithologies in some sites was not straightforward because of intervals of low-amplitude change in some physical property data sets. All sites also proved to have differences in stratigraphy between adjacent holes, showing that there is often considerable local variation within the drift sequences. Particularly expanded sedimentary sequences were drilled in Miocene-Oligocene, EoceneOligocene, and middle Eocene sequences. Comparison of our drilling results with seismic stratigraphy from the Southeast Newfoundland Ridge indicates large-scale lateral changes in age and thickness of sediment drift packages. The diverse overlapping drift sequences suggest that the area presents an attractive target for future expeditions aimed at recovering high deposition-rate records from many parts of the Cenozoic.

On 6-8 June 2012, before the main leg of Expedition 342 , a sea trial of the MDHDS with the temperaturedual-pressure probe (T2P) was conducted at Site U1402 on the New Jersey margin. This deployment was the culmination of the testing and development phase of a delivery system designed to remotely deploy and recover penetrometers. The benefit of this system over its predecessor is the complete decoupling of the penetrometer from the drill string, negating the effect of ship heave on the quality of data. The second of two deployments of this system fulfilled the mission goals by successfully deploying and acquiring in situ data with complete decoupling from the ship. The in situ pore pressure measured at Site U1402 was $7.536 \mathrm{MPa}$, just slightly above hydrostatic pressure. This is the first in situ pressure measurement made on the Atlantic margin in scientific ocean drilling and confirms previous indirect pressure estimates. Accelerometer data collected within the T2Ps electronic housing showed perfect decoupling from the drill string. We now have a dependable method to deploy pore pressure penetrometers successfully, which will allow the rapid measurement of in situ pressure in sediment. This new capability opens an exciting range of future science for the drilling program.

\section{Background and objectives: Newfoundland sediment drifts}

Earth's history holds a rich record of abrupt climate and ecological changes. However, the dynamics of these state changes in Earth's ecosystems are often 
not well resolved, particularly in past warm climates that have analogs to future global change. The complexity of Earth's biological and climatological systems hinders the use of models to confidently predict future ecosystem dynamics, yet the planet is rapidly approaching a highly altered climate forcing that has no historical analog for the past 30 m.y. Our approach is to seek historical analogs to future climates in Earth's past. However, to understand the dynamics of rapidly shifting environments, it is critical that we target records that have adequate fidelity to study the processes we seek to understand.

A long-standing approach to understanding Paleogene and Cretaceous oceanography has been to drill sediments that record the long sweep of Earth's history. This methodology has allowed reconstruction of ocean climate and ecosystem changes over the past 180 m.y. and has allowed many "extreme climate" events to be placed into context both with respect to broad climate trends and increasingly well resolved chronologies. Such deep time records, however, necessarily involve a trade-off between outlining long histories and understanding ocean dynamics on timescales similar to (or shorter than) the $\sim 1500$ y mixing time of the ocean. The vast majority of work on Pliocene-Pleistocene climate dynamics long ago began to target archives with finely resolved chronologies (millennial to century scale) and, in the case of ocean sediments, high deposition rates. This focus on highly resolved records has the potential to reveal dynamics that operate on timescales that have relevance to human society. Expedition 342 is founded on the objective of extending this dynamics-focused approach, for the first time, into the archives of the past greenhouse Earth.

Our program requires a high sedimentation-rate record of the Eocene and Oligocene in which we can resolve both rates and magnitudes of past extreme climate events as well as the background variability in climate and ecosystems from these times. Because we target sediment drifts that accumulate faster than typical deep-sea sediments, we should be able to reconstruct the history of a warm Earth with unusual fidelity. A related objective is to acquire these records along a depth transect of drill cores between $\sim 5$ and $3 \mathrm{~km}$ water depth. Because the ocean is layered, with different water masses formed in various regions around the world arranged above one another, our depth transect of drill sites will permit a detailed reconstruction of the chemistry, circulation, and history of greenhouse Earth's oceans. These two things-an unusually detailed climate history and a detailed assessment of the structure and circulation of the warm-world ocean-will help us test models of Earth's climate and ecosystem evolution that have been difficult or impossible to resolve with typical deep-sea or land-based records of the warm Earth and its transition into the icehouse world.

\section{Geological record of abrupt climate dynamics as future-Earth analogs}

The primary objective of Expedition 342 is to answer a series of pressing questions about the rate and magnitude of past ecosystem changes:

- How similar are past abrupt climate changes to model expectations for the environmental changes triggered by human modification of Earth's environments?

- What are the consequences for Earth's biota of variations in magnitude or rate of change during abrupt events?

- Are there any ancient analogs to what we are doing to the planet now or has humanity launched a carbon cycle perturbation without geological analog?

- How long will perturbations similar to those of the "Anthropocene" last?

- Are we missing fundamental feedbacks in our bid to model the Earth's future under higher greenhouse gas forcing?

- What is the climate sensitivity to different rates or magnitudes of greenhouse gas forcing?

The Eocene is not a perfect analog to the near future (e.g., Haywood et al., 2011) but understanding Eocene climate dynamics will provide information on what to expect from a warmer planet.

\section{Rapid ecosystem change on a warm Earth}

A particular goal of Expedition 342 is to reconstruct the carbonate lysocline to provide constraints for carbon cycle models. An extremely successful result of Ocean Drilling Program (ODP) Leg 208 (Zachos, Kroon, Blum, et al., 2004) was the acquisition of a $\sim 2000 \mathrm{~m}$ depth transect that permitted estimation of the magnitude of carbonate compensation depth (CCD) fluctuations in the Paleogene, particularly the Paleocene/Eocene Thermal Maximum (PETM) (Zachos et al., 2005). This depth transect showed that the CCD excursion associated with the PETM was $>2000 \mathrm{~m}$ and suggested that the amount of $\mathrm{CO}_{2}$ added to the biosphere during the PETM must have been much greater than previously documented (Panchuk et al., 2008). In turn, these data were interpreted to suggest that the source of greenhouse gases could not have been primarily gas hydrates because the combined magnitude of the temperature excursion, the CCD fluctuation, and the size of the $\delta^{13} \mathrm{C}$ anomaly all suggest a carbon source more similar to marine organic carbon than bacterial methane (Pan- 
chuk et al., 2008). This example emphasizes how important it is to capture the magnitude of these carbonate preservation excursions because they provide a direct estimate of the change in ocean undersaturation and hence the transient change in $\mathrm{CO}_{2}$ storage during extreme climate events. When combined with $\delta^{13} \mathrm{C}$ data sets and a range of numerical modeling approaches, the size of the CCD excursion can be used to study the source of isotopically light carbon transferred during such events and, ultimately, climate sensitivity to $\mathrm{CO}_{2}$ forcing (e.g., Pagani et al., 2006a; Goodwin et al., 2009; Dunkley Jones et al., 2010; Dickens, 2011; DeConto et al., 2012; Pälike et al., 2012).

Understanding the spatial and depth dimensions of the CCD change is clearly key to modeling the likely sources and amounts of carbon added to the biosphere during the PETM, but our current observational data do not yet provide a clear picture of either variable. If the methane hydrate hypothesis is untenable for the PETM and other extreme warm transients-so called "hyperthermals"-then it becomes even more important to identify a viable alternative. This task would be made much easier if we had a clear idea of the total amount of $\mathrm{CO}_{2}$ put into the ocean and atmosphere during the PETM and other Paleogene hyperthermal events. A well-resolved depth transect that could be used to identify the full depth range of the CCD excursion is critical to resolving the amount and type of carbon introduced into the biosphere during Paleogene hyperthermals. Recent evidence that the PETM and Paleogene global warming events may be orbitally forced or at least conditioned (Lourens et al., 2005; Galeotti et al., 2010; Sexton et al., 2011) implies that the source of carbon was not an extraterrestrial impact or one-time volcanic eruption (Kent et al., 2003; Svensen et al., 2004). Thus, long astronomically calibrated records of CCD changes through the warm Eocene may be critical to unraveling the origins of the PETM and other Paleogene events (e.g., the Middle Eocene Climatic Optimum [MECO], a prominent reversal in the long-term global cooling trend from peak Cenozoic warmth in the early Eocene) (Bohaty et al., 2009; Bilj et al., 2010).

The carbonate content of deep-sea sediments is a sensitive measure of the productivity, weathering, and fluxes of carbon within the biosphere. The CCD reflects changes in carbon erosion, deposition, and silicate weathering and, in association with $\delta^{13} \mathrm{C}$ of marine and terrestrial proxies (benthic foraminifers, terrestrial biomarkers, and planktonic-benthic gradients), can be used to gauge changes in the size and distribution of carbon reservoirs (Higgins and Schrag, 2006; Leon-Rodriguez and Dickens, 2010).
However, although the general form of CCD changes has long been moderately well known for the various ocean basins (van Andel, 1975; Peterson et al., 1992), we are only just starting to gather well-resolved records at the secular scale and to lay the foundations to reveal the rates and amplitude of change in the CCD on short timescales. This information is very important for understanding transient episodes such as the various extinction events, hyperthermals, and glacial events of the Paleogene (e.g., Pälike et al., 2012). Expedition 342 is well placed to provide records of CCD change from the North Atlantic Ocean at unprecedented temporal resolution across the largest Paleogene water depth transect ever attempted.

In addition to reconstructing the sources and fate of carbon that produces extreme climate events, we also need to know the rate and full magnitude of these events and the response of marine biota. In most deep-sea records, slow sedimentation rates mean that the full magnitude of the events may have been bioturbated or dissolved away (Zeebe and Zachos, 2007). The first solution to the problem of resolving transient events is to target sites where sedimentation rates are higher than the ocean average. Expedition 342 is aimed first and foremost at obtaining highly expanded records suitable for studies of Paleogene climate by targeting drift sediments of hypothesized Oligocene-middle Eocene age. The depth transect approach and acquisition of expanded carbonate-rich sections near the limits of their northern extent will allow us to study faunal and floral processes such as population turnover and latitudinal and stratigraphic range expansion during intervals of ocean acidification and global warming (e.g., Gibbs et al., 2006; Edgar et al., 2010, 2013).

The record on the Newfoundland ridges should allow a companion study to Walvis Ridge drilling (Leg 208) to be conducted under the flow path of northern-source deep water. We have not previously obtained a good record of the history of the carbonate chemistry of the Deep Western Boundary Current in the North Atlantic. The Leg 208 transect on Walvis Ridge is likely influenced mainly by southern source waters by virtue of its location on the eastern side of the South Atlantic Basin. Furthermore, we can see in the Newfoundland seismic data that the toe of JAnomaly Ridge (at $\sim 5 \mathrm{~km}$ water depth) likely lies close to the average depth of the CCD because the drift package thins markedly at this point (Fig. F1). Therefore, drilling on J-Anomaly Ridge, combined with the shallower sites on Southeast Newfoundland Ridge, positioned us to recover a depth transect spanning $>2.5 \mathrm{~km}$ (Fig. F2). It is of course possible that the amplitude of CCD shift during the most ex- 
treme Paleogene transient events could still exceed our transect, but we are better placed to obtain a record of the full magnitude of CCD excursions than previous studies. The transect is particularly suited to resolving fluctuations in the carbonate chemistry of the truly deep ocean, a large change from most previous ocean drilling sites that recovered Paleogene records, which rarely targeted paleodepths below $\sim 2500 \mathrm{~m}$.

\section{Rapid ecosystem changes on a cold Earth}

In many ways the EOT represents the obverse of the PETM. Across the EOT, the Pacific Ocean appears to undergo pronounced deacidification associated with the onset of major Cenozoic polar ice sheets (Fig. F3) (Coxall et al., 2005; Merico et al., 2008). Ultimately, ice sheet initiation appears to have been triggered by an orbitally forced interval inhibiting warm summers, but some other factor, probably long-term drawdown in atmospheric carbon dioxide levels, must have conditioned the climate system (DeConto and Pollard, 2003; Coxall et al., 2005; DeConto et al., 2008). Records from the tropical Pacific (ODP Leg 199; Lyle, Wilson, Janecek, et al., 2002) and IODP Expedition 320/321 demonstrate that the CCD deepened permanently (by $\sim 1 \mathrm{~km}$ ) in the earliest Oligocene in two 40 k.y. "jumps" and in lockstep with the stepwise onset of Antarctic glaciation, as recorded in benthic foraminifer $\delta^{18} \mathrm{O}$ (Coxall and Wilson, 2011; Coxall et al., 2005). However, it is unclear to what extent this lockstep behavior represents the global picture because sufficiently complete EOT depth transects from other ocean basins and latitudes are not available. Comparatively low resolution records across a highly condensed and reworked Eocene/Oligocene boundary from Walvis Ridge (Leg 208; Zachos, Kroon, Blum, et al., 2004) have been interpreted in terms of a much smaller $(\sim 200 \mathrm{~m})$ and nonpermanent CCD deepening. Furthermore, a new reconstruction of the carbonate compensation system based upon Leg 199 and Expedition 320/321 results suggests that the CCD in the equatorial Pacific underwent temporary large-amplitude changes in the middle and late Eocene (Pälike et al., 2012). In the end, it is not clear whether CCD behavior in the equatorial Pacific represents the global picture, driven by wholesale change in deep-sea $\mathrm{CO}_{3}$ ion concentration, or is to some extent a regional signal driven by changes in export production with important implications for our understanding of contemporaneous carbon cycling (Dunkley Jones et al., 2008; Coxall and Wilson, 2011; Pälike et al., 2012).

The large but temporary CCD events of the middle Eocene equatorial Pacific, or "calcium carbonate accumulation events" (Lyle et al., 2005), have been in- terpreted (by analogy with the EOT and on the basis of discontinuous stable isotope records) to be a lithologic expression of large-scale bipolar continental glaciation (Tripati et al., 2005, 2008), but this interpretation is contested (Edgar et al., 2007; Eldrett et al., 2007, 2009; DeConto et al., 2008). The middle Eocene to lower Oligocene depth transect on the Newfoundland ridges presents an ideal opportunity to generate high-resolution records of changes in mass accumulation of $\mathrm{CaCO}_{3}$ needed to test the hypothesis that the CCD changes recently documented in the equatorial Pacific are globally representative and intimately associated with the onset of continental glaciation. Together with the floral, faunal, and geochemical proxy records, such as compoundspecific $\delta^{13} \mathrm{C}_{\text {org }}$ and $\delta^{11} \mathrm{~B}$ in foraminiferal calcite (e.g., Pagani et al., 2005; Pearson et al., 2009) that could be generated, it would be possible to test for biotic turnover and $p \mathrm{CO}_{2}$ drawdown across these intervals, with important implications for our understanding of the causes and consequences of Cenozoic cooling.

\section{History of the Deep Western Boundary Current}

Numerous models suggest that thermohaline circulation can exist in multiple equilibrium states (e.g., Marotzke and Willebrand, 1991), with the potential for catastrophic disruption or collapse. For example, in the recent past the warmth and stability of interglacial climates is notably distinct from the rapid and abrupt cycles of warming and cooling so striking in the late Pleistocene glacials (e.g., Dansgaard et al., 1993). It has been proposed that enhanced climate instability during cold periods may originate from salinity feedbacks, which set up multiple thermohaline modes (Keeling and Stephens, 2001; Rahmstorf, 1995; Stommel and Arons, 1960), or from instabilities that lead to periodic purges and the collapse of large ice sheets (Alley and Clark, 1999). Analogs to Pleistocene suborbitally paced ice-rafting cycles are documented in the latest Pliocene and earliest Pleistocene North Atlantic associated with the intensification of northern hemisphere glaciation and development of a Laurentide ice sheet (Bailey et al., 2010, 2012). Yet the pre-Pliocene history of continental ice sheet variability in the northern hemisphere is controversial (e.g., Tripati et al., 2005, 2008; DeConto et al., 2008; Edgar et al., 2007), and we know nothing of Paleogene suborbital variability in climate and ocean structure in the North Atlantic.

Deep ocean circulation is crucial to defining the global climatic regime and its stability for two reasons. First, the sinking of surface water distributes thermal energy around the globe. Second, the chemistry and nutrient composition of the dominant 
deepwater masses influence the partitioning of $\mathrm{CO}_{2}$ between the deep ocean and the atmosphere. The pattern, strength, and stability of thermohaline circulation arise from a combination of wind forcing (Toggweiler and Samuels, 1995) and thermal or salinity density contrasts.

Something akin to modern North Atlantic Deep Water appears to be absent until the late Miocene or early Pliocene, when a combination of tectonic subsidence of the Greenland-Scotland Ridge and northern hemisphere refrigeration began to form cold, dense overflow waters in the Nordic seas and the Labrador Sea (Oppo et al., 1995; Wright and Miller, 1993; Wright et al., 1992). However, a northern component of deep water clearly formed in the North Atlantic throughout the Neogene and Oligocene, judging from geochemical differences between Atlantic and Indo-Pacific waters (Wright et al., 1992). Intensification of deepwater formation in the North Atlantic is proposed to account for acceleration of the Deep Western Boundary Current during the Oligocene, leading to widespread erosion along continental margins and formation of the seismic reflection, Horizon $\mathrm{A}_{\mathrm{u}}$, in the western North Atlantic. Subsequent current-controlled sedimentation formed major sediment drifts throughout the North Atlantic (Arthur et al., 1989; Miller and Fairbanks, 1985; Miller et al., 1987; Tucholke and Mountain, 1986; Tucholke, 1979; Tucholke and Vogt, 1979).

\section{Determining the flow history of the Atlantic Deep Western Boundary Current}

Direct evidence for significant flow in a deep boundary current before the Oligocene is sparse (Davies et al., 2001; Hohbein et al., 2012). Tucholke and Mountain (1986) suggested that the Erik and Gloria Drifts south of Greenland may have begun to grow in the middle Eocene, based on interpreted ages of deep reflections in the drifts. The presence of onlapping reflectors and depositional structures on Blake Nose along the mid-Atlantic margin suggest erosion by an intermediate water mass centered above 2000 meters below sea level (mbsl) in the early Eocene (Katz et al., 1999; Norris et al., 2001a, 2001b). The seismic record from Blake Nose also shows evidence of condensed sections and slumps on the tip of Blake Nose $(\sim 2600$ mbsl) that could indicate deeper erosional flow along the Blake Escarpment in the early Eocene (Norris, Kroon, Klaus, et al., 1998). Erosion on Blake Nose may have been caused by shallow parts of the Deep Western Boundary Current rather than by the northward-flowing Gulf Stream. The area of erosion is $>100 \mathrm{~km}$ east of the main flow of the Gulf Stream, which is constrained by the location of the Florida Straight and Suwanee Channel. In the deep western
North Atlantic basin, Mountain and Miller (1992) presented seismic evidence for late Paleocene bottom currents over the Bermuda Rise that could have a source analogous to Antarctic Bottom Water. Although limited, all of these data suggest that both a southern-source water mass and a northern-source water mass may have been present in the deep North Atlantic and circulated strongly enough to control seafloor deposition and erosion during the relatively warm climates of the early Paleogene. This conclusion raises the possibility that our drilling operations can expand upon some of the extraordinary paleoclimate results yielded during IODP coring in the Arctic (e.g., Brinkhuis et al., 2006; Moran et al., 2006; Pagani et al., 2006b; Sluijs et al., 2006).

The Expedition 342 drilling transect lies directly under the flow path of the present Atlantic Deep Western Boundary Current and is therefore ideally placed to monitor the chemistry and temperature of water exiting the Nordic basins in the Paleogene (Fig. F4). Therefore, the J-Anomaly Ridge and Southeast Newfoundland Ridge sites are perfectly placed to act as end-members for studying the contribution of northern-source water to the rest of the global ocean. We already have a South Atlantic/Southern Ocean end-member site (Weddell Sea, ODP Site 690) and Pacific end-member sites (Shatsky Rise, ODP Leg 198), but we have nothing equivalent in the North Atlantic except for the subtropical Blake Nose (ODP Leg 171B) sites, many of which are located in water depths that are too shallow to truly record Deep Western Boundary Current properties.

Why do we need end-members? If all we had were equatorial sites (far from the high-latitude sites of deepwater formation), we could still determine whether Atlantic water was being exported into the Pacific and vice versa, but we would not know where this water originated. Barring the unexpected revival of models of warm, saline deep water (Brass et al., 1982; Friedrich et al., 2008), it seems most likely that deep water dominantly forms at high latitudes (Bice and Marotzke, 2002; Bice et al., 1997), as is the case today and as is predicted in ocean circulation models for the Paleogene. Hence, in order to offer any concrete observational data to test ocean modeling for past warm climates, we must know where deep water is sourced and how deepwater production varies during different climate states. Drilling Newfoundland Ridge sediment drifts offers a first-rate opportunity to obtain a true North Atlantic end-member for these studies. The large depth range covered by the depth transect will also allow studies of the full range of ocean properties from the abyss to intermediate waters for the first time anywhere in the Paleogene. 
In order to capture rapid shifts in circulation patterns, it is critical to obtain records that allow us to reconstruct climate at suborbital temporal resolution. The Newfoundland sediment drifts offer an unprecedented opportunity to achieve this goal from sites close to the source of northern overflow water in the Paleogene.

These drifts also allow us to resolve the changes in circulation that accompany various Paleogene extreme climate events. A case in point is the inferred reversal in deepwater overturning during the PETM (Nuñes and Norris, 2006; Tripati and Elderfield, 2005). A compilation of $\delta^{13} \mathrm{C}$ data from benthic foraminifers suggests that the "aging gradient" in $\delta^{13} \mathrm{C}$ between Southern Ocean and northern hemisphere sites abruptly reverses during this interval of global warming (Fig. F5) (Nuñes and Norris, 2006). Southern Ocean overturning in the late Paleocene is interpreted to give way to northern overturning during the PETM and then gradually revert to Southern Ocean deepwater formation over the next $~ 100-150$ k.y. An alternative explanation is that the reconstructed gradient reversal is a stratigraphic artifact created by the effects of dissolution on sediment accumulation in northern Atlantic sites (Zeebe and Zachos, 2007). A reversal in deep ocean circulation is seen in global climate model experiments of the PETM (e.g., Bice and Marotzke, 2001) and may have occurred during other Paleogene climate events.

Drilling on the Newfoundland ridges can be used to look for such reversals in deepwater formation during a host of extreme climate events using three techniques. First, we can use depth transects to produce highly resolved records of the vertical structure of deep water at critical sites such as the Newfoundland ridges. Second, we can examine geographic gradients in benthic foraminifer geochemistry (e.g., $\delta^{13} \mathrm{C}$ ) or neodynium isotopes on fish teeth using the Newfoundland sites as a northern end-member for comparison with sites elsewhere in the world. Third, we can use the history of drift formation itself to assess the strength of the Deep Western Boundary Current and estimate the rate of formation of deep water in the North Atlantic.

Depth transects have been shown to produce highly resolved records of changes in the source of deep water in the Pleistocene (e.g., ODP Leg 154; Curry, Shackleton, Richter, et al., 1995) and the Paleogene (ODP Legs 198, 207, and 208). For example, the hypothesized change in deepwater circulation during the PETM (Fig. F5) may have similarities to changes in deepwater formation during Pleistocene interstadials, in which outflow from the Nordic seas shift from deepwater formation to intermediate water formation as North Atlantic overturning wanes. In the
Pleistocene, reduced North Atlantic overturning is associated with the intrusion of Antarctic Bottom Water well into the northern North Atlantic beneath Glacial North Atlantic Intermediate Water (Oppo and Lehman, 1993). We can look for similar changes in deepwater source areas by geochemical analysis of benthic foraminiferal calcite along depth transects. Appropriately well-preserved material can also be used to generate proxy records for the total $\mathrm{CO}_{3}{ }^{2-}$ content of the deep and intermediate waters using planktonic foraminifer weight and percent fragmentation.

Expedition 342's deepest sites lie within the carbonate lysocline in the Paleogene and may have very little carbonate given the condensed nature of the transparent (Eocene) horizon on J-Anomaly Ridge (Fig. F1). Foraminifer preservation will clearly suffer in sediments that have been subjected to extensive calcite dissolution and may well preclude foraminifer-based geochemical studies, particularly in planktonic foraminifers. However, if the sites can be correlated (by physical property records) to well-dated upslope sites (as was done during Leg 154), we can use the deepwater site to pin the depth of the CCD and therefore evaluate the full magnitude of CCD variations throughout the Paleogene. The deepwater sites should also preserve a record of more refractory substrates, such as fish teeth, that can be used in $\mathrm{Nd}$ isotope studies of deep ocean flow paths (e.g., Via and Thomas, 2006; Scher et al., 2011; Thomas et al., 2003).

An additional approach for identifying patterns of deepwater formation relies on dating drift sedimentary packages and analyzing their thicknesses and distributions in seismic profiles. The dates we currently have for the sediment drifts on the Newfoundland ridges strongly suggest that major drift formation began with the deposition of thick acoustically transparent sequences and then changed character in the early Oligocene to a more mudwavedominated system (Fig. F6). Verification of Eocene drift formation would require a reassessment of our inferences of the relationship between the rates of deepwater formation and perhaps polar glaciation because it has been generally held that drift formation began at the major onset of Antarctic glaciation in the earliest Oligocene (Davies et al., 2001) (although recent results from the Greenland-Scotland Ridge indicate drift formation began at the early to middle Eocene transition [Hohbein et al., 2012]).

Studies of deposition rates, sediment sources, and grain size would help us evaluate the origins and current regimes under which these drifts formed, as well as provide precise dates for changes in drift formation that could be compared with geochemical evi- 
dence for changes in deepwater sources. To achieve these primary goals we propose to combine proxies from sedimentology, clay mineralogy, and organic/ isotope geochemistry to be applied specifically to the current-sensitive silt fraction. Continuous granulometric records will provide direct information on the variability of current strength and thus the history of the Deep Western Boundary Current. Clay mineral assemblages are excellent tracers for provenance studies, and organic matter composition will support the identification of source areas of fine-grained material and the presence of allochthonous organic matter from higher northern latitudes. As a working hypothesis we consider that intervals of enhanced strength of the Deep Western Boundary Current should have resulted in stronger advection of a higher latitude component and generally coarser grain sizes in the silt fraction, whereas intervals of reduced current activity should primarily record more local sediment sources and surface-ocean signatures as well as finer grained sediments.

\section{High-resolution records of the onset and development of Cenozoic glaciation}

The canonical view of the onset of Cenozoic glaciation is that it took place in two main steps: (east) Antarctic ice sheets were established around the time of the Eocene/Oligocene boundary $(\sim 34 \mathrm{Ma})$, whereas northern hemisphere glaciation was not triggered until 3-7 Ma (e.g., Miller et al., 1987; Zachos et al., 2001). However, on the basis of sediment recovered in the last phase of ODP and the initial phase of IODP, it has been suggested that this view of Earth's climate history may need revision. Dropstones have been reported from the Arctic (IODP Expedition 303) in sediments of $\sim 45 \mathrm{Ma}$ age (Backmann et al., 2005). Discontinuous $\delta^{18} \mathrm{O}$ records in bulk and benthic foraminiferal calcite from the equatorial Pacific (Leg 199) were interpreted in terms of extensive ice sheet development in both hemispheres, together with a huge $(>150 \mathrm{~m})$ eustatic sea level fall around 42 Ma (Tripati et al., 2005, 2008). This interpretation is controversial (Lear et al., 2004; Edgar et al., 2007; DeConto et al., 2008). Records from the Norwegian-Greenland Sea and the Arctic Lomonosov Ridge suggest that winter sea-ice formation was initiated around the start of the middle Eocene and that isolated alpine outlet glaciers existed on Greenland by the late Eocene (Eldrett et al., 2007; Stickley et al., 2009). In contrast with early interpretations (Lear et al., 2000), it is now also clear that the magnitude of the $\delta^{18} \mathrm{O}$ increase across the EOT $(\sim 33.5$ $\mathrm{Ma}$ ) is too large to reflect ice growth on Antarctica alone (Coxall et al., 2005), and there is growing evi- dence for contemporaneous global cooling (Lear et al., 2004, 2008; Liu et al., 2009; Eldrett et al., 2009).

Expedition 342 provided an opportunity to shed new light on these aspects of Paleogene climate in the high northern latitudes in unprecedented stratigraphic detail. The middle to upper Eocene and lower Oligocene sections targeted here will allow us to generate the high-resolution records of changes in sedimentation rate, clay mineral assemblages, and occurrence and provenance of ice-rafted debris (IRD) that are needed to achieve these goals. A potential problem exists with differentiating between putative Paleogene IRD and sediment eroded from the continental margin. In Pleistocene strata, IRD is often identified because of its coarse grain size (sand sized and larger) and its distinctive provenance (e.g., "redcoated grains" from Labrador and basalt from Iceland) (Bond and Lotti, 1995; Hemming et al., 1998). IRD in the silt fraction has been identified by a number of techniques, including modeling of end-member components using a wide spectrum of grain-size analyses (Weltje, 1997; Weltje and Prins, 2003; Prins et al., 2002). IRD might also be identified by combining grain size (especially sand content) and mineralogical information during "cold" events inferred from light stable isotope studies and geochemical assessment of provenance.

Clay minerals are excellent tracers of provenance in the modern North Atlantic and should have broadly similar distributions in the Paleogene. Continentalsourced clay should dominate the west Greenland and Canadian margins, whereas volcanic-sourced clay should be more typical of the Paleogene flood basalt province in eastern Greenland. In the modern North Atlantic, smectite, illite, chlorite, and kaolinite constitute the major proportion of the clay fraction. Smectite has been regarded as a major tracer for Iceland-Faeroe-derived material (Fagel et al., 1996) and could be expected from the Greenland volcanic province in the Paleogene. Where smectites are lacking, chlorite is the typical high-latitude clay from old metamorphic sources. A lack of volcanogenic and weathered basalt-derived clay (nontronite and amorphous minerals) suggests a rather restricted contribution from eastern Greenland and mid-ocean-ridge sources. Clay mineral type (e.g., montmorillonite versus beidellite) and percentage data and Sm/Nd ratios in the clay fraction of Reykjanes Ridge sediment indicates a dominant terrigenous contribution from young continental crust that may derive from Europe and/or the Arctic (Fagel et al., 2001; Innocent et al., 2000). Today, the clay fraction may also contain terrigenous calcite and dolomite derived from glacier milk in the Hudson Bay area. Such a signal could be 
transported for much longer distances than sandsized IRD.

\section{Astronomical calibration of chronostratigraphic markers and the geological timescale}

A detailed geological timescale that can be applied widely was a primary goal of Expedition 342 drilling. Indeed, a highly resolved timescale is becoming increasingly critical in studies of Paleogene paleoceanography as we begin to extend work on millennial timescales into deep time and require increasingly high resolution correlation to evaluate the evolution of interbasin geochemical gradients. Determination of the rates at which Earth processes take place and how these rates change are key not only to developing an understanding of Earth history but also to accurately describing the nature and rate of the processes themselves.

The discovery of orbitally driven variations in Earth's climate and their preservation in the marine sedimentary record has been a major advance in chronostratigraphy. The application of this technique is not without assumptions, including the predictability of the exact beat of the climatic metronome (Pälike and Shackleton, 2000; Pälike et al., 2004). However, if constrained by a paleomagnetic reversal stratigraphy, and if the same ages are obtained for geologic boundaries in different regions with different sensitivities to each of the different orbital forcings, we can develop a strong confidence in the timescale. A complete orbitally tuned Cenozoic timescale can provide estimates of process rates that have comparable precision throughout the Cenozoic.

We are working toward an astronomically tuned Cenozoic timescale. There is a semianchored astronomical timescale back to $30 \mathrm{Ma}$ (mostly from Leg 154). No magnetostratigraphy was recovered during Leg 154 (Curry, Shackleton, Richter, et al., 1995), but investigations from ODP Legs 177 (Gersonde, Hodell, Blum, et al., 1999) and 199 have resulted in verification and refinement of results from Leg 154 (e.g., Billups et al., 2004; Wade and Pälike, 2004), as well as an extension of the tuning across the EOT (Coxall et al., 2005). Several other ODP legs and IODP expeditions have provided suitable data for work of this sort, most recently from the Pacific Equatorial Age Transect (Expedition 320/321; Pälike et al., 2010). Additional records are available for the time intervals of 35-42 Ma (Legs 171B and 177), 45-56 Ma (Leg 207), 53-57 Ma (Legs 171B, 198, and 208), and 6265 Ma (Legs 165, 171B, 198, and 208) (Pälike et al., 2001; Westerhold and Röhl, 2009; Norris and Röhl,
1999; Lourens et al., 2005; Sigurdsson, Leckie, Acton, et al., 1997). From this perspective, acquisition of an astronomically tuned record of the late Eocene and the early middle Eocene would be extremely important to span existing gaps in our tuning efforts and to provide single-site, high-resolution data that allow splicing, verification, and extension of previous efforts.

For the Paleocene and Eocene, a shallow CCD has hampered efforts to obtain long, uninterrupted carbonate sequences that allow high-resolution paleoclimatic studies with traditional geochemical studies (e.g., stable isotope analysis). The tectonic setting of the sites targeted by Expedition 342 is likely to overcome this problem because the sites track above the CCD for the critical time slices needed, with potentially very expanded Paleocene, Eocene, and Oligocene sedimentary deposits. In addition, for the time intervals that have already been astronomically tuned, a comparison between low-latitude sites from the Pacific and Atlantic will be complemented by the North Atlantic setting of Expedition 342, offering the chance to decipher the processes controlling the amplification of, for example, $41 \mathrm{k} . \mathrm{y}$. obliquity versus $\sim 100$ and 405 k.y. eccentricity cycles and to test the hypothesis that there are different dominant astronomical forcing mechanisms between Earth's warm and cool periods.

\section{Drilling strategy}

A primary challenge in recovering highly detailed records of past greenhouse conditions is the typically low sedimentation rates found throughout much of the deep ocean. Most ocean drill cores that recover Paleogene and Cretaceous records, for example, have sedimentation rates of $1 \mathrm{~cm} / \mathrm{k} . \mathrm{y}$. or less-rates that are too low to resolve events with durations $<1000 \mathrm{y}$ in the best of cases. Indeed, burrowing and other mixing processes distort these slowly accumulating records still further, distributing even instantaneous events such as meteorite impact ejecta or volcanic ash beds over tens of centimeters of the sediment record (Hull et al., 2011). Mixing therefore both reduces the apparent magnitude of past abrupt events or transitions and makes these events appear to occur much more slowly than was actually the case. It is possible, of course, to unmix the record, either by modeling the mixing process or by inverse modeling (Heinze et al., 1999; Panchuk et al., 2008; Ridgwell, 2007), but these methods will always produce a hypothesis about rates or magnitudes of events that is difficult to test empirically.

Another challenge in Paleogene paleoceanography is that old sediment is typically buried beneath younger sediment, with consequent impacts for the 
preservation of the substrates used in proxy-based paleoenvironmental reconstruction and our ability to obtain full records of sedimentary sequences. Low-temperature diagenesis degrades the quality of most microfossil groups as well as chemical tracers of ocean conditions. Burial diagenesis also impedes coring, decreasing the probability that sequences can be recovered in continuous sections and producing gaps in the resulting record. Because hard sediments cannot be obtained by piston coring, we also lose the ability to obtain oriented cores for paleomagnetic work. Finally, burial beneath a thick sedimentary pile increases drilling time and reduces the time available to obtain extensive records of deeply buried, older sediments.

Our strategy, therefore, was to focus on drift sediments with high deposition rates as opposed to open-ocean pelagic records. We targeted drifts that are not buried significantly and are likely to preserve sediments that have not undergone major burial diagenesis. The lack of burial improves the chance that the upper sediment column is available through piston coring and the acquisition of oriented cores. Our approach also samples drift packages that occur over a wide variety of water depths with the hope of obtaining cores over the widest possible range of water depths.

Expedition 342 is focused on the Paleogene record on the Newfoundland ridges. Although there is an extensive Cretaceous record of both drifts and fossil reefs in the seismic record, we did not have time to do justice to Cretaceous objectives without sacrificing our studies of the Paleogene system. Furthermore, our particular area of focus was the middle Eocene to Oligocene interval where thick sediment drift deposits preserve unusually expanded records of the transition from the greenhouse world of the Eocene climatic optimum to the glaciated world of the Oligocene.

Drilling during Expedition 342 completed the North Atlantic objectives laid out in a 1997 Marine Aspects of Earth System History workshop on warm-period dynamics and the ODP Extreme Climates program planning group (PPG) (see www.odplegacy.org/ program_admin/sas/ppg.html). Expedition 342 had its genesis in the Extreme Climates PPG, which backed proposals that later became Legs 198, 199, 207, and 208. It is somewhat fitting that Expedition 342 is the last of this powerful lineup of drilling programs because it is the only one to focus on drilling high deposition-rate sequences rather than long but low temporal resolution records. Drilling also addressed initiatives of the IODP Initial Science Plan in the areas of extreme climates and rapid climate change. Finally, our expedition takes up proposals of the recent National Research Council report Understanding Earth's Deep Past: Lessons for Our Climate Future (National Research Council, 2011), which advocates focused efforts to resolve the timescale and use mechanisms of past hyperthermal events as possible analogs for future global change.

\section{The Newfoundland ridges}

On 15 April 1912, the RMS Titanic, en route westward from Southampton, England, to New York City, USA, hit an iceberg off the Grand Banks of Newfoundland and sank, killing more than 1500 people. The two halves of the wreck lie between the volcanic seamounts of the Southeast Newfoundland Ridge because there the southward-flowing surface water of the cold Labrador Sea carries icebergs to their intersection with the warm tongue of the Gulf Stream. Today the Titanic is bathed by the Deep Western Boundary Current because this new abyssal water passes at depth under the Gulf Stream on its circuit throughout the deep basins of the world oceans (Fig. F4). The shape of the North Atlantic margin suggests that a similar current configuration occurred in the past, with any deep water formed in the North Atlantic constrained to flow over the Newfoundland ridges. Therefore, Expedition 342 drill sites are particularly useful to monitor the overturning history of the North Atlantic Ocean.

The Newfoundland ridges are mantled with some of the oldest sediment drifts known in the deep sea and range in age from the Late Cretaceous to Paleogene. Pliocene-Pleistocene drifts in the northeastern Atlantic commonly have sedimentation rates of 4-20 $\mathrm{cm} / \mathrm{k}$.y. and therefore can be used to study rates of abrupt climate change (Channell et al., 2010). Previous drilling of drifts on Blake Nose (off the southeastern United States) revealed sedimentation rates in the middle Eocene of $\sim 5-6 \mathrm{~cm} / \mathrm{k} . \mathrm{y}$. , far higher than the $\sim 1 \mathrm{~cm} / \mathrm{k} . \mathrm{y}$. rates typical of previous Paleogene-focused drilling targets (Norris et al., 2001b). The Newfoundland sediment drifts also have high accumulation rates, which will allow us to obtain records of warm-period climates and evolution with unusual fidelity, and these will be particularly useful for assessing rates of change in the Earth system during both transient episodes of extreme warming (analogous to the near future) and transitions from warm climates into the glaciated world.

\section{Structure and stratigraphy of J-Anomaly Ridge and Southeast Newfoundland Ridge}

J-Anomaly Ridge and Southeast Newfoundland Ridge (Fig. F7) formed along the axis of the mid-Cretaceous Mid-Atlantic Ridge in a fashion analogous to the modern Reykjanes Ridge and Iceland (Tucholke 
and Ludwig, 1982). The tops of both ridges were above sea level in the Aptian and subsequently subsided to abyssal depths by the Late Cretaceous (Tucholke and Vogt, 1979). Aptian rudist platform carbonates were drilled at Deep Sea Drilling Project (DSDP) Site 384 (now at 3900 mbsl) (Tucholke, Vogt, et al., 1979), and buried reef-like seismic features are present on the flank of J-Anomaly Ridge and Southeast Newfoundland Ridge. Pelagic carbonates began to blanket the tops of the ridges by $\sim 75-80 \mathrm{Ma}$ (Tucholke, Vogt, et al., 1979) and accumulated to thicknesses of nearly $1.5 \mathrm{~km}$ by the late Neogene.

Five principal sedimentary sequences are evident on the Newfoundland ridges, bounded by reflection Horizons A-D (Fig. F6). The uppermost sequence displays well-defined internal reflections and mantles the northern side of Southeast Newfoundland Ridge. Nearly all piston cores of this sequence collected from the Newfoundland ridges (Fig. F8) are of Pleistocene age, including "long piston" Core MD952027. The presence of thick Pleistocene sections on the north side of the Newfoundland ridges may reflect the accumulation of iceberg-transported sediment derived from the Hudson Bay and Greenland. To the south, on Southeast Newfoundland Ridge and $\mathrm{J}$-Anomaly Ridge, the Pleistocene cover is nearly absent and is represented by only a thin (3-5 m thick) layer of Pleistocene foraminifer sand mixed with glacially transported sediment based on gravity cores collected during the Knorr 179-1 site survey. The thin Pleistocene sediment that covers our target sediment likely reflects the barrier imposed by the warm Gulf Stream to icebergs drifting southward along the Newfoundland margin. Pleistocene glacial sand protects the Paleogene sediment drifts from extensive erosion and preserves them in unconsolidated condition, as seen in piston Cores KNR179-1-13PC and KNR179-1-15PC from Southeast Newfoundland Ridge.

The second sequence, bounded by reflection Horizons $\mathrm{A}$ and $\mathrm{B}$, displays poorly defined, discontinuous reflections (Fig. F6) and is probably of Oligocene and Neogene age on the basis of its similar acoustic character to other drifts in the North Atlantic (Davies et al., 2001). In some areas, the discontinuous reflections can be resolved as fields of sediment waves, suggesting that much of the unit was deposited under strong directional bottom currents. Large parts of the southern flank of Southeast Newfoundland Ridge and the northern end of J-Anomaly Ridge are covered by this sequence, with thicknesses of $>700$ $\mathrm{m}$. We have no cores that firmly date this sequence because of failure of the hydraulic winch during the site survey cruise.
The third sequence, bounded by reflection Horizons $\mathrm{B}$ and $\mathrm{C}$, is seismically transparent and has a poorly defined contact with the overlying sequence of discontinuous reflections (Fig. F6). The absence of a strong reflector between these seismic units suggests that seismic Unit 3 has a conformable relationship with overlying Unit 2 . Piston cores and seismic ties to Site 384 show that this sequence is of early Eocene age (nannofossil Zones NP14 and NP15) and younger. Its great thickness (as thick as $800 \mathrm{~m}$; Figs. F9, F10) suggests an unusually expanded sequence of lower and middle Eocene sediment on J-Anomaly Ridge. Furthermore, it is possible that there is a complete Eocene-Oligocene sequence in the drilling transect on Southeast Newfoundland Ridge (Fig. F10). Piston core samples show the main lithology in the lower to middle Eocene section is a clay-rich white to yellow nannofossil ooze. The absence of strong internal reflections suggests that the sequence is not punctuated by major hiatuses but was deposited steadily like many modern Pliocene-Pleistocene drifts in the North Atlantic. This sequence thins below $\sim 4.5 \mathrm{~km}$ present water depth $(\sim 4 \mathrm{~km}$ in the Eocene), apparently reflecting reduced sedimentation rates in the lysocline and below the CCD. Thinning of the Eocene package at $\sim 4 \mathrm{~km}$ paleodepth is broadly consistent with the position of the Eocene CCD estimated from prior North Atlantic drilling (Fig. F2) (Tucholke and Vogt, 1979).

The fourth sequence, bounded by reflection Horizons C and D (Fig. F6), is of Cretaceous-Paleogene age, is $>500 \mathrm{~m}$ thick, and crops out on the base of JAnomaly Ridge (e.g., Site U1403; Fig. F1) and in numerous places on the crest of Southeast Newfoundland Ridge, including outcrops in moats around several seamounts. These strata also display drift-like morphology, albeit of smaller size than the Eocene drifts, and are characterized by mostly well defined parallel reflections like the Pleistocene cover section. This sequence was drilled at Site 384 (Figs. F6, F10), which recovered Campanian to lowermost Eocene beige calcareous ooze and soft chalk with excellent magnetic stratigraphy and well-preserved foraminifers and calcareous nannofossils, as well as radiolarians in the upper Paleocene (Berggren et al., 2000). The unconformities at the $\mathrm{K} / \mathrm{Pg}$ boundary and the Paleocene/Eocene boundary at Site 384 are expected because the site is located in a condensed section on top of a ridge. All recent Paleogene-Cretaceous drilling expeditions (Legs 171B, 198, 199, 207, and 208) (Norris, Kroon, Klaus, et al., 1998; Bralower, Premoli Silva, Malone, et al., 2002; Lyle, Wilson, Janecek, et al., 2002; Erbacher, Mosher, Malone, et al., 2004; Zachos, Kroon, Blum, et al., 2004) recovered one or 
more of these boundary sections despite their absence in older DSDP holes upon which the new drilling legs were based.

The fifth sequence, underlying reflection Horizon D, displays dense but parallel reflections (Fig. F6) and crops out on the northwest slope of J-Anomaly Ridge, the crest and flanks of Southeast Newfoundland Ridge, and apparently in the pelagic caps of several seamounts. This sequence consists of several discrete seismic sequences separated by possible unconformities, indicated by truncations of reflectors. This entire seismic package is likely of mid-Cretaceous to early Late Cretaceous age on the basis of seismic ties to Site 384 . Some of these sequences lap up against seismically identified buried reefs and are as thick as $450 \mathrm{~m}$. The reefs and surrounding sediment are probably Barremian-Albian in age on the basis of results from Site 384 (Tucholke and Vogt, 1979) and Sr isotope stratigraphy (P. Wilson, unpubl. data), in keeping with the estimated ages of buried reefs off Florida (Hutchinson et al., 1995; Norris et al., 2001a). Representative summaries of our interpretations of the sequence of sedimentary packages on J-Anomaly and Southeast Newfoundland Ridges are shown in Figure F10.

\section{The modern Deep Western Boundary Current}

The area east of the Grand Banks is a region critical to understanding the history of deepwater circulation in the North Atlantic because it is the gateway between bottom water sources in the NorwegianGreenland and Labrador Seas to the north and the main basins of the North Atlantic to the south. Denmark Straight Overflow Water is the main deepwater mass, centered at $\sim 3500 \mathrm{mbsl}$ and overlain by Labrador Sea Water at 1500 mbsl (Pickart et al., 1999). Southeast Newfoundland Ridge is a major barrier to deep southward flow and diverts the Deep Western Boundary Current offshore into the path of the northeasterly flow of the Gulf Stream. The deepest part of the bottom current follows submarine contours around the southeastern end of the ridge and continues west around J-Anomaly Ridge and along the Nova Scotian continental rise (Fig. F4). Shallower portions of the current follow contours around the crest of Southeast Newfoundland Ridge and also interact with seamounts on the ridge, forming local moats and drifts (Fig. F9). A particularly good example of these current-formed drifts are the sinuous deposits of calcareous clay and nannofossil ooze that form drifts over J-Anomaly Ridge (Fig. F11).

The Gulf Stream actually reaches the seafloor over Southeast Newfoundland Ridge and may contribute to bottom scouring. East of the ridge, Meinen and Watts (2000) found that the mean North Atlantic
Current clearly extends to the bottom. The measured bottom currents are strong enough to suspend sediments but probably not strong enough to cause extensive erosion. Still, we must bear in mind the possibility that erosion on J-Anomaly and Southeast Newfoundland Ridges is related to a southward-flowing deep boundary current and/or a northward-flowing surface current that regionally extends to the bottom.

\section{Newfoundland sediment drifts}

One of the main advantages of drilling the Newfoundland sediment drift complex is the near-absence of Neogene sedimentary cover. Most areas were swept by sufficiently strong currents during the later Cenozoic to prevent extensive deposition of younger strata on the southern side of the ridges or in patches around the seamounts. Although we do not have firm dates on when these strong currents were initiated, they are probably a post-Oligocene feature (on the basis of sedimentation rate changes at ODP Site 1276 in the Newfoundland Basin) and may reflect the full development of North Atlantic Deep Water, possibly in combination with a strengthened Gulf Stream. Before this time, the remarkable thickness, absence of internal reflections, and drift morphology suggest that the Paleogene section is likely to be hugely expanded, with sedimentation rates much higher than the $0.5-1 \mathrm{~cm} / \mathrm{k} . \mathrm{y}$. typically encountered in the deep sea. A similar transition from drift deposition to nondeposition in the latest Eocene was observed on Blake Plateau off the Florida-South Carolina margin during Leg 171B (Norris, Kroon, Klaus, et al., 1998). On Blake Nose, the Eocene and older sections are unusually expanded, with deposition rates as high as $6 \mathrm{~cm} / \mathrm{k} . \mathrm{y}$. throughout the later middle and late Eocene (Norris et al., 2001a, 2001b). We viewed the Leg 171B results as a favorable prognosis for the outcome of drilling the Newfoundland ridges.

The primary drilling targets for Expedition 342 are in plastered drifts that exist in two places: (1) the southern toe and eastern flank of J-Anomaly Ridge (Fig. F11) and (2) the north-facing slopes of seamounts on Southeast Newfoundland Ridge (Fig. F12). In total, we targeted four different drifts during Expedition 342 to compare the sedimentation histories of drifts formed under different hydrodynamic conditions.

Drift sedimentation clearly has a complex history on the Newfoundland ridges, with an initial phase of drift formation on the eastern flank of J-Anomaly Ridge in the Late Cretaceous (probably starting in the Campanian or early Maastrichtian, judging from Site 384 drilling results) (Berggren et al., 2000; Tucholke and Ludwig, 1982) and continuing 
through most or all of the Paleocene. Site 384 was spot cored in a highly condensed section, and the Paleocene/Eocene boundary was not recovered. However, acoustic character does change at some point in the upper Paleocene or lower to middle Eocene with the deposition of an acoustically transparent layer (seismic Unit 3; Fig. F6). This transparent seismic unit is our primary drilling target because the absence of internal reflectors suggests that it is a conformable sequence with a good likelihood of being correlative across the depth transect.

Drift morphology suggests that the primary drift deposits formed mostly under a southward-flowing bottom current in the Eocene. This current formed plastered drifts on the northeast and southwest faces of seamounts on Southeast Newfoundland Ridge, as well as a long episodically growing and accreting ridge system between J-Anomaly Ridge and Southeast Newfoundland Ridge (Fig. F11). The southeastern flank of Southeast Newfoundland Ridge has a very thick seismically transparent drift (part of seismic Unit 3) that is overlain by a younger drift deposit that displays complex internal reflectors consistent with sediment waves (seismic Unit 2). We provisionally assigned the transition between these drift packages to the EOT.

The considerable thickness of the middle Eocene to ?upper Eocene seismically transparent interval (seismic Unit 3) requires that traditional methods of coring Paleogene targets will have to give way to more focused drilling objectives. Most previous Paleogene and Cretaceous drilling was designed to obtain records spanning tens of millions of years. In contrast, previous drilling legs that targeted Pleistocene drifts typically cored the upper parts of the sediment packages in order to obtain highly expanded records of the late Pleistocene. Our goal was to follow the "Pleistocene strategy," in which we cored expanded drift records at the expense of long time series.

\section{Background and objectives: MDHDS sea trials}

The ability to measure pressure and permeability in mudstone is critical to understanding the impact of fluid pressure/flow on the occurrence, stability, and dissociation of gas hydrate (Hyndman and Davis, 1992; Kvenvolden, 1993; Dickens et al.,1997; Ruppel, 1997; Dillon et al., 2000; Liu and Flemings, 2009), the geometry, structure, fluxes, and earthquake mechanics of accretionary complexes (Davis et al.,1983; Dahlen et al., 1984; Bekins and Dreiss, 1992; Saffer and Bekins, 2002; Screaton et al., 2002), and the cause of submarine landslides (Terzaghi,
1950; Bombolakis, 1981; Haneberg, 1995; Dugan and Flemings, 2000, 2002). Models of these systems await validation because of the sparsity of direct pressure measurements. IODP has started to implement short-term measurements with penetrometers (Flemings et al., 2008) and downhole formation testers (Saffer, McNeill, Byrne, Araki, Toczko, Eguchi, Takahashi, and the Expedition 319 Scientists, 2010) and long-term observatories (Fisher et al., 2005).

\section{Why the MDHDS?}

Previously, the temperature-dual-pressure probe (T2P) and the Sediment Temperature-Pressure Tool (SETP; formerly the Davis-Villinger Temperature Pressure Probe), the two penetrometers used by IODP, were deployed by wireline on the colleted delivery system (CDS). The CDS is analogous to an oldstyle pointer, in which a series of cylinders slide past each other to increase or decrease the system's length. In this configuration, the penetrometer is pushed in by the drill string and then the drill string is raised to decouple the drill string from the formation. However, the penetrometer remains connected to the drill string through the CDS, which should expand and contract during ship heave. Analysis of previous deployments showed that when the drill string was raised, the penetrometer was pulled out of the formation $>80 \%$ of the time, resulting in a rapid drop in measured pressure and a compromised measurement (Fig. F13).

The MDHDS (Fig. F14) was designed to overcome this problem and is an engineering development intended to serve as the foundation for future penetrometer and other downhole tool formation measurements. The MDHDS allows in situ tools to be hydraulically driven into the formation and then decoupled from the heave of the drill string, which often compromises the fidelity of these measurements.

The MDHDS can be deployed either on the coring wireline or on an armored conductor cable such as the logging line. The MDHDS allows the bottomhole assembly (BHA) to remain $2 \mathrm{~m}$ off the bottom of the borehole (Fig. F14). This clearance reduces the possibility of jamming borehole cuttings or other detritus inside the BHA, which could result in coupling between the tool and the BHA. The penetrometer is extracted from the formation by lowering the wireline through the upper latch union, allowing the "running shoe" (designed to retrieve downhole tools by wireline) overshot to latch onto the running shoe fishing neck attached to the upper piston rod. In the case of a hotline deployment, the soft tether recoils inside the upper piston rod, allowing the running shoe overshot to latch onto the running shoe fishing neck. 
The primary objective of the MDHDS sea trials was to test the MDHDS. The goal was to wash to a depth of 100 meters below seafloor (mbsf), test the MDHDS in situ for at least $30 \mathrm{~min}$, turn on the pumps to clean the hole, take an advanced piston corer (APC) core, test the tool in situ again, and take three more APC cores. The site chosen for the tests was a reoccupation of ODP Site 1073, New Jersey margin. This sea trial was the culmination of multiple land-based tests, and a successful deployment means that this tool can be reliably deployed during future expeditions

\section{Principal results: Newfoundland sediment drifts}

\section{Paleogene drift sedimentation in the northwest Atlantic Ocean}

Expedition 342 drill sites are in plastered drifts that exist in two places: (1) the southern flank of J-Anomaly Ridge and (2) the slopes of seamounts on Southeast Newfoundland Ridge (Fig. F15). Both accretionary drifts and plastered drifts have formed adjacent to passages between bathymetric highs, most commonly on the northeastern and southwestern sides of seamounts. Some of these drifts are highly localized features that form lenticular bodies over a depth gradient of $>1000 \mathrm{~m}$ in some cases, which gives them their typical "slug" appearance on seismic reflection profiles (Fig. F16). Other drifts are clearly accretionary features that have built toward moats adjacent to seamounts. A particularly elongate sediment ridge exists next to Titanic Canyon between J-Anomaly Ridge and Southeast Newfoundland Ridge (Fig. F11). Seismic records show that the Titanic Canyon drift is made entirely of sediment and was built as a series of spur ridges lapping against the northwestern flank of J-Anomaly Ridge. These ridges appear to be constructed largely of mudwaves based upon their seismic character and enclose ponds of young, likely Pleistocene, sediment. The accretionary drifts, in particular, offer an attractive drilling target for future expeditions because they offer the opportunity to core very high deposition rate sequences with offset shallow penetration sites.

Expedition 342 cored four of these drift sequences, each covered by a thin veneer of Pliocene and Pleistocene, or sometimes Miocene to uppermost Oligocene, sediment. The sites in the deepest water were drilled on J-Anomaly Ridge, where drilling encountered a carbonate-rich Cretaceous to Paleocene sequence overlain by a clay-rich Eocene to lower Miocene sequence (Sites U1403-U1406) (Fig. F16). Three additional drifts were drilled on the crest of Southeast Newfoundland Ridge near the wreck of the Titanic. Each of these drifts appears to preserve a middle Eocene to Lower Cretaceous sequence overlying an Albian or older reef complex. Coring at Sites U1407 and U1408 recovered much of this sequence in one of the drifts. Coring in another drift (Sites U1409 and U1410) focused on the younger, middle Eocene to Paleocene portion of the record. Finally, Site U1411 targeted still another drift that proved to have a highly expanded record of the upper Eocene and Oligocene overlying an uncored section that is likely of middle Eocene age based on seismic ties to Site U1410.

Results from Expedition 342 indicate that the onset of relatively clay-rich, high accumulation rate $(>3$ $\mathrm{cm} / \mathrm{k}$.y.) sedimentation, which we interpret as the onset of drift deposition, is early middle Eocene age $(\sim 47 \mathrm{Ma})$ at both J-Anomaly Ridge and Southeast Newfoundland Ridge (Fig. F17). This result closely matches new findings of the timing of drift onset in the Greenland-Scotland Ridge basins of the northeast Atlantic (Hohbein et al., 2012). Onset of drift deposition to the north (Labrador Sea and Northeast Atlantic) and to the south (Blake, Hatteras, and Chesapeake Drifts) is thought to occur no older than middle to late Eocene ( 40 Ma) (Mountain and Tucholke 1985; Arthur et al., 1989). However, erosion associated with a significant regional unconformity that developed during the EOT (Reflector $A_{u}$ ) is interpreted to have removed sediment possibly associated with early to middle Eocene drifts along the eastern United States margin (Mountain and Tucholke, 1985). The discovery and recovery of an expanded middle Eocene section at multiple sites preserved in the Newfoundland drift complex is a significant achievement of Expedition 342.

Drift accumulation through the EOT was recovered at two sites on J-Anomaly Ridge (Sites U1404 and U1406) and one site on Southeast Newfoundland Ridge (Site U1411). The drifts with the highest sedimentation rates of the expedition $(>10 \mathrm{~cm} / \mathrm{k} . \mathrm{y}$.) span the latest Oligocene and Oligocene/Miocene boundary (Fig. F17). These higher maximum sedimentation rates (three times higher than the Eocene drifts) across the Oligocene-Miocene transition and during the Miocene isotope Event 1 (Mi1) glaciation are suggestive of an intensification of boundary current flow strength, sediment transport, and drift development. Why the drift deposits on J-Anomaly Ridge are of late Oligocene and early Miocene age and not of early Oligocene age remains uncertain. It is unclear at this time whether this pattern of lower accumulation rate in the older drifts is due to diminished supply of terrigenous sediment (e.g., as a result of cli- 
matic change), weaker currents (resulting in less sediment transport), or perhaps stronger currents (i.e., less material being deposited).

Insignificant thicknesses of late Miocene to Pliocene age drift deposits were recovered during Expedition 342. It is important to reiterate that the drilling strategy of Expedition 342 was to avoid thick accumulations of Neogene sediments to access and recover Paleogene sediments with the APC. Thus, the record of drift sedimentation depicted in Figures F17 and F18 shows the late Miocene to Pliocene dominated by nondeposition and inherently emphasizes the Paleogene history. However, as discussed above, seismic reflection data indicate that many areas on Southeast Newfoundland Ridge have Neogene drift accumulations several hundreds of meters to nearly $1 \mathrm{~km}$ in thickness.

\section{Acoustic units of the Newfoundland ridges}

Expedition 342 provided strong constraints on the ages of the major acoustic units on the Newfoundland ridges. Correlation of a prominent regional reflector interpreted as volcanic basement is straightforward and shows that the overlying sedimentary package generally drapes this inherited topography. However, some modern bathymetric features are primarily composed of drift sediments-these include the majority of the crest of Southeast Newfoundland Ridge and the linear ridge within Titanic Canyon. The deepest sedimentary reflector package consists of strong, usually highly continuous reflections that intersect mounded, internally structureless reflector units interpreted as buried reefs and flanking shallow-marine sediments. The reef sediments have been sampled at both the crest of J-Anomaly Ridge (Site 384) (Tucholke and Vogt, 1979) and on a seamount crest on Southeast Newfoundland Ridge (Site U1407). Overlapping the seismic expression of the reefs is a partially transparent reflector package that passes upward into a zone of discontinuous reflections. In some cases the discontinuous reflector unit grades laterally into well-developed, parallel, strong reflections. Site U1407 showed that this entire package consists of Albian-Campanian chalk and black shale. The interval from the K/Pg boundary through the middle early Eocene is represented by mostly strong, often continuous reflections associated with a zone of chert interbedded with chalk and calcareous ooze. Above this, the sedimentary pile is represented by a thick sequence of mostly acoustically transparent units that pass upward into more distinct wavy reflections suggestive of large-wavelength mudwaves. The entire transparent sequence is well dated by Expedition 342 coring and ranges in age from the middle early Eocene to the middle Mio- cene. The uppermost parts of the mudwave package have not been cored, but the absence of strong reflectors that could be unconformities suggest that the mudwave unit probably preserves an extensive Miocene and Pliocene record. Pleistocene (and possibly Pliocene) sediments, represented by strong parallel reflections, cap the entire sedimentary pile.

Subdivisions of the general reflector stratigraphy are possible. Most of the time during Expedition 342 was spent coring the upper acoustically transparent unit of Eocene to Miocene age. This unit can be divided into three subunits based upon reflection character. The lowest of these is a zone of generally fuzzy, acoustically dense reflections that typically do not have well-developed layers. Coring at Sites U1403U1406 on J-Anomaly Ridge shows that this acoustically dense reflector unit is of early Eocene to middle Eocene age and tends to contain more calcium carbonate and opal than overlying sediments. Above the lower acoustically fuzzy subunit is an interval of dispersed reflections that are often discontinuous or faint. Coring at Site U1411 showed that the discontinuous reflections correspond to the zone of high sedimentation rates and changes in calcium carbonate abundance around the Eocene/Oligocene boundary. This boundary is not visible everywhere because there is very little seismic expression in the Eocene/ Oligocene boundary sections on J-Anomaly Ridge. The upper part of the acoustically transparent unit typically is completely transparent but may, in places, show patches of wavy reflections similar to but far less continuous than the overlying mudwavedominated sequence. Sites U1404-U1406 and U1411 encountered a lower Miocene to middle Oligocene section of clay and nannofossil clay. Other sites (U1403 and U1407-U1410) encountered condensed sequences, often of clay with low carbonate content and multiple sharp surfaces indicative of nondeposition or erosion.

Reef and shallow-marine carbonates form a pair of strong reflectors just above volcanic basement over much of Southeast Newfoundland Ridge. Drilling at Site U1407 showed that the prominent reflectors at the very base of the sedimentary sequence on Southeast Newfoundland Ridge include shallow-marine carbonate grainstone and packstone of probable late Albian and older age. The late Albian reflector overlies acoustic features that indicate probable reef buildups. Morphological reefs without internal reflectors are also visible in seismic lines from much of the expedition drilling area. Similar shallow-marine carbonates were extensively drilled on the crest of JAnomaly Ridge at Site 384, where they were dated to the early Albian, early Aptian, and late Barremian (Tucholke and Vogt, 1979). 


\section{Lithostratigraphic summary}

The sedimentary sequence on J-Anomaly Ridge and Southeast Newfoundland Ridge comprises six general expedition lithostratigraphic units (Table T1).

\section{Unit A}

Unit A is composed of clay, foraminifer sand, and nannofossil ooze containing dropstones, ice-rafted sand, and manganese nodules of Pleistocene to Pliocene age. Lithic fragments interpreted as IRD include subrounded pebbles and cobbles of basalt, granitic rocks, amphibolite, dolomite, and fossiliferous packstone and grainstone. Sediment is commonly shades of brown, tan, red, and green, reflecting variations in clay content, ice-transported sediment, and siliceous and calcareous microfossils and is extensively bioturbated, but centimeter to decimeter bedding is common. Pleistocene cover sediments tend to exhibit high magnetic susceptibility (Fig. F19) and strong contrasts in other physical properties, reflecting the large lithologic differences between glacial and interglacial sediments (Figs. F20, F21, F22). These sequences were cored only in thin, surficial cover during Expedition 342, but seismic reflection data suggest this unit reaches thicknesses of at least 200$500 \mathrm{~m}$ on the crest of Southeast Newfoundland Ridge and its northern slope.

\section{Unit B}

Unit B is composed of clay (often noncalcareous) and nannofossil ooze of Pliocene to early Oligocene age (Figs. F23, F24). Clay deposits were recovered at most of the Expedition 342 sites as condensed sequences. Sediment is commonly yellow, tan, brown, or pale green. Sand- and silt-sized lithic grains are common, probably reflecting ice rafting (Fig. F25). Typically, sediment in Unit B has low magnetic susceptibility and shows an abrupt shift in many physical properties compared to the overlying Pleistocene sediment (Figs. F19, F20, F21, F22). Multiple unconformities are common in this sequence, sometimes marked by burrowed firmgrounds or glauconitic horizons (Fig. F26B). Burrowing is often intense, creating smooth-textured clay-rich sediment without much physical stratification. Lithologic cycles are usually faint, either because of very low sedimentation rates or very high deposition rates in fairly uniform sediment. This general lithostratigraphic unit is likely roughly time-correlative to seismic sequences of mudwaves elsewhere on J-Anomaly Ridge and Southeast Newfoundland Ridge that are 1000-2000 $\mathrm{m}$ thick. We did not core thick sequences of mudwaves, so their lithologic expression is unknown in detail.

\section{Unit C}

Unit $\mathrm{C}$ is composed of nannofossil clay, nannofossil ooze, and biosiliceous ooze of early Miocene to middle Eocene age. In smear slides, the carbonate and biosilica are typically well preserved (Figs. F23, F24). Such sediment was cored at all Expedition 342 sites and consists of green, gray, and white deposits with often well-developed cycles in color, magnetic susceptibility, and bulk density (Figs. F20). Sedimentation rates are often higher than in other lithologic units, with rates as high as $3-10 \mathrm{~cm} / \mathrm{k} . y$. largely because of high clay fluxes. Probable ice-rafted sand and silt occurs in the Miocene, Oligocene, and uppermost Eocene part of this unit, often as subrounded grains of fine carbonate-cemented sandstone that degrades to blebs of silt- to sand-sized angular quartz (Figs. F26D, F25). The paler sediment in Unit C is typically carbonate rich (40-80 wt\%) and displays cycles in carbonate abundance on decimeter to tens of meters wavelengths. Calcareous microfossils are often well preserved, particularly in clay-rich facies. Siliceous sediment, sometimes with well-preserved diatoms and radiolarians, is common in the Miocene part of this sequence (Figs. F23, F24). A prominent horizon interpreted to represent ejecta from the Chesapeake Bay impact event is notable at Site U1403, whereas a rare occurrence of a native copper-filled vein occurs in sediment of middle to late Eocene age at Site U1406 on J-Anomaly Ridge (Fig. F26A, F26C). Lithostratigraphic Unit C is represented by acoustically transparent drift packages in the deeper parts of the Southeast Newfoundland Ridge sedimentary record as well as in plastered drifts around seamounts.

\section{Unit D}

Unit D is composed of nannofossil ooze, chert, and biosiliceous ooze of early Eocene to Campanian age (Figs. F23, F24). These sediments are commonly white, brown, and pink ooze and chalk with mottles and interbedded tan, pale green, and dark brown chert. Sedimentation rates are low $(\sim 1 \mathrm{~cm} / \mathrm{k} . \mathrm{y}$. or less), reflecting mostly pelagic biogenic sediment deposition and low terrestrial clay fluxes. Burrows are common, and bedding is mostly confined to decimeter-scale cycles of varying carbonate concentration. In sites on Southeast Newfoundland Ridge, carbonate content can be $\sim 80-90 \mathrm{wt} \%$ and microfossil preservation is commonly moderate to poor with overgrowths and carbonate infilling. This lithostratigraphic unit typically is rich in radiolarians, particularly in the Paleocene and early Eocene, although the chalk immediately above and below chert layers commonly has rare, poorly preserved radiolarians. Magnetic susceptibility and bulk density 
are commonly high in this unit, and natural gamma radiation (NGR) characteristically is low, reflecting the low-terrigenous sediment fraction and relatively extensive diagenetic cementation (Figs. F19, F20, F21, F22). The contact with the middle Eocene graygreen nannofossil clay is often unconformable, but at least one of the sites (U1410) apparently has a biostratigraphically complete contact. Prominent volcanic ash layers are notable in sediment of Paleocene age and are associated with downhole spikes in magnetic susceptibility that can be readily correlated among sites (Fig. F27). Lithostratigraphic Unit D exists as pelagic sediments below the main drift sequences over much of Southeast Newfoundland Ridge and was encountered in the deeper parts of Expedition 342 drill sites.

\section{Unit E}

Unit $\mathrm{E}$ is composed of nannofossil chalk and organic-rich claystone of Santonian to Albian age (Figs. F23, F24). We cored this sequence at Site U1407, where we found it to be brown, tan, and pale green nannofossil chalk. Burrowing is extensive, and bedding is confined to decimeter-scale cycles of darker and lighter sediment. Carbonate content is typically high (80-90 wt\%), and chert is present but rare. Bulk density and magnetic susceptibility are typically high and variable (Figs. F19, F20, F21, F22). Black shale and green laminated nannofossil clay is present in intervals near the Cenomanian/Turonian boundary. Total organic carbon reaches $11 \mathrm{wt} \%$ in the black shale, from background levels of $\sim 0.5 \mathrm{wt} \%$ in the surrounding nannofossil chalk. A gradational contact exists between Unit $\mathrm{E}$ and both the overlying and underlying units.

\section{Unit F}

Unit $\mathrm{F}$ is composed of shallow-marine carbonate sandstone, pelletal packstone, skeletal grainstone, and oolitic limestone of Albian or older age cored at Site U1407 (and at Site 384) (Figs. F23, F24). This lithostratigraphic unit is interpreted to have been deposited in a variety of shallow-marine carbonatedominated environments, ranging from reefs to lagoons and shelf-carbonate sandstones. We did not recover sediment from this unit with much fidelity, but the small rollers we did obtain are typically pale tan to brown moldic skeletal grainstone, pelletal grainstone, and pelletal packstone. A variety of shallow-marine fossil groups are represented, including belemnites, gastropods, bivalves, echinoderms, and corals. The seismic expression of this unit is of morphologic reefs as thick as $400 \mathrm{~m}$ and strong parallel reflectors that represent hardgrounds composed of carbonate grainstone and lagoon sediments.

\section{Interstitial water geochemistry}

Alkalinity and ammonium concentrations are expected to increase with depth in interstitial water as sedimentary organic matter undergoes degradation. At the J-Anomaly Ridge sites, alkalinity and ammonium concentrations are $<10 \mathrm{mM}$ and $380 \mu \mathrm{M}$, respectively, which are typical in an organically lean sediment (Fig. F28). The overall downhole trends in alkalinity and ammonium concentrations increase with depth to between 100 and 250 mbsf, suggesting that this depth interval marks the locus of peak organic matter consumption. The depth profile of dissolved manganese concentration closely follows those of alkalinity and ammonium, indicating that the organic matter decomposition process drives the reduction of manganese (IV) oxide as expressed by

$$
\begin{gathered}
\left(\mathrm{CH}_{2}\right)_{x}\left(\mathrm{NH}_{3}\right)_{y}\left(\mathrm{H}_{2} \mathrm{PO}_{4}\right)_{z}+2 x \mathrm{MnO}_{2}+3 x \mathrm{CO}_{2}+x \mathrm{H}_{2} \mathrm{O} \rightarrow \\
4 x \mathrm{HCO}_{3}{ }^{-}+y \mathrm{NH}_{3}+z \mathrm{H}_{3} \mathrm{PO}_{4}+2 x \mathrm{Mn}^{2+} .
\end{gathered}
$$

A comparison of alkalinity and ammonium concentrations from the J-Anomaly Ridge sites indicates low values at Sites U1403 and U1406, especially in ammonium. This suggests that the sedimentary organic matter at Site U1406 exists at lower concentration and/or lesser reactivity than at other J-Anomaly Ridge sites (Fig. F28). The prediction of higher sedimentary organic matter content at Sites U1404 and $\mathrm{U} 1405$ is borne out by measurements of nitrogen at Site U1404 (Fig. F29), which has the highest total nitrogen content of all J-Anomaly Ridge sites.

Dissolved iron concentrations are low at Sites U1403, U1404, and U1406 ( $<15 \mu \mathrm{M})$ (Fig. F28). Iron concentrations are similarly low at Site U1405 from 0 to 75 mbsf but then increase downhole to values as high as $35 \mu \mathrm{M}$ between 75 and 250 mbsf, to $100 \mu \mathrm{M}$ at $265 \mathrm{mbsf}$, and then to $<5 \mu \mathrm{M}$ at 300 mbsf. Dissolved manganese concentrations at Site U1405 reach a maximum at 220 mbsf and decrease with greater depth, suggesting that manganese (IV) reduction changes to iron (III) reduction with depth, as expressed in the following equation:

$$
\begin{gathered}
\left(\mathrm{CH}_{2} \mathrm{O}\right)_{x}\left(\mathrm{NH}_{3}\right)_{y}\left(\mathrm{H}_{2} \mathrm{PO}_{4}\right)_{z}+4 x \mathrm{Fe}(\mathrm{OH})_{3}+3 x \mathrm{CO}_{2}+x \mathrm{H}_{2} \mathrm{O} \\
\rightarrow 8 x \mathrm{HCO}_{3}^{-}+y \mathrm{NH}_{3}+z \mathrm{H}_{3} \mathrm{PO}_{4}+4 x \mathrm{Fe}^{2+}+3 x \mathrm{H}_{2} \mathrm{O} .
\end{gathered}
$$

These data indicate that sedimentary organic matter at Site U1405 was present in higher concentrations during the deposition of the sediment than at the other J-Anomaly Ridge sites.

Concentrations of calcium and strontium generally increase monotonically with depth at Sites U1403U1405 (Fig. F30). The profiles for calcium and strontium at Site U1406 reach maxima at 180 and 210 mbsf, respectively, and then decease slightly, sug- 
gesting that the effect of carbonate recrystallization deep within the sequence ( 200-250 mbsf) in Eocene-aged sediments is greater at Site U1406 than at other J-Anomaly Ridge sites. Magnesium concentration profiles show overall decreases downcore, with some minor fluctuations. $\mathrm{Mg} / \mathrm{Ca}$ ratios decrease smoothly and eventually flatten with depth and, in the case of Site U1406, undergo a slight reversal below 200 mbsf (Fig. F30).

Concentration gradients of calcium, strontium, and magnesium appear to reflect the effects of exchange reactions within basaltic basement with some contribution from carbonate recrystallization mainly from below the drilled interval at Site U1405 and from the base of the drilled interval at Site U1406. The gradient of calcium concentrations at Site U1403 is the steepest, whereas that of Site U1406 is the weakest among all J-Anomaly Ridge sites. At Site U1406, the decrease in calcium concentrations below $200 \mathrm{mbsf}$ corresponds to a decrease in alkalinity and an interval of well-cemented chalks, indicating precipitation of carbonate (Fig. F30). The downhole increase in magnesium below 210 mbsf suggests "fresh" seawater flux to the deeper layers at this site, presumably a function of their outcropping close to the "nose" of the sediment drift.

Interstitial water profiles at Southeast Newfoundland Ridge Sites U1407-U1410 display evidence of compartmentalization with prominent abrupt downhole shifts in magnesium, manganese, and potassium at 100-120, 180-190, 125-130, and 220-230 mbsf, respectively (Figs. F31, F32), suggesting that the unrecovered sequences of Eocene chert act as aquicludes, a feature also characteristic of the roughly correlative sections drilled on Blake Nose (Leg171B; Rudnicki et al., 2001).

Despite smaller scale fluctuations (see discussion below), the overall trends of alkalinity, ammonium, manganese, and iron in interstitial water at Southeast Newfoundland Ridge sites increase with depth, reaching maximum values of $6 \mathrm{mM}$ and 160,28, and $80 \mu \mathrm{M}$, respectively. These concentrations are much lower than those observed in cores at the J-Anomaly Ridge sites, suggesting lower TOC contents or that less reactive organic matter survives into the interstitial water at the Southeast Newfoundland Ridge sites. Depth profiles of alkalinity and manganese concentrations are well correlated with each other. This covariation of alkalinity and manganese concentrations indicates that organic matter degradation associated with manganese reduction controls the observed profiles, analogous to what was observed at the J-Anomaly Ridge sites (e.g., Fig. F30). However, in contrast to J-Anomaly Ridge sites, Southeast Newfoundland Ridge depth profiles of alkalinity, manga- nese, and iron show fluctuations with depth, displaying multiple local maxima through the recovered sequences. This implies that the levels of organic matter varied considerably over the sampled depth interval, with the subsequent degradation of organic matter resulting in the complex observed patterns, with some modification by subsequent diffusional processes. Sulfate concentrations steadily decrease with depth, suggesting its distribution is driven by diffusion of seawater sulfate as well as organic matter variations. Where cherts occur, sulfate concentrations drop rapidly, especially at $\sim 150 \mathrm{mbsf}$ at Site U1409 (Fig. F31).

Depth profiles of calcium increase to $150 \mathrm{mbsf}$, whereas magnesium and $\mathrm{Mg} / \mathrm{Ca}$ ratios generally decrease over this interval, suggesting exchange reactions of pore fluid with volcanic basement as seen at J-Anomaly Ridge sites. At greater depths, most profiles tend to flatten (Site U1410 is an exception) and in some cases slightly increase. These inflections can be attributed to chert layers acting as aquicludes. At Site U1407, however, calcium concentrations tend to decrease slightly below the chert layer, whereas magnesium increases; again, these observations imply a source of fresh seawater below the bottom of the hole (Fig. F32).

\section{Paleoproductivity indicators}

Three of the four sites drilled on the J-Anomaly Ridge depth transect (Sites U1404, U1405, and U1406) captured a record of biostratigraphically datable upper Oligocene to lower Miocene sediments. Downhole records of paleoproductivity indicators suggest elevated export production during the Oligocene-early Miocene. The abundant occurrence of infaunal calcareous benthic foraminifers, including abundant Globobulimina pacifica at Site U1404 (Fig. F33), suggests the presence of low-oxygen bottom water conditions associated with high organic matter supply to the seafloor. The high abundance and excellent preservation of the diatom assemblage, including the dominance of high-productivity indicator Chaetoceros resting spores, further suggest high productivity during this period.

These data suggest a first-order pattern of high export production to the seafloor at J-Anomaly Ridge (Sites U1404-U1406) from the late Oligocene to early Miocene. At the deepest of these three sites, Site U1404 (4746 mbsl), there is benthic foraminifer evidence (from G. pacifica) of persistent low-oxygen bottom water conditions in the lower Miocene. At Site U1405 (4286 mbsl; $460 \mathrm{~m}$ shallower water depth), intermittent low-oxygen bottom water conditions are also indicated during the lower Miocene, whereas at Site U1406 (3814 mbsl), 930 m shal- 
lower than Site U1404, oxic seafloor conditions are maintained throughout the Oligocene to Miocene.

Oligocene to lower Miocene sediment was drilled on Southeast Newfoundland Ridge at all five sites, but apart from Site U1411, the sediment is restricted to only short intervals of time (Fig. F34). Downhole records of benthic foraminifers are remarkably similar to the J-Anomaly Ridge sites and suggest elevated export production through the Oligocene-early Miocene interval. In agreement with the upslope trend toward more oxygenated deep water across the JAnomaly Ridge depth transect, benthic foraminiferal assemblages at the shallower Southeast Newfoundland Ridge sites (3000-3500 mbsl) are dominated by infaunal taxa (Fig. F34) but lack clear indicators of suboxic bottom water (e.g., G. pacifica). Although diatoms and radiolarians are abundant in lower Miocene and upper Oligocene sediment at Sites U1404 and U1405, they are very rare or absent at the Southeast Newfoundland Ridge sites (compare Figs. F23, F24).

Given the high accumulation rates of drift sediment identified in the late Oligocene to early Miocene at JAnomaly Ridge sites and in the Oligocene at Southeast Newfoundland Ridge sites, this sediment will allow for high-resolution studies of paleoproductivity proxies like benthic foraminiferal assemblages, siliceous microfossils (diatoms and radiolarians), and nitrogen isotopes. Especially high sedimentation rates across the Oligocene-Miocene transition hold promise for future studies related to the OligoceneMiocene transition glaciation and suborbital-scale variability in paleoproductivity. Another valuable aspect of the recovered Expedition 342 sequences is the opportunity to study changes in oxygenation and paleoproductivity across the drilled depth transect at J-Anomaly Ridge, covering $1200 \mathrm{~m}$ of water depth (3813-4946 mbsl). This record can be combined with Site U1411 (3300 mbsl) at Southeast Newfoundland Ridge to expand the transect even further.

All Southeast Newfoundland Ridge sites show sporadic occurrences of infaunal-dominated benthic foraminifer assemblages in the middle Eocene (Fig. F34). This dominance of infaunal taxa suggests short-term increases in export production to the seafloor. For example, the upper interval of nannofossil Zone NP16 and lower interval of Zone NP17, spanning the MECO, are characterized by increased abundances of infaunal taxa, suggesting a response to warming associated with the MECO event.

\section{Paleogene and Cretaceous organic matter}

Organic matter preserved in marine sediments provides important information on paleoceanographic and paleoclimatologic changes. In the past few decades, organic biomarker studies have significantly advanced our understanding in this field (e.g., Brassell, 1984; Simoneit, 1986; Volkman et al., 1988; Hayes, 1993; Schouten et al., 2003; Pagani et al., 2005). During this expedition, we performed $>1600$ organic analyses using the Flash EA to derive TOC and total nitrogen contents and also analyzed a small set of sediment samples for organic matter characterization using the Source Rock Analyzer. Organic-rich sediment from OAE 2 was recovered at Site U1407 and characterized in some detail on board (see "Ocean Anoxic Event 2").

TOC and total nitrogen profiles from J-Anomaly Ridge sites indicate that organic matter preservation peaked in the early Miocene (Fig. F29), which, together with the abundance of diatoms and infaunal benthic foraminifers (see "Paleoproductivity indicators"), suggests high productivity during the early Miocene. Sites U1403-U1406 comprise a depth transect (4946-3813 mbsl) along the southwestern flank of J-Anomaly Ridge. TOC values reach $\sim 2 \mathrm{wt} \%$ at the two middle sites on J-Anomaly Ridge (Sites U1404 and U1405) and are somewhat lower (1.5 $\mathrm{wt} \%)$ at the sites on either end of the depth transect (Sites U1403 and U1406). Total nitrogen contents at all four sites vary between 0.1 and $0.2 \mathrm{wt} \%$ in the early Miocene section. In early Eocene-Paleocene sediment recovered from Site U1403, TOC content is highly variable, but total nitrogen values remain low (mostly $<0.05 \mathrm{wt} \%$ ) through the sedimentary sequence (Fig. F29).

TOC and total nitrogen profiles from Southeast Newfoundland Ridge sites are remarkably similar in that organic matter concentration increases substantially across the early/middle Eocene boundary (Fig. F35), corresponding to changes in carbonate content and lithostratigraphy. TOC content changes from $\sim 0.5$ $w \mathrm{t} \%$ or lower in the early Eocene to $1.0-1.5 \mathrm{wt} \%$ in the middle Eocene, whereas total nitrogen content ranges from almost 0 to $0.05-0.15 \mathrm{wt} \%$.

Results suggest that sediment recovered during Expedition 342 provides great opportunities for organic geochemistry work, such as sea-surface temperature reconstruction based on the $\mathrm{TEX}_{86}$ and alkenone proxies, alkenone-based $p \mathrm{CO}_{2}$ reconstruction, biomarker reconstruction of terrestrial and marine ecosystems, and other specific biomarkers that indicate past oceanic and climatic conditions (e.g., Schouten et al., 2003; Pagani et al., 2005; Liu et al., 2009). In general, organic matter content is higher at J-Anomaly Ridge sites than at Southeast Newfoundland Ridge sites. Given the high sedimentation rates of drift sediment identified in the late Oligocene to early Miocene at J-Anomaly Ridge sites (as high as 10 
$\mathrm{cm} / \mathrm{k} . \mathrm{y}$.$) and in the middle Eocene at Southeast New-$ foundland Ridge sites $(\sim 3 \mathrm{~cm} / \mathrm{k} . \mathrm{y}$.$) , this sediment will$ allow high-resolution studies on organic compounds. Variance in geochemical parameters such as TOC and total nitrogen through events such as OAE 2 (see "Ocean Anoxic Event 2"), the K/Pg boundary, and the PETM (Figs. F29, F35) also hold promise for future organic geochemical studies.

\section{Exceptional preservation in drift clay-rich sediment}

One of the primary objectives of Expedition 342 was the recovery of high accumulation-rate, clay-rich sediment containing well-preserved microfossils suitable for trace element geochemistry, isotope geochemistry, and faunal studies. At almost all Expedition 342 sites where drift sediment was recovered, we observed calcareous microfossil preservation that was good and moderate to good and significantly better than the quality of preservation that is typical of deep-sea deposits. Furthermore, significant intervals of these drift successions contained exceptionally well preserved calcareous microfossils, including glassy foraminifers, and diverse, minute, and fragile calcareous nannofossils. Such high-quality preservation is usually only found in clay-rich shelf and slope sections (Pearson et al., 2001; Bown et al., 2008), so the recovery of stratigraphically continuous and expanded middle Eocene through lower Miocene successions with exceptional microfossil preservation is a significant outcome of the expedition.

The preservation of calcareous microfossils is strongly affected by the carbonate saturation state of bottom water and, therefore, proximity to the CCD and lysocline (e.g., Berger, 1970). Preservation is also affected by the composition of the sediment, in particular clay and carbonate contents (Norris and Wilson, 1998; Pearson et al., 2001; Wilson and Norris, 2001; Sexton et al., 2006b; Bown et al., 2008). Carbonate-rich sediment (e.g., nannofossil ooze) tends to promote the overgrowth and recrystallization of calcareous microfossils, whereas clay-rich sediment (e.g., nannofossil clay) typically contains well-preserved microfossils (Pearson et al., 2001; Sexton et al., 2006b; Bown et al., 2008). The spectrum of observed preservation states is dependent on the claycarbonate balance. Exceptional preservation of planktonic and calcareous benthic foraminifers is characterized by the observation of glassy, translucent, unfilled tests with surface ornamentation (Fig. F36) (Sexton et al., 2006b; Sexton and Wilson, 2009). In calcareous nannofossils, unusually excellent preservation is identified by high diversity and the presence of abundant minute coccoliths $(<3 \mu \mathrm{m})$ and larger preservation-sensitive taxa such as holococcoliths and Blackites spp. (Fig. F37) (Bown et al., 2008).

Siliceous plankton preservation is also affected by sediment composition. The best preservation occurs in clay-rich sediment, although good preservation is often found in carbonate-rich sediment. The oceans are everywhere undersaturated with respect to biogenic opal (Archer et al., 1993; Racki and Cordey, 2000), so to a first approximation preservation of siliceous microfossils is controlled by interstitial concentrations of dissolved silica. Dissolved silica is largely determined by rates of supply of opal and the other sedimentary components, such as clay and carbonates, to the seafloor. Hence, preservation of radiolarians and diatoms tends to be maximized at sites of high-export production, such as zones of surface ocean divergence and upwelling.

Sediment recovered from J-Anomaly Ridge and Southeast Newfoundland Ridge spans a wide range of lithologies, from siliceous and calcareous biogenic ooze to clay with minor biogenic components. This range of lithologies is the result of several factors, including original biotic production and export rates, clastic particle flux, and seafloor dissolution. The amount of dissolution is time dependent as a function of both the paleodepth (subsidence) history of each site and basin-scale fluctuations in the CCD in response to long-term variability in global biogeochemical cycles. This dissolution signal is most clearly seen at the deepest sites on the J-Anomaly Ridge depth transect (Sites U1403 and U1404), where the preserved sedimentary record reflects varying degrees of seafloor carbonate dissolution close to or beneath the CCD or lysocline (Figs. F38, F39). The occurrence of high carbonate contents in the Paleocene and Maastrichtian at Site U1403, the deepest site on the Newfoundland drifts sediment transect, suggests that the CCD was deeper at this time compared to previous estimates based on Site 384 (Fig. F2). Our records also indicate that the CCD in the North Atlantic was substantially deeper (by $\sim 1.5 \mathrm{~km}$ ) during the early Eocene than it was in the equatorial Pacific (see "Paleogene and Cretaceous carbonate compensation depth in the northwest Atlantic") and then shoaled substantially by the middle Eocene. At Site U1404, short-lived intervals of good calcareous microfossil preservation within middle Eocene strata that are otherwise largely noncalcareous suggest transient (million year scale) shoaling and deepening events during this interval akin to those documented in the equatorial Pacific (Lyle et al., 2005; Pälike et al., 2012). The sites at Southeast Newfoundland Ridge are currently at 3500 mbsl or less and typically contain abundant and 
moderate to exceptionally well preserved calcareous microfossils (Fig. F39) that are less affected by CCDrelated dissolution. However, intervals of low or no carbonate and accompanying poor calcareous microfossil preservation occur in the condensed Pliocene, Miocene, and upper Oligocene sequences and may be related to relatively extended exposure at the seafloor.

A compilation of shipboard qualitative estimates of microfossil preservation and abundance made during biostratigraphic analyses reveals a strong link between the preserved fossil record and the interlinked factors of site paleodepth/subsidence history and ocean CCD but also highlights the strikingly different sensitivities to dissolution across the fossil groups (Fig. F38, F39). Planktonic foraminifers have the most dissolution-sensitive record of the calcareous microfossil groups and are absent for long intervals at the deepest Sites U1403 and U1404. In strata of Eocene age at these deep sites, it appears that carbonate values of $\sim 50 \mathrm{wt} \%$ are required to ensure the conservation of planktonic foraminifers, but foraminifers are present at far lower carbonate values in the clay-rich Oligocene and Miocene ( $<10$ wt $\%)$. Planktonic foraminifers are consistently present at the shallower Sites U1406-U1411, where a range of preservation is associated with fine-scale clay-carbonate variability. Preservation is typically consistently good and very good in the drift sediment at Southeast Newfoundland Ridge Sites U1407-U1411. Here, the glassy unfilled tests indicative of exceptionally high quality foraminifer preservation are common (Fig. F36) and are likely the result of the clay-rich nature of the sediment entombing carbonate microfossils and reducing their interaction with surrounding interstitial water (Norris and Wilson, 1998; Pearson et al., 2001; Wilson and Norris, 2001; Sexton et al., 2006b; Bown et al., 2008; Sexton and Wilson, 2009). Where high carbonate contents coincide with low clay values, for example in the lower Eocene and, where present, the Paleocene (Sites U1406-U1409), preservation declines, with foraminifers exhibiting a frosty appearance (sensu Sexton et al., 2006b), reflecting both dissolution and secondary calcite overgrowth.

Calcareous nannofossils and benthic foraminifers are typically less susceptible to dissolution than planktonic foraminifers, particularly in the Eocene section, and their states of preservation closely track the carbonate content at the deeper sites (U1403-U1404) (Fig. F38). This is not surprising given that coccoliths are, for the most part, the major carbonate contributors to this sediment. Nevertheless, both nannofossil and benthic foraminiferal preservation co-vary strongly with carbonate content, even when carbon- ate values are low and planktonic foraminifers are absent. Abundant and moderate to well-preserved nannofossils and good to very well preserved benthic foraminifers are consistently present through most of the succession at Sites U1405-U1411 (Figs. F38, F39).

Our data sets do not differentiate a "very good" preservation category for nannofossils, but the drift deposits do contain assemblages that can be described as excellent to exceptional (Fig. F37). High diversity and the presence of holococcoliths, minute coccoliths, and fragile forms indicate high-quality preservation. These forms are not usually found in typical deep-sea nannofossil ooze lithology because of both dissolution and secondary calcite overgrowth (Bown et al., 2008; Dunkley Jones et al., 2009). The occurrence of these high-quality nannofossil preservation indicators is typically coincident with observations of glassy planktonic foraminifers. It is notable that the benthic foraminifer records show consistently excellent preservation below the preservation quality threshold that marks the step-up to glassy preservation in planktonic foraminifers and holococcolith and minute coccolith preservation in nannofossils (Figs. F38, F39).

Wherever siliceous microfossils have been found in abundance during Expedition 342, they are generally very well preserved. At J-Anomaly Ridge Sites U1404-U1406, abundant and well-preserved radiolarians occur in the lower Miocene to upper Oligocene drift sediment, typically accompanied by abundant diatoms. By contrast, at the Southeast Newfoundland Ridge sites radiolarians were absent from the Eocene to Oligocene drift sediment. At all sites, radiolarians are typically abundant and well preserved in the subdrift sediment in the lower middle and lower Eocene (Sites U1403 and U1406U1410) and the lower Paleocene (Sites U1403, U1407, and U1409).

The pattern of radiolarian occurrence may be explained by two factors: productivity and temperature. Radiolarians are abundant and well preserved in intervals of varying carbonate content in the upper Oligocene-lower Miocene drift sediment at Sites U1404-U1406. Here, the abundance of diatoms and benthic foraminifer high-productivity indicators suggest high organic productivity and export production of biosilica and therefore enhanced preservation potential for siliceous microfossils, in general. In the Paleocene and lower Eocene, radiolarian occurrence is more likely related to the northward expansion of subtropical-tropical waters, as the assemblages are very similar to the diverse and rich assemblages previously reported from Blake Nose (Sanfillipo and Blome, 2001) and lower latitudes (Ka- 
mikuri et al., 2012). The absence of radiolarians in the middle Eocene through lower Oligocene may reflect the contraction of subtropical-tropical waters in response to cooling. Radiolarian preservation tends to worsen in the proximity of chert horizons, especially in the early Eocene and through the Paleocene-Eocene transition, reflecting the diagenetic transformation of biogenic silica into the cryptocrystalline quartz that constitutes the chert.

\section{Biochronology}

Coring at nine sites and 25 holes during Expedition 342 recovered sequences ranging from upper Pleistocene to upper Albian, representing $100 \mathrm{~m}$.y. of geological history (Figs. F40, F41). The youngest 15 m.y. portion of this record (middle Miocene to recent) is typically represented by thin Pleistocene foraminifer-rich sandy clay and thin stratigraphically short sections of Pliocene and upper Miocene clay, often including manganese nodules. These Neogene sections are frequently barren of all microfossils, therefore preventing us from unequivocally identifying hiatuses within these condensed sections (see "Unit B"). Below the middle Miocene, the stratigraphic histories of the sites can be divided into two distinct groups, corresponding to the J-Anomaly Ridge and Southeast Newfoundland Ridge locations.

J-Anomaly Ridge sites typically comprise lower Miocene to upper Oligocene sequences with high sedimentation rates and occasional minor hiatuses, whereas middle Oligocene to Paleocene sequences show lower sedimentation rates (Fig. F40). The lower Eocene to upper Paleocene sequence is condensed (Site U1406) and/or contains one or two minor hiatuses (Sites U1403 and U1406). Stratigraphic highlights include apparently complete Oligocene/Miocene boundary sections at Sites U1404-U1406 and complete but comparatively condensed Eocene/Oligocene boundary sections at Sites U1404 and U1406. For the most part, these intervals contain well-preserved and continuous calcareous microfossil records (see "Exceptional preservation in clay-rich drift sediment"). Radiolarians are abundant and well preserved through the Oligocene-Miocene transition but are consistently absent through the EOT. Site U1403 is the deepest site drilled during the expedition and has a somewhat different stratigraphic history compared with the other J-Anomaly Ridge sites, comprising a lower Eocene section with relatively high sedimentation rates over a Paleocene through Upper Cretaceous sequence. Coring at this site recovered several key events, including the Eocene Thermal Maximum 2 (ETM2), PETM, and the K/Pg boundary mass extinction event (see "Cretaceous/ Paleogene boundary").
Southeast Newfoundland Ridge sites comprise short Pleistocene and Neogene sequences overlying Oligocene through Paleocene sections with higher sedimentation rates (Fig. F41). The highest sedimentation rates are found in clay-rich drift sediments of middle Eocene age at Sites U1408-U1410 and late Eocene through Oligocene age at Site U1411. The drift lithologies contain exceptionally well preserved calcareous microfossils, including glassy planktonic and benthic foraminifers and a diverse range of fragile and small nannoplankton. These Paleogene drift sequences, together with the slightly younger Oligocene-Miocene drift successions at J-Anomaly Ridge sites, will provide middle Eocene through lower Miocene paleoceanographic and paleobiologic records at unprecedented orbital to suborbital temporal resolution. The carbonate-rich lower Eocene lithologies contain less well preserved calcareous microfossils but, compared to previously drilled sequences, provide a relatively expanded and extremely valuable stratigraphic record through this interval of peak greenhouse climatic warmth (Fig. F42). PETM excursion microfossils have been identified at Site U1409, but the stratigraphy is condensed and/or includes minor hiatuses and, in the core of the event, sediment is indurated and silicified and includes chert beds. Coring at Site U1407 recovered an extensive Cretaceous sedimentary record from the upper Maastrichtian to upper Albian, although a relatively large hiatus cuts out the lower Maastrichtian and upper Campanian. Sedimentation rates are low but there appears to be a relatively continuous record from the upper Albian through lower Campanian. Stratigraphic highlights include a striking Cenomanian/ Turonian boundary black shale sequence representing OAE 2 and an Albian-Cenomanian section overlying shallow-water carbonate facies with photic zone paleontological indicators (e.g., larger benthic foraminifers, coralline algae, and ooids).

The middle Miocene through mid-Cretaceous sections recovered during Expedition 342 have great potential for postcruise studies that will

- Improve age calibrations of biostratigraphic datums through integration of paleomagnetic and cyclostratigraphic data;

- Provide records of biotic response in unprecedented detail through periods of rapid environmental change during past greenhouse climates and during times of widespread glaciation;

- Provide the opportunity to discover new, shortlived species of phyto- and zooplankton as well as studies of evolutionary rates by exploiting the high sedimentation rates of the Miocene and Paleogene drifts; and 
- Allow a detailed assessment of possible temporal $\left(10^{4}\right.$ to $10^{6} \mathrm{y}$ timescale) diachroneity of microfossil datums during the Paleogene and early Neogene, an achievement previously restricted to expanded sequences of late Neogene age (e.g., Raffi et al., 2006; Sexton and Norris, 2008; Wade et al., 2011).

\section{Magnetochronology and paleolatitudes}

To establish magnetostratigraphic age models for Expedition 342 sites, APC- and extended core barrel (XCB)-recovered archive section halves were demagnetized using a peak alternating field (AF) of $20 \mathrm{mT}$ and measured using a pass-through superconducting rock magnetometer (SRM). Discrete samples were also collected and measured from working section halves to verify the data from archive section halves. Bulk magnetic susceptibility and the anisotropy of magnetic susceptibility were also measured on some of these discrete samples.

Overall, paleomagnetic inclination from archive section half data is biased toward positive values, indicating a substantial drilling overprint even after 20 mT AF demagnetization. However, APC-recovered cores oriented with the FlexIT orientation tool often show declination values that cluster at $\sim 0^{\circ}$ and $\sim 180^{\circ}$. We interpret intervals with declination values of $\sim 0^{\circ}\left(\sim 180^{\circ}\right)$ to indicate normal (reversed) magnetozones. In addition, discrete samples often give more shallow inclinations than their counterpart values in the archive section halves, particularly in intervals with $\sim 180^{\circ}$ declinations (i.e., probable reversed magnetzones). With the aid of the discrete sample measurement data, we established magnetostratigraphic age models for most APC-recovered intervals from all Expedition 342 sites. A few intervals at each site, as well as much of Site U1404, are characterized by especially low magnetization intensity (e.g., $10^{-5} \mathrm{~A} / \mathrm{m}$ ) or ambiguous magnetic polarity; shipboard magnetostratigraphies were not established for these intervals. At some sites, shipboard paleomagnetic data from XCB-recovered intervals are especially good, enabling us to construct a shipboard magnetochronostratigraphic age model for these more deeply recovered intervals. We emphasize that the success of the magnetostratigraphic age models for Expedition 342 is due in large part to the routine use of nonmagnetic core barrels and the FlexIT core orientation tool in APC-recovered intervals.

Downhole paleomagnetic inclination and magnetization intensity variations for Sites U1403U1406 (J-Anomaly Ridge) are shown in Figures F43 and F44. At Site U1403, several early to late Eocene chrons are recognized: lower Chron C16n.2n ( 36.7 $\mathrm{Ma})$ to lower Chron C22n ( 49.3 Ma). Paleomagnetic results from Site U1404 are correlated to early Oligocene to middle Eocene chrons of lower Chron C12r ( $33.2 \mathrm{Ma})$ through lower Chron C19r ( 42.3 $\mathrm{Ma})$. For Site U1405, chrons from upper Chron C5Cn.1n $(\sim 16.0 \mathrm{Ma})$ to middle Chron C6Cr $(\sim 23.7$ Ma) are identified. For Site U1406, the magnetostratigraphy is correlated to the Miocene-Oligocene upper Chron C5Dr.1r ( 17.5 Ma) through upper Chron C15n ( 35.0 Ma).

The similar highly expanded late Oligocene-early Miocene magnetostratigraphy observed in many of the J-Anomaly Ridge sites facilitates not only precise dating of key oceanographic, biologic, and climatic events at each site but also precise age correlation among these sites to examine depth- and time-dependent changes in ocean chemistry, faunal assemblages, and drift sedimentation dynamics during the Oligocene-Miocene transition and Mi1. For example, shipboard magnetostratigraphic age models revealed several short ( $<1.5$ m.y.) and lithostratigraphically subtle hiatuses during the late early Miocene at several of the J-Anomaly Ridge sites. Except at Site U1403, magnetization intensity for J-Anomaly Ridge sediment is generally weak $\left(\sim 10^{-5} \mathrm{~A} / \mathrm{m}\right)$ throughout the entire recovered interval (Fig. F44). Although the magnitude of magnetic intensity at J-Anomaly Ridge sites is low, the downhole record at many sites shows low-amplitude, high-frequency oscillations that are promising for stratigraphic correlation, cyclostratigraphy, and long-term environmental magnetic studies.

For Sites U1407-U1411 (Southeast Newfoundland Ridge), downhole paleomagnetic inclination and magnetization intensity variations are illustrated in Figures F45 and F46. The magnetostratigraphy at Site U1407 is correlated to lower Chron C20r ( 43.4 Ma) to upper Chron C22r ( 49.4 Ma). Sediment at Site U1408 records Chrons C17n.3n through 21n ( 38.3-45.7 Ma). The magnetostratigraphy at Site U1409 primarily consists of two time intervals, the first from lower Chron C6Cr ( 23.9 Ma) through upper Chron C13r ( 33.7 Ma); the second is from lower Chron C19r ( 42.3 Ma) through upper Chron C22r $(\sim 49.4 \mathrm{Ma})$. Sediment at Site U1410 also represents two distinct but different time intervals, the first from Chron C1n (Brunhes; modern) through upper Chron C2An.1n (Gauss; $2.6 \mathrm{Ma}$ ) and the second from upper Chron C18n.1n ( 39.6 Ma) through upper Chron C21r ( 47.4 Ma). Two distinct time intervals are also recognized at Site U1411, the first spanning Chron C1n (Brunhes; modern) to upper Chron 
C1r.3r ( 1.2 Ma) and the second from lower Chron C8n.2n ( 25.9 Ma) through upper Chron C15n ( $35.0 \mathrm{Ma})$.

The similar highly expanded middle Eocene magnetostratigraphy observed in many of the Southeast Newfoundland Ridge sites facilitates precise dating of key oceanographic climatic events, including the EOT and MECO. It also enables precise age correlation among these sites to examine depth- and timedependent changes in ocean chemistry, faunal assemblages, and drift sedimentation dynamics. Exceptionally detailed records of two successive Eocene geomagnetic field transitions (Chrons C18n.1n to C18n.1r to C18n.2n) are recorded over $\sim 7 \mathrm{~m}$ of sediment at Sites U1408 and U1410. The paleomagnetic records of these transitions from two widely separated sites are remarkably coherent, suggesting that Paleogene drift sediment has recorded Eocene geomagnetic field behavior in unprecedented detail. Downhole magnetic intensity trends at the Southeast Newfoundland Ridge sites are characterized by distinct zones of low and high magnetic intensity, with low-amplitude, high-frequency intensity oscillations superposed on these first-order trends (Fig. F46). The magnetic intensity records at Southeast Newfoundland Ridge show promise for stratigraphic correlation and cyclostratigraphic and environmental magnetic studies. Moreover, intervals with strong and stable downhole magnetization intensity are promising for long-term middle Eocene relative paleointensity records.

Coring during Expedition 342 recovered sediment deposited during the break-up and subsequent seafloor spreading between North America, Greenland, and Eurasia. These tectonic events established new physiographic boundary conditions in the North Atlantic region that set the stage for the regional and global Cenozoic oceanographic circulation changes recorded in the sediment collected at J-Anomaly and Southeast Newfoundland Ridges. A series of paleogeographic reconstructions for the North Atlantic from $70 \mathrm{Ma}$ to present are shown in Figure F47. This kinematic reconstruction is described in detail by van Hinsbergen et al. (2011) and shows relative plate motions. Time intervals highlight the opening of the northeast Atlantic in the early Paleogene, restriction of the Tethys during the late Paleogene, and development of deeper connections between the North Atlantic and Arctic Oceans during the Neogene. The excellent magnetics recorded in the expanded Paleocene-Eocene sediment drifts recovered at J-Anomaly and Southeast Newfoundland Ridges are promising for developing a continuous and robust paleolatitude record for the North Atlantic. When coupled with terrestrial paleomagnetic poles, this paleolatitude record will not only anchor the reconstructions shown in Figure F47 in latitudinal space but also may reveal gradual and minor paleolatitude changes that could be significant to threshold climate events in the early Paleogene.

\section{Astrochronology and calibration of the Cenozoic timescale}

A major objective of the expedition was to obtain records of the Cenozoic, particularly the Eocene, that can be used to link the astronomic timescale developed for the last $40 \mathrm{~m}$.y. to the "floating" timescale of the early Paleogene developed over a series of IODP and earlier drilling expeditions. From this perspective, acquisition of sedimentary records suited to generating an astronomically tuned record of the late Eocene and the early middle Eocene is an extremely important expedition result that should make it possible to span existing gaps in our tuning efforts. Coring at Sites U1404-U1406 and U1411 captured records of the late Eocene through early Miocene with high-quality biostratigraphic and magnetostratigraphic control (Magnetochrons C17 through C6 and nannofossil Zones NP17 through NN2), including spectacular records through the EOT and Oligocene-Miocene transition. Coring at Sites U1403 and U1408-U1410 recovered records of the middle Eocene through early Eocene, including the Paleocene/Eocene boundary. Many of these sites display striking color banding that has orbital frequencies, with particularly notable examples at Sites U1408-U1410. For the time intervals that have already been astronomically tuned elsewhere, the expedition will allow a comparison between low-latitude sites from the Pacific and Atlantic, offering the chance to decipher the processes controlling the amplification of, for example, $\sim 41$ k.y. obliquity versus $\sim 100$ and 405 k.y. eccentricity cycles and to test the hypothesis of different dominant astronomical forcing between Earth's "warm" and "cool" periods (Boulila et al., 2011).

\section{Orbital cycles in early Miocene data series}

The lower Miocene sequence at Site U1405 is highly expanded $(10 \mathrm{~cm} / \mathrm{k} . \mathrm{y}$. sedimentation rates) and is composed of clayey sediment with varying contributions of biogenic components, diatoms, radiolarians, and calcareous nannofossils. Color reflectance $\left(\mathrm{L}^{*}\right)$ data show cyclic variations throughout site-specific lithostratigraphic Subunit IIb (Fig. F48A, F48B). Power spectrum and filtering of these data reveal two prominent wavelength bands of $16.67 \mathrm{~m}$ and 3.89- 
$4.74 \mathrm{~m}$ exceeding the 99\% confidence level (Fig. F48C). A weaker but significant peak (above 99\% confidence level) is detected at a wavelength of 0.73 $\mathrm{m}$. On the basis of the age-depth model, the $16.67 \mathrm{~m}$ and 3.89-4.74 $\mathrm{m}$ wavelength bands are hypothesized to represent the 405 and 100 k.y. period bands, respectively, of the orbital eccentricity; the $0.73 \mathrm{~m}$ band matches the climatic precession period. The two peaks of closely spaced wavelengths (3.89 and $4.74 \mathrm{~m}$ ) are perhaps the 98 and $128 \mathrm{k} . \mathrm{y}$. eccentricity components. We hypothesize that orbitally induced oscillations in sediment color that are in tune with precession and eccentricity modulation cycles may reflect detrital input, redox cycles, carbonate content variations, or a combination of these processes.

\section{Orbital cycles in Eocene data series}

The Eocene sequences recovered at Sites U1408U1410 show strong variations of carbonate content (Figs. F49) at a number of depth scales that can be correlated to color reflectance data sets across sites (Fig. F50). Spectral analysis of $\mathrm{L}^{*}$ data shows two strong peaks of wavelengths of $\sim 0.5$ and $\sim 0.6 \mathrm{~m}$ that correspond to the mean thickness of an alternation (or couplet) of greenish-white bands (Fig. F51). The greenish bands are nannofossil clay, whereas the white bands are nannofossil ooze with foraminifers. This prominent contrast of carbonate versus clay contents within these two lithologies is fingerprinted in several physical proxies. These couplets show a modulation by long-wavelength cycles. We hypothesize that the greenish-white couplets are precession in origin, modulated by distorted longperiod 405 k.y. eccentricity cycles. At a shorter scale, visual inspection shows bundling of the precession cycles, most likely by $\sim 100$ k.y. eccentricity cycles. We suggest that the climatic precession may exert oscillations in marine-surface productivity and detrital flux processes through solar radiation change in the North Atlantic Basin. Multiproxy studies are needed to decipher orbital-scale oceanic and climatic changes and to delineate a depositional model that links climatically driven sedimentary processes to sea level changes during this middle Eocene greenhouse period.

\section{Orbital forcing of Paleocene-Eocene transition: implications for timing and duration of the hyperthermal events}

Magnetic susceptibility at Site U1403 of the interval spanning the early Cenozoic hyperthermal events (PETM at $\sim 55.9 \mathrm{Ma}$ and ETM2 at $\sim 54.1 \mathrm{Ma}$ ) shows relatively high amplitude variations (Fig. F52). Highfrequency magnetic susceptibility oscillations display a cyclic pattern, with a prominent long-wave- length magnetic susceptibility cycle occurring over $\sim 20 \mathrm{~m}$, bounding the two events. Both the ETM2 and PETM show higher magnetic susceptibility values compared to the intervening section. Sediments are greenish gray in this interval, possibly indicating oxygen-poor conditions close to the sediment/water interface and thus fewer ferrimagnetic minerals incorporated in the sediments. Magnetic susceptibility shows no correspondence with carbonate content. The onset of the PETM is placed at the base of the first occurrence of PETM excursion radiolarians (Fig. F52). Magnetic susceptibility variations in Hole U1403A display higher amplitudes than those seen in Hole U1403B and exhibit prominent $\sim 5 \mathrm{~m}$ thick cyclicity through the interval between the two events.

\section{Eocene astronomical timescale}

The first absolute astronomical timescale was established for the Neogene (Lourens et al., 2004) owing to the validity of astronomical solutions over this time conjointly with high-fidelity climatic proxies. The astronomical calibration of pre-Neogene series is in a floating format, which relies on a calibration of the paleoclimate records to the $405 \mathrm{k} . \mathrm{y}$. stable periodicity of the orbital eccentricity back to $\sim 40 \mathrm{Ma}$ (Laskar et al., 2004; Pälike et al., 2006b). The records we captured during Expedition 342 present an opportunity to extend this approach back to at least middle/early Eocene boundary time. The striking greenish-white sediment alternations observed in the middle Eocene at Sites U1408-U1410 may record primary environmental changes that directly control the lithologic oscillations. Shore-based work will focus on high-resolution multiproxy studies that will, for example,

1. Decipher precession-scale oceanic and climatic changes preserved in multiple proxies;

2. Look for possible differential (nonlinear) responses of the oceanic-climatic system to orbital forcing through the studied proxies;

3. Delineate depositional models that link oceanic and climatic variations to sea level changes in these middle Eocene North Atlantic sediment; and

4. Decipher possible solar-induced cyclicities in carbonate productivity, detrital flux, and redox conditions.

\section{Sedimentation rates}

All the sediment drifts drilled during Expedition 342 are lenticular packages of sediment that have much higher sedimentation rates in their mid-sections than at their edges. We found the highest sedimentation rate $(\sim 10 \mathrm{~cm} / \mathrm{k} . \mathrm{y}$.$) in the Miocene-Oligocene re-$ 
cord at Site U1405. Sedimentation was considerably slower $(2-3 \mathrm{~cm} / \mathrm{k} . \mathrm{y}$.) in the Eocene and early Oligocene but still 2-5 times faster than those of typical ocean records from these time periods. The higher sedimentation rates in the Oligocene-Miocene compared to the early Paleogene may reflect a long-term trend in drift sediment dynamics. It is impressive to compare the massively thick sequences of late Neogene sediment waves in the seismic record of Southeast Newfoundland Ridge with the relatively modest size of the acoustically transparent early Paleogene drifts of J-Anomaly Ridge and the seamount area of Southeast Newfoundland Ridge.

Sites U1403-U1406 comprise a depth transect (4946$3813 \mathrm{mbsl}$ ) along the southwestern flank of J-Anomaly Ridge. Figure F53 summarizes linear sedimentation rate histories for Expedition 342 drill sites. The data from the four J-Anomaly Ridge sites (Fig. F53A) suggest two main influences on sedimentation rates, water depth and location within the sediment drift, that are superimposed on a background of slow tectonic subsidence at J-Anomaly Ridge.

All J-Anomaly Ridge sites are characterized by slow rates of sedimentation in the uppermost $10-70 \mathrm{~m}$ of the sediment column. At the deep end of our transect, Site U1403, this condensed section spans the last $\sim 40$ m.y., whereas at the shallow end of the JAnomaly Ridge depth transect, Site U1406, the upper sequence of slowly accumulating sediments spans only the last 20 m.y. These two sites were drilled into the edges of the J-Anomaly Ridge sediment drift and record the two most condensed sequences recovered along this depth transect.

In contrast, Sites U1404 and U1405 were drilled into the center of the drift and recovered much more expanded sequences. The sequence penetrated at Site U1405 was positioned close to the mid-section of the drift and captures a remarkably expanded sequence through the late Oligocene and early Miocene, particularly the Oligocene-Miocene transition. Equally striking is the seismic stratigraphic evidence that the lower half of the J-Anomaly Ridge drift not reached by either Site U1404 or U1405 is middle and early Eocene age, implying that drift formation not only began in the early Eocene, but also produced nearly as much sediment as that deposited during the Oligocene-Miocene.

Mass accumulation rates (MAR) at J-Anomaly Ridge sites reach $1-2 \mathrm{~g} / \mathrm{cm}^{2} / \mathrm{k}$.y. during periods of drift deposition. Significantly lower MAR, $<0.5 \mathrm{~g} / \mathrm{cm}^{2} / \mathrm{k}$.y., are recorded during times of low sedimentation, prior to and following high sedimentation rates during drift formation. Carbonate accumulation rate (CAR) is the predominant sedimentary component during the Paleocene peak in MAR at Site U1406 (Fig. F54). During the Eocene, noncarbonate MAR (nCAR) is predominant across the J-Anomaly Ridge sites.

A striking observation of sediment accumulation on $\mathrm{J}$-Anomaly Ridge during the Eocene is an anticorrelation between periods of high MAR between the ridge flank (Site U1403) and the ridge crest (Site U1406) (Fig. F54). This observation supports the interpretation from seismic data that drift formation varies not only in time but also in water depth. In contrast, the pattern of sedimentation with depth on J-Anomaly Ridge during the Oligocene and Miocene appears to be in phase among the three sites where peaks in MAR occur at the Oligocene/Miocene boundary ( 3.8 to $\sim 4.9 \mathrm{~km}$ present water depth) (Fig. F55). Sites U1404-U1406 all exhibit a pronounced double peak in MAR in the latest Oligocene to earliest Miocene sediment sequences. Because the mechanism for drift formation is closely linked to the region of peak sediment transport and deposition in a deepcurrent system, the pattern of accumulation with depth may serve as a proxy for deep-current dynamics. Using this line of reasoning, it can be tentatively concluded that the deep-current system that draped J-Anomaly Ridge with sediment varied in depth during the Eocene and became more uniform with depth, and perhaps stronger, in the Oligocene and Miocene. This interpretation should inform postcruise sampling for paleocurrent proxy records (i.e., sortable silt and coarse lithic MAR).

Trends in sedimentation rate at the sites drilled on the Southeast Newfoundland Ridge are very similar to those from J-Anomaly Ridge. The key difference is that the main bodies of the various drifts and highest sedimentation rates are older, occurring during the middle and early Eocene at Sites U1407-U1410 and through the EOT at Site U1411. In contrast to the J-Anomaly Ridge sites, there is only $500 \mathrm{~m}$ difference in water depth between the shallowest and deepest sites. Consequently, the primary influence of sedimentation rate variations between these sites is location within a given drift.

The three sites within the central parts of sediment drifts yielded remarkably similar sedimentation rate histories. Sites U1408 and U1410 have condensed upper sections spanning $40 \mathrm{~m}$.y. followed by greatly expanded middle Eocene sections in which sedimentation rates reached $2.6-2.8 \mathrm{~cm} / \mathrm{k} . \mathrm{y}$. The initiation of drift sedimentation is clearly marked by an uphole increase in sedimentation rate from $<1 \mathrm{~cm} / \mathrm{k}$.y. to these higher rates. Site U1411 shows a very similar trend, although it sampled a younger sequence comprising a condensed Neogene-upper Oligocene section followed by a highly expanded section that 
spans the Oligocene/Eocene boundary. We did not drill deeply enough at site U1411 to date the onset of drift sedimentation.

Sites U1407 and U1409 are at the head and tail, respectively, of drift bodies. The distinction between head and tail, shallow and deep, or proximal and distal appears to have had little effect on the parallel sedimentation histories at these two sites. Both comprise a condensed upper section that spans 40-45 m.y. followed by a moderately expanded section through the middle to lower Eocene, with maximum sedimentation rates of $1.4-2 \mathrm{~cm} / \mathrm{k} . \mathrm{y}$. , and a lowermost Eocene-Paleocene section in which sedimentation rate decreases progressively. Only Site U1407 penetrated into the Cretaceous sediment of Southeast Newfoundland Ridge. This site shows that the uppermost Cretaceous was very condensed $(\sim 0.1 \mathrm{~cm} /$ k.y.), but moderately high rates of sedimentation $(\sim 0.5 \mathrm{~cm} / \mathrm{k} . \mathrm{y}$.$) are recorded in the Turonian-Albian$ sequence.

MAR at the drill sites at the head and tail of drift bodies are lower, on average, than those drilled into the main body of drifts (Figs. F56, F57). CAR is higher at the Southeast Newfoundland Ridge sites than at the J-Anomaly Ridge sites, presumably because of the shallower depths.

In summary, these sedimentation rate histories validate the strategy that underpinned this expedition. These drift sediments have been shown to contain greatly expanded sedimentary successions, generally rich in well-preserved microfossils (although seldom all groups in the same interval) that span critical episodes in Earth's climate history.

\section{Paleogene and Cretaceous carbonate compensation depth in the northwest Atlantic}

One of the primary objectives of Expedition 342 is to provide new insights on the history and dynamics of the Paleogene carbon cycle. A particular goal is to reconstruct the depth history of the carbonate lysocline and CCD of the North Atlantic Ocean. This effort will improve our understanding of changes in carbonate saturation state over Cenozoic time. Before this expedition, records of Cenozoic CCD change in the North Atlantic were of poor stratigraphic and depth resolution because they were compiled largely from dispersed, often spot-cored DSDP sites and a handful of ODP drill sites (van Andel, 1975; Peterson and Backman, 1990). An important result of Leg 208 was the acquisition of a 2000 $m$ depth transect that permitted estimation of the magnitude of CCD fluctuations at short timescales across the PETM (Zachos et al., 2005). Similarly, the latitudinal and age-depth transects recovered during Leg 199 and Expedition 320/321 have allowed the reconstruction of the long-term behavior of the CCD in the equatorial Pacific at unprecedented resolution (see fig. 2 in Pälike et al., 2012). One aim of Expedition 342 was to test the reproducibility of these findings in the North Atlantic Ocean where changes in ocean circulation are tightly coupled to changes in global climate during the late Pleistocene.

Of particular interest are the multiple transient Eocene CCD deepening events seen in the equatorial Pacific as well the large CCD perturbations associated with the "overshoots" in carbonate ocean chemistry observed during the EOT, PETM, and K/Pg boundary. All three of these extreme events are thought to involve increased deep-sea carbonate burial flux and a rebalancing of oceanic carbonate chemistry following major shocks to the Earth system (Dickens et al., 1997; Coxall, et al., 2005; Zachos et al., 2005; Merico et al., 2008). A key aspect of the Expedition 342 strategy was to target much deeper sites for the bottom end of our depth transect than has been common in modern paleoceanographic transect drilling. The reason for this approach is the need to quantify the full amplitude of these CCD perturbations to better constrain the size of the carbon cycle anomaly involved.

The sedimentary sequence on J-Anomaly Ridge and Southeast Newfoundland Ridge has yielded the following results:

- Upper Cretaceous and Paleocene sediments at JAnomaly Ridge are markedly carbonate rich, even at our deepest water site (paleodepth 5.5 $\mathrm{km}$ at $50 \mathrm{Ma}$ and $4.5 \mathrm{~km}$ at $70 \mathrm{Ma}$ ).

- The deep Site U1403 contains lower Eocene strata that are carbonate rich, indicating that during a peak interval of sustained Cenozoic warmth the CCD in the North Atlantic Ocean was much deeper than in the equatorial Pacific (by $>1.5 \mathrm{~km}$ ).

- In our mid-depth to deepwater sites (Sites U1403 and U1404), we observed discrete carbonate-rich intervals interspersed throughout strata of middle to late Eocene age. These intervals indicate that the behavior and timing of CCD deepening and shoaling in the North Atlantic is broadly similar to the equatorial Pacific.

- We captured records of the K/Pg boundary, the PETM, and the EOT, and in each case these events are expressed in our deepwater sites by prominent "spikes" in carbonate content and preservation of calcareous microfossils, suggesting large-amplitude CCD overdeepening events 
during the recovery phases from these major shocks to the carbon cycle and global climate.

- Numerous discrete carbonate-rich beds are also observed clustered around the Oligocene-Miocene transition, and the nannofossil composition of some of these beds suggests unusual surface water, possibly shelf-related conditions.

- The thin veneer of Pliocene-Pleistocene sediment encountered at all of the sites is always more carbonate rich (with superimposed glacial-interglacial cycles) than the immediately underlying sediments with superimposed glacial-interglacial cycles.

\section{Onset and development of Cenozoic glaciation}

The canonical view of the onset of Cenozoic glaciation is that it took place in two main steps: (East) Antarctic ice sheets were established around EOT time ( 33 Ma), whereas northern hemisphere glaciation was not triggered until $\sim 3-7$ Ma (e.g., Miller et al., 1987; Zachos et al., 2001). It is clear that northern hemisphere glaciation underwent a major phase of intensification in the latest Pliocene to earliest Pleistocene around marine isotope Stage G6 ( 2.75 $\mathrm{Ma})$ and that large ice sheets grew on multiple continents in the high northern latitudes, triggering sustained iceberg rafting events across the North Atlantic and North Pacific Oceans in glacials from marine isotope Stage 100 ( 2.55 Ma) (Shackleton et al., 1984; Lisieki and Raymo 2005; Bailey et al., 2010, 2011), yet little is understood of the timing and chain of events involved in the transition into this climate state from one with a nonglaciated northern hemisphere featuring a genuinely green Greenland.

Dropstones have been reported from the Arctic (IODP Expedition 303) in sediment of $\sim 45 \mathrm{Ma}$ age (Backman 2005; Moran et al., 2006). Discontinuous $\delta^{18} \mathrm{O}$ records in bulk and benthic foraminiferal calcite from the Pacific Ocean have been interpreted to indicate extensive ice sheet development in both hemispheres together with a huge $(>150 \mathrm{~m})$ eustatic sea level fall around $42 \mathrm{Ma}$ (Tripati et al., 2008). This interpretation is controversial (Lear et al., 2004; Miller et al., 2005; Pekar et al., 2005; Edgar et al., 2007; DeConto et al., 2008). In contrast to early interpretations (Lear et al., 2000), it is now also clear that the amplitude of the $\delta^{18} \mathrm{O}$ increase across the EOT $(\sim 33.5 \mathrm{Ma})$ is impossibly large to reflect ice growth on Antarctica alone (Coxall et al., 2005) and must incorporate some component of global cooling (Lear et al., 2004, 2008; Eldrett et al., 2009; Liu et al., 2009).
Yet, there is little evidence that conditions were cold enough to develop a substantial ice sheet in the northern hemisphere, even on southeast Greenland, until the initiation of the major phase of northern hemisphere glaciation at $2.75 \mathrm{Ma}$ (e.g., Larsen et al., 1994; Bailey et al., 2012). Winter sea-ice formation appears to have been initiated in the Arctic by the start of the middle Eocene, and isolated alpine outlet glaciers are thought to have existed on southeast Greenland by the EOT (Eldrett et al., 2007; Stickley et al., 2009). This picture agrees with the results of coupled global climate-ice sheet model experiments that suggest that the northern hemisphere is likely to have contained glaciers and small isolated ice caps at high elevations through much of the Cenozoic, especially during favorable orbital periods, but that major continental-scale glaciation is unlikely prior to the Miocene (DeConto et al., 2008). Only by the Miocene do paleo- $\mathrm{CO}_{2}$ records (Pagani et al., 2005, 2011; Pearson et al., 2009) suggest that Cenozoic carbon dioxide levels first intercept the model threshold for the growth of large ice sheets in the northern hemisphere. In fact, if the proxy $\mathrm{CO}_{2}$ records and the climate-ice sheet models are representative, then transient northern hemisphere ice sheets growing and disappearing on orbital timescales might help to explain the pronounced variability we see in the Neogene deep-sea benthic $\delta^{18} \mathrm{O}$ record regardless of the strong hysteresis (Pollard and DeConto, 2005) in the model Antarctic ice sheet systematics. Particularly notable in this context is the earliest Miocene glacial maximum that corresponds to the Mi1 event in the terminology of Miller et al. (1991) and the multiple, relatively short lived ( 100 to $\leq 400$ k.y.) subsequent glaciation "events" (Flower et al., 1997; Zachos et al., 1997, 2001; Paul et al., 2000; Billups et al., 2002, 2004; Pälike et al., 2006b; Liebrand et al., 2011). These events have been largely interpreted to reflect shifts between complete and partial ice coverage of Antarctica, but we must consider the possibility of a northern hemisphere contribution to the global ice budget.

Expedition 342 provided an opportunity to shed new light on these aspects of Paleogene climate in the high northern latitudes at unprecedented stratigraphic detail. The middle Eocene through lower Miocene sections obtained will allow us to generate the high-resolution records of changes in sedimentation rate, clay mineral assemblage, and occurrence and provenance of possible IRD that are needed to test for early ice in the northern hemisphere. A potential problem exists with differentiating between putative Paleogene IRD and sediment eroded from the continental margin. In Pleistocene strata, IRD is 
often identified because of its coarse grain size (sand sized and larger) and its distinctive provenance (e.g., "red-coated grains" from Labrador, basalt from Iceland) (Bond and Lotti, 1995; Hemming et al., 1998). IRD in the silt fraction has been identified by a number of techniques including modeling of end-member components using a wide spectrum of grain-size analyses (Weltje, 1997; Prins et al., 2002; Weltje and Prins, 2003). IRD might also be identified by combining grain size (especially sand content) and mineralogical information during "cold" events inferred from light stable isotope studies and geochemical assessment of provenance. Finally, ice-transported sediment has been identified using geochemical markers such as $\mathrm{Sr} / \mathrm{Ca}$ ratios in core-scanning X-ray fluorescence data sets and provenance studies by lead isotope work (e.g., Bailey et al., 2012; Channel et al., 2012).

Preliminary results indicate the consistent presence across multiple sites of abundant lithic grains in the 63-150 $\mu \mathrm{m}$ size fraction in some of the intervals drilled, most notably in lower Miocene and particularly in Oligocene strata (Fig. F25). In some cases (such as at Site U1411), these grains can be resolved to be parts of larger, coarse sand-sized carbonate-cemented lithics that disaggregate easily into their component silt-sized grains (see "Lithostratigraphy" in the "Site U1411" chapter [Norris et al., 2014b]). Quartz grains are by far the most commonly observed of these particles, many of which are angular and some of which are stained a distinctive purple-red color. Metamorphic (e.g., schist) and mafic rock fragments are also present but are much less abundant. A second pulse of sand-sized lithic grains occurs within the Oligocene-Miocene transition and are indistinguishable from those documented at the base of the Oligocene sequence. At nearly all sites, lithics are observed for the first time in the early Oligocene (Zone NP22/NP23). The distribution of these grains in sediment throughout the post-Eocene sediment column at J-Anomaly and Southeast Newfoundland Ridges indicates the presence of granitic or clastic sedimentary sources, presumably located north of the Newfoundland ridges, and possibly indicating ice-rafted transportation. The relatively coarse grain size of some of the lithics is consistent with iceberg transport as early as the basal Oligocene.

Clay minerals are excellent tracers of provenance in the modern North Atlantic and should have broadly similar distributions in the Paleogene. Continentalsourced clays should dominate the west Greenland and Canadian margins, whereas volcanic-sourced clays should be more typical of the Paleogene flood basalt province in east Greenland. In the modern
North Atlantic, smectite, illite, chlorite, and kaolinite constitute the major proportion of the clay fraction. Smectite has been regarded as a major tracer for Iceland-Faeroe-derived material (Fagel et al., 2001) and could be expected from the Greenland volcanic province in the Paleogene. Where smectites are lacking, chlorite is the typical high-latitude clay from old metamorphic sources. A lack of volcanogenic and weathered basalt-derived clays (nontronite and amorphous minerals) suggest a rather restricted contribution of east Greenland and mid-ocean-ridge sources. Clay mineral type (e.g., montmorillonite versus beidellite) and percentage data and $\mathrm{Sm} / \mathrm{Nd}$ ratios in the clay fraction of Reykjanes Ridge sediment indicate a dominant terrigenous contribution from young continental crust that may derive from Europe and/or the Arctic (Innocent et al., 2000; Fagel et al., 2001). Today, the clay fraction may also contain terrigenous calcites and dolomites derived from glacier milk in the Hudson Bay area. Such a signal could be transported for much longer distances than sandsized IRD.

\section{Oligocene-Miocene transition}

The Oligocene-Miocene transition includes the last large, transient glaciation (Mi1) before the onset of widespread northern hemisphere glaciation around 3-7 Ma (see "Onset and development of Cenozoic glaciation"). The Oligocene-Miocene sediment recovered from J-Anomaly Ridge holds great promise for addressing outstanding questions regarding climatic and paleoceanographic dynamics of this time through a combination of highly expanded sedimentation rates, a depth transect, and exceptional calcareous microfossil preservation.

The three sites at J-Anomaly Ridge with an Oligocene-Miocene transition lie along a depth transect from the deep Site U1404 (4745 mbsl) to the middepth Site U1405 (4286 mbsl) to the shallow Site U1406 (3813 mbsl). All three sites occur in a single sediment drift. Sites U1404 and U1405 are close to the middle of the drift and capture the highly expanded Oligocene-Miocene sequence with much higher sedimentation rates (up to $10 \mathrm{~cm} / \mathrm{k} . \mathrm{y}$.) than is typical in pelagic settings $(\sim 1 \mathrm{~cm} / \mathrm{k} . \mathrm{y}$.$) . Site \mathrm{U} 1406$ is near the nose of the same drift where sedimentation rates are $\sim 2.5$ to $\sim 1.5 \mathrm{~cm} / \mathrm{k} . \mathrm{y}$. Taken together, these three sites record a near-continuous sequence of the early Miocene to late Oligocene interval ( 22.0 to $\sim 26.5 \mathrm{Ma}$ ), coincident with drift formation and the deposition of IRD (see "Onset and development of Cenozoic glaciation"). The calcareous microfossil preservation at Site U1405 is exceptional-planktonic foraminifers appear glassy (i.e., see-through) and small, delicate coccoliths abound (see "Excep- 
tional preservation in clay-rich drift sediments"). The preservation at Site U1406 is similar. Both Sites $\mathrm{U} 1405$ and $\mathrm{U} 1406$ have a high clay/ $\mathrm{CaCO}_{3}$ ratio, a factor known to be crucial for this type of preservation (Norris and Wilson, 1998; Sexton et al. 2006b).

The occurrence of the nannofossil Sphenolithus delphix at Sites U1405 and U1406 marks the time period immediately preceding the Mi1 glaciation interval. The range of $S$. delphix is in line with the paleomagnetic placement of the Oligocene/Miocene boundary at the Chron C6Cn.2n/C6Cn.2r reversal (Fig. F58). The exact position of the Oligocene/Miocene boundary at Site U1404 is currently unclear because the preliminary magnetostratigraphy is ambiguous and $S$. delphix is absent in shipboard samples. Rare, lightcolored Braarudosphaera beds are recognized at Sites U1405 and U1406 in at least four intervals within $\sim 40 \mathrm{~m}$ of the boundary (Fig. F59). The presence of Braarudosphaera beds is surprising because they are typically associated with older sediments (Oligocene aged), particularly from the South Atlantic.

The high sedimentation rates and outstanding calcareous microfossil preservation of the Oligocene and Miocene successions recovered at Sites U1404U1406 have the potential to resolve climate changes to a millennial scale. The Miocene succession presents the opportunity to generate the first pre-Pliocene suborbital deep-sea record and promises to greatly increase our understanding of climate dynamics during the onset and demise of the Mi1 glaciation.

\section{Eocene-Oligocene transition}

The EOT is one of the most profound climate shifts of the Cenozoic and the final stage of the switch from greenhouse to glacial climates. Although our understanding of this transition has improved in recent years, many of the key sections around the globe have only discontinuous carbonate or contain one or more hiatuses (e.g., Coxall et al., 2005; Coxall and Wilson, 2011; Wade et al., 2012). No complete Eocene/Oligocene boundary record currently exists for the northern North Atlantic.

Coring during Expedition 342 recovered the EOT (Fig. F60) at Sites U1404 (4746 mbsl), U1406 (3813 mbsl), and U1411 (3299 mbsl). The EOT is identified on the basis of biostratigraphic and magnetostratigraphic observations and is characterized by a series of changes in calcium carbonate content and lithostratigraphy above the Eocene/Oligocene boundary (Chron C13r/C13n, nannofossil Zone NP21, and, at Site U1411, the extinction level of the planktonic foraminifer Hantkenina alabamensis). The Site U1411 EOT section is particularly notable in that it falls within a drift deposit with sedimentation rates of $\sim 3$ $\mathrm{cm} / \mathrm{k} . \mathrm{y}$. The EOT at Sites U1404 and U1406 both lie beneath upper Oligocene-lower Miocene drift sequences and are relatively condensed, with sedimentation rates of 0.3 and $0.9 \mathrm{~cm} / \mathrm{k} . \mathrm{y}$., respectively. However, the lithologic expression of the EOT is broadly similar at Sites U1404, U1406, and U1411, with intersite differences in background carbonate and clay content affecting the observed magnitude of change in carbonate content and sedimentary brightness $\left(\mathrm{L}^{*}\right)$. At all sites, carbonate content increases markedly between the latest Eocene and earliest Oligocene, from 5 to $50 \mathrm{wt} \%$ at Site U1404, from 40 to 80 $\mathrm{wt} \%$ at Site U1406, and from 15 to $55 \mathrm{wt} \%$ at Site U1411. The different values are likely predominantly the effect of proximity to the CCD/lysocline at Sites U1404 and U1406 and the combined effects of the CCD and clay dilution at Site U1411. Lithostratigraphically, sediment in the high-carbonate interval is lighter than that in underlying and overlying sediment at the sites, with the greatest changes in color contrast observed across the EOT at Site U1404. At all three sites, sand-sized lithic grains, mostly composed of angular quartz grains in the 63 to $150 \mu \mathrm{m}$ size fraction, are observed in lowermost Oligocene sediment and possibly uppermost Eocene sediment at Site U1411 (green triangles in Fig. F60).

These findings appear to be broadly in line with those of Coxall et al. (2005), suggesting that the CCD deepening event associated with the EOT is not restricted to the equatorial Pacific Ocean but also occurs in the North Atlantic Ocean. However, these new Expedition 342 sites contain continuous carbonate across the EOT and, in particular at Site U1411, host well-preserved and glassy planktonic foraminifers, and therefore provide an unprecedented opportunity to generate a full range of paleoceanographic proxies at high temporal resolution at a location in the North Atlantic. Such a record will allow us to investigate the relationships between paleotemperatures, ice volume, and $\mathrm{CO}_{2}$ through this major climate shift. Furthermore, the high quality of calcareous microfossil preservation will enable us to study the faunal and floral response to this major climate shift event and specifically to examine the relative timing of a sequence of plankton extinction events (e.g., Pearson et al., 2008).

\section{Middle Eocene climatic optimum and carbonate accumulation events}

The long-term global cooling through the middlelate Eocene is punctuated by a series of (at least seven) carbonate accumulation events (CAEs) documented in the equatorial Pacific that reflect major depressions of the Pacific CCD (Lyle, Wilson, 
Janecek, et al., 2002; Lyle et al., 2005; Pälike et al., 2010, 2012). The late middle Eocene is also marked by a brief ( 500 k.y.) interval of global warming and CCD shoaling (MECO) at $\sim 40 \mathrm{Ma}$ (Bohaty and Zachos, 2003; Bohaty et al., 2009). CCD shoaling and coincident global warming are consistent with a transient rise in atmospheric $\mathrm{CO}_{2}$ concentrations during the MECO, although the mechanisms driving this rise are still debated (Bohaty et al., 2009). Regardless, the MECO had a marked effect on plankton communities in terms of biogeographic range shifts, evolutionary turnover, and changes in community structure (e.g., Edgar et al., 2010, 2013; Toffanin et al., 2011; Agnini et al., 2011).

Expedition 342 recovered spectacular records of the middle Eocene as sediment drift deposits on the Southeast Newfoundland Ridge composed of light grayish green nannofossil clay interlayered with nannofossil ooze. The recovered sequences are notable for the quality of magnetostratigraphic and biostratigraphic age control, the extremely high quality of preservation of calcareous microfossils, and high sedimentation rates (up to $3 \mathrm{~cm} / \mathrm{k} . \mathrm{y}$.). The middle Eocene records all show intervals of relatively high carbonate concentrations and mass accumulation rates suggestive of a North Atlantic equivalent to the "carbonate accumulation events" of the equatorial Pacific (e.g., Fig. F50). These sequences hold great promise for refining the Eocene timescale and addressing outstanding questions of climatic and biotic dynamics during the middle Eocene. In particular, data generated on these sequences will

- Help refine the timing, global extent, and cause of the CAEs;

- Provide a high northern hemisphere Atlantic record across the MECO; and

- Enable orbital- to suborbital-scale studies of the climatic, paleoceanographic, and biotic response to climate change in a nonicehouse climatic regime.

We recovered particularly high quality MECO records at Southeast Newfoundland Ridge Sites U1408 and U1410 (Fig. F61). Both sites yielded expanded sequences (sedimentation rates of $1-2 \mathrm{~cm} / \mathrm{k} . \mathrm{y}$.) with exceptionally well preserved calcareous microfossils. The glassy preservation of benthic and planktonic foraminiferal calcite at Site U1408, in particular, offers unprecedented potential for geochemical investigations of the MECO. Sediment spanning the MECO was also recovered at J-Anomaly Ridge Sites U1403, U1404, and U1406. Site U1403, at the deepest end of the expedition transect (4946 mbsl), is bar- ren of carbonate throughout the middle Eocene interval and provides a constraint on the maximum depth of the local CCD.

We identified the MECO at Sites U1403, U1404, U1406, U1408, and U1410 on the basis of calcareous nannofossil and planktonic foraminiferal biostratigraphy. In particular, at Site U1408 the onset of the MECO is pinned to Section 342-U1408A-8H-2 by the base of Dictyococcites bisectus and the top of Sphenolithus furcatolithoides (calcareous nannofossil species) (Toffanin et al., 2011; Agnini et al., 2011). The evolutionary rise of Sphenolithus predistentus, associated with the peak in abundance of Sphenolithus spiniger and its subsequent extinction, point to the relative completeness of our record across the MECO (Fig. F61). The lithologic and geochemical structure of the Site U1410 record suggests another complete record of the MECO. Prominent changes in calcareous nannofossil assemblages starting just below the Chron C18r/C18n.2n boundary are thought to mark the warmest interval of the MECO, a $\sim 50$ k.y. pulse of additional warming following several hundred thousand years of prior warming. Orbulinoides beckmanni, a planktonic foraminiferal marker species with a total range closely coincident with the MECO (Edgar et al., 2010), first appears immediately after the remarkable rise in abundance of $S$. spiniger and the base of $S$. predistentus. The MECO also coincides with a peak in the dominance of infaunal benthic foraminifers at Site U1408, possibly indicating increasing export productivity coincident with warming. However, barite and carbonate accumulation rates from the equatorial Pacific have been interpreted to indicate the opposite; that is, a peak in export productivity during the CAEs and relatively low export productivity during the MECO (Griffith et al., 2010).

The relative duration and spacing of the intervals of low versus high color cyclicity suggest that the longperiod, million-year variability in cyclicity may correspond to the middle Eocene CAEs documented in the Pacific (Pälike et al., 2012). At Southeast Newfoundland Ridge sites, we tentatively identified four intervals of increased color contrast between layers that are broadly correlative across Sites U1408U1410 (Fig. F50). These intervals are broadly coincident with four Pacific CAEs in magnetochrons C20r through C18n.2n; however, at finer resolution there are indications that the Southeast Newfoundland Ridge CAEs may be diachronous with equatorial Pacific CAEs. Regardless of their exact temporal relationship to the Pacific, the expanded middle Eocene sequences from Southeast Newfoundland Ridge promise to provide key information on the timing, 
extent, and mechanisms of changes in the CCD and carbonate accumulation through the middle Eocene in the North Atlantic.

\section{Early to middle Eocene transition}

\section{Ocean circulation and the onset of sediment drift deposition}

During Expedition 342, the lower to middle Eocene transition was recovered at four sites (U1403, U1407, U1409, and U1410) (Figs. F62, F63). This is a major and unprecedented achievement because the lower/ middle Eocene boundary has, for over $40 \mathrm{y}$ of deepsea drilling, been almost universally represented in sediment sequences by a hiatus of $\sim 1$ to $2 \mathrm{~m}$.y. duration (Aubry, 1995; Norris et al., 2001a). This boundary also correlates closely in age to seismic Reflector $A_{C}$, which is widespread throughout the North Atlantic and represents either a diagenetic boundary between cherts and biosilica-rich oozes (Tucholke and Mountain, 1986) or an unconformity (Norris et al., 2001a). Consequently, we know very little of the climatic and oceanographic significance of this boundary, despite indications that it represents a critical threshold transition in Earth's climate evolution. For example, the onset of the long-term Cenozoic global climatic cooling trend appears to commence close to this boundary (Sexton et al., 2006a; Zachos et al., 2008). Significant reorganization of global overturning circulation is suggested by the expansion of interbasin $\delta^{13} \mathrm{C}$ gradients from the early to middle Eocene (Sexton et al., 2006a), suggesting either a switch to a single dominant source of deep water, a fundamental increase in biological export production (and consequent deep-sea remineralization), or both.

At all four Expedition 342 sites spanning the lower/ middle Eocene boundary, sedimentary calcium carbonate content shows a pronounced drop in Chron C21n to $>80 \mathrm{wt} \%$ in the earliest middle Eocene from the Southeast Newfoundland Ridge sites and 40 $\mathrm{wt} \%$ in the later middle Eocene (Fig. F62). Multiple physical properties, including magnetic susceptibility, NGR, and color reflectance, show a distinct step change across this interval (Figs. F19, F20, F21, F22, F62). These changes in physical properties are associated with pronounced uphole increases in MAR at all sites, which correlate with increases in nCAR, primarily clay but probably including a significant biosiliceous component, particularly in the radiolarianrich sediments at Site U1403 (Figs. F54, F56). These observations suggest that the major uphole decreases in carbonate content at least partly represent dilution of carbonate by enhanced clay input. The increase in MAR across this transition may be symp- tomatic of an intensification of bottom water currents that can carry greater sediment loads.

Enhanced vigor of deep ocean currents across this critical transition in Earth's climate is supported by the contemporaneous onset of sediment drift deposition within a small basin dissecting the GreenlandScotland Ridge, a key gateway for Arctic Ocean overflow into the North Atlantic (Hohbein et al., 2012). Furthermore, on Blake Nose in the subtropical North Atlantic, winnowed and silicified foraminiferal sands are found associated with the lower/middle Eocene boundary unconformity (Norris et al., 2001a). These observations, combined with the initial findings from Expedition 342 Southeast Newfoundland Ridge drilling, suggest that a major change in ocean circulation occurs across the lower-middle Eocene transition. The continuous sequence recovered across Southeast Newfoundland Ridge will allow postcruise studies to explore the response of ocean overturning to this critical switch in Earth's long-term climate evolution.

\section{Climate-carbon cycle perturbations in the early to middle Eocene}

The early/middle Eocene boundary coincides with the onset of global cooling following the Early Eocene Climatic Optimum (EECO; 51-53 Ma) when Earth reached the warmest temperatures of the entire Cenozoic (e.g., Sexton et al., 2006a; Zachos et al., 2008). A series of hyperthermals, or acute carbon cycle-driven global warming events, are superimposed on the $\sim 5$ m.y. interval leading up to the EECO as well as the subsequent onset of cooling approaching the early-middle Eocene transition (e.g., Cramer et al., 2003; Zachos et al., 2010; Sexton et al., 2011). The total number of these dramatic perturbations to Earth's carbon cycle and climate remains unclear, particularly across the EECO, though their occurrence appears to wane following the early/middle Eocene boundary (e.g., Sexton et al., 2006a; Zachos et al., 2008), until later in the middle Eocene when two more isolated events are encountered in Chron C19n (Edgar et al., 2007) and at the Chron C18r/ C18n.2n boundary (Bohaty et al., 2009).

Sites U1404, U1409, and U1410 together recovered a nearly complete lower Eocene sedimentary sequence, whereas Sites U1407 and U1403 recovered expanded lower-middle Eocene sequences (sedimentation rates up to $3.5 \mathrm{~cm} / \mathrm{k} . \mathrm{y}$.) with excellent cyclostraphic and paleomagnetic control. An example of the imprint of hyperthermals upon deep-sea sediments is shown in Figure F63, which highlights several "clay layers" marked by increases in magnetic susceptibility and a darkening of sediment color, 
both likely caused by intensified dissolution of $\mathrm{CaCO}_{3}$ upon deep-sea acidification. Collectively, the lower and middle Eocene sequences recovered during Expedition 342 will allow a detailed reconstruction of the frequency and total number of these carbon-cycle perturbations from the height of Cenozoic warmth through the onset of middle Eocene global cooling, thereby providing a detailed framework with which to evaluate the boundary conditions and forcing mechanisms required for their genesis.

\section{Paleocene/Eocene Thermal Maximum}

During Expedition 342, drilling operations penetrated the Paleocene/Eocene boundary at Sites U1403 and U1406-U1409. At Site U1406, sediments of middle Eocene age unconformably overlie the upper Paleocene, whereas at Site U1407, the lower Eocene and upper Paleocene were drilled without recovery because of thick chert beds. Sequences of lower Eocene to upper Paleocene (including nannofossil Zones NP9 and NP10) were recovered at Sites U1403, U1408, and U1409 (Fig. F64), providing a depth transect of 3022 to 4946 mbsl. PETM calcareous nannofossil excursion taxa (nannofossil Subzone NP9b) were recovered at Sites U1403 and U1409 but not at Site U1408, where presumably the Paleocene/ Eocene boundary falls within a hiatus.

A notable feature common to each of the Expedition 342 Paleocene-Eocene sequences is the presence of siliceous sediments at or near the Paleocene/Eocene boundary, including siliceous claystone, siliceous limestone, porcellanite, and chert. These lithologies are likely also present in the Paleocene/Eocene boundary interval sediments at Site U1407, which had poor recovery in the lower Eocene chert-rich interval, and Site U1410, which was terminated in lower Eocene sediments because of slow and poor recovery, with fragments of chert present in the deepest core. Chert is also common as frequent centimeter-scale beds higher up in the lower Eocene at Sites U1406-U1410. The occurrence of abundant well-preserved radiolarians in upper Paleocene sediments at Sites U1403 and U1407-U1409 and the persistence of poorly preserved assemblages through the Paleocene-Eocene transition is consistent with the derivation of cherts through diagenetic alteration of biogenic silica. The presence of chert at the Paleocene/ Eocene boundary and in the lower Eocene, an interval of previously documented hyperthermal events (e.g., Cramer et al., 2003; Lourens et al., 2005; Zachos et al., 2010), suggests an association between hyperthermal events and siliceous sedimentation or alteration in the Newfoundland drifts. An association between warm climates and chert deposition in the North Atlantic has been previously identified for the middle and early Eocene (McGowran, 1989; Muttoni and Kent, 2007), but not for the PETM.

Site U1407 and U1408 sediment is carbonate-rich above and below the siliceous PETM interval $(>70$ $\mathrm{wt} \% \mathrm{CaCO}_{3}$ ), suggesting a paleodepth above the CCD during most of the Paleogene. High-resolution shipboard sampling at Site U1408 (not performed at Site U1407) shows a temporary decline in carbonate content from $\sim 70 \mathrm{wt} \%$ to a low of $\sim 30 \mathrm{wt} \%$ within the siliceous claystone of the PETM interval (Fig. F64). This decrease in carbonate content is similar to other pelagic PETM records (Colosimo et al., 2006; Zachos et al., 2005), where it is interpreted as documenting shoaling of the CCD in response to the rapid injection of thousands of gigatons of carbon into the ocean-atmosphere system.

Site U1403, however, is carbonate-free below the Paleocene/Eocene boundary, suggesting a depositional depth below the late Paleocene CCD. The exact placement of the Paleocene/Eocene boundary is uncertain because of a lack of reliable upper Paleocene biostratigraphic markers but may be represented by a prominent siliceous claystone layer at $182.2 \mathrm{mbsf}$ in Hole U1403A. At $\sim 30 \mathrm{~cm}$ above this layer, carbonate content increases rapidly from $<1$ to $\sim 30 \mathrm{wt} \%$ (Fig. F64), driven mostly by an abundance of calcareous nannofossils representing Subzone NP9b. This may be direct evidence of a CCD overshoot during the PETM recovery phase, a global ocean carbonate oversaturation relative to pre-event steady-state conditions. This effect is predicted by carbon cycle models (e.g., Dickens et al., 1997) in which enhanced rock weathering in response to elevated atmospheric $\mathrm{CO}_{2}$ increases the supply of alkalinity and dissolved inorganic carbon to the ocean, causing carbonate oversaturation and deepening of the CCD. The result of this carbonate neutralization is greater preservation of calcium carbonate in sediments where the excess carbon is ultimately preserved. Carbonate oversaturation has previously been suggested by increased carbonate mass accumulation rates during the PETM recovery at ODP Site 690 (Farley and Eltgroth, 2003) and ODP Site 1266 (Kelly et al., 2010); however, direct evidence of CCD deepening has remained elusive. Site U1403, carbonate-barren before the PETM and carbonate-rich shortly afterward, places important constraints on the evolution of the Atlantic CCD during the PETM recovery phase that promise to guide understanding of the carbon cycle perturbation during the PETM and the processes involved in restoring steady state.

\section{Paleocene and Danian-Selandian transition}

The Paleocene is generally overshadowed by the major boundary events at either end: the K/Pg bound- 
ary mass extinction and the PETM. Our understanding of major biotic, paleoceanographic, and geochemical changes between these well-studied intervals is limited by a lack of sites and records spanning the $\sim 6 \mathrm{~m}$.y. from the late Danian to late Thanetian. Outstanding issues for this broad sweep of the Paleocene include

- The mechanisms leading to the diversification and turnover of calcareous plankton during the Danian-Selandian transition (Coxall et al., 2006; Fuqua et al., 2008);

- The rediversification of assemblages dominated by photosymbiotic planktonic foraminifers following the $\mathrm{K} / \mathrm{Pg}$ boundary mass extinction (Norris, 1996; Berggren and Norris, 1997; Quillévéré et al., 2001);

- The relationship between paleoceanographic change and the global carbon cycle (e.g., Kurtz et al., 2003; Hilting et al., 2008); and

- The nature of short-lived carbon isotope and/or biotic events in the Paleocene (e.g., Quillévéré et al., 2002; Petrizzo, 2005; Bornemann et al., 2009; Westerhold et al., 2011).

During Expedition 342, sediment of late Danian to late Selandian age was recovered from J-Anomaly Ridge Site U1403 (4946 mbsl) and Southeast Newfoundland Ridge Site U1407 (3074 mbsl). Biostratigraphy and preliminary magnetostratigraphic data indicate that the Danian-Selandian transition (nannofossil Zones NP4-NP6) is largely complete at Site U1407 (Fig. F65). Site U1403 suffers from poor calcareous microfossil preservation and poor core recovery but also may span this interval based on preliminary evidence from nannofossils and radiolarians.

Our new records span two short-lived climatic and biotic events in the Paleocene, the Latest Danian Event (LDE) at the Chron C27n/C26r boundary (Westerhold et al., 2008) and the Mid-Paleocene Biotic Event (MPBE) at 58.9 Ma (Bernaola et al., 2007; Petrizzo, 2005). Both events coincide with changes in calcareous microfossil assemblages (Bernaola et al., 2007; Petrizzo, 2005; Fuqua et al., 2008). Whereas the LDE is associated with a 200 k.y. hyperthermal excursion and an inferred perturbation to the carbon cycle (Bornemann et al., 2009; Westerhold et al., 2011), the only tenuous evidence for climatic or paleoceanographic change at the MPBE is a dissolution horizon coincident with this event (Petrizzo, 2005).

The Danian-Selandian succession at Site U1403 may be as thick as $\sim 30 \mathrm{~m}$, although it includes substantial recovery gaps (Fig. F65). Sediment is composed of carbonate-free grayish brown siliceous clay in the upper part of the transition and shifts toward pre- dominantly light reddish brown clayey nannofossil ooze with radiolarians below 198 mbsf, covering mainly nannofossil Zone NP4. At Southeast Newfoundland Ridge, Site U1407 includes $\sim 32 \mathrm{~m}$ of thick pinkish to white nannofossil chalk with radiolarians in the upper part of the Danian-Selandian interval, gradually changing to light greenish gray nannofossil chalk below 175 mbsf. Calcareous microfossil preservation is considered to be moderate to good at this site. As the northernmost long Paleocene section drilled to date, the J-Anomaly Ridge and Southeast Newfoundland Ridge sites have the potential to unravel the mechanisms leading to both events.

A significant pattern of radiolarian occurrence is noted across the Danian/Selandian boundary. At all sites, radiolarians are absent in the lower Paleocene but become very abundant and well preserved from the upper part of nannofossil Zone NP4 (radiolarian Zone RP6) to the uppermost Paleocene (see "Paleocene/Eocene Thermal Maximum"). At Site U1407, they are accompanied by diatoms, suggesting that the Selandian-Thanetian interval was a period of high biosiliceous productivity.

\section{Cretaceous/Paleogene boundary}

The mass extinction at the K/Pg boundary is one of the five largest extinction events in Earth history, with a loss of $\sim 75 \%$ of Late Cretaceous marine species (Sepkoski et al., 1981; Norris, 2001). The Chicxulub impact (Yucatan, Mexico) at the K/Pg boundary is now widely considered to be the primary cause of the end-Cretaceous mass extinction (Alvarez et al., 1980; Hildebrand et al., 1991; Schulte et al., 2010). The asteroid, estimated to be $10-13 \mathrm{~km}$ in diameter (Hildebrand et al., 1991; Morgan et al., 1997), would have caused immediate devastation through massive earthquakes, tsunamis, and wildfires, as well as longer lasting effects including ejecta-induced solar dimming and acid rain (Toon et al., 1997; D'Hondt, 2005).

Ocean drilling has been critical to resolving various debates regarding the cause and consequences of the $\mathrm{K} / \mathrm{Pg}$ boundary extinction, including

- Whether an impact occurred at the $\mathrm{K} / \mathrm{Pg}$ boundary (e.g., Officer and Drake, 1983; Alvarez et al., 1984; Michel et al., 1981, 1985; Claeys et al., 2002);

- Whether the impact was temporally and mechanistically linked to the mass extinction (Pospichal, 1994; Huber, 1996; Huber et al., 1994; Keller, 1993; Norris et al., 1999); and

- Whether the magnitude and duration of environmental perturbation caused by the $\mathrm{K} / \mathrm{Pg}$ boundary impact was greater than that of Deccan volcanism, another hypothesized cause of 
the K/Pg boundary extinction (Ravizza and Peucker-Ehrenbrink, 2003; Robinson et al., 2009; Schulte et al., 2010).

At J-Anomaly Ridge Site U1403, coring recovered two K/Pg boundary sections (Holes U1403A and U1403B) with an $\sim 0.5-1 \mathrm{~cm}$ thick graded impact spherule bed (Fig. F66). Of the $>24 \mathrm{~K} / \mathrm{Pg}$ boundary sites drilled during the history of ocean drilling (summarized from the supplemental table in Schulte et al., 2010), only about nine contain discrete ejecta beds with a thickness of $1 \mathrm{~cm}$ or more (Fig. F67). Thus, this new K/Pg boundary section, with a distinct sequence of impact markers, has potential to provide detailed chronostratigraphic and geochemical records that will work to further resolve details related to the impact proper and to test the relative chronology, magnitude, and competing importance of the K/Pg boundary impact and Deccan volcanism. The impact spherule bed in Section 342-U1403B28X-1 provides a better target than Core 342U1403A-26X for such studies because it is less fragmented by drilling and preserves the original horizontal orientation and spherule bed grading across the $\mathrm{K} / \mathrm{Pg}$ boundary.

The K/Pg boundary cores (342-U1403A-26X and 342U1403B-28X) are biostratigraphically complete across the K/Pg boundary and indicate sedimentation rates of $1.08 \mathrm{~cm} / \mathrm{k} . \mathrm{y}$. in the latest Maastrichtian and $0.31 \mathrm{~cm} / \mathrm{k} . \mathrm{y}$. in the earliest Paleocene. Cores 342-U1403A-26X and 342-U1403B-28X both capture the same general lithostratigraphic sequence (Fig. F66), including (from bottom to top):

1. Moderately bioturbated splotchy pink and white-gray latest Cretaceous chalk with abundant, diverse Late Cretaceous nannoplankton assemblages;

2. A pale green $\sim 0.5 \mathrm{~cm}$ thick unbioturbated bed of chalk immediately below the ejecta horizon;

3. A $\sim 0.5 \mathrm{~cm}$ thick bed of green sand to silt-sized impact spherules topped by a $\sim 0.5 \mathrm{~cm}$ thick bed of light greenish gray chalk with abundant calcispheres and early Paleocene biomarkers; and

4. A distinctly bioturbated pink bed topped by light brown chalk containing early Danian planktonic foraminifers and nannoplankton.

Biogeographically, the K/Pg boundary at Site U1403 is of great interest because it captures the highest northern latitude, open-ocean $\mathrm{K} / \mathrm{Pg}$ boundary site drilled to date. The abundant and well-preserved calcareous microfossils will allow us to explore recent ideas concerning plankton extinction, recovery, and survivorship (e.g., Bown, 2005a; Coxall et al., 2005; Jiang et al., 2010; Hull and Norris, 2011). Specifically, we will be able to work toward addressing three unresolved questions:
1. Does the change in oceanic export productivity across the K/Pg boundary vary geographically (e.g., Hollis et al., 1995; Alegret and Thomas, 2009; Hull and Norris, 2011)?

2. Is there diachroneity in pelagic recovery (e.g., Coxall et al., 2006; Jiang et al., 2010)?

3 . Is the recovery of export productivity within one site tied to the recovery of pelagic foodwebs (e.g., D'Hondt, 2005; Coxall et al., 2006; Hull et al., 2011b)?

Site U1403 has the potential to provide valuable multiproxy records (e.g., stable isotopes, biogenic barium, faunal assemblages, and organic proxies and biomarkers) to these ends.

\section{Late Cretaceous sedimentation}

Warm mid-Cretaceous supergreenhouse climates were followed by long-term climate cooling in the Late Cretaceous (Huber et al., 2002; Friedrich et al., 2012) that culminated in the latest Campanian to Maastrichtian. However, rapid short-term climate shifts are superimposed on this long-term cooling trend, indicated by short stable isotope excursions, including the Campanian/Maastrichtian Boundary Event (Voigt et al., 2010) and the Mid-Maastrichtian Event (e.g., Frank et al., 2005).

Both of these events have been linked with changes in Earth's climate and ocean circulation and explained by changes in intermediate to deepwater circulation (e.g., Barrera et al., 1997; Frank and Arthur, 1999; Koch and Friedrich, 2012) or by temporary build-up of ice sheets on Antarctica (e.g., Barrera and Savin, 1999; Miller et al., 2003, 2005). Both of these explanations remain controversial, not least because our understanding of Cretaceous oceanic circulation is limited. It has been suggested that Atlantic Ocean circulation was driven by multiple intermediate to deepwater sources during the mid-Cretaceous greenhouse climate (e.g., MacLeod et al., 2008; Martin et al., 2012) and that the Campanian interval saw significant changes in Atlantic deepwater circulation, potentially including the encroachment of southern component waters (e.g., Frank and Arthur, 1999; Friedrich et al., 2009; Robinson et al., 2010) and northern North Atlantic Deep Water (MacLeod et al., 2011). But even with these new data, the mode of ocean circulation during the latest Cretaceous to Paleocene times $(75-55 \mathrm{Ma})$ is still poorly understood, and possible sites of deepwater formation relative to the opening of the Atlantic Ocean are hotly debated.

One of the major barriers to better understanding Cretaceous ocean circulation is the lack of truly deep ocean sites that provide a record of changes in deepwater masses. In this respect, the Expedition 342 sequences of late Campanian to Paleocene age (espe- 
cially Site U1403) provide the opportunity to fill the gap in our understanding of the evolution of ocean circulation during this time interval. Site U1403 provides a $\sim 43 \mathrm{~m}$ thick sequence of late Campanian to Maastrichtian sediment and is located in the pathway of a potential North Atlantic Deep Water current (a possible end-member of the latest Cretaceous ocean circulation). Paleoceanographic data from this site will therefore provide critical information concerning the role of North Atlantic Deep Water during the latest Cretaceous and Paleocene interval.

\section{Ocean Anoxic Event 2}

OAE 2 is characterized by widely distributed deposition of organic matter-rich sediments and ${ }^{13} \mathrm{C}$ enrichment in carbonate and organic carbon (Arthur et al., 1987; Schlanger et al., 1987; Tsikos et al., 2004). Over a period of $\sim 400$ to 600 k.y. (Sageman et al., 2006; Voigt et al., 2008), the ocean was characterized by widespread anoxia linked to major faunal turnover in marine plankton (Leckie et al., 2002) and perturbations of the carbon, sulfur, nitrogen, and phosphorus cycles on a global scale (e.g., Arthur et al., 1988; Kuypers et al., 2004; Junium and Arthur, 2007; Mort et al., 2007; Adams et al., 2010; Barclay et al., 2010). The trigger for OAE 2 is thought to be the rapid addition of carbon dioxide to the ocean-atmosphere system associated with large igneous province volcanism (Kuroda et al., 2007; Turgeon and Creaser, 2008; Adams et al., 2010). In this sense, OAE 2 is similar to the Paleogene ocean acidification and hyperthermal events in that they are a direct response to addition of carbon to the Earth system. However, the net result of $\mathrm{CO}_{2}$ addition in the mid-Cretaceous was distinctly different from the Eocene dissolution of calcium carbonate followed by high rates of carbonate production (overshoot). During OAE 2, carbon dioxide was rapidly sequestered as organic matter and is expressed by the quasi-global distribution of organic matter-rich rocks known as black shales (for review see Jenkyns, 2010).

\section{Newfoundland ridges record of OAE 2}

The recovery of Cenomanian-Turonian black shales deposited during OAE 2 at Site U1407 was an unexpected but fortuitous discovery that fills a gap in existing OAE 2 geologic records. The presence of wellconstrained biostratigraphy from a pelagic depositional setting will help better define the temporal transience of black shale deposition that is recognized through the OAE 2 interval but poorly understood (Tsikos et al., 2004). Additionally, the Site U1407 record is one of the most shallowly buried OAE 2 black shales yet recovered through ocean drilling and holds great promise for geochemical studies.

Drilling operations recovered an OAE sequence in all three holes drilled at Site U1407 that is defined on the basis of lithology and calcareous nannofossil biostratigraphy. The significant differences in the lithostratigraphic sequence and thickness of beds that exist between Holes U1407A, U1407B, and U1407C are due in part to drilling disturbances and mass wasting indicated by slump features in the overlying Turonian strata (Figs. F68, F69, F70).

Shipboard nannofossil stratigraphy from Holes U1407A and U1407B indicate a relatively complete yet highly condensed OAE 2 sequence. Elsewhere, the last occurrence of Corollithion kennedyi at 232.6 and 232.8 mbsf in Holes U1407A and U1407B, respectively, occurs after the initial rise in $\delta^{13} \mathrm{C}$ of carbonate and organic carbon reservoirs that defines the initiation of OAE 2 (Arthur et al., 1987; Sageman et al., 2006). This suggests that the OAE 2 interval begins in the underlying nannofossil chalk and that black shale deposition at Site 1407 lags onset of the global increase in the fractional burial of organic carbon defined by the $\delta^{13} \mathrm{C}$ excursion as observed elsewhere (e.g., Wunstorf, Germany; Voigt et al., 2008). The first occurrence of Quadrum intermedium occurs in greenish white nannofossil chalk $\sim 80 \mathrm{~cm}$ above the black shale at Site U1407 and recorded elsewhere within the $\delta^{13} \mathrm{C}$ excursion plateau that defines the heart of OAE 2. The termination of OAE 2 elsewhere (Sageman et al., 2006) occurs shortly after the first occurrence of Quadrum gartneri in the early Turonian (Tsikos et al., 2004; Hardas and Mutterlose, 2006) (Fig. F68). The lack of well-developed pink chalk in Hole U1407B suggests the presence of a hiatus or slumping at $230.64 \mathrm{mbsf}$ in this hole.

\section{Global context}

The pelagic style of sedimentation is distinctly different from the proximal turbiditic OAE 2 sequence in the Newfoundland Basin (Site 1276) and the carbonate-free sequence from Hatteras Rise (DSDP Hole 603B) (Dean and Arthur, 1987).

The lithologic expression of black shale deposition at J-Anomaly Ridge is more suggestive of the "black band" sequences from the Tethys and England where black shales occur principally in a narrow interval of time within the heart of the $\mathrm{OAE} \delta^{13} \mathrm{C}$ excursion, nested in calcareous sediments (Tsikos et al., 2004). The carbonate-poor black bands in Holes U1407AU1407C are interbedded with dark gray claystone that is relatively organic carbon poor but almost exclusively laminated and free of preserved benthic foraminifers. Despite the lower organic carbon con- 
tent, the presence of laminations and lack of benthic foraminifers indicates that suboxic bottom water conditions remained through the whole black band interval. Significant variability in organic carbon content in the black bands is also a characteristic of other locations (Tsikos et al., 2004; Erbacher et al., 2005; Jenkyns et al., 2007; Voigt et al., 2008) and may reflect temporary fluctuations in productivity, water column ventilation, or winnowing of organic matter.

The color progression of greenish white to black to pink through the OAE 2 interval at Site U1407 is very similar to Cenomanian/Turonian boundary sequences from the Umbria-Marche Basin of Italy. The greenish white to pink nannofossil chalk is reminiscent of the Scaglia Bianca and Scaglia Rossa limestones that bound the siliceous Bonarelli horizon (Arthur and Premoli Silva, 1982). Associated lithologies include the presence of radiolarian sand interbedded with the black shales and chert and silicified limestone with radiolarians. This stratigraphic progression is also very similar to the Italian sequences. However, the preliminary biostratigraphy at Site U1407 indicates that the $\delta^{13} \mathrm{C}$ excursion must predate black shale deposition and, in this sense, is more similar to continental records from England, North Germany (Tsikos et al., 2004; Voigt et al., 2008), and DSDP Site 551 (Goban Spur) (de Graciansky and Bourbon, 1985).

\section{Albian reef and beginning of pelagic sedimentation}

Aptian-Albian sediment along the easternmost margin of North America has long been recognized as an extensive carbonate depositional environment (Mountain and Tucholke, 1985). At Site U1407, we recovered sediment of Albian age at the bottom of Hole U1407A (Fig. F71). The topmost interval of this sediment is a current-laminated fine sand with common belemnite rostra. The paleowater depth of these deposits is inferred to be tens of meters deep (shelf sediment). Beneath this sandy sediment of Albian age lies an unconformity between the overlying pelagic sediment and the top of the main shallow-water (neritic) carbonate facies. The top of the neritic shallow-water carbonate unit corresponds to a ubiquitous reflector on the North American eastern margin, called Reflector $\beta$ by Mountain and Tucholke (1985). In Hole U1407A, this "ringing" reflector is a coarse-grained sand, cemented and coated by iron manganese oxides (Sample 342-U1407A-31X-CC, 17-18 cm) (Fig. F71A). From a neritic carbonate facies standpoint, lithology transitions downhole from heavily cemented (iron manganese cement) beach sediment into back-reef sediment that includes large
Orbitolina benthic foraminifers (found in Section 342-U1407A-33X-CC) (Fig. F71E). Deeper within the hole we recovered pelleted carbonate mud (Sample 342-U1407A-32X-CC, 0-3 cm) (Fig. F71B) consistent with a deeper lagoonal environment. Finally, at the base of the hole, sediment is composed of grainstone and framestone more typical of a back-reef environment, examples of which include molds of scleractinian corals, rudist bivalves, and other mollusks (Fig. F71C, F71D, F71F).

\section{Principal results: MDHDS sea trials}

One successful deployment of the MDHDS was achieved at $96.4 \mathrm{~m}$ drilling depth below seafloor (DSF) at Site U1402 (Fig. F72). The MDHDS was successfully delivered to the BHA and released with the electronic RS (ERS). In addition, the inner MDHDS subassembly was successfully unlatched from the outer subassembly and the T2P was driven into the formation with no damage to the penetrometer tip. The ERS was unlatched with the tether system and raised $2 \mathrm{~m}$ above the BHA. The drill string pressure was raised and the T2P penetrometer was successfully deployed into the formation. Temperature and pressure signals were successfully transmitted to the rig floor for $30 \mathrm{~min}$ and recorded downhole. Accelerometer data clearly show that the tool was completely decoupled from the drill string (Fig. F72). The in situ pressure was successfully measured and was equal to $7.536 \mathrm{MPa}$, just slightly above hydrostatic pressure (Fig. F73).

\section{Site summaries}

\section{Site U1402}

\section{Background and objectives}

The MDHDS is an engineering development intended to serve as a foundation for future penetrometer and other downhole tool formation measurements. The MDHDS is designed so that downhole tools that are in the formation can be driven into the formation hydraulically and decoupled from the heave of the drill string, which negatively impacts these measurements.

The plan for the sea trial of the MDHDS was to carry out two tests of the tool set in the water column, wash to a depth of $100 \mathrm{mbsf}$, test the MDHDS in situ for at least $30 \mathrm{~min}$, turn on the pumps to clean the hole, take an APC core, test the tool in situ again, and take three more APC cores. The site chosen for the tests was a reoccupation of ODP Site 1073, New Jersey margin. 


\section{Principal results}

After a $582 \mathrm{nmi}$ transit from Bermuda to Site U1402 (Site 1073), the vessel arrived at the first expedition location to perform engineering qualification tests on the MDHDS. The vessel was at Site U1402 at 1542 h (UTC - 3 h) on 6 June 2012. Two holes were drilled at Site U1402. Hole U1402A was drilled without coring to $96.4 \mathrm{mbsf}$ to perform MDHDS testing. Hole U1402B was drilled to $15.03 \mathrm{mbsf}$ to obtain two cores, test laboratory equipment, and provide experience for the science staff.

Initially, the drill pipe was suspended above the seafloor at 608 meters below rig floor (mbrf), and the MDHDS with the T2P tool was made up for deployment using the developmental ERS tool on the Schlumberger wireline. After running the tools through the blocks, a surface test was performed to check all components prior to deployment. A communication problem with the tool was fixed and the Schlumberger wireline was run into the drill pipe to $\sim 250$ mbrf, where the ERS released prematurely, allowing the MDHDS and T2P to fall $400 \mathrm{~m}$ to the landing seat in the BHA. An unsuccessful attempt was made to relatch the ERS tool to the MDHDS, and the Schlumberger wireline was pulled from the drill pipe. An MDHDS mechanical latch assembly with sinker bars was assembled and deployed on the coring line in an attempt to fish the MDHDS tool, but this did not work. Upon retrieval of the coring line, the sinker bars were observed to have parted from the retrieval sub overshot, leaving a configuration that was impossible to fish. The decision was made to pull the drill string out of the hole to retrieve the test equipment inside the BHA. After tripping out of the hole, the test equipment was removed from the BHA and inspected for damage. It was found that the ERS was in the unlatched position. This may have caused the tool to drop in the first place and may have been the reason the MDHDS could not be retrieved with the ERS.

The drill string was again deployed and Hole U1402A was spudded at $1405 \mathrm{~h}$ on 7 June, with the seafloor recorded at 650 mbrf. Hole U1402A was washed down to $96.4 \mathrm{mbsf}$ (746.4 mbrf) and the MDHDS, T2P, and ERS were assembled and deployed for a second test. The MDHDS was lowered by the ERS to the BHA at 96.4 mbrf. The ERS was unlatched with the tether system and raised $2 \mathrm{~m}$ above the BHA. The drill string pressure was raised, and the T2P penetrometer was successfully deployed into the formation. Temperature and pressure signals were successfully transmitted to the rig floor for $30 \mathrm{~min}$ and recorded downhole. When circulation was reestablished to clear the BHA of settled sediment, telemetry was lost. The ERS was then lowered and relatched into the MDHDS. However, it was found that the MDHDS could not be retrieved with the wireline system. The wireline tension was increased to $\sim 8000 \mathrm{lb}$. We interpreted that the MDHDS had jammed in the BHA. The ERS was released and the Schlumberger wireline was pulled from the hole, the top drive was set back, and the drill string was tripped from the hole. The bit cleared the rotary table at $0110 \mathrm{~h}$, ending Hole U1402A. We found that the tether within the MDHDS had worked between the tool and the inside of the BHA aperture, jamming the tool in place and preventing recovery. Significant sediment was also found within the BHA. This concluded the MDHDS sea trial. The ERS and the MDHDS worked well in this second deployment. The in situ pressure was successfully measured and equal to $7.536 \mathrm{MPa}$, just slightly above hydrostatic pressure.

The MDHDS was successfully delivered to the BHA and released with the ERS. Additionally, the inner MDHDS subassembly was successfully unlatched from the outer subassembly and the T2P was driven into the formation with no damage to the penetrometer tip. Analysis of accelerometer and pressure data showed no coupling with the drill string. Although real-time data were acquired through the tethered system, problems with the tether associated with drill string pressurization suggest that this component (real-time telemetry with a tether) is not ready for regular shipboard use.

When the MDHDS tests were concluded, several hours remained until a helicopter would arrive to exchange departing engineers with arriving science support technicians. The science party requested that a few cores be obtained from Site U1402 to test laboratory equipment and provide experience for the science staff. The vessel was offset $20 \mathrm{~m}$ to the east, the drill string was deployed a third time, and Hole U1402B was spudded at $0625 \mathrm{~h}$ on 8 June. Two cores were taken from 0 to 15 mbsf, with $100 \%$ recovery. Core 342-U1402B-1H was a $7 \mathrm{~m}$ long mudline core, and Core $2 \mathrm{H}$ was an $8 \mathrm{~m}$ long partial stroke core that suffered significant core liner damage.

While working on retrieving the second core, a scheduled helicopter arrived on deck at $0932 \mathrm{~h}$ with four United States Implementing Organization (USIO) staff. The helicopter refueled, took on five MDHDS scientists/engineers and luggage and departed the R/V JOIDES Resolution at $1020 \mathrm{~h}$. The rig floor was secured at $1330 \mathrm{~h}$ on 8 June, ending Hole U1402B, and the vessel was under way at full speed to Site U1403 (proposed Site JA-1A).

Analysis of Cores 342-U1402B-1H and 2H showed the sediment to be unconsolidated, sticky, gray to dark gray-brown Pleistocene-Holocene silty mud- 
stone. The mud contains abundant woody organic matter and patches of sulfides as well as mollusk shell fragments. The sediment is similar to proglacial muds elsewhere along the continental margin. The microfossil assemblage consists of sponge and diatom fragments, a foraminifer assemblage dominated by benthic species, and a late Pleistocene calcareous nannoplankton assemblage. Both the benthic foraminifer and calcareous nannoplankton assemblages include, in addition to Pleistocene species, a mixed reworked assemblage. For example, reworked calcareous nannoplankton includes markers for the lower Oligocene, the upper Eocene, and the Cretaceous. Planktonic foraminifers are dominated by cold-water Pleistocene species. Benthic foraminifers are typical of slope water depths of 400-600 mbsl. Section 342U1402B-1H-1 has normal magnetic polarity, and a short reversed interval was detected in Section 1H-3. A similar reversal event was reported at 14.8-15.7 mbsf at Site 1073 and was provisionally identified as the Laschamp or Blake excursion. Nannofossil biostratigraphy indicates that the base of Hole U1402B cannot be older than $70 \mathrm{ka}$, so we interpret the reversal at 6.15-6.20 mbsf to be the $\sim 38-40 \mathrm{ka}$ Laschamp excursion.

\section{Site U1403}

\section{Background and objectives}

Site U1403 (proposed Site JA-01) is the first and the deepest water site to be drilled on J-Anomaly Ridge, pinning the deep end of the Paleogene Newfoundland sediment drifts depth transect. The site is positioned to capture deep excursions of the CCD during the Paleogene and to help improve stratigraphic control on the sediments drilled on J-Anomaly Ridge. A secondary goal at Site U1403 was to identify the age and lithology of a reflector-rich sediment package that lies beneath the acoustically homogeneous unit that was a primary drilling target for Expedition 342.

\section{Principal results}

After a $946 \mathrm{nmi}$ transit from Site U1402, the vessel stabilized over Site U1403 at 1708 h (UTC -2.5 h) on 11 June 2012. The original plan called for drilling three holes to a depth of $\sim 250 \mathrm{~m}$ drilling depth below seafloor (DSF), but the science decision was ultimately to complete operations with two holes: Hole U1403A to $253.3 \mathrm{~m}$ DSF and Hole U1403B to 265.1 $\mathrm{m}$ DSF. Hole U1403A was spudded at $1020 \mathrm{~h}$ on 12 June. Water depth based on the $5.85 \mathrm{~m}$ long mudline core was $4944.3 \mathrm{mbsl}$. The APC system recovered Cores $342-\mathrm{U} 1403 \mathrm{~A}-1 \mathrm{H}$ through $17 \mathrm{H}$, where a hard layer was encountered at $\sim 148 \mathrm{~m}$ DSF. The XCB system was deployed for Cores $18 \mathrm{X}$ through $29 \mathrm{X}$ to a final depth of $253.3 \mathrm{~m}$ DSF. The seafloor was cleared at
$1240 \mathrm{~h}$ on 14 June, ending Hole U1403A. Overall core recovery for Hole U1403A was $231.82 \mathrm{~m}$ for the $253.3 \mathrm{~m}$ interval cored (91\% recovery).

The vessel was offset $20 \mathrm{~m}$ east, and Hole U1403B was spudded at $1730 \mathrm{~h}$ on 14 June. The intent was to recover $\sim 8 \mathrm{~m}$ in the mudline core. The $3.9 \mathrm{~m}$ core recovery was a surprise, yielding a water depth of 4948.7 mbsl, $4.4 \mathrm{~m}$ deeper than recorded in Hole U1403A. This and correlation of features across the two holes led to the suspicion that the water depth estimate for Hole U1403A was incorrect for unknown reasons. The APC was used for Cores 342U1403B-1H through $16 \mathrm{H}$. The XCB was deployed for Cores 17X through 18X until we broke through the chert layers at $150.4 \mathrm{~m}$ DSF. The APC was again deployed for Cores $19 \mathrm{H}$ through $22 \mathrm{H}$ to $175.9 \mathrm{~m} \mathrm{DSF}$. After a partial-stroke core with 2.97 m recovery, the $\mathrm{XCB}$ was again deployed for Cores $23 \mathrm{X}$ through $32 \mathrm{X}$ to a final depth of $265.1 \mathrm{~m}$ DSF. Overall, core recovery for Hole U1403B was $229.81 \mathrm{~m}$ for the $265.1 \mathrm{~m}$ cored interval (87\% recovery).

Site U1403 yielded diverse types of deep-sea pelagic sediments within five lithostratigraphic units of Pleistocene to Late Cretaceous (Campanian) age. Core recovery and condition were excellent overall and included records of the $\mathrm{K} / \mathrm{Pg}$ boundary extinction event, the late Eocene Chesapeake Bay impact (see "Paleomagnetism" in the "Site U1403" chapter [Norris et al., 2014a] for a possible caveat), and the Eocene ETM2 and PETM hyperthermals. The majority of the Paleogene is carbonate poor but relatively rich in siliceous microfossils. This record is consistent with paleodepths below the local CCD and anchors the deepest water site of the Expedition 342 depth transect. Initial results reveal episodic deepening of the CCD, which may be evidence of carbonate compensation "overshoots" that enhance carbonate deposition in the deep sea, a predicted response to transient global warming and ocean acidification events.

The downhole lithostratigraphy at Site U1403 includes foraminifer sandy clay; unfossiliferous clay; red, brown, and black chert; clay with radiolarians; clay with nannofossils and radiolarians; nannofossil ooze; and chalk. Uppermost sediment includes foraminifer sand with manganese nodules that overlie a succession of unfossiliferous clay and clay with nannofossils and radiolarians. Chert horizons are present below 150 mbsf between intervals of radiolarian clay and nannofossil ooze and chalk. The chert horizons are typically poorly recovered. A thin, graded, green spherule horizon is present at the $\mathrm{K} / \mathrm{Pg}$ boundary and interpreted as debris from the Chicxulub impact event. Underlying sediment largely consists of color-banded nannofossil chalk to $\sim 262$ mbsf. 
At Site U1403, we recovered a sequence of HolocenePleistocene to Campanian sediment. Quaternary calcareous nannofossils and planktonic foraminifers are present in the uppermost $2 \mathrm{~m}$ of the section, but from 2 to 70 mbsf the sediment contains no age-diagnostic fossils. Calcareous nannofossils and radiolarians indicate a middle Eocene (44.5 Ma) and lower Eocene to $\mathrm{K} / \mathrm{Pg}$ boundary sequence from $\sim 70$ to 220 mbsf. Radiolarian assemblages are diverse and well preserved in the middle and lower Eocene and provide the only age control between 70 and 119 mbsf. Preliminary biostratigraphic analysis suggests that minor hiatuses may exist in the lower Eocene and middle-upper Paleocene. Fossiliferous sequences of both the PETM and ETM2 hyperthermal events were recovered and include "excursion" calcareous nannofossil assemblages. The K/Pg boundary section appears to be biostratigraphically complete. A high-diversity uppermost Maastrichtian calcareous nannofossil assemblage occurs below the $\mathrm{K} / \mathrm{Pg}$ boundary impact ejecta bed, and very low diversity, post-mass extinction assemblages occur above this bed. Lowest Danian assemblages are dominated by calcareous dinoflagellates, and a handful of Cretaceous calcareous nannofossil survivor species and are followed uphole by a record of nannoplankton recovery and diversification. Hole U1403B bottomed at 262 mbsf in upper Campanian sediments consisting largely of nannofossil chalk. Planktonic foraminifers are absent or very poorly preserved through most of the succession, except for an interval of wellpreserved assemblages in the lowermost Danian and uppermost Maastrichtian. Benthic foraminiferal assemblages characterized by calcareous taxa are present throughout the Paleocene to Cretaceous.

Paleomagnetic results from Site U1403 revealed a continuous series of normal and reversed magnetozones between Sections 342-U1403A-6H-1 and $16 \mathrm{H}-1$ ( 46-140 mbsf) and between Sections 342U1403B-6H-5 and 16H-5 ( 41-137 mbsf). This magnetic stratigraphy correlates well to Chrons C16n.1r through C22n on the geomagnetic timescale and indicates that we have collected a continuous early to late Eocene section (35.892-49.344 Ma). Site U1403 magnetostratigraphy also indicates that the distinctive gray-blue interval at 342-U1403A-6H-2, 80-120 $\mathrm{cm}$, and 342-U1403B-6H-5, 50-90 cm, was deposited during Chron C16n.1n (35.706-35.892 Ma). Thus, this stratigraphic interval, which is characterized by the occurrence of euhedral feldspars and a large spike in NGR, appears to mark the Chesapeake Bay impact event. A similar, but more securely dated, lithologic bed in Site U1404 occurs during Chron 17, raising the possibility that these distinctive beds do not represent a unique event or the Site U1403 bed is incorrectly dated.

A partially spliced composite depth record was produced for Holes U1403A and U1403B. The mudlines could not be reliably aligned because of an inconsistency in the apparent seafloor depths between the two holes. A composite spliced record was achieved between Holes U1403A and U1403B from 20 and $150 \mathrm{~m}$ core composite depth below seafloor (CCSF). Below 150 m CCSF, where chert layers were encountered in both holes, floating composite sections for the ETM2, PETM, and the K/Pg boundary and upper Maastrichtian were constructed.

Age-depth relationships are based largely upon biostratigraphic datums for radiolarians and calcareous nannofossils in Hole U1403A and a combination of paleomagnetic data from Holes U1403A and U1403B. The upper $\sim 46 \mathrm{~m}$ of the sediment column at Site U1403 is undated other than an $~ 2 \mathrm{~m}$ thick layer of Holocene-Pleistocene sediment. The magnetostratigraphic identification of Chron C16n.1n (35.706-35.892 Ma) in Core 342-U1403A-6H (and discovery of the same interval in Hole U1403B) represents the first of a series of dated Paleogene horizons at Site U1403. Our correlation indicates that average clay accumulation rates from $\sim 40$ to $50 \mathrm{Ma}$ were $\sim 1 \mathrm{~cm} / \mathrm{k} . \mathrm{y}$. and diminished to $\sim 0.2 \mathrm{~cm} / \mathrm{k} . \mathrm{y}$. from $\sim 35$ to $40 \mathrm{Ma}$. Average linear rates of sedimentation of $\sim 0.6 \mathrm{~cm} / \mathrm{k} . \mathrm{y}$. are relatively stable to $\sim 148 \mathrm{mbsf}$. Between 148 and 149 mbsf, a 3 m.y. interval from 50.5 to $53.7 \mathrm{Ma}$ is recorded by a series of chert horizons. The lower Eocene to the PETM sequence accumulated at average linear sedimentation rates of $\sim 1.4$ $\mathrm{cm} / \mathrm{k}$.y. Immediately underlying the PETM, a highly condensed chert-rich interval with at least one hiatus between 182 and 189 mbsf corresponds to $~ 56-$ $62 \mathrm{Ma}$. Average linear sedimentation rates of $\sim 0.8$ $\mathrm{cm} / \mathrm{k} . \mathrm{y}$. are recorded in the interval spanning the $\mathrm{K} /$ Pg boundary ( 62-69 Ma).

Headspace gas analysis for the purpose of safety monitoring yielded low concentrations of methane that gradually increased to $17 \mathrm{ppmv}$ with depth. Other higher hydrocarbon gases were not detected. TOC content was quite low in the upper $34 \mathrm{~m}$ of Hole U1403A, ranging from 0.14 to $0.46 \mathrm{wt} \%$, except for the interval 27-31 mbsf in which TOC content ranged from 1.4 to $1.7 \mathrm{wt} \%$. Carbonate content varied between 0.04 and $0.80 \mathrm{wt} \%$ in Cores 342U1403A-1H through 13H. In the bottom of Core $13 \mathrm{H}$ ( $137 \mathrm{mbsf})$, carbonate increases to $60 \mathrm{wt} \%$ and fluctuates between $\sim 2$ and $40 \mathrm{wt} \%$ to the bottom of the recovered sequence.

Grain density values are typically low $\left(\sim 1.5 \mathrm{~g} / \mathrm{cm}^{3}\right)$ in site-specific lithostratigraphic Units I-IV, which are 
dominated by clay, and then increase to $1.6 \mathrm{~g} / \mathrm{cm}^{3}$ and gradually to $1.8 \mathrm{~g} / \mathrm{cm}^{3}$ in Unit $\mathrm{V}$ toward the deepest recovered sequences at the site. Porosity values are generally high $(80 \%)$ in the radiolarian-rich sediments of Unit III and decrease $(\sim 60 \%)$ in the carbonate-rich section of Unit V. Magnetic susceptibility decreases from Unit I into the upper 18 mbsf of Unit II. Below 150 mbsf, magnetic susceptibility shows large fluctuations between $\sim 20$ instrument units to values over 120 instrument units. These large-amplitude increases in magnetic susceptibility are linked with major events such as the ETM2, PETM, K/Pg boundary, and Campanian/Maastrichtian boundary. Another large-amplitude magnetic susceptibility peak was documented in Paleocene sediments at Site U1403. $P$-wave velocity increases progressively downhole in the upper $150 \mathrm{mbsf}$ to $1550 \mathrm{~m} / \mathrm{s}$, takes a step to a velocity of $1600 \mathrm{~m} / \mathrm{s}$ in the chert at the top of Unit V, and continues to increase to $\sim 1650 \mathrm{~m} / \mathrm{s}$ at the bottom of the recovered section. NGR measurements average 30 cps until 110 mbsf, fall to $20 \mathrm{cps}$ in the nannofossil clays of Unit VI, and then show high-frequency fluctuations in carbonate sediments of Unit V.

At the conclusion of coring at $2200 \mathrm{~h}$ on 16 June, the hole was swept clean with $30 \mathrm{bbl}$ of high-viscosity mud and the drill string was pulled from the hole to $78.43 \mathrm{~m}$ DSF for logging with the triple combination (triple combo) and Formation MicroScanner (FMS)sonic tool strings. Two attempts to deploy the logging tools failed and the tools became firmly stuck inside the BHA with $\sim 17 \mathrm{~m}$ of the tool string extending out from the bit. After working the tools for several hours with no progress, the wireline was severed and the pipe tripped to the surface. When the tools arrived on the rig floor it was discovered that the triple combo tool string had parted, leaving $\sim 17 \mathrm{~m}$ of tools missing from the bottom of the tool string, including the density and porosity tools.

A video and sonar survey was planned to find and recover the lost tools. During deployment, the camera was shaking, vibrating, and rotating around the pipe because of strong ocean currents. At $2145 \mathrm{~h}$, with the bit $\sim 30 \mathrm{~m}$ from seafloor, the signals from the subsea camera and the Mesotech sonar were lost. The pipe was tripped back to the rig floor with the camera frame resting on top of the bit. Our suspicion that the coaxial cable supporting the camera system had failed was confirmed when the camera cable arrived at the rig floor.

Repair of the camera system would have taken 1-2 days, and redeployment was likely to result in the same problems. In addition, the loss of the only reentry system available for this vessel would have been detrimental to future operations. The decision not to deploy the camera system again at this site meant that we were unable to locate the lost logging tool or Hole U1403B. The drill floor was secured at $1415 \mathrm{~h}$ on 19 June, ending Site U1403 and Hole U1403B.

\section{Site U1404}

\section{Background and objectives}

Site U1404 is the second deepest drill site of the Expedition 342 Newfoundland sediment drifts depth transect. Principal goals included recovery of a Paleogene record of the position of the North Atlantic CCD and a more expanded record of sedimentation compared to the condensed, sub-CCD record at Site U1403. A related objective was to discover the types of sediments that contribute to the expanded, acoustically transparent sediment drift deposits that are so prominent on J-Anomaly Ridge.

\section{Principal results}

After a $4.2 \mathrm{nmi}$ transit from Site U1403, the vessel arrived at Site U1404 at $1455 \mathrm{~h}$ (UTC - $2.5 \mathrm{~h}$ ) on 19 June 2012. The original plan called for drilling three holes to a depth of $\sim 250 \mathrm{~m}$ DSF.

Hole U1404A was spudded at $1030 \mathrm{~h}$ on 20 June, and the mudline was established at 4753.8 mbrf (4742.3 mbsl), which was $35.4 \mathrm{~m}$ below the precision depth recorder (PDR) depth estimate. The discrepancy between the PDR depth and the drill pipe depth might have been caused by strong currents creating an Sshape in the drill pipe or the thermal and current layering in the water column, as indicated by the poor quality of the acoustic signal received from the acoustic beacon on the seafloor. Cores 342-U1404A$1 \mathrm{H}$ through $32 \mathrm{H}$ were taken to a depth of $271.0 \mathrm{~m}$ DSF, with a recovery of $257.97 \mathrm{~m}$. Cores $22 \mathrm{H}$ through $32 \mathrm{H}$ were partial strokes, and the hole was advanced by recovery. The XCB was deployed for Cores 33X through 36X to a final depth of $308.8 \mathrm{~m}$ DSF, with a recovery of $23.05 \mathrm{~m}$ for the $37.8 \mathrm{~m}$ interval cored. Overall core recovery for Hole U1404A was $281.02 \mathrm{~m}$ for the $308.8 \mathrm{~m}$ interval cored (91\% recovery).

The vessel was offset $20 \mathrm{~m}$ east, and Hole U1404B was spudded at $2255 \mathrm{~h}$ on 22 June. Water depth was 4747.6 mbsl based on mudline core. Cores 342U1404B-1H through $27 \mathrm{H}$ were recovered to a total depth of $228.7 \mathrm{~m}$ DSF. Cores $21 \mathrm{H}$ through $27 \mathrm{H}$ were partial strokes, and the hole was advanced by recovery. Eight core liners were either collapsed or broken and three of those had to be pumped out of the core barrel with a high-pressure pump. Total recovery was $228.04 \mathrm{~m}$ (100\%). 
The vessel was offset $20 \mathrm{~m}$ south, and Hole U1404C was spudded at 1445 h on 24 June. Hole U1404C was drilled to $16 \mathrm{~m}$ DSF and then cored to $44.5 \mathrm{~m}$ DSF (Cores 342-U1404C-2H through $4 \mathrm{H}$ ) in an attempt to recapture a zone that potentially contained gas hydrate based on observations in the previous two holes. Seafloor and water depths were assumed to be the same as those at Hole U1404B (4759.1 mbrf; $4747.6 \mathrm{mbsl})$. The total advance was $28.5 \mathrm{~m}$, with $28.98 \mathrm{~m}$ of core recovered (102\%).

The bit cleared the seafloor at $1945 \mathrm{~h}$ on 24 June, ending Hole U1404C. The drill floor was secured and the vessel began moving to Site U1405 in dynamic positioning mode at $0.9 \mathrm{kt}$. The total time spent on Hole U1404C was $6.5 \mathrm{~h}$. The total time spent at Site U1404 was 5.2 days.

The downhole sedimentary sequence at Site U1404 reveals four site-specific lithostratigraphic units. Unit I is $\sim 2 \mathrm{~m}$ thick and composed of Pliocene-Pleistocene brown foraminiferal sandy clay and nannofossil ooze with manganese nodules and a cobble-sized dolomitic dropstone, transitioning to Pliocene brown clay with silt. Unit II is a green and greenish gray carbonate-poor Oligocene to Miocene clay that occurs in a nearly $200 \mathrm{~m}$ thick sequence and contains abundant diatoms, radiolarians, and sponge spicules. Unit II is divided into upper Subunit IIa (20 $\mathrm{m}$ thick), which is barren of microfossils, and lower Subunit IIb (180 m thick), which contains abundant siliceous microfossils (diatoms, radiolarians, and sponge spicules) and a minor abundance of calcareous nannofossils. Unit III is an $26 \mathrm{~m}$ interval of carbonate-rich nannofossil ooze alternating with clayrich nannofossil ooze and clay that spans the lowermost Oligocene and uppermost Eocene. Unit IV is an $\sim 75 \mathrm{~m}$ thick succession of clay and claystone with some intervals containing abundant radiolarians, calcareous nannofossils, or both. Clastic lithoclasts are found in the $>63 \mu \mathrm{m}$ size fraction in Site U1404 sediment, particularly in the Miocene and Oligocene sequences, and may represent IRD.

The biochronology for Site U1404 consists of a lower Miocene ( $19 \mathrm{Ma})$ to middle Eocene ( 43 Ma) succession with a thin $(\sim 2.5 \mathrm{~m})$ Pliocene-Pleistocene cover. This abyssal, carbonate-poor green clay is challenging to date biostratigraphically, as none of the microfossil groups are continuously present and the calcareous fossils are frequently poorly preserved or absent. Planktonic foraminifers are generally absent except in the lower Miocene. Radiolarians occur more consistently from lower Miocene to middle Eocene, although they are absent in the cores spanning the EOT. When combined with the lower to middle Eocene radiolarian succession at Site U1403, these assemblages will help to refine radiolarian biostratig- raphy in the North Atlantic. Abundant diatoms suggest high productivity in the lower Miocene, supported by the occurrence of well-preserved benthic foraminifer assemblages that indicate high organic matter flux and/or oxygen consumption at the seafloor. We recovered an Oligocene/Eocene boundary interval that appears to be stratigraphically complete with variable but consistent carbonate and good preservation of calcareous nannofossils and benthic foraminifers. A succession of nannofossil events that characterizes this interval globally, including the extinction of the multiradiate discoasters and the Clausicoccus acme, is also recorded.

Paleomagnetic results from Site U1404 revealed a semicontinuous series of normal and reversed magnetozones that can be correlated to chron boundaries C12r/C13n (29.477 Ma) through C19n/C19r $(41.390 \mathrm{Ma})$ on the geomagnetic polarity timescale. This correlation provides a chronostratigraphic framework for late Eocene carbonate accumulation events observed in the Site U1404 record. It also suggests that the EOT was recovered in Section 342U1404B-24H-3, just below $115 \mathrm{~cm}$. This correlation also dates the distinctive blue-gray horizon in intervals 342-U1404A-26H-1, 82-130 cm, and 342U1404B-26H-3, 110-150 cm, which is also found in intervals $342-\mathrm{U} 1403 \mathrm{~A}-6 \mathrm{H}-2,80-120 \mathrm{~cm}$, and $342-$ U1403B-6H-5, 50-90 cm, to within Chron C16r. This raises the possibility that these distinctive beds do not represent a unique Chesapeake Bay impact event or that the Site U1403 bed is incorrectly dated.

Geochronologic analyses suggest continuous lower Miocene-upper Oligocene and upper-middle Eocene intervals with comparatively high sedimentation rates (7.0 and $1.4 \mathrm{~cm} / \mathrm{k} . y$. ., respectively) and an Oligocene to EOT interval with a lower sedimentation rate $(0.5-1.0 \mathrm{~cm} / \mathrm{k} . \mathrm{y}$.). A $\sim 2 \mathrm{~m} . \mathrm{y}$. hiatus is inferred in the lower Oligocene ( 34-32 Ma).

Methane concentrations in headspace gas samples are 1.75-28.8 ppmv. In the upper $212 \mathrm{mbsf}$, methane concentration did not exceed 4.24 ppmv. Below 212 mbsf (Core 342-U1404A-25H), there was a concomitant increase in methane and ethane concentrations to $\sim 28.8$ and $\sim 1.79 \mathrm{ppmv}$, respectively. Hole U1404C was drilled and sampled to determine the presence of gas hydrates, as suggested by effervescent sediment, expelled section caps, bulging core liners, a drop in bulk density, and the presence of massive pyrite in one core. However, methane concentrations in headspace samples (1.82-2.99 ppmv) were not above atmospheric levels, no other hydrocarbon traces were detected, and uniform chlorinity profiles from Rhizon samples do not suggest the presence of methane hydrates. Overall, downhole profiles of pore water components reflect 
- Organic matter degradation,

- Diffusion-related gradients produced from deep sources and sinks for chemical constituents,

- Sorption of ions onto clay minerals, and

- Secular variability in seawater chemistry over the depositional age of the sediments.

Downhole analysis of sediment geochemistry shows that the sediment is nearly carbonate free $(<5 \mathrm{wt} \%)$ in the surficial 200 mbsf. However, carbonate content prominently increases to $>10 \mathrm{wt} \%$ around 60 , 75, 90, and 170 mbsf. Between 200 and 300 mbsf, we observed four distinctive increases in calcium carbonate at 200-206, 208-213, 239-245, and 265-279 mbsf, with two less distinct events between 213 and 226 mbsf. The maximum carbonate content recorded is $57 \mathrm{wt} \%$ at $202.75 \mathrm{mbsf}$, coincident with the EOT. Calculated TOC values are typically low $(\sim 0.2 \mathrm{wt} \%)$, with highest values (>1 wt\%) in the 50 170 mbsf interval.

Sediment physical properties show increasing bulk density toward $1.8 \mathrm{~g} / \mathrm{cm}^{3}$ in the carbonate-rich sections (below $\sim 200 \mathrm{mbsf}$ ). Grain density averages 2.7 $\mathrm{g} / \mathrm{cm}^{3}$ in Hole U1404A. Porosity is generally high in the radiolarian-rich sediment $(80 \%)$ and decreases in the carbonate-rich sediment ( 40\%). Magnetic susceptibility decreases from 100 to 2 instrument units (IU) between the top of the sediment column and 20 mbsf and remains low until the carbonate content increases near the Eocene/Oligocene boundary ( $204 \mathrm{mbsf})$. $P$-wave velocity increases progressively downhole and shows a small step increase to $\sim 1630$ $\mathrm{m} / \mathrm{s}$ in carbonate-rich lithostratigraphic Unit III. NGR measurements vary between 20 and 55 cps and also increase downhole. A significant peak in NGR is seen at 200 mbsf, which corresponds to the EOT. Color reflectance follows the same trend as magnetic susceptibility with a distinctive drop at $~ 15$ mbsf and a significant increase below the EOT.

Direction of drilling operations by stratigraphic correlation at Site U1404 was difficult because of a lack of strong signals in the physical property data. The greenish gray Miocene to late Oligocene sediment spanning 20-230 m CCSF had extremely low magnetic susceptibility (below $15 \mathrm{IU}$, which is near the detection limit of the instrument), so only gamma ray attenuation (GRA) bulk density data were available for real-time correlation. GRA density data contained slightly more structure than magnetic susceptibility, but few clear features existed on which to base drilling adjustments. A sudden increase in magnetic susceptibility at $\sim 238 \mathrm{~m}$ CCSF corresponds to the interval immediately preceding the EOT. The primary goal of stratigraphic correlation was to cover the coring gap between Cores 342-U1404A-23H and $24 \mathrm{H}$, interpreted as the EOT. Initial correlation sug- gested that Hole U1404B had not bridged this gap, further suggesting that a third hole might be necessary. Further consideration of Hole U1404B, including Whole-Round Multisensor Logger data and lithologic interpretation of split cores, suggested that the coring gap was, in fact, covered by Core 342U1404B-24H.

\section{Site U1405}

\section{Background and objectives}

Site U1405 is a mid-depth site on the Expedition 342 Newfoundland sediment drifts depth transect. Principal goals were

- To test the hypothesis that the seismically homogeneous package prominent on J-Anomaly Ridge is a plastered drift deposit of Paleogene age,

- To obtain a sedimentary section suited to paleoceanographic study at suborbital timescales featuring very high rates of deposition compared to those typically found in deep-sea pelagic sites (1-2 cm/k.y.), and

- To capture excursions of the Cenozoic CCD.

\section{Principal results}

The vessel arrived at Site U1405 (4286 mbsl) at 0745 h (UTC - $2.5 \mathrm{~h}$ ) on 25 June 2012 after a $7.5 \mathrm{nmi}$ transit from Site U1404. The plan for Site U1405 called for drilling three holes to a depth of $\sim 250 \mathrm{~m}$ DSF.

Cores $342-\mathrm{U} 1405 \mathrm{~A}-1 \mathrm{H}$ through $26 \mathrm{H}$ were recovered to $241.9 \mathrm{~m}$ DSF. Advanced piston corer temperature tool (APCT-3) formation temperature measurements were taken on Cores $4 \mathrm{H}, 7 \mathrm{H}$, and $10 \mathrm{H}$ with good results. Core $26 \mathrm{H}$ was the first partial stroke, and the core had to be pumped out of the core barrel. The XCB was deployed for Cores $27 \mathrm{X}$ through $33 \mathrm{X}$ to a total depth of $308.6 \mathrm{~m}$ DSF. Overall core recovery for Hole U1405A was $270.34 \mathrm{~m}$ for the $308.6 \mathrm{~m}$ interval cored (88\% recovery).

The vessel was offset $20 \mathrm{~m}$ east, and Cores 342U1405B-1H through $24 \mathrm{H}$ were recovered to a total depth of $218.5 \mathrm{~m}$ DSF. An interval of $5 \mathrm{~m}$ was drilled without coring in an attempt to cover coring gaps in Hole U1405A. Coring the $218.5 \mathrm{~m}$ interval yielded $219.60 \mathrm{~m}$ of core (101\% recovery). The vessel was offset $20 \mathrm{~m}$ south, and Cores 342-U1405C-1H through $25 \mathrm{H}$ were recovered to a total depth of $232.0 \mathrm{~m}$ DSF. The cored interval of $232.0 \mathrm{~m}$ yielded $227.77 \mathrm{~m}$ of core (98\% recovery). The seafloor was cleared at $0200 \mathrm{~h}$ on 30 June, ending Hole U1405C.

After clearing the seafloor the drill string was raised to $\sim 3500$ mbrf and the vessel began moving in dynamic positioning mode to the next site at a speed of $1.5 \mathrm{nmi} / \mathrm{h}$. The positioning beacon was left on site 
for a later recovery to minimize the risk of losing it during recovery in difficult weather conditions. The total time spent at Site U1405 was 4.8 days.

The lithostratigraphy at Site U1405 is composed of $\sim 20 \mathrm{~m}$ of Pliocene-Pleistocene nannofossil ooze and clay (lithostratigraphic Unit I) overlying an expanded sequence ( $250 \mathrm{~m}$ thick) of upper Oligocene through lower Miocene distinctive greenish gray clay and ooze (Unit II). Unit II contains varying abundances of radiolarians, diatoms, and nannofossils and is divided largely according to changes in carbonate content ( $\sim 0$ to $30 \mathrm{wt} \%)$. Pale carbonate-rich intervals are present around the Oligocene-Miocene transition. Some of these intervals contain common to abundant Braarudosphaera nannofossil occurrences and even thin (1-2 mm), discrete Braarudosphaera ooze layers that have been disrupted by bioturbation. Signal processing of color reflectance parameter $L^{*}$ data reveals significant peaks in spectral power concentrated at wavelengths of $\sim 16$ and $\sim 4 \mathrm{~m}$, indicating a possible orbital control over sediment composition that may be particularly useful for detecting hiatuses and changes in sedimentation rate.

Biostratigraphic analysis of Site U1405 shows that the site records a middle Miocene $(\sim 14 \mathrm{Ma})$ to late Oligocene $(\sim 30 \mathrm{Ma})$ succession with a thin $(0-6.2 \mathrm{~m})$, Pliocene-Pleistocene cover. Between 6.2 and 26.2 mbsf, siliceous and calcareous microfossils are absent. Below 26.2 mbsf, nannofossils, radiolarians, and planktonic foraminifers provide a well-defined biostratigraphy that is in good agreement with paleomagnetically determined chron boundaries. Nannofossils are predominantly abundant and moderately well preserved. Planktonic foraminifers are generally common and well preserved throughout the hole. Except for the top and bottom of the hole, radiolarians occur consistently from the early Miocene to late Oligocene. As seen at Site U1404, abundant diatoms suggest high productivity in the lower Miocene, supported by the occurrence of well-preserved infaunal benthic foraminifer assemblages that imply high organic matter flux to the seafloor. The lower Miocene interval has comparatively high sedimentation rates $(3.3 \mathrm{~cm} / \mathrm{k} . \mathrm{y}$.$) , whereas the Oligo-$ cene-Miocene transition has still higher sedimentation rates $(\sim 10 \mathrm{~cm} / \mathrm{k} . \mathrm{y}$.$) . Paleomagnetic data indicate$ a potential hiatus between 19 and 21.5 Ma.

Paleomagnetic results from Site U1405 reveal a continuous series of normal and reversed magnetozones in all three holes, between $~ 39$ and $~ 240$ mbsf. Magnetozones can be straightforwardly correlated between all three holes, especially below $\sim 90$ mbsf. Although the pattern and stratigraphic thickness of magnetozones in all three holes are similar, there are significant offsets between the mbsf depths of these magnetozone boundaries in Hole U1405A and those in Holes U1405B and U1505C. We primarily used nannofossil and foraminifer biostratigraphy to correlate Hole U1405A magnetostratigraphy to chron boundaries C5Br/C5Cn.1n (15.974 Ma) through C5Cn.2r/C5Cn.3n (16.543 Ma) and C6AAr.3r/ C6Bn.1n (21.767 Ma) to C6Cn.3n/C6Cr (23.295 Ma) on the geomagnetic polarity timescale. This correlation provides a shipboard chronostratigraphic framework for interpreting the latest late Oligocene-middle Miocene at this site. Hole U1405A magnetostratigraphy indicates at least two substantial (1-3 Ma) unconformities during rapid ( 3.3-5.7 $\mathrm{cm} / \mathrm{k} . \mathrm{y}$.) deposition of the middle-late Miocene green clay drift deposits, whereas in Holes U1405B and $\mathrm{U} 1405 \mathrm{C}$, only one of these hiatuses is recognized.

Direction of drilling operations by stratigraphic correlation at Site U1405 was difficult because magnetic susceptibility data were below the detection limit for most of the sediment column in Holes U1405AU1405C. A prominent color change from tan to greenish gray in the uppermost three cores provides a clear correlation between the three holes. This was used to make initial adjustments to drilling operations in order to offset coring gaps. The majority of the recovered strata at Site U1405 were Miocene to Oligocene in age; this sediment was very homogeneous and showed few distinctive features downhole to 200 mbsf. A clear color change and associated GRA bulk density peak present in all three holes provided a strong tie just below the Oligocene/Miocene boundary. This tie suggests that we successfully recovered a complete Oligocene-Miocene transition between the three holes. Whole-core physical property data series between these two ties are not straightforward to interpret. Large lateral variations may exist in the sediment drift and cause differences in the recovered strata between each hole. As a result, most of our tie points are tentative, and the splice for Site U1405 will require postcruise revision based upon high-resolution X-ray fluorescence analysis.

Headspace gas results obtained from routine safety monitoring revealed methane in low concentrations (1.59-3.49 ppmv). Higher molecular weight hydrocarbons were not detected in measurable amounts. Calculated TOC values are typically low $(\sim 0.2-0.5$ wt $\%$ ) with highest values ( $>2 \mathrm{wt} \%$ ) in the middle of site-specific lithostratigraphic Subunit IIa (50-150 mbsf). Interstitial water profiles from Hole U1405A suggest organic matter degradation through manganese oxide and iron oxide metabolic pathways. The downhole interstitial water concentration profiles 
for manganese, iron, sulfate, and ammonium suggest that organic matter consumption has not driven pore fluid geochemistry to sulfate reduction. Interstitial $\mathrm{pH}$ and alkalinity profiles show regular trends downhole (decreasing and increasing, respectively) and reflect changes in dissolved inorganic carbon in response to organic matter consumption. Interstitial water concentrations of calcium and strontium and elemental ratios of $\mathrm{Sr} / \mathrm{Ca}$ and $\mathrm{Mg} / \mathrm{Ca}$ suggest that two processes are at work: carbonate recrystallization and exchange reactions with the basaltic basement (a source of $\mathrm{Ca}$ and sink for $\mathrm{Mg}$ ) and diffusion through the sedimentary sequence. Additionally, potassium concentrations have been modified through authigenic alteration of clay minerals.

Carbonate content is generally between 0 and 10 $\mathrm{wt} \%$ but increases to $10-20 \mathrm{wt} \%$ in the lower portion of Subunit IIa. Several distinct intervals of high carbonate (up to $46 \mathrm{wt} \%)$ and low carbonate $(<15 \mathrm{wt} \%)$ are observed. Based on the shipboard biostratigraphic and paleomagnetic derived age model, high carbonate intervals in Subunit IIa are likely to correspond with lowermost Miocene and upper Oligocene carbonate peaks observed at Site U1404. Intervals of carbonate in the uppermost Oligocene are driven by calcareous nannofossil abundance, particularly Braarudosphaera.

Almost all of the physical properties measured at Site U1405 show two major trends, both related to lithostratigraphy. Magnetic susceptibility, color reflectance parameters $\mathrm{a}^{*}$ and $\mathrm{b}^{*}$, and bulk density show higher values in lithostratigraphic Unit I than Unit II, whereas porosity and water content show the opposite trend. $P$-wave velocity gradually increases downhole from 1500 to $1650 \mathrm{~m} / \mathrm{s}$, a typical compaction trend similar to that seen in bulk density and water content in Unit II. L* and NGR measurements show different trends in all three holes, which suggests lateral heterogeneity in the sediment section in agreement with paleomagnetic results. Subtle changes in $\mathrm{L}^{*}$ likely reflect cyclic changes in calcium carbonate.

\section{Site U1406}

\section{Background and objectives}

Site U1406 (3814 mbsl) was at $\sim 3300$ mbsl paleodepth at $50 \mathrm{Ma}$ (Tucholke and Vogt, 1979) and is in the mid-range of the Expedition 342 Paleogene Newfoundland sediment drifts depth transect. The site was positioned to capture a record of sedimentation $>1.1 \mathrm{~km}$ shallower than the largely sub-CCD record drilled at Site U1403. Our primary scientific objectives for drilling Site U1406 were
- To reconstruct the mid-depth CCD in a primarily carbonate-dominated record;

- To obtain records of the Oligocene-Miocene transition and EOT events in carbonate-rich sediments that host abundant foraminifers suitable to the construction of geochemical climate records;

- To evaluate the history of deepwater and possible northern hemisphere glaciation on sediment chemistry, grain size, and provenance; and

- To evaluate biological evolution during Paleogene climate transitions.

\section{Principal results}

The vessel arrived at Site U1406 after a $14.9 \mathrm{nmi}$ transit from Site U1405, which was made in dynamic positioning mode at a speed of $1.4 \mathrm{kt}$ with the drill pipe suspended below the vessel. The vessel stabilized over Site U1406 at 1435 h (UTC - 2.5 h) on 30 June 2012. The plan for Site U1406 called for drilling three holes to $\sim 250 \mathrm{~m}$ DSF. Cores 342-U1406A-1H through $25 \mathrm{H}$ were retrieved from the seafloor to $217.7 \mathrm{~m}$ DSF. The first partial stroke was recorded when shooting for Core $16 \mathrm{H}$, and the APC was advanced by recovery for this and subsequent cores. The XCB was deployed for Cores 26X through 34X to a total depth of $283.3 \mathrm{~m}$ DSF. Overall core recovery for Hole U1406A was $267.30 \mathrm{~m}$ for the $283.3 \mathrm{~m}$ interval cored (94\%).

The vessel was offset $20 \mathrm{~m}$ east, and Cores 342U1406B-1H through $22 \mathrm{H}$ were retrieved to $188.8 \mathrm{~m}$ DSF. The XCB was deployed for Cores 23X through $30 X$ to a total depth of $253.6 \mathrm{~m}$ DSF. The recovery for Hole U1406B was $241.34 \mathrm{~m}$ over the $253.6 \mathrm{~m}$ cored (95\%). The vessel was offset $20 \mathrm{~m}$ south, and Cores $342-\mathrm{U} 1406 \mathrm{C}-1 \mathrm{H}$ through $18 \mathrm{H}$ were recovered to $161.4 \mathrm{~m}$ DSF. The XCB was deployed to the final depth at $241.4 \mathrm{~m}$ DSF. Two intervals, 3 and $2 \mathrm{~m}$ thick, were drilled without coring.

After clearing the seafloor, the drill string was tripped to the surface. The BHA was set back in the derrick with the exception of the lower seal bore drill collar plus subs. The Schlumberger logging tools were then rigged up for a pass-through check on the lower portion of the BHA. The drill floor was secured at $1600 \mathrm{~h}$ on $6 \mathrm{July}$, ending Hole U1406C. The acoustic positioning beacon was recovered, and the vessel began the move to Site U1405 to recover the beacon left behind there. The total time spent on Site U1406 was $145.5 \mathrm{~h}$ (6.1 days).

At Site U1406 we recovered a sedimentary succession of deep-sea pelagic sediment of Pleistocene to middle 
Eocene age, with four lithostratigraphic units. Unit I is $\sim 2 \mathrm{~m}$ thick and composed of Pleistocene brown foraminiferal sand and nannofossil ooze with manganese nodules. Unit II changes from brown to green Miocene and Oligocene nannofossil ooze that occurs in a $\sim 180 \mathrm{~m}$ thick sequence and contains abundant diatoms and/or radiolarians in some intervals. Unit III is an $\sim 40 \mathrm{~m}$ interval of carbonate-rich nannofossil ooze alternating with clay-rich nannofossil ooze and clay that spans the lowermost Oligocene, late Eocene, and middle Eocene. Unit IV marks the transition from reduced to oxidized sediment, largely nannofossil oozes, that are middle Eocene to Paleocene in age. Sand-sized lithoclasts are found in the $>63$ $\mu \mathrm{m}$ size fraction, particularly in the Miocene and Oligocene sequences, and may represent ice-rafted or current-transported sediment.

The uppermost brown foraminifer sandy clay and nannofossil ooze (Cores 342-U1406A-1H through $2 \mathrm{H}$; 0-2.25 mbsf) contain nannofossils and planktonic foraminifers that indicate Pleistocene ages (nannofossil Zones NN18 to NN19). Below 2.25 mbsf, nannofossils, planktonic foraminifers, and radiolarians provide a well-defined biostratigraphy indicating upper lower Miocene to middle Eocene sediment. Siliceous microfossils are more poorly preserved than at Sites U1404 and U1405 in sediment of early Miocene and late Oligocene age, and diatoms are consistently rare or absent. Radiolarians are present in the lower Miocene-upper Oligocene and in the middle Eocene-upper Paleocene but are absent from the $\sim 110 \mathrm{~m}$ thick interval $(\sim 130-240$ mbsf) spanning the EOT. Nannofossils are present and show good preservation continuously across the Eocene/Oligocene boundary interval and through the upper to middle Eocene section. A major unconformity at $\sim 255$ mbsf is inferred to span the entire lower Eocene and uppermost Paleocene, including the PETM. Below this unconformity, a complete succession of uppermost to middle Paleocene microfossil zones is identified. Benthic foraminifers are generally rare (the "present" category) but increase in abundance in upper Eocene to upper Oligocene sediment ( 110-220 mbsf). Benthic foraminifer preservation is generally good to very good.

Paleomagnetic results from Site U1406 reveal a series of normal and reversed magnetozones between $~ 10$ and 204 mbsf. Magnetozones can be straightforwardly correlated between all three holes, especially below $\sim 66$ mbsf. We used nannofossil, radiolarian, and foraminifer biostratigraphic datums to correlate the Hole U1406A magnetostratigraphy to chron boundaries C5Dn/C5Dr.1r (17.533 Ma) through C5Dr.2r/C5En (18.056 Ma), C6n/C6r (19.722 Ma) through C6An.1n/C6An.1r (20.213 Ma), C6AAr.3r/
C6Bn.1n (21.767 Ma) through C7An/C7Ar (24.984 $\mathrm{Ma}), \mathrm{C} 8 \mathrm{r} / \mathrm{C} 9 \mathrm{n}(26.420 \mathrm{Ma})$, and C10r/C11n.1n (29.183 Ma) through C13r/C15n (34.999 Ma) on the geomagnetic polarity timescale. Hiatuses at Site U1406 are generally co-eval with those recognized at Site U1405, and at least three hiatuses were identified to occur during rapid deposition of the middle Miocene drift deposits. We estimate the age of these hiatuses to range from 0.25 to $\sim 3 \mathrm{Ma}$. The lower Miocene to middle Eocene succession appears to be stratigraphically complete, at the resolution of shipboard biostratigraphy and magnetostratigraphy, but a significant hiatus occurs between the middle Eocene and uppermost Paleocene. Sedimentation rates are relatively consistent around $\sim 3 \mathrm{~cm} / \mathrm{k}$.y. for the lower Miocene to upper middle Eocene but are lower $(\sim 0.5 \mathrm{~cm} / \mathrm{k} . \mathrm{y}$.$) through the lower middle Eocene and$ the Paleocene.

The shipboard splice for Site U1406 is stratigraphically continuous for most of the sediment column, with only four appended cores in the interval covered in all three holes ( 0-240 mbsf). The splice is mainly based on NGR values, but magnetic susceptibility was also useful below $\sim 200$ mbsf, where values exceed 20 instrument units. In particular, our splice indicates a stratigraphically continuous record across the EOT between $\sim 215$ and 230 m CCSF, including cores from all three holes. Distinct color changes in the upper sediment column at Site U1406 aided realtime stratigraphic correlation between holes, allowing initial offset of coring gaps. From $\sim 25$ to 200 mbsf, magnetic susceptibility is below the detection limit and GRA bulk density shows an overall increase but few prominent features. Changing from APC to $\mathrm{XCB}$ resulted in poor recovery in Holes U1406A and U1406B around 200 mbsf. By switching to XCB earlier in Hole U1406C, most of this missing interval was successfully recovered.

Gradients in calcium concentrations, strontium concentrations, and $\mathrm{Sr} / \mathrm{Ca}$ ratios of interstitial water suggest that the upper 70 mbsf reflects a mature diffusion profile from deep basaltic exchange reactions. Between 70 and 180 mbsf, carbonate dissolution contributes to the shape of the interstitial water profiles, indicated by a switch from decreasing to uniform $\mathrm{Sr} / \mathrm{Ca}$ ratios at $70 \mathrm{mbsf}$. In lithostratigraphic Unit IV, decreasing interstitial water alkalinity and calcium concentrations are consistent with precipitation of authigenic carbonate from pore fluids. Carbonate overgrowths on benthic foraminifers in the sediments of middle Eocene and Paleocene age in Unit IV are consistent with this interpretation.

The sediment column at Site U1406 is generally carbonate rich (21-92 wt\%) with low TOC content (0.01-0.5 wt\%) and low headspace gas contents. A 
prominent increase in carbonate content occurs around 190-200 mbsf associated with the EOT, as defined by biostratigraphy and magnetostratigraphy. However, peak values (92 wt $\% \mathrm{CaCO}_{3}$ ) occur lower in the sediment column at Site U1406 in middle to upper Eocene strata.

Sediment bulk density at Site U1406 increases downhole from 1.4 to $1.9 \mathrm{~g} / \mathrm{cm}^{3}$. Grain density averages $2.7 \mathrm{~g} / \mathrm{cm}^{3}$, and both porosity and water content show a decreasing trend downhole (from 50 to 80 vol\% and from 25 to $60 \mathrm{wt} \%$, respectively), with the lowest values occurring in carbonate-rich sediment (below $170 \mathrm{mbsf}$ ). Magnetic susceptibility averages 9 IU throughout all holes, but significant peaks occur at $\sim 182,205$, and 235 mbsf. $P$-wave velocity increases progressively downhole from 1500 to 1800 $\mathrm{m} / \mathrm{s}$, reflecting increased compaction and lithification. Significant peaks in NGR, reflectance, and magnetic susceptibility are observed associated with the EOT.

\section{Site U1407}

\section{Background and objectives}

Site U1407 is a mid-depth site $(3074 \mathrm{mbsl}$; 2600 mbsl at $50 \mathrm{Ma}$ ) (Tucholke and Vogt, 1979) in the upper end of the Expedition 342 Paleogene Newfoundland sediment drifts depth transect. The site was positioned to capture a record of sedimentation $\sim 1.9$ $\mathrm{km}$ shallower than the largely sub-CCD record drilled at Site U1403. The location above the average late Paleogene CCD should be sensitive to both increases and decreases in carbonate burial, whether these reflect variations in dissolution related to changes in the $\mathrm{CCD}$, changes in carbonate production, or variations in background noncarbonate sedimentation. Our primary scientific objectives for drilling Site U1407 were

- To reconstruct the mid-depth CCD in a primarily carbonate-dominated record for the early and middle Eocene;

- To obtain records of the Eocene and Paleocene in carbonate-rich sediments that host abundant foraminifers suitable to the construction of geochemical climate records;

- To evaluate the history of deep water on sediment chemistry, grain size, and provenance; and

- To evaluate biological evolution during Paleogene climate transitions.

Secondary objectives included dating acoustic horizons to better constrain regional sedimentation during the Paleogene and Cretaceous and allow us to anticipate the likely age of the sedimentary sequence at the remaining Expedition 342 sites.

\section{Principal results}

After a $120 \mathrm{nmi}, 11 \mathrm{~h}$ transit from Site U1406 at a speed of $10.9 \mathrm{kt}$, the vessel arrived at Site U1407 at $0800 \mathrm{~h}$ (UTC $-2.5 \mathrm{~h}$ ) on 7 July 2012. The plan for Site U1407 called for drilling three holes to $\sim 250 \mathrm{~m}$ DSF. A mudline core established water depth for Hole U1407A at 3073.1 mbsl. Cores 342-U1407A-1H through $15 \mathrm{H}$ were retrieved using nonmagnetic core barrels and the FlexIT core orientation tool. The first partial stroke was experienced with Core $11 \mathrm{H}$, and the APC was advanced by recovery to Core $15 \mathrm{H}$ at $121.9 \mathrm{~m}$ DSF. The XCB was deployed for Cores 16X through $35 \mathrm{X}$ to a final depth of $308.7 \mathrm{~m}$ DSF. Overall core recovery for Hole U1407A was $205.64 \mathrm{~m}$ for the $308.7 \mathrm{~m}$ cored (66\% recovery). This relatively low recovery can most likely be attributed to the high heave and large pitch and roll of the vessel during coring operations.

The vessel was offset $20 \mathrm{~m}$ east, and Cores 342U1407B-1H through $11 \mathrm{H}$ were recovered using nonmagnetic core barrels and the FlexIT core orientation tool. A $3 \mathrm{~m}$ interval (27.4-30.4 m DSF) was drilled without coring in an attempt to cover a coring gap in Hole U1407A. Based on the recovery of an interval of chert layers in Hole U1407A, the interval from 95 to $127 \mathrm{~m}$ DSF was drilled without coring using the $\mathrm{XCB}$. Cores $13 \mathrm{X}$ through $28 \mathrm{X}$ were then recovered to the final depth of $276.3 \mathrm{~m}$ DSF. The recovery for Hole U1407B was $234.54 \mathrm{~m}$ over the $241.3 \mathrm{~m}$ cored (97\% recovery).

The vessel was offset $40 \mathrm{~m}$ west, and Cores 342U1407C-1H through 11H (0-93.0 m DSF) were recovered using nonmagnetic core barrels. A $3 \mathrm{~m}$ interval (27.4-30.4 m DSF) was drilled without coring to optimize core overlap in multiple holes. Once again, a $21 \mathrm{~m}$ interval (96-117 m DSF) was drilled without coring through the chert layers using the XCB. Cores $13 \mathrm{X}$ through $29 \mathrm{X}$ were then recovered to the final depth of $261.6 \mathrm{~m}$ DSF. Overall recovery for Hole U1407C was $244.4 \mathrm{~m}$ from the $237.6 \mathrm{~m}$ interval cored (103\% recovery). The rig was secured for a dynamic positioning move to the next site at $1915 \mathrm{~h}$ on 11 July, ending Site U1407. The overall recovery for Site U1407 was $87 \%$. The total time spent on Site U1407 was $107.25 \mathrm{~h}$ (4.5 days).

The downhole sedimentary sequence at Site U1407 consists of a Pleistocene to uppermost Lower Cretaceous column of pelagic sediment overlying reef sediment of late Albian age. The sequence is divided into six lithostratigraphic units. Unit I is $\sim 8 \mathrm{~m}$ thick and composed of Pleistocene foraminiferal nannofossil ooze intermittently interbedded at decimeter scale with foraminiferal sand and clay with nannofossils. Rock fragments of pebble to cobble size and coarse silt- to sand-sized quartz and amphibole are 
pervasive. Unit II is a $\sim 10 \mathrm{~m}$ thick sequence of early Oligocene age composed of clay with nannofossils with disseminated manganese nodules and sulfide patches and intercalated millimeter- to centimeterscale sulfide layers. Unit III consists of $\sim 70 \mathrm{~m}$ of middle Eocene nannofossil ooze with foraminifers; sulfide patches and layers are also present. An abrupt downhole change in color from light greenish gray to white marks the contact between Units III and IV and is associated with significant changes in physical proxies and a downhole increase in carbonate content. Unit IV consists of $\sim 20$ m of lower Eocene nannofossil ooze with foraminifers. Unit $\mathrm{V}$ is composed of Paleocene to Cenomanian nannofossil chalk divided into two subunits ( $\mathrm{Va}$ and $\mathrm{Vb}$ ). The contact between Unit IV and Subunit Va was not recovered because of the operations decision to drill without attempting to recover a sequence interpreted to contain well-developed chert. Subunit Va is composed of $\sim 60 \mathrm{~m}$ of Paleocene nannofossil chalk with foraminifers and radiolarians. Subunit $\mathrm{Vb}$ is mainly nannofossil chalk or nannofossil chalk with foraminifers and spans the Cenomanian to Campanian over a $\sim 85 \mathrm{~m}$ thick sequence. Subunit $\mathrm{Vb}$ contains black shales of Cenomanian/Turonian boundary age (OAE 2; 93 Ma). Unit VI is divided into two subunits (VIa and VIb). Subunit VIa is $\sim 1 \mathrm{~m}$ thick and comprises fine-grained, partially silicified and dolomitized calcareous grainstone with horizontal laminations and is of late Albian age. Subunit VIb consists of extremely poorly recovered fossiliferous reef deposits of Albian age.

The biochronology of Site U1407 is based on nannofossils and planktonic and benthic foraminifers throughout the $\sim 300 \mathrm{~m}$ thick sequence. Nannofossils, planktonic foraminifers, and smaller benthic foraminifers are present in all but the basal Albian neritic limestone, which contains larger benthic foraminifers and macrofossils. Thin Pleistocene and lower Oligocene intervals overlie an expanded middle Eocene through upper Albian succession. A detailed biozonation of Upper to mid-Cretaceous sediment reveals a condensed sequence that records the Campanian/Santonian, Santonian/Coniacian, Coniacian/Turonian, and Albian/Cenomanian boundaries. Biostratigraphy of black shale recovered at $\sim 230$ mbsf indicates the presence of Turonian nannofossil Zone UC6 above and Cenomanian nannofossil Zone UC5/UC4 below, providing strong evidence that this lithology represents OAE 2 . Benthic foraminiferal assemblages support this conclusion, with the black shale dominated by agglutinated species and calcareous taxa that indicate low oxygen concentrations at the seafloor. Radiolarians are abundant and well preserved in the lower middle Eocene and the Paleocene but are either absent or age-indeterminate in both the upper Pleistocene-lower middle Eocene and lowermost Paleocene-Cretaceous intervals.

Geochronologic analyses suggest that the late to middle Eocene transition is continuous to the magnetochron level with comparatively high average linear sedimentation rates $(2.0-8.7 \mathrm{~cm} / \mathrm{k} . \mathrm{y}$.). A series of distinct magnetochrons have been identified between Cores 342-U1407A-6H and 10H (and correlative intervals in Holes U1407B and U1407C) that have a biochronology consistent with Chrons C20r through C22r ( 43.4-49.4 Ma). The magnetostratigraphy and biochronology suggest that sedimentation rates varied between 2.0 and $8.7 \mathrm{~cm} / \mathrm{k} . \mathrm{y}$. across the late Eocene-middle Eocene transition. The Chron C25r/C26n boundary is present in Section 342-U1407A-19X-2.

Headspace methane concentrations (1.4-4.12 ppmv) were not above atmospheric levels. Interstitial water profiles show evidence of compartmentalization with prominent abrupt downhole shifts in $\mathrm{Mg}, \mathrm{Mn}$, and $\mathrm{K}$ at $~ 100-120$ mbsf, suggesting that the unrecovered sequence of chert acts as an aquiclude. The downhole profile for $\mathrm{Mg}$ shows a reversed gradient to the base of the sediment column, suggestive of a source of $\mathrm{Mg}$ within the highly porous underlying reefal sediment. Carbonate content in the whole sediment column at Site U1407 ranges from 0 to 93 $\mathrm{wt} \%$. The most prominent change in carbonate content is a step increase associated with the transition downhole from middle Eocene to lower Eocene sediment (from 59.0 to $82.5 \mathrm{wt} \% \mathrm{CaCO}_{3} ; \sim 80 \mathrm{mbsf}$ ). This step correlates with shifts in several proxies (e.g., $\mathrm{L}^{*}$, magnetic susceptibility, NGR, TOC, and total nitrogen values). TOC values are typically $0.1-0.5 \mathrm{wt} \%$ over this whole interval. Homogeneous to microlaminated organic-rich black shale from Holes U1407A and $\mathrm{U} 1407 \mathrm{C}$ is rich in TOC ( 4 and $17 \mathrm{wt} \%$, respectively). Organic matter is thermally immature and relatively well preserved, as shown by both the high hydrogen indexes ( 600-620 mg hydrocarbons per gram organic carbon) and low $T_{\max }$ values $\left(<415^{\circ} \mathrm{C}\right)$. $\mathrm{C} / \mathrm{N}$ ratios increase as organic carbon concentrations increase. Organic matter is Type II kerogen, derived from algal and microbial primary production.

Sediment bulk density shows a downhole-increasing trend from $\sim 1.5 \mathrm{~g} / \mathrm{cm}^{3}$ at the uppermost part of the hole to $\sim 2.2 \mathrm{~g} / \mathrm{cm}^{3}$ at the contact between the basal Albian pelagic sediment and the lithified cap of the underlying reef carbonate sediment ( 270 mbsf). Grain density peaks at the same contact to $2.9 \mathrm{~g} / \mathrm{cm}^{3}$ in Hole U1407A. Porosity values are generally highest in the upper $\sim 50$ mbsf of the sediment column and between $\sim 150$ and 175 mbsf $(\sim 60 \%)$, whereas 
porosity is low in the basal pelagic carbonate $(\sim 40 \%)$. Magnetic susceptibility measurements decrease from high values (up to $120 \mathrm{IU}$ ) to $5 \mathrm{IU}$, associated with the downhole transition from the thin veneer of Oligocene-Pleistocene sediment into the underlying Eocene nannofossil ooze. $P$-wave velocity increases progressively downhole and shows abrupt changes at $\sim 180,206,225$, and 270 mbsf. These changes in $P$ wave velocity may contribute to development of weak reflections in the seismic reflection profiles crossing the site. NGR shows an overall downhole increase at Site U1407 with multiple superimposed prominent features that are readily correlated among all three holes, such as

- A sharp peak (to $\sim 50 \mathrm{cps}$ at $\sim 10 \mathrm{mbsf}$ ) at the contact between the Pleistocene cover at the top of the sediment column and the underlying Oligocene clay,

- A downhole step decrease from $\sim 30$ to 5 cps ( $\sim 80 \mathrm{mbsf})$ associated with the step increase in carbonate content across the contact between the middle and lower Eocene nannofossil ooze, and

- A distinctive peak (to $\sim 40-50$ cps at $\sim 230 \mathrm{mbsf}$ ) associated with the Cenomanian-Turonian black shale.

Color reflectance follows a trend similar to magnetic susceptibility, with distinctive peaks in $\mathrm{a}^{*}$ and $\mathrm{b}^{*}$ and a minimum associated with the black shale sequence that can be correlated among all three holes.

The stratigraphic splice constructed for Site U1407 is stratigraphically continuous from 0 to $\sim 112 \mathrm{~m} \mathrm{CCSF}$ and $\sim 200$ to $312 \mathrm{~m} \mathrm{CCSF}$. Part of the gap between these two spliced intervals ( 112-133 m CCSF) is attributable to the operations decision to drill without attempting to recover a horizon with well-developed cherts. The interval between 133 and $200 \mathrm{~m}$ CCSF is characterized by modest changes in physical properties data sets and proved impossible to splice using shipboard data alone. Both magnetic susceptibility and NGR were used for stratigraphic correlation and construction of the two spliced intervals. These two data sets show clear, correlative features throughout the sediment column. NGR is the most useful data set for correlation from 0 to $\sim 112 \mathrm{~m} \mathrm{CCSF}$ and magnetic susceptibility is most useful from $\sim 135$ to 200 $\mathrm{m}$ CCSF, whereas both data series show distinctive features from $\sim 200$ to $312 \mathrm{~m}$ CCSF. The black shale sequence associated with OAE 2 was successfully recovered in all three holes, although the exact lithostratigraphic expression of this interval differs quite markedly among the three holes.

\section{Site U1408}

\section{Background and objectives}

Site U1408 is a mid-depth site ( 3022 mbsl; 2575 mbsl at $50 \mathrm{Ma}$ ) (Tucholke and Vogt, 1979) and is the shallowest site drilled on the Expedition 342 Paleogene Newfoundland sediment drifts depth transect. The site was positioned to capture a record of sedimentation $\sim 2 \mathrm{~km}$ shallower than the largely subCCD record drilled at Site U1403. The location, well above the average late Paleogene CCD, should be sensitive to both increases and decreases in carbonate burial, whether these reflect variations in dissolution related to changes in the CCD, changes in carbonate production, or variations in background noncarbonate sedimentation. The site was also intended to sample the core of a small sediment drift for comparison with the age structure and depositional processes of other drift deposits on Southeast Newfoundland Ridge and J-Anomaly Ridge.

\section{Principal results}

The vessel arrived at Site U1408 after a $1.46 \mathrm{nmi}$ transit from Site U1407 in dynamic positioning mode, which took $1.75 \mathrm{~h}$ at $0.83 \mathrm{kt}$. The vessel stabilized over Site U1408 at 2045 h (UTC - 2.5 h) on 11 July 2012. Cores 342-U1408A-1H through $20 \mathrm{H}$ were retrieved using nonmagnetic core barrels and the FlexIT core orientation tool. Core $14 \mathrm{H}$ experienced the first partial stroke, and the APC was advanced by recovery to the APC total depth of $182.9 \mathrm{~m}$ DSF. The $\mathrm{XCB}$ was deployed for Cores $21 \mathrm{X}$ through $27 \mathrm{X}$ to the final depth of $246.5 \mathrm{~m}$ DSF. The seafloor was cleared at $1045 \mathrm{~h}$ on $13 \mathrm{July}$, ending Hole U1408A. Overall core recovery for Hole U1408A was $243.92 \mathrm{~m}$ for the $246.5 \mathrm{~m}$ interval cored (99\% recovery). The total time spent on Hole U1408A was 38.00 h.

The vessel was offset $20 \mathrm{~m}$ east and Cores 342U1408B-1H through $18 \mathrm{H}$ were retrieved using nonmagnetic core barrels and the FlexIT core orientation tool. A $3 \mathrm{~m}$ long interval (25.7-28.7 m DSF) was drilled without recovery to optimize coverage of coring gaps in Hole U1408A. Coring was slowed when the FlexIT housing sheared at the overshot connection above the core barrel three times during APC coring in Hole U1408B. Total advance, including the drilled interval with the APC, was $154.5 \mathrm{~m}$. The XCB was deployed for Cores 19X through 26X to a final depth of $217.5 \mathrm{~m}$ DSF. The seafloor was cleared at $1700 \mathrm{~h}$ on 14 July, ending Hole U1408B. The recovery for Hole U1408B was $224.09 \mathrm{~m}$ over the $214.5 \mathrm{~m}$ cored (105\% recovery). The total time spent on Hole $\mathrm{U} 1408 \mathrm{~B}$ was $30.25 \mathrm{~h}$. 
The vessel was offset $20 \mathrm{~m}$ south, and Hole U1408C was spudded at $1905 \mathrm{~h}$ on 14 July. Cores 342U1408C-1H through 19H (0-165.1 m DSF) were retrieved using nonmagnetic core barrels. A $3 \mathrm{~m}$ long interval (8.8-11.8 m DSF) was drilled without recovery to optimize coverage of coring gaps in Hole U1408A. Core orientation was performed with Cores $6 \mathrm{H}$ through $8 \mathrm{H}$. Again, the FlexIT tool was thought responsible for mechanical trouble, including one mechanical shear at the overshot and one mechanical shear of the APC shear pins. During APC operations, an intermittent electrical fault developed, and coring operations were suspended for $6.5 \mathrm{~h}$ while the problem was fixed. The XCB was deployed for Cores 20X through $23 \mathrm{X}$ to a final depth of $187.5 \mathrm{~m}$ DSF. The recovery for Hole U1408C was $181.52 \mathrm{~m}$ over the $184.5 \mathrm{~m}$ cored (98\% recovery). The total time spent on Hole U1408C was 38.25 h. The drill string was pulled to the surface and the drill floor was secured at $0715 \mathrm{~h}$ on 16 July, ending Hole U1408C and Site U1408. The overall recovery for Site U1408 was 106\%. The total time spent on Site U1408 was 106.5 h (4.4 days).

The $\sim 250 \mathrm{~m}$ thick sedimentary succession recovered in Holes U1408A-U1408C consists of pelagic deepsea sediments of Pleistocene to late Paleocene age; however, all stratigraphic epoch boundaries (Paleocene/Eocene, Eocene/Oligocene, Oligocene/Miocene) are represented by hiatuses. The succession is divided into four lithostratigraphic units. Unit I is $\sim 13 \mathrm{~m}$ thick and includes sediment of Pleistocene to Oligocene age composed of uppermost brown silty clay followed by decimeter-scale alternations of brownish foraminiferal nannofossil ooze and reddish brown clay, likely representing Pleistocene glacial-interglacial cycles. Manganese nodules and dropstones are common. Unit II, $10 \mathrm{~m}$ thick, consists of well-homogenized silty clay with nannofossils and nannofossil clay with silt of Oligocene age. Sand-sized lithoclasts are found in the $>63 \mu \mathrm{m}$ size fraction from Section 342-U1408A-4H-3 (Oligocene nannofossil Zone NP23) uphole. Unit III is $202 \mathrm{~m}$ thick and displays a predominantly greenish gray color but also cyclical color changes between greenish gray to dark green and very light gray intervals on a decimeter-scale in middle Eocene sediment. Burrowing is mostly of moderate intensity; in particular, Zoophycos, Planolites, and Chondrites burrows are common. Unit IV was recovered only in Hole U1408A and consists principally of whitish and pinkish brown nannofossil chalk. This unit spans parts of the early Eocene and the late Paleocene. Biostratigraphy constrains the Paleocene/Eocene boundary close to the base of Section 342-U1408A-
26X-2; however, the PETM was not recovered because of an unconformity.

Nannofossils, planktonic foraminifers, and benthic foraminifers are present through most of the Pleistocene to upper Paleocene succession recovered at Site U1408. Radiolarians are only present in a short interval of the middle Eocene and upper Paleocene. Thin Pleistocene, upper Miocene, and lower Oligocene intervals overlie a middle Eocene-upper Paleocene succession with significant hiatuses between the Oligocene and middle Eocene ( 7 m.y.) and middle and lower Eocene ( 3 m.y.) and a minor hiatus or condensed interval around the Paleocene/Eocene boundary. Sedimentation rates are high $(\sim 1.49-3.14$ $\mathrm{cm} / \mathrm{k} . \mathrm{y}$.) through the middle Eocene, low through the lower Eocene $(\sim 0.08 \mathrm{~cm} / \mathrm{k} . \mathrm{y}$.$) , and relatively high$ through the upper Paleocene $(\sim 1.27 \mathrm{~cm} / \mathrm{k} . \mathrm{y}$.$) .$

Shipboard results reveal a series of normal and reversed magnetozones between Cores 342-U1408A$4 \mathrm{H}$ and 25X ( 29-220 mbsf), between Cores 342U1408B-5H and 18H ( 30-154 mbsf), and between Cores 342-U1408C-5H and 19H ( 35-165 mbsf). These magnetostratigraphies can be correlated between all three holes and consist of lower Chron C17n.3n ( 38.3 Ma) through upper Chron C20r $(\sim 43.4 \mathrm{Ma})$. The geomagnetic field transitions from Chron C18n.1n to C18n.1r to C18n.2n are recorded in exceptional detail in all three holes at Site U1408. Chron C20r is continuously recognized downhole to the bottom of the APC-cored interval and continues into the XCB portion, where we recognize the C2Or/ C21n chron boundary (45.724 Ma). The magnetochronology suggests that sedimentation rates varied between $\sim 1.5$ and $3.1 \mathrm{~cm} / \mathrm{k} . \mathrm{y}$. across the middle Eocene. Sedimentation rates were higher before the MECO ( 41.5 Ma) than after it.

Physical properties at Site U1408 largely reflect compaction and calcium carbonate content. Bulk density globally increases downhole from 1.40 to 1.95 $\mathrm{g} / \mathrm{cm}^{3}$, but an abrupt step down to $\sim 1.4 \mathrm{~g} / \mathrm{cm}^{3}$ occurs at the transition between lithostratigraphic Units I and II. Grain density averages $2.77 \mathrm{~g} / \mathrm{cm}^{3}$ in Hole U1408A. Overall in Hole U1408A, water content and porosity show a decreasing trend downhole (from 50 to $25 \mathrm{wt} \%$ and 75 to 50 vol\%, respectively). $P$-wave velocity increases progressively downhole from 1500 to $1800 \mathrm{~m} / \mathrm{s}$. Color reflectance parameters $\mathrm{a}^{*}$ and $\mathrm{b}^{*}$ show higher values in Units I, II, and IV and display cyclicity in Unit III ( $\mathrm{a}^{*}$ averages 0.5 and $\mathrm{b}^{*}$ averages -0.35). Magnetic susceptibility drops from $\sim 60$ to $10 \mathrm{IU}$ at $12 \mathrm{mbsf}$ and also cycles regularly around an average value of $\sim 14$ IU to the bottom of the sediment column. NGR and $L^{*}$ show a 
relatively low variability and average 25 cps and 55 , respectively. Throughout Unit III, variations in magnetic susceptibility, NGR, and $\mathrm{L}^{*}$ correlate with calcium carbonate content (with peaks at $~ 95,155$, and $230 \mathrm{mbsf}$ ).

A clear signal in magnetic susceptibility made the construction of a splice of the three holes at Site U1408 comparatively straightforward in much of the sequence. The expression of orbital (most likely precession) cycles between 35 and $220 \mathrm{~m}$ CCSF was a particular aid to the correlation. The overall trends and patterns are very similar among the three holes. The splice for the upper $150 \mathrm{~m}$ CCSF of the section is quite robust and could be used for high-resolution sampling. However, low variability in magnetic susceptibility between 70 and $80 \mathrm{~m}$ CCSF and between 150 and $226 \mathrm{~m}$ CCSF creates intervals with a tentative splice. Our correlation results in a growth rate of $13 \%$.

The downhole patterns of alkalinity, manganese, and iron suggest two zones of organic matter degradation within the recovered sequence. Very high concentrations of manganese in the upper $30 \mathrm{mbsf}$ coupled with iron concentrations of $0 \mu \mathrm{m}$ suggest ongoing oxic to suboxic diagenesis driven by microbial reduction of manganese oxides. Below $30 \mathrm{mbsf}$, the reduction of iron oxides is evident from the rapid increase in iron concentrations. The broad peak in iron between 40 and 90 mbsf suggests a locus of organic matter consumption at this depth. Increasing alkalinity concentrations beginning at 50 mbsf corroborate this interpretation. Relatively high carbonate contents throughout the recovered sequence in Hole U1408A are consistent with the relatively shallow paleodepth of the site throughout the Eocene. Carbonate concentrations are roughly 40 $\mathrm{wt} \%$ in Unit I and fall to $0-10 \mathrm{wt} \%$ in Unit II, which is consistent with low carbonate levels observed in other Oligocene sequences recovered during Expedition 342. In the expanded middle Eocene sequence represented by Unit III, carbonate content ranges from 40 to $50 \mathrm{wt} \%$, with a few peaks up to $80-90$ wt $\%$. Carbonate content increases to $90 \mathrm{wt} \%$ in Unit IV, which corresponds to lower Eocene sediment. The downhole increase in carbonate content at the Unit III/IV boundary (225 mbsf) is typical of the lower/upper Eocene boundary in Expedition 342 sediment cores. It is possible that the change in carbonate is linked to a change in production, preservation, or dilution by other sedimentary components.

\section{Site U1409}

\section{Background and objectives}

Site U1409 is a mid-depth site ( 3501 mbsl; 3050 mbsl at $50 \mathrm{Ma}$ ) (Tucholke and Vogt, 1979), in the up- per mid-depth end of the Expedition 342 Paleogene Newfoundland sediment drifts depth transect. The site was positioned to capture a record of sedimentation $\sim 1.5 \mathrm{~km}$ shallower than the largely sub-CCD record drilled at Site U1403. Site U1409, therefore, is located well above the average late Paleogene CCD and should be sensitive to both increases and decreases in carbonate burial, whether these reflect variations in dissolution related to changes in the CCD, changes in carbonate production, or variations in noncarbonate sedimentation. Site U1409 is a companion site to Site U1410, at which we employ an offset drilling strategy to obtain APC/XCB records through a thicker section of the same sediment drift than would be possible by drilling a single site. Our objective at Site U1409, situated at the edge of the sediment drift, was to penetrate a more condensed middle Eocene sequence than anticipated in the midsection of the drift, making it possible to penetrate lower Eocene and Paleocene sediments at relatively shallow burial depth $(<250 \mathrm{~m})$.

\section{Principal results}

The vessel arrived at Site U1409 at $1010 \mathrm{~h}$ (UTC - 2.5 h) on 16 July 2012 after a $26.3 \mathrm{nmi}$ transit from Site $\mathrm{U} 1408$ that took $3.0 \mathrm{~h}$ at $8.8 \mathrm{nmi} / \mathrm{h}$. The pipe trip to the seafloor was interrupted at $2863.3 \mathrm{~m}$ DRF for a test of the subsea camera system, which had been damaged at Site U1403, but strong ocean currents led to the early termination of the test. After completing the pipe trip, Cores 342-U1409A-1H through $16 \mathrm{H}$ were recovered to $127.0 \mathrm{~m}$ DSF using nonmagnetic core barrels and the FlexIT core orientation tool. Core $15 \mathrm{H}$ experienced the first partial stroke, and the APC was advanced by recovery to Core $16 \mathrm{H}$. The XCB was deployed for Cores 17X through 26X to $200.1 \mathrm{~m}$ DSF. The seafloor was cleared at $0550 \mathrm{~h}$ on 18 July, ending Hole U1409A. Overall core recovery for Hole U1409A was $183.33 \mathrm{~m}$ for the $200.1 \mathrm{~m}$ interval cored ( $92 \%$ recovery). The total time spent on Hole U1409A was $43.5 \mathrm{~h}$.

The vessel was offset $20 \mathrm{~m}$ east, and Cores 342U1409B-1H through $14 \mathrm{H}$ were retrieved to $122.5 \mathrm{~m}$ DSF using nonmagnetic core barrels and the FlexIT core orientation tool. The XCB was deployed for Cores $15 \mathrm{X}$ through $19 \mathrm{X}$ to $170.5 \mathrm{~m}$ DSF. The seafloor was cleared at $0340 \mathrm{~h}$ on 19 July, ending Hole U1409B. The recovery for Hole U1409B was 167.09 $\mathrm{m}$ over the $170.5 \mathrm{~m}$ cored (98\% recovery). The total time spent on Hole U1409B was $22.00 \mathrm{~h}$. The vessel was offset $20 \mathrm{~m}$ south, and Cores 342-U1409C-1H through14H (124.2 m DSF) were retrieved using nonmagnetic core barrels. Core orientation was not performed in Hole U1409C. XCB coring continued from Core $15 \mathrm{X}$ through $21 \mathrm{X}$ to the final depth of 
$160.8 \mathrm{~m}$ DSF. The recovery for Hole U1409C was $160.98 \mathrm{~m}$ over the $160.8 \mathrm{~m}$ cored (100\% recovery).

The drill string was pulled to $3200 \mathrm{~m}$ DRF, and the rig prepared for a transit in dynamic positioning mode to Site U1410. Poor weather conditions and high surface currents foiled the recovery of the beacon, which was declared lost at $1515 \mathrm{~h}$ on 20 July, ending Hole U1409C. The total time spent on Hole U1409C was $35.50 \mathrm{~h}$. The overall percentage recovery for Site U1409 was 96\%. The total time spent on Site U1409 was 101.0 h (4.2 days).

Four lithostratigraphic units characterize the $\sim 200 \mathrm{~m}$ thick sedimentary succession of deep-sea pelagic sediment recovered at Site U1409. Unit I contains alternating brown to reddish brown Pleistocene silty clay and nannofossil ooze with varying abundances of foraminifers and diatoms and occasional layers of muddy sand with foraminifers. Both the Unit I/II and II/III boundaries are erosive contacts. Unit II is a heavily bioturbated, light yellowish brown Oligocene silty clay to nannofossil clay containing manganese nodules, patches of disseminated sulfides, and rare concentrations of faint red oxide horizons. Unit III contains alternating beds of light greenish gray nannofossil clay and white nannofossils ooze. Some intervals are associated with oxide horizons and dampened color contrast between adjacent beds. Unit IV contains lithologies ranging from pinkish white nannofossil ooze with varying abundances of radiolarians and foraminifers to dark brown claystone, siliceous limestone, and chert. The middle Eocene to early Paleocene sediments of Unit IV are divided into three subunits. Subunits IVa-IVc contain pinkish white nannofossil oozes with radiolarians; frequent cherts and highly varied lithologies including pink to dark brown or gray nannofossil ooze to chalk with interbedded chert, siliceous nannofossil limestone, and nannofossil claystone; and pink to pale gray or pale brown nannofossil chalk.

Nannofossils, planktonic foraminifers, and benthic foraminifers are present through most of the Pleistocene to lower Paleocene succession, although all microfossil groups are absent through a short interval between the Pleistocene and Oligocene. Radiolarians are only present in the uppermost Pleistocene and the lower middle Eocene through upper Paleocene. Thin Pleistocene and Oligocene sequences overlie a middle Eocene through lower Paleocene succession with significant hiatuses between the lower Pleistocene and upper Oligocene (22 m.y. duration) and lower Oligocene and middle Eocene (8.3 m.y. duration). A short hiatus or condensed interval is also identified at the Paleocene/ Eocene boundary. The Oligocene is highly condensed and may contain significant hiatuses. Sedi- mentation rates are $0.68-1.31 \mathrm{~cm} / \mathrm{k} . \mathrm{y}$. through the middle Eocene, $0.51-1.44 \mathrm{~cm} / \mathrm{k} . \mathrm{y}$. through the lower Eocene, and $\sim 0.47-1.80 \mathrm{~cm} / \mathrm{k} . \mathrm{y}$. through the Paleocene.

Magnetochronology reveals a series of normal and reversed magnetozones between Cores 342-U1409A$1 \mathrm{H}$ and $13 \mathrm{H}(\sim 0-115 \mathrm{mbsf})$, between Cores 342$\mathrm{U} 1409 \mathrm{~B}-1 \mathrm{H}$ and $13 \mathrm{H}(\sim 0-120 \mathrm{mbsf})$, and between Cores 342-U1409C-1H and 13H ( 0-115 mbsf). These magnetostratigraphies are straightforward to correlate among all three holes and primarily consist of two time intervals. The first interval is from lower Chron C6Cr ( 23.9 Ma) through upper Chron C13r $(\sim 33.7 \mathrm{Ma})$, and the second interval is from lower Chron C19r ( 42.3 Ma) through upper Chron C22r $(\sim 49.4 \mathrm{Ma})$. Chrons C9n, C9r, and C10n.1n are not observed in any hole at Site U1409, indicating a hiatus at $\sim 27.5 \mathrm{Ma}$. The $\mathrm{C} 13 \mathrm{n} / \mathrm{C} 13 \mathrm{r}$ chron boundary $(33.705 \mathrm{Ma})$ is tentatively identified in Section 342U1409A-5H-2, between Sections 342-U1409B-4H-5 and $4 \mathrm{H}-6$, and in Section 342-U1409C-5H-2. The magnetochronology suggests that sedimentation rates were $\sim 0.3 \mathrm{~cm} / \mathrm{k} . \mathrm{y}$. through the Oligocene and varied between $\sim 0.5$ and $\sim 1.3 \mathrm{~cm} / \mathrm{k} . \mathrm{y}$. across the middle Eocene. Sedimentation rates were higher before the MECO ( 41.5 Ma) than after, similar to results from Site U1408.

Bulk density generally increases downhole from 1.40 to $1.95 \mathrm{~g} / \mathrm{cm}^{3}$, with a superimposed abrupt step decrease to $\sim 1.5 \mathrm{~g} / \mathrm{cm}^{3}$ at the transition between lithostratigraphic Units I and II. Grain density averages $2.75 \mathrm{~g} / \mathrm{cm}^{3}$ in Hole U1409A. Overall in Hole U1409A, water content and porosity decreases downhole (from 25 to $60 \mathrm{wt} \%$ and 45 to $80 \mathrm{vol} \%$, respectively). At $\sim 15$ mbsf, water content and porosity both show a decrease associated with the major hiatus between the Oligocene and Eocene. $P$-wave velocity increases progressively downhole from 1500 to $1800 \mathrm{~m} / \mathrm{s}$. Magnetic susceptibility decreases from $\sim 120$ to 30 IU at $18 \mathrm{mbsf}$ and remains near constant ( 9 IU) to the bottom of the sediment column, except for three notable peaks within Unit III at $\sim 50, \sim 72$, and $\sim 90 \mathrm{mbsf}$ corresponding to oxide-rich layers. Color reflectance parameters $\mathrm{a}^{*}$ and $\mathrm{b}^{*}$ show very distinct downhole variation throughout the sediment column. NGR and $L^{*}$ show five major peaks at $\sim 38,47,70,100$, and 155 mbsf. All of these depths correlate with the major variations in calcium carbonate content.

The stratigraphic splice constructed for Site U1409 is stratigraphically continuous from 0 to $\sim 130$ and 150 to $190 \mathrm{~m}$ CCSF. From 130 to $150 \mathrm{~m}$ CCSF, poor recovery associated with the change to XCB prevented the generation of a continuous splice. Magnetic susceptibility, which shows clear, correlative cycles, was used for correlation and splice construction from 0 
to 130 m CCSF. NGR was most useful for correlation below $\sim 130$ m CCSF, whereas magnetic susceptibility data were noisy as a result of drilling disturbance associated with numerous chert layers. The chert associated with the Paleocene/Eocene boundary was recovered in Cores 342-U1409A-20X and 342-U1409B$18 \mathrm{X}$, and the boundary appears to fall in the core catcher of Core 342-U1409C-21X. However, physical properties in the interval preceding the PETM appear quite different in Hole U1409C compared to Holes U1409A and U1409B.

Headspace methane concentrations (1.79-6.43 ppmv) were not above atmospheric levels. Interstitial water profiles display evidence of compartmentalization with pronounced abrupt downhole shifts in magnesium, manganese, and potassium at $~ 125$ $130 \mathrm{mbsf}$, suggesting that the unrecovered sequence of cherts acts as an aquiclude. Overall, interstitial water profiles of potassium, calcium, and magnesium are consistent with those resulting from exchange with and alteration of basaltic basement at depth. Potassium and magnesium concentrations decrease and calcium concentrations increase with depth. The downhole patterns of manganese and sulfate suggest two zones of organic matter degradation within the recovered sequence, one above the chert-rich interval and one below. In general, sulfate concentrations are high, consistent with low TOC content. A broad downhole peak in boron concentrations at $59 \mathrm{mbsf}$ presumably indicates increased supply from the terrigenous sediment component in Unit II.

Carbonate content in the whole sediment column at Site U1409 ranges from 0 to $93 \mathrm{wt} \%$. As with other sites drilled to date on the Southeast Newfoundland Ridge (Sites U1407 and U1408), the most prominent change is a downhole step increase (50 to $90 \mathrm{wt} \%$ at $\sim 100 \mathrm{mbsf}$ ) in sediment of Zone NP14 age (around the early/middle Eocene boundary). This step correlates with shifts in several proxies (e.g., color reflectance, magnetic susceptibility, NGR, TOC, and total nitrogen values) and marks a transition from pelagic chalk sedimentation to clay deposition in the initial stages of sediment drift development. Middle Eocene sedimentation appears cyclic, with alternating green clay-rich beds and white nannofossil ooze layers with carbonate contents of 40 and $85 \mathrm{wt} \%$, respectively. TOC values are typically $0.1-0.5$ wt $\%$ throughout the sediment column. Organic matter is thermally immature and relatively well preserved with low $T_{\max }$ values $\left(380^{\circ}-420^{\circ} \mathrm{C}\right)$. Organic matter is a mixture of Type II (algal and microbial) and Type III (land plant/detrital) kerogen.

\section{Site U1410}

\section{Background and objectives}

Site U1410 is a mid-depth site $(3387 \mathrm{mbsl}$; 2950 mbsl at $50 \mathrm{Ma}$ ) (Tucholke and Vogt, 1979) in the upper mid-depth end of the Expedition 342 Paleogene Newfoundland sediment drifts depth transect. The site was positioned to capture a record of sedimentation $\sim 1.5 \mathrm{~km}$ shallower than the largely sub-CCD record drilled at Site U1403. The location, well above the average late Paleogene CCD, should be sensitive to both increases and decreases in carbonate burial, whether these reflect variations in dissolution related to changes in the CCD, changes in carbonate production, or variations in background noncarbonate sedimentation. Our primary scientific objectives for drilling Site U1410 were

- To obtain an expanded record of lower to middle Eocene drift sedimentation to compare directly to the relatively condensed record at Site U1409 drilled on the edge of the same drift;

- To capture fine-scale variations in carbonate preservation and lysocline shifts in carbonaterich sediment that is $\sim 400 \mathrm{~m}$ deeper than at Site U1408; and

- To evaluate the history of deep water and the CCD on sediment chemistry, grain size, and provenance.

Secondary objectives included the possible recovery of specific Paleogene hyperthermals such as the MECO for comparison with the record of these events elsewhere, particularly Sites U1404, U1406, and U1408 along the Expedition 342 depth transect.

\section{Principal results}

The vessel arrived at Site U1410 at $1845 \mathrm{~h}$ (UTC - 2.5 h) on 20 July 2012 after a $3.46 \mathrm{nmi}$ transit from Site U1409 in dynamic positioning mode that took $3.5 \mathrm{~h}$ at $1.0 \mathrm{nmi} / \mathrm{h}$. The plan for Site U1410 called for drilling three holes to $250 \mathrm{~m}$ DSF. Hole U1410A (3387.2 mbsl) was spudded at $2125 \mathrm{~h}$ on 20 July. Cores 342 U1410A-1H through $16 \mathrm{H}$ were recovered to $151.0 \mathrm{~m}$ DSF using nonmagnetic core barrels and the FlexIT core orientation tool. Core $16 \mathrm{H}$ experienced the first partial stroke. The XCB was deployed for Cores $17 \mathrm{X}$ through $28 \mathrm{X}$ to a final depth of $259.8 \mathrm{~m}$ DSF. The seafloor was cleared at $0500 \mathrm{~h}$ on 22 July, ending Hole U1410A. Overall core recovery for Hole $\mathrm{U} 1410 \mathrm{~A}$ was $256.88 \mathrm{~m}$ for the $259.8 \mathrm{~m}$ interval cored (99\% recovery). The total time spent on Hole U1410A was $34.25 \mathrm{~h}$. 
The vessel was offset $20 \mathrm{~m}$ east. Hole U1410B (3398.7 mbrf) was spudded at $0650 \mathrm{~h}$ on 22 July. Cores 342 U1410B-1H through $18 \mathrm{H}$ were recovered to $153.8 \mathrm{~m}$ DSF using nonmagnetic core barrels and the FlexIT core orientation tool. The XCB was deployed for Cores 19X through 28X to a final depth of $245.2 \mathrm{~m}$ DSF. The seafloor was cleared at $1620 \mathrm{~h}$ on 23 July, ending Hole U1410B. The recovery for Hole U1410B was $244.84 \mathrm{~m}$ over the $245.2 \mathrm{~m}$ cored (100\% recovery). The total time spent on Hole U1410B was 35.25 hours.

The vessel was offset $20 \mathrm{~m}$ south, and Hole U1410C (3386.9 mbsl) was spudded at $1825 \mathrm{~h}$ on 23 July. Cores $342-\mathrm{U} 1410 \mathrm{C}-1 \mathrm{H}$ through $16 \mathrm{H}$ were recovered to $146.8 \mathrm{~m}$ DSF using nonmagnetic core barrels. No core orientation was performed in Hole U1410C. The $\mathrm{XCB}$ was deployed for Cores $17 \mathrm{X}$ through $27 \mathrm{X}$ to a final depth of $243.8 \mathrm{~m}$ DSF. Recovery for Hole $\mathrm{U} 1410 \mathrm{C}$ was $238.81 \mathrm{~m}$ over the $243.8 \mathrm{~m}$ cored (98\% recovery). Recovery for Site U1410 was $740.5 \mathrm{~m}$ out of $748.8 \mathrm{~m}$ cored (98\% recovery). The seafloor was cleared and the vessel was secured for transit at 0915 h on 25 July, ending Hole U1410C. The total time spent on Hole U1410C was $41.00 \mathrm{~h}$.

The sedimentary sequence at Site U1410 comprises four lithostratigraphic units. Unit I is a $\sim 34 \mathrm{~m}$ thick succession of Pleistocene sediment with alternating reddish brown clay, gray to dark brown muddy/ clayey foraminiferal ooze with nannofossils, grayish brown foraminiferal sand, and occasional sand- to pebble-sized lithic grains. Unit II is a $\sim 30 \mathrm{~m}$ thick succession of clay, clay with nannofossils, and nannofossil clay of late Miocene to Oligocene age. Manganese, present as discrete nodules or disseminated silt- to sand-sized flecks, and disseminated sulfides are common. Sedimentological and biostratigraphic information indicate that Unit II contains multiple hiatal surfaces in addition to the unconformities that define its upper and lower boundaries. Middle to early Eocene Unit III is the thickest of the four units $(63-68 \mathrm{~m})$ and contains greenish gray nannofossil clay and greenish nannofossil clay to clayey nannofossil ooze with distinctive $10-25 \mathrm{~cm}$ thick bands of light gray to white nannofossil ooze that occur as a secondary lithology. Lithostratigraphic Unit IV is a $48 \mathrm{~m}$ thick sequence of white to pinkish white nannofossil chalk with foraminifers and/or radiolarians of middle Eocene to early Eocene age. This unit is divided into two generally similar subunits, with the lower subunit containing several chert beds.

Nannofossils, planktonic foraminifers, and benthic foraminifers are present through most of the Pleistocene to lower Eocene succession. Short barren intervals occur between thin Pleistocene, upper Miocene, and lower Miocene-Oligocene sequences. Radiolar- ians are only present in the uppermost Pleistocene and lower Eocene. Thin Pleistocene, upper Miocene and lower Miocene-Oligocene sequences overlie a middle Eocene through lower Eocene succession. Hiatuses or highly condensed intervals occur between the lower Pleistocene and upper Miocene (7.1 m.y. duration), upper and lower Miocene (7.4 m.y. duration), lower Miocene and upper Oligocene (5.4 m.y. duration), and lower Oligocene and middle Eocene (7.4 m.y. duration). The Oligocene is highly condensed and may also contain significant hiatuses.

Shipboard results reveal two series of normal and reversed magnetozones. These zones are observed between Cores 342-U1410A-1H and 4H ( 0-33 mbsf), between Cores 342-U1410B-1H and 5H ( 0-33 mbsf), and between Cores $342-\mathrm{U} 1410 \mathrm{C}-1 \mathrm{H}$ and $4 \mathrm{H}$ ( 0-32 mbsf). The second series is observed between Cores 342-U1410A-8H and 24X ( 69-218 mbsf), between Cores 342-U1410B-9H and 15H ( 69-121 mbsf), and Cores 342-U1410C-8H and 14H ( 70-118 mbsf). These magnetostratigraphies are straightforward to correlate among all three holes and represent two distinct time intervals. The first interval is from Chron C1n (Brunhes; modern) through upper Chron C2An.1n (Gauss; $2.6 \mathrm{Ma}$ ). The second interval is from upper Chron C18n.1n ( 39.6 Ma) through upper Chron C21r $(\sim 47.4 \mathrm{Ma})$. The lower part of Chron C20n, as well as Chrons C21n and $\mathrm{C} 21 \mathrm{r}$, have not yet been correlated in the XCB-recovered intervals in Holes U1410B and U1410C. Finally, the geomagnetic field transitions from C18n.1n to C18n.1r to C18n.2n are recorded in exceptional detail in Hole U1410B and show remarkably similar behavior as the same transitions recorded at Site U1408.

The magnetochronology and biochronology suggests that average linear sedimentation rates (LSRs) were $\sim 1.5-2.3 \mathrm{~cm} / \mathrm{k} . \mathrm{y}$. during the Pleistocene, with higher sedimentation rates during Chron $\mathrm{C} 2$ than during Chron C1. Sedimentation rates are $0.2 \mathrm{~cm} / \mathrm{k} . \mathrm{y}$. through the Oligocene. Average LSRs varied from $1.30 \mathrm{~cm} / \mathrm{k} . \mathrm{y}$. at the beginning of the middle Eocene to $1.98 \mathrm{~cm} / \mathrm{k} . \mathrm{y}$. at the end of the middle Eocene. Within the middle Eocene, LSRs peak at $2.63 \mathrm{~cm} / \mathrm{k} . \mathrm{y}$. during Chron C20n, one chron younger than the interval of peak LSRs at Site U1409. Finally, biochronology suggests sedimentation rates of $0.6 \mathrm{~cm} / \mathrm{k}$.y. in the lower Eocene.

The stratigraphic splice constructed for Site U1410 is continuous from 0 to $\sim 256 \mathrm{~m} \mathrm{CCSF}$, with the exception of one append at $226 \mathrm{~m}$ CCSF. Correlation during drilling operations was possible because of clear, correlative signals in magnetic susceptibility. Magnetic susceptibility and NGR were used for refining the real-time correlation and constructing the splice. 
All three holes recorded the prominent lithologic transition from greenish clay to carbonate-rich sediment, characterized by a step change to lower magnetic susceptibility and NGR at 220-230 m CCSF (across the early middle Eocene). Core 342-U1410A23X, showing the transitional physical property data, exhibits clear green to white cycles, which are absent from the equivalent cores in Holes U1410B and U1410C. As a result, we append Core 23X in the splice and add large offsets to Cores 342-U1410B26X and 342-U1410C-24X (13.3 and $4.8 \mathrm{~m}$, respectively).

Headspace methane concentrations (2.11-6.72 ppmv) were not above atmospheric levels. Pore water profiles display evidence of compartmentalization with prominent abrupt downhole shifts in magnesium, manganese, and potassium at 220-230 mbsf, suggesting that the unrecovered sequence of cherts functions as an aquiclude. Overall, pore water profiles of potassium, calcium, and magnesium are consistent with those resulting from exchange with and alteration of basaltic basement at depth. Potassium and magnesium concentrations decrease and calcium concentrations increase with depth. The downhole patterns of manganese, iron, and sulfate suggest organic matter degradation. Low alkalinity, ammonium, and manganese concentrations and high sulfate concentrations suggest that the influence of organic matter respiration within the sediment column at Site U1410 is modest. The broad downhole peak in boron concentrations at $\sim 30 \mathrm{mbsf}$ presumably indicates increased supply from the terrigenous sediment component in lithostratigraphic Unit II.

Carbonate content in the entire sediment column at Site U1410 ranges from 0.7 to $92 \mathrm{wt} \%$. As observed at the other drill sites on Southeast Newfoundland Ridge (Sites U1407-U1409), the most prominent change is a step increase (from 46 to $52 \mathrm{wt} \%$; 210 mbsf) in calcium carbonate content in sediment around the early/middle Eocene boundary (Zone NP14). This step correlates with shifts in several proxies (e.g., color reflectance, magnetic susceptibility, NGR, TOC, and total nitrogen values) and marks a transition in time from pelagic chalk sedimentation to clay deposition in the initial stages of sediment drift development. Middle Eocene sediment appears cyclic, with alternating clay-rich beds and white nannofossil ooze layers that have $\sim 30$ and 80 $\mathrm{wt} \%$ carbonate, respectively. TOC values are typically $0.01-0.57 \mathrm{wt} \%$ throughout the sediment column. Organic matter is thermally immature and relatively well preserved with low $T_{\max }$ values $\left(380^{\circ}-\right.$ $420^{\circ} \mathrm{C}$ ). Organic matter throughout the sediment column is a mixture of Type II (algal and microbial) and Type III (land plant/detrital) kerogen.

Bulk density shows a general increase downhole from 1.5 to $2.4 \mathrm{~g} / \mathrm{cm}^{3}$. Grain density is $\sim 2.7 \mathrm{~g} / \mathrm{cm}^{3}$ in Hole U1410A, and both water content and porosity show a decreasing trend downhole (from 53 to 21 $\mathrm{wt} \%$ for water content and 76 to $43 \mathrm{vol} \%$ for porosity). $P$-wave velocity increases progressively downhole from 1490 to $1960 \mathrm{~m} / \mathrm{s}$. Magnetic susceptibility decreases from $\sim 290$ to -2 IU, with notable steps at 30 and 45 mbsf, but exhibits uniform (-2 to 20 IU) values below $45 \mathrm{mbsf}$ to the bottom of the sediment column. Color reflectance parameters $\mathrm{a}^{*}$ and $\mathrm{b}^{*}$ gradually increase from -3 to 3 downhole to 210 mbsf. Below 210 mbsf, $\mathrm{a}^{*}$ and $\mathrm{b}^{*}$ increase to 12 and 8, respectively. $L^{*}$ increases downhole from 13 to 91, with steps at 115, 150, and 210 mbsf. NGR fluctuates from 21 to $47 \mathrm{cps}$ downhole to $210 \mathrm{mbsf}$ but then decreases from 27 to $\sim 10 \mathrm{cps}$ from $210 \mathrm{mbsf}$ to the bottom of the hole. Color reflectance and NGR reflect calcium carbonate content. Thermal conductivity gradually increases downhole from 0.9 to $1.5 \mathrm{~W} /$ $(\mathrm{m} \cdot \mathrm{K})$.

\section{Site U1411}

\section{Background and objectives}

Site U1411 is a mid-depth site $(3299 \mathrm{mbsl}$; 2850 mbsl at $50 \mathrm{Ma}$ ) (Tucholke and Vogt, 1979) in the upper end of the Expedition 342 Paleogene Newfoundland sediment drifts depth transect. The site is positioned to capture a record of sedimentation $\sim 1.65$ $\mathrm{km}$ shallower than the largely sub-CCD record drilled at Site U1403. The location, well above the average late Paleogene CCD, should be sensitive to both increases and decreases in carbonate burial, whether these reflect variations in dissolution related to changes in the CCD, changes in carbonate production, or variations in background noncarbonate sedimentation. Our primary scientific objectives for drilling Site U1411 were

- To obtain an expanded record of the upper half of a Miocene(?) to lower Eocene(?) sediment drift to directly compare to the timing and nature of drift development at the Sites U1407 and U1408 drift and the Sites U1409 and U1410 drift;

- To recover a Eocene/Oligocene boundary sequence;

- To capture fine-scale variations in carbonate preservation and lysocline shifts in MioceneEocene carbonate-rich sediments that are $\sim 550$ $\mathrm{m}$ shallower than the Site U1406 OligoceneMiocene section; and 
- To evaluate the history of deep water and the CCD on sediment chemistry, grain size, and provenance.

Secondary objectives include the possible recovery of the Oligocene/Miocene boundary for comparison with the record of these events elsewhere, particularly at Sites U1404-U1406 along the Expedition 342 depth transect.

\section{Principal results}

The vessel arrived at Site U1411 at $1115 \mathrm{~h}$ (UTC - 2.5 h) on 25 July 2012 after a $19.0 \mathrm{nmi}$ transit from Site U1410, which took $2.0 \mathrm{~h}$ at $9.5 \mathrm{nmi} / \mathrm{h}$. The plan for Site U1411 called for drilling three holes to $\sim 250 \mathrm{~m}$ DSF.

Hole U1411A was spudded at $2320 \mathrm{~h}$ on 25 July. The first core for Hole U1411A, Core 342-U1411A-1H, with a length of $9.87 \mathrm{~m}$, failed to capture the mudline and the hole was terminated. The seafloor was cleared at $2320 \mathrm{~h}$ on 25 July, ending Hole U1411A. Recovery for Hole U1411A was $9.87 \mathrm{~m}$ for the $9.5 \mathrm{~m}$ interval recovered (104\% recovery). The total time spent on Hole U1411A was $12.00 \mathrm{~h}$. The vessel was offset $20 \mathrm{~m}$ east and Hole U1411B (3298.8 mbsl) was spudded at $0035 \mathrm{~h}$ on 26 July. Cores 342-U1411B-1H through $20 \mathrm{H}$ were recovered to $177.4 \mathrm{~m}$ DSF using nonmagnetic core barrels and the FlexIT core orientation tool. The XCB was deployed for Cores $21 \mathrm{X}$ through $28 \mathrm{X}$ to a final depth of $254.2 \mathrm{~m}$ DSF. The seafloor was cleared at $1310 \mathrm{~h}$ on $27 \mathrm{July}$, ending Hole U1411B. Recovery for Hole U1411B was 233.94 $\mathrm{m}$ over the $254.2 \mathrm{~m}$ cored (92\% recovery). The total time spent on Hole U1411B was 38.00 hours.

The vessel was offset $20 \mathrm{~m}$ south. Hole U1411C (3300.2 mbsl) was spudded at $1505 \mathrm{~h}$ on 27 July. Cores $342-\mathrm{U} 1411 \mathrm{C}-1 \mathrm{H}$ through $2 \mathrm{H}$ were recovered to $9.2 \mathrm{~m}$ DSF. After recovering Core $2 \mathrm{H}$, the hole was drilled without coring from 9.2 to $100 \mathrm{~m}$ DSF in order to save operational time for deeper objectives. After the drilling advance, APC coring continued with Cores $4 \mathrm{H}$ through $9 \mathrm{H}$ (100-152.2 m DSF). All APC cores were oriented with the FlexIT core orientation tool and recovered using the nonmagnetic core barrels. The XCB was deployed for Cores 10X through $17 \mathrm{X}$ to a final depth of $223.9 \mathrm{~m}$ DSF. After Core 17X, a medical emergency arose and it was decided to terminate operations and transit to St. Johns, Newfoundland (Canada). The seafloor was cleared and the vessel was secured for transit at $0500 \mathrm{~h}$ on 29 July, ending Hole U1411C. Recovery for Hole U1411C was $118.62 \mathrm{~m}$ over the $133.1 \mathrm{~m}$ cored (89\% recovery). The total time spent on Hole U1411C was $39.75 \mathrm{~h}$.
Overall recovery for Site U1411 was 91\%. The total time spent on Site U1411 was 89.75 h (3.7 days).

At Site U1411, we recovered a $254.5 \mathrm{~m}$ thick sedimentary succession of deep-sea pelagic sediment of Pleistocene to late Eocene age highlighted by an expanded record of the EOT. The sedimentary sequence at Site U1411 comprises three site-specific lithostratigraphic units. Unit I is a $13 \mathrm{~m}$ thick succession of Pleistocene sediment of alternating gray and reddish brown clayey foraminiferal ooze, gray silty sand with foraminifers, and brown to grayish brown silty clay with foraminifers. Dropstones and sandsized lithic grains are prominent in Unit I. Unit II is a $198 \mathrm{~m}$ thick succession of silty clay, clay with nannofossils, and silty nannofossil clay of early Miocene to late Eocene age. Nannofossil ooze is also present in Unit II but only in the interval immediately above the Eocene/Oligocene boundary. Small blebs of quartz silt on core surfaces, interpreted as ice-rafted siltstone clasts, are very common in the Miocene and Oligocene sediment of Unit II. Nannofossil ooze occurs just above the Eocene/Oligocene boundary, possibly representing the widespread carbonate overshoot observed at other Expedition 342 sites. Unit III is $42 \mathrm{~m}$ thick and composed of greenish gray and dark greenish gray nannofossil clay with foraminifers, clayey nannofossil chalk with foraminifers, and clayey foraminiferal chalk. Laminated intervals, some of which are highly concentrated in foraminifers, are common in Unit III and provide evidence for significant reworking and winnowing by currents associated with drift formation.

Nannofossils, planktonic foraminifers, and benthic foraminifers are present through most of the Pleistocene to upper Eocene succession. A short barren interval occurs between the Pleistocene and lower Miocene-Eocene sequence. Radiolarians are only present in the uppermost Pleistocene. A relatively thin Pleistocene sequence overlies a lower Miocene to midOligocene succession with relatively poor carbonate microfossil preservation, followed by an expanded lower Oligocene through upper Eocene succession with excellent preservation of calcareous microfossils. Average linear sedimentation rates across the EOT are up to $\sim 5 \mathrm{~cm} / \mathrm{k} . \mathrm{y}$.

Shipboard results reveal two series of normal and reversed magnetozones. The first zone is observed in Core 342-U1411B-2H ( 1-11 mbsf) and Cores 342U1411C-1H through $2 \mathrm{H}$ ( $\sim-7 \mathrm{mbsf})$. The second series is observed between Cores 342-U1411B-4H and $20 \mathrm{H}$ ( 20-177 mbsf). Part of this second series is observed between Cores 342-U1411C-7H and $8 \mathrm{H}$ ( 127-143 mbsf). These magnetostratigraphies can 
be correlated between both holes and represent two distinct time intervals. The first interval is from Chron C1n (Brunhes; modern) through upper Chron C1r.3r ( 1.2 Ma). The second interval is from lower Chron C8n.2n ( 25.9 Ma) through upper Chron C15n ( 35.0 Ma). At least four significant conclusions can be drawn from this shipboard magnetostratigraphy:

1. Site U1411 contains a nearly complete and expanded Oligocene record, with average LSRs of $1.53 \mathrm{~cm} / \mathrm{k} . \mathrm{y}$. and peak LSRs of $3.22 \mathrm{~cm} / \mathrm{k} . \mathrm{y}$.

2 . The $\mathrm{C} 11 \mathrm{r} / \mathrm{C} 12 \mathrm{n}$ and $\mathrm{C} 12 \mathrm{n} / \mathrm{C} 12 \mathrm{r}$ chron boundaries are not clearly identified in the shipboard paleomagnetic data, suggesting a hiatus of at least $\sim 0.5 \mathrm{~m} . y$. in the lower Oligocene. This interval also corresponds to a $10 \mathrm{~m}$ broad zone of depressed NGR values, a sharp lithostratigraphic contact in Section 342-U1411B-10H-5, and a hiatus inferred from nannofossil and foraminifer biostratigraphic datums.

3. The EOT is highly expanded, with average LSRs of $2.63 \mathrm{~cm} / \mathrm{k} . \mathrm{y}$. and peak LSRs of $5.02 \mathrm{~cm} / \mathrm{k} . \mathrm{y}$. The Chron C13n/C13r boundary (33.705 Ma) is recognized in Section 342-U1411B-17H-1 at $\sim 144.15$ mbsf and Sections 342-U1411C-8H-5 and $8 \mathrm{H}-6$ at $\sim 142.50 \mathrm{mbsf}$.

4. Shipboard paleomagnetic data indicate at least three cryptochrons within Chron C13r. The second and longest of these cryptochrons occurs in the same stratigraphic interval as the first downhole appearance of the Eocene marker foraminifer Hantkenina alabamensis.

The stratigraphic splice constructed for Site U1411 is composed of a series of stratigraphically continuous intervals from 0 to $\sim 20, \sim 100$ to $128, \sim 128$ to 178 , $\sim 207$ to 226 , and $\sim 226$ to $236 \mathrm{~m}$ CCSF. Coring in Hole U1411A did not recover a mudline, so Hole U1411A was ended after the first core. Hole U1411B spans the thickest sediment column recovered at this site, with a maximum depth of $\sim 269$ m CCSF, whereas Hole U1411C has a maximum depth of $\sim 236 \mathrm{~m}$ CCSF. The large number of appended intervals in the splice is due to a drilling advance without coring from 20 to $100 \mathrm{~m}$ CCSF in Hole U1411C. As a result, only Hole U1411B recovered this interval. Correlation during drilling for the interval from $\sim 100$ to $236 \mathrm{~m}$ CCSF was possible based on magnetic susceptibility and GRA bulk density data, though magnetic susceptibility was low from 100 to $148 \mathrm{~m}$ CCSF. Magnetic susceptibility was used for refining the real-time correlation and constructing the splice. The longest continuous intervals in the splice are from $\sim 100$ to $128 \mathrm{~m}$ CCSF and $\sim 128$ to $178 \mathrm{~m} \mathrm{CCSF}$; the former covers the Eocene/Oligocene boundary. The appended cores from $\sim 178$ to $269 \mathrm{~m} \mathrm{CCSF}$ are a function of poor XCB recovery in both Holes U1411B and U1411C.

Methane was the only hydrocarbon detected in the headspace samples from Hole U1411B. Methane increases very slightly downhole, with values between 2.11 and 4.12 ppmv. Pore water constituents in Hole U1411B are consistent with consumption of organic matter under oxic to suboxic conditions. However, sulfate concentrations remain high throughout the sequence, indicating that pore fluid diagenesis does not proceed to sulfate reduction. Overall, pore water profiles of potassium, calcium, and magnesium are consistent with those resulting from exchange with and alteration of basaltic basement at depth. Potassium concentrations may be responding to adsorption onto clay particles. As with other sites where the EOT was recovered (Sites U1404 and U1406), carbonate content shows an uphole increase across the transition followed by a decrease in carbonate contents within the lower Oligocene. TOC ranges from 0.01 to 0.50 wt $\%$, with many samples falling below detection limits. Total nitrogen values generally fall below $0.1 \mathrm{wt} \%$, with slightly lower values at the bottom of Hole U1411B.

Bulk density increases downhole from 1.5 to 1.95 $\mathrm{g} / \mathrm{cm}^{3}$, but an abrupt step down to $\sim 1.5 \mathrm{~g} / \mathrm{cm}^{3}$ occurs at the transition between lithostratigraphic Units I and II between Pleistocene and Miocene sediments. Grain density averages $2.75 \mathrm{~g} / \mathrm{cm}^{3}$, and water content and porosity exhibit a decreasing trend downhole (from 55 to $25 \mathrm{wt} \%$ and 80 to 45 vol\%, respectively), as expected for sediment compaction. $P$-wave velocity increases progressively downhole from 1500 to $1700 \mathrm{~m} / \mathrm{s}$. Magnetic susceptibility drops from $\sim 160$ to 30 IU at $18 \mathrm{mbsf}$ and remains constant downhole other than a small increase at $\sim 140 \mathrm{mbsf}$. Color reflectance parameters $a^{*}$ and $b^{*}$ follow similar trends throughout the hole, but in Units II and III some superimposed peaks appear in $b^{*}$. NGR and $L^{*}$ show a major peak at $\sim 140$ mbsf that correlates with the major variation in calcium carbonate content. Almost all the physical properties show a shift or a peak in their values at $\sim 140$ mbsf associated with the post-Eocene-Oligocene pulse of carbonate deposition.

\section{Preliminary scientific assessment: Newfoundland sediment drifts \\ Summary of expedition objectives}

Expedition 342 to the Newfoundland sediment drifts was a ground-breaking expedition that achieved 
both record IODP recovery in mid-Cretaceous to Miocene sediment as well as overall core recovery. In total, $5724 \mathrm{~m}$ of sediment was cored, of which 5413 $\mathrm{m}$ was recovered (average 94\%; Table T2) in $25 \mathrm{APC} /$ XCB holes across 10 sites (U1402-U1411). Sediment of Paleogene age, our main objective, makes up the majority of our recovery including particularly spectacular records of the Eocene together with Paleocene/Eocene and Eocene/Oligocene boundaries. However, we also obtained some exceptional Cretaceous and Neogene sections that include the Cenomanian/Turonian boundary, a deepwater record of the Cretaceous/Paleogene boundary and, at three sites, the Oligocene/Miocene boundary. The nine drill sites form a depth transect between $\sim 5$ and $3 \mathrm{~km}$ water depth in clay-rich sediment drifts at the modern front between warm surface waters of the Gulf Stream flowing north and the southward-flowing Labrador Current. The intersection of these currents ponds icebergs drifting from Greenland over the site of the sinking of the Titanic a century ago. The sediment recovered at the drill sites is characterized, for the most part, by excellent age control and over substantial intervals they contain exquisitely well preserved microfossils that accumulated at much faster rates than in typical deep-sea settings.

Expedition 342 was designed to examine four major objectives:

\section{To reconstruct the detailed history of the carbonate saturation state of the North Atlantic through numerous episodes of abrupt global warming.}

An interval of particular focus was the middle Eocene to early Oligocene where we expected to find expanded records of hyperthermal events and the MECO. This history of the carbonate system, coupled with detailed geochemical studies, would allow us to test theories for the origin of hyperthermalsabrupt periods of greenhouse gas-fueled warming known to punctuate the Paleocene and Eocene (Galeotti et al., 2010; Quillévéré et al., 2008; Sexton et al., 2011). Natural experiments with global change like hyperthermals can enhance our understanding of the consequences of abrupt climate change for Earth's ecosystems, climate, and chemistry. Reconstruction of the CCD was expected to be enhanced by the expedition objective to obtain the first depth transect that captures dynamics of the truly deep ocean as well as the intermediate depths captured in pervious drilling programs (Bralower et al., 2002; Zachos, 2005).

2. To obtain a very detailed record of the flow history of the Deep Western Boundary Current issuing from the

\section{North Atlantic.}

Today, deepwater formation draws warm water into the Nordic seas, thus keeping them warm. Expedition 342 was designed to show how far into the past this pattern of overturning circulation extends and its influence on climates of the past greenhouse world.

\section{To obtain a detailed record of the EOT ( 33.7 Ma) and the onset of major glaciation following the warm climates of the Eocene.}

Drill cores through the EOT were anticipated to yield highly resolved records of the events leading up to and following the greenhouse-to-icehouse transition, as well as a history of how Greenland and high northern latitudes responded to this event.

\section{To obtain cores useful for resolving major} uncertainties in Eocene chronostratigraphy that can be used to link the astronomical timescale developed for the last $\sim 40$ m.y. to the floating timescale of the early Paleogene developed over a series of IODP and earlier drilling expeditions.

The material we recovered makes it possible to address all of these scientific objectives as well as some unanticipated objectives:

- The long-term history of change in the CCD in the North Atlantic Ocean over the past 100 m.y.;

- The amplitude of rapid CCD change associated with extreme perturbations to the Earth system (e.g., the K/Pg mass extinction, PETM, and EOT);

- The amplitude, frequency, and cause of Paleogene and Cretaceous hyperthermal and hypoxic events and the response of the hydrological and terrestrial system;

- Changes in deep-sea ventilation, vertical ocean structure, and circulation in the North Atlantic in the Eocene greenhouse;

- The timing of the initiation of sediment drift formation in the North Atlantic;

- Climate sensitivity to changes in atmospheric greenhouse gas concentrations under contrasting baseline climate conditions;

- The stability of climate, ice sheets, and biotic systems at orbital and millennial scales in the pre-Pliocene-Pleistocene North Atlantic;

- The stability of Cenozoic ice sheets and the prePliocene history of glaciation in the northern hemisphere; and

- Astrochronology and calibration of the Cenozoic timescale. 


\section{North Atlantic history of carbonate compensation depth change}

One main expedition objective was to reconstruct the Paleogene CCD in the North Atlantic for reference to recent high-fidelity records of the CCD obtained in the equatorial Pacific. Our deepest water site (Site U1403) was at a paleodepth of $\sim 4.5 \mathrm{~km} 50$ m.y. ago, whereas our shallowest one (Site U1408) can be backtracked to a paleodepth of $2.5 \mathrm{~km}$ at this time. This combination of sites yields a record of the history of CCD change over a $2 \mathrm{~km}$ depth range from the ocean abyss to middle water depths. A main shipboard result of the expedition was that the long-term position of the CCD in the North Atlantic appears to have been markedly deeper during the Late Cretaceous through early Eocene than in the late Eocene through Miocene. A second result was that during the early Eocene, a time interval for which data are now available from both the Pacific and Atlantic Oceans, the CCD in the North Atlantic was positioned much deeper (by $\sim 2 \mathrm{~km}$ ) than in the equatorial Pacific. A third notable result was discovery of intermittent calcareous sediment in the Cretaceous, Paleocene, and early to middle Eocene at 4.5 $\mathrm{km}$ paleodepth, suggesting a deep Atlantic CCD during these times. Still another notable result was to find frequent intervals in the Oligocene without carbonate, in contrast to the Pacific where the CCD reaches its deepest point in the Cenozoic during the Oligocene and early Miocene. We also found evidence of carbonate deposition events following the $\mathrm{K} / \mathrm{Pg}$ mass extinction, PETM, and EOT.

\section{North Atlantic history of ocean structure and sediment drift formation}

A second objective of our depth transect drilling strategy was to capture records of changes in deepsea ventilation, vertical ocean structure, and circulation in the North Atlantic, both at the secular timescale comparing the Eocene greenhouse to the Oligocene icehouse baseline states and to test for reversals in deepwater formation patterns across abrupt extreme climate transitions. The sequences that we have recovered can be used to trace highly resolved geochemical records (e.g., $\delta^{13} \mathrm{C}$ and $\mathrm{Nd}$ isotopes) of the vertical structure of deep water in the North Atlantic, and these records can, in turn, be used to examine regional gradients using results from the expedition as a "northern end-member" for comparison with sites elsewhere in the world. It will also be possible to use the history of drift formation itself and information on bottom water flow strength (using, for example, sortable silt records) to monitor the strength of the Deep Western Boundary Current and estimate the rate of formation of deep water in the North Atlantic.

\section{High-resolution records of climate from rapidly accumulating sediment drifts}

A third major objective of Expedition 342 was to drill sediment drift deposits to recover sequences with high rates of accumulation in comparison to the modest rates of accumulation $(\sim 0.5-1 \mathrm{~cm} / \mathrm{k} . \mathrm{y}$. in the Paleogene) typically encountered at pelagic sites. A major expedition highlight was the recovery of sequences with high sedimentation rates (up to 3 to 10 times higher than typical pelagic rates) having excellent age control. Recovery of these sections will enable studies of the suborbital dynamics of past abrupt climate change, including both transitions into greenhouse and icehouse climate states, the full magnitudes of hyperthermal events, and rates of change in the CCD. We found that the thickest central sections through the various sediment drifts typically record the same depositional packages that were recovered in the thin noses and tails of these drifts, but these central sections are often massively expanded with clay. Times of peak accumulation of drift deposits drilled during the expedition include the middle Eocene, earliest and latest Oligocene, and early Miocene. As anticipated, the task of creating spliced records of multiple holes at some of our sites was not always straightforward shipboard because of some intervals of low-amplitude change in some physical property data sets (most notably magnetic susceptibility) and lateral variations in stratigraphy. High-quality shipboard biostratigraphic, magnetostratigraphic, and other physical property data sets (e.g., NGR), however, suggested that this issue could be addressed using shore-based scanning X-ray fluorescence work, and initial shore-based results support that interpretation

\section{Exceptional preservation of calcareous microfossils in sediment drifts}

A fourth major objective of Expedition 342 was the recovery of high-accumulation rate, clay-rich sediment containing well-preserved microfossils. A major expedition highlight was the recovery of intervals and sites containing assemblages of calcareous and siliceous microfossils exhibiting exceptional preservation. These include, in the case of calcareous flora and fauna, the intervals with the highest sedimentation rates, for example the Oligocene/Miocene boundary interval at Site U1405, the middle Eocene sequence at Sites U1408 and U1410, and the EOT at Site U1411. The presence of holococcoliths and minute coccoliths is an indicator of high-quality preser- 
vation, and the conspicuous occurrence of these is coincident with observations of glassy planktonic foraminifers at Sites U1403, U1405, U1408, U1410, and U1411. It is notable that the benthic foraminifer record shows excellent preservation even when the quality of preservation is no longer exceptional in planktonic foraminifers and nannofossils. The best preserved assemblages recovered are virtually unprecedented in deep-sea sections and have been previously found only in shelf environments with clay deposits (e.g., Tanzania, Gulf Coast). Expedition 342 material will allow shore-based studies of major expedition objectives (e.g., climate sensitivity to greenhouse gas forcing and floral and faunal turnover) to proceed effectively free of the usual concerns over taphonomic bias.

\section{Paleogene and Cretaceous hyperthermal and hypoxic events}

A major goal of the expedition was to acquire records of multiple hyperthermal events-abrupt intervals of greenhouse gas-fueled warming from the early Paleogene such as the PETM and ETM2. This objective was achieved at multiple sites across a depth transect of $\sim 2 \mathrm{~km}$, extending our knowledge of these events for the first time into near-abyssal water depths. We also recovered a complete record of the early Eocene-middle Eocene transition, a rarity in the drill hole record of the Atlantic. The early/middle Eocene boundary is typically unconformable or is represented by chert. Hence, we are now in a position to create the first highly detailed paleoceanographic records of the boundary interval. Furthermore, we recovered sediment at multiple sites from the MECO and various carbonate accumulation events which should yield suborbitally resolved records of these events. An additional related but unanticipated result was the recovery at one site at shallow burial depth of a black shale sequence rich in Type II organic matter across the Cenomanian/Turonian boundary OAE 2, probably the biggest carbon cycle perturbation and global warming event in the last 100 m.y.

A notable feature common to each of the Expedition 342 Paleocene/Eocene and Cenomanian/Turonian boundary sequences is the presence of siliceous sediment, including siliceous claystone, siliceous limestone, porcellanite, and chert. These Cretaceous and Paleogene hyperthermal and hypoxic events will be used to enhance our understanding of the consequences of abrupt climate change for Earth's ecosystems, climate, and chemistry, including the response of the hydrological cycle and terrestrial systems.

\section{Stability of Cenozoic ice sheets and early northern hemisphere glaciation}

Another major objective of Expedition 342 was the recovery of paleoceanographic sections to assess competing hypotheses for the stability of Cenozoic ice sheets on Antarctica and the chain of events leading up to the intensification of northern hemisphere glaciation during the latest Pliocene-early Pleistocene. Major highlights of Expedition 342 were the recovery at multiple sites of high-latitude North Atlantic sections across three intervals of Cenozoic time that are key to the assessment of these problems, the middle Eocene interval (Chron C19; 40.5$42.5 \mathrm{Ma})$ on the run-up to the MECO, the EOT ( 38.5-32 Ma), and the latest Oligocene-earliest Miocene transition ( 23.5-22.5 Ma). A potentially important discovery in this context is the presence, consistently across multiple sites, of angular lithic grains of the 63-150 $\mu \mathrm{m}$ size fraction and sand-sized lithic clasts in some of these intervals, most notably in lower Miocene and particularly in Oligocene strata.

\section{Astrochronology and calibration of the Cenozoic timescale}

A further main objective of the expedition was to obtain records of the Eocene that can be used to link the astronomical timescale developed for the last $\sim 40$ m.y. to the floating timescale of the early Paleogene developed over a series of IODP and earlier drilling expeditions. Expedition 342 sites not only record well-developed cyclicity bundled into familiar orbital periods but also show promise for the development of magnetostratigraphy and refined biochronology. From this perspective, acquisition of sedimentary sections suited to generating an astronomically tuned record of the late Eocene and early middle Eocene is an extremely important expedition result that should make it possible to span existing gaps in our tuning efforts. For the Paleocene and Eocene, a shallow CCD has hampered efforts to obtain long, uninterrupted carbonate sequences that allow high-resolution paleoclimatic studies with traditional geochemical studies of stable isotope and trace element analysis. Shore-based studies of Expedition 342 sediment will make a major contribution to overcoming this particular problem. In addition, for the time intervals that have already been astronomically tuned elsewhere, the expedition will allow a comparison between low-latitude sites from the Pacific and Atlantic, offering the chance to decipher the processes controlling the amplification of, for example, 41 k.y. obliquity versus $\sim 100$ and 405 k.y. 
eccentricity cycles and to test the hypothesis that there are different dominant astronomical forcing between Earth's warm and cool periods.

\section{Preliminary scientific assessment: MDHDS sea trials}

In situ pore pressure was directly measured at Site U1402. Pore pressure was $7.536 \mathrm{MPa}$, just slightly above hydrostatic pressure. This is the first in situ pressure measurement made on the Atlantic margin in ocean drilling, and it confirms previous indirect pressure estimates. Accelerometer data collected within the T2P's electronic housing showed perfect decoupling from the drill string. We now have a dependable method to deploy pore pressure penetrometers successfully, which will allow the rapid measurement of in situ pressure in sediment. This new capability opens an exciting range of future science for the drilling program.

The MDHDS performed well and successfully emplaced a penetrometer with full decoupling and without bending the tip. The T2P penetrometer successfully measured in situ pressure and temperature. The ERS performed acceptably; however, the tool can overlatch, which resulted in dropping the MDHDS in one instance at Site U1402. Real-time data were acquired through the tethered system, but problems with the tether associated with drill string pressurization suggest that this component (real-time telemetry with a tether) is not ready for regular shipboard use.

The following decisions were made based on shipboard results and subsequent shore-based discussions between the MDHDS development team and the USIO. The MDHDS will undergo minor modifications before certification for shipboard deployment. The decision to remove the real-time telemetry tether allows a decrease in diameter of the MDHDS inner barrel subassembly, which provides space to install a larger, stronger spring in the MDHDS latching mechanism. This will make the inner barrel subassembly stronger and will reduce the risk of the MDHDS latch failing to release at depth. These modifications are currently being completed by Pettigrew Engineering. The T2P penetrometer successfully measured in situ pressure and temperature and will be certified by the USIO. The ERS performed acceptably yet will need additional modifications prior to regular shipboard deployment. The primary issue to address is overlatching, which can be resolved by installing a mechanical stop on the latching mechanism. A secondary but important issue to address is the ERS motors, which tend to leak (and leak more at depth) and need slight electrical modifications to ensure proper functionality during deployment. These modifications are currently being made by Stress Engineering with funding from IODP-Management International, Inc. The ERS is not ready to be adopted. A successful deployment of the Simple Cabled Instrument for Measuring Properties In Situ will be the bar for acceptance of the ERS.

\section{References}

Adams, D.D., Hurtgen, M.T., and Sageman, B.B., 2010. Volcanic triggering of a biogeochemical cascade during oceanic anoxic Event 2. Nat. Geosci., 3(3):201-204. doi:10.1038/ngeo743

Agnini, C., Fornaciari, E., Giusberti, L., Grandesso, P., Lanci, L., Luciani, V., Muttoni, G., Pälike, H., Rio, D., Spofforth, D.J.A, and Stefani, C., 2011. Integrated biomagnetostratigraphy of the Alano section (NE Italy): a proposal for defining the middle-late Eocene boundary. Geol. Soc. Am. Bull., 123(5-6):841-872. doi:10.1130/ B30158.1

Alegret, L., and Thomas, E., 2009. Food supply to the seafloor in the Pacific Ocean after the Cretaceous/Paleogene boundary event. Mar. Micropaleontol., 73(1-2):105116. doi:10.1016/j.marmicro.2009.07.005

Alley, R.B., and Clark, P.U., 1999. The deglaciation of the Northern Hemisphere: a global perspective. Annu. Rev. Earth Planet. Sci., 27(1):149-182. doi:10.1146/ annurev.earth.27.1.149

Alvarez, L.W., Alvarez, W., Asaro, F., and Michel, H.V., 1980. Extraterrestrial cause for the Cretaceous-Tertiary extinction. Science, 208(4448):1095-1108. doi:10.1126/ science.208.4448.1095

Alvarez, W., Alvarez, L.W., Asaro, F., and Michel, H.V., 1984. The end of the Cretaceous: sharp boundary or gradual transition? Science, 223(4641):1183-1186. doi:10.1126/science.223.4641.1183

Archer, D., Lyle, M., Rodgers, K., and Froelich, P., 1993. What controls opal preservation in tropical deep-sea sediments? Paleoceanography, 8(1):7. doi:10.1029/ 92PA02803

Arthur, M.A., Dean, W.E., and Pratt, L.M., 1988. Geochemical and climatic effects of increased marine organic carbon burial at the Cenomanian/Turonian boundary. Nature (London, U. K.), 335(6192):714-717. doi:10.1038/335714a0

Arthur, M.A., and Premoli-Silva, I., 1982. Development of widespread organic carbon-rich strata in the Mediterranean Tethys. In Schlanger, S.O., and Cita, M.B. (Eds.), Nature and Origin of Cretaceous Carbon-Rich Facies: London (Academic Press), 7-54.

Arthur, M.A., Schlanger, S.O., and Jenkyns, H.C., 1987. The Cenomanian-Turonian oceanic anoxic event, II. Palaeoceanographic controls on organic matter production and preservation. In Brooks, J., and Fleet, A.J. (Eds.), Marine Petroleum Source Rocks. Geol. Soc. Spec. Publ., 26(1):401-420. doi:10.1144/GSL.SP.1987.026.01.25 
Arthur, M.A., Srivastava, S.P., Kaminski, M., Jarrard, R., and Osler, J., 1989. Seismic stratigraphy and history of deep circulation and sediment drift development in Baffin Bay and the Labrador Sea. In Srivastava, S.P., Arthur, M.A., Clement, B., et al., Proc. ODP, Sci. Results, 105: College Station, TX (Ocean Drilling Program), 957-988. doi:10.2973/odp.proc.sr.105.118.1989

Aubry, M.-P., 1995. From chronology to stratigraphy: interpreting the lower and middle Eocene stratigraphic record in the Atlantic Ocean. In Berggren, W.A., Kent, D.V., Aubry, M.-P., and Hardenbol, J. (Eds.), Geochronology, Time Scales, and Global Stratigraphic Correlation: A Unified Temporal Framework for an Historical Geology. Spec. Publ.-SEPM (Soc. Sediment. Geol.), 54:213-274.

Backman, J., Moran, K., McInroy, D., and the IODP Expedition 302 Scientists, 2005. IODP Expedition 302, Arctic Coring Expedition (ACEX): a first look at the Cenozoic paleoceanography of the central Arctic Ocean. Sci. Drill., 1:12-17. doi:10.2204/iodp.sd.1.02.2005

Bailey, I., Bolton, C.T., DeConto, R.M., Pollard, D., Schiebel, R., and Wilson, P.A., 2010. A low threshold for North Atlantic ice rafting from "low-slung slippery" late Pliocene ice sheets. Paleoceanography, 25(1):PA1212. doi:10.1029/2009PA001736

Bailey, I., Foster, G.L., Wilson, P.A., Jovane, L., Storey, C.D., Trueman, C.N., and Becker, J., 2012. Flux and provenance of ice-rafted debris in the earliest Pleistocene subpolar North Atlantic Ocean comparable to the Last Glacial Maximum. Earth Planet. Sci. Lett., 341-344. doi:10.1016/j.epsl.2012.05.034

Bailey, I., Liu, Q., Swann, G.E.A., Jiang, Z., Sun, Y., Zhao, X., and Roberts, A.P., 2011. Iron fertilisation and biogeochemical cycles in the sub-Arctic northwest Pacific during the late Pliocene intensification of northern hemisphere glaciation. Earth Planet. Sci. Lett., 307(34)253-265. doi:10.1016/j.epsl.2011.05.029

Barclay, R.S., McElwain, J.C., and Sageman, B.B., 2010. Carbon sequestration activated by a volcanic $\mathrm{CO}_{2}$ pulse during oceanic anoxic Event 2. Nat. Geosci., 3(3):205208. doi:10.1038/ngeo757

Barrera, E., and Savin, S.M., 1999. Evolution of Campanian-Maastrichtian marine climates and oceans. In Barrera, E., and Johnson, C.C. (Eds.), Evolution of the Cretaceous Ocean-Climate System. Spec. Pap.-Geol. Soc. Am., 332:245-282. doi:10.1130/0-8137-2332-9.245

Barrera, E., Savin, S.M., Thomas, E., and Jones, C.E., 1997. Evidence for thermohaline-circulation reversals controlled by sea-level change in the latest Cretaceous. Geology, 25(8):715-718. doi:10.1130/00917613(1997)025<0715:EFTCRC>2.3.CO;2

Bekins, B.A., and Dreiss, S.J., 1992. A simplified analysis of parameters controlling dewatering in accretionary prisms. Earth Planet. Sci. Lett., 10(3-4)9:275-287. doi:10.1016/0012-821X(92)90092-A

Berger, W.H., 1970. Biogenous deep-sea sediments: fractionation by deep-sea circulation. Geol. Soc. Am. Bull., 81(5):1385-1402. doi:10.1130/00167606(1970)81[1385:BDSFBD]2.0.CO;2

Berggren, W.A., Aubry, M.-P., van Fossen, M., Kent, D.V., Norris, R.D., and Quillévéré, F., 2000. Integrated Paleo- cene calcareous plankton magnetobiochronology and stable isotope stratigraphy: DSDP Site 384 (NW Atlantic Ocean). Palaeogeogr., Palaeoclimatol., Palaeoecol., 159(12):1-51. doi:10.1016/S0031-0182(00)00031-6

Berggren, W.A., and Norris, R.D., 1997. Biostratigraphy, phylogeny and systematics of Paleocene trochospiral planktic foraminifera. Micropaleontology, 43(S1):1-116. doi:10.2307/1485988

Bernaola, G., Baceta, J.I., Orue-Etxebarria, X., Alegret, L., Martin-Rubio, M., Arostegui, J., and Dinarès-Turell, J., 2007. Evidence of an abrupt environmental disruption during the mid-Paleocene biotic event (Zumaia section, western Pyrenees). Geol. Soc. Am. Bull., 119(7-8):785795. doi:10.1130/B26132.1

Bice, K.L., Barron, E.J., and Peterson, W.H., 1997. Continental runoff and early Cenozoic bottom-water sources. Geology, 25(10):951-954. doi:10.1130/00917613(1997)025<0951:CRAECB >2.3.CO;2

Bice, K.L., and Marotzke, J., 2001. Numerical evidence against reversed thermohaline circulation in the warm Paleocene/Eocene ocean. J. Geophys. Res.: Oceans, 106(C6):11529-11542. doi:10.1029/2000JC000561

Bice, K.L., and Marotzke, J., 2002. Could changing ocean circulation have destabilized methane hydrate at the Palaeocene/Eocene boundary? Paleoceanography, 17(2):1018-1039. doi:10.1029/2001PA000678

Bijl, P.K., Houben, A.J.P., Schouten, S., Bohaty, S.M., Sluijs, A., Reichart, G.-J., Sinninghe Damsté, J.S., and Brinkhuis, H., 2010. Transient middle Eocene atmospheric $\mathrm{CO}_{2}$ and temperature variations. Science, 330(6005):819-821. doi:10.1126/science.1193654

Billups, K., Channell, J.E.T., and Zachos, J., 2002. Late Oligocene to early Miocene geochronology and paleoceanography from the subantarctic South Atlantic. Paleoceanography, 17(1):1-11. doi:10.1029/ 2000PA000568

Billups, K., Pälike, H., Channell, J.E.T., Zachos, J.C., and Shackleton, N.J., 2004. Astronomic calibration of the late Oligocene through early Miocene geomagnetic polarity time scale. Earth Planet. Sci. Lett., 224(1-2):3344. doi:10.1016/j.epsl.2004.05.004

Bohaty, S.M., and Zachos, J.C., 2003. Significant Southern Ocean warming event in the late middle Eocene. Geology, 31(11):1017-1020. doi:10.1130/G19800.1

Bohaty, S.M., Zachos, J.C., Florindo, F., and Delaney, M.L., 2009. Coupled greenhouse warming and deep-sea acidification in the middle Eocene. Paleoceanography, 24(2):PA2207. doi:10.1029/2008PA001676

Bombolakis, E.G., 1981. Analysis of a horizontal catastrophic landslide. In Carter, N.L., Friedman, M., Logan, J.M., and Stearns, D.W. (Eds.), Mechanical Behavior of Crustal Rocks. Geophys. Monogr., 24:251-258. doi:10.1029/GM024p0251

Bond, G.C., and Lotti, R., 1995. Iceberg discharges into the North Atlantic on millennial time scales during the last glaciation. Science, 276(5200):1005-1010. doi:10.1126/ science.267.5200.1005

Bornemann, A., Schulte, P., Sprong, J., Steurbaut, E., Youssef, M., and Speijer, R.P., 2009. Latest Danian carbon isotope anomaly and associated environmental 
change in the southern Tethys (Nile Basin, Egypt). J. Geol. Soc. (London, U. K.), 166(6):1135-1142. doi:10.1144/0016-76492008-104

Boulila, S., Galbrun, B., Miller, K.G., Pekar, S.F., Browning, J.V., Laskar, J., and Wright, J.D., 2011. On the origin of Cenozoic and Mesozoic "third-order" eustatic sequences. Earth-Sci. Rev., 109(3-4):94•112. doi:10.1016/j.earscirev.2011.09.003

Bown, P., 2005a. Selective calcareous nannoplankton survivorship at the Cretaceous-Tertiary Boundary. Geology, 33(8):653-656. doi:10.1130/G21566.1

Bown, P.R., 2005b. Palaeogene calcareous microfossils from the Kilwa and Lindi areas of coastal Tanzania (Tanzania Drilling Project 2003-4). J. Nannoplankton Res., 27(1):21-95.

Bown, P.R., Dunkley Jones, T., Lees, J.A., Randell, R.D., Mizzi, J.A., Pearson, P.N., Coxall, H.K., Young, J.R., Nicholas, C.J., Karega, A., Singano, J., and Wade, B.S., 2008. A Paleogene calcareous microfossil KonservatLagerstätte from the Kilwa Group of coastal Tanzania. Geol. Soc. Am. Bull., 120(1-2):3-12. doi:10.1130/ B26261.1

Bralower, T.J., Premoli Silva, I., Malone, M.J., et al., 2002. Proc. ODP, Init. Repts., 198: College Station, TX (Ocean Drilling Program). doi:10.2973/odp.proc.ir.198.2002

Brass, G.W., Southam, J.R., and Peterson, W.H., 1982. Warm saline bottom water in the ancient ocean. Nature (London, U. K.), 296(5858):620-623. doi:10.1038/ 296620a0

Brassell, S.C., 1984. Aliphatic hydrocarbons of a Cretaceous black shale and its adjacent green claystone from the southern Angola Basin, Deep Sea Drilling Project, Leg 75. In Hay, W.W., Sibuet, J.C., et al., Init. Repts. DSDP, 75: Washington, DC (U.S. Govt. Printing Office), 1019-1030. doi:10.2973/dsdp.proc.75.133.1984

Brinkhuis, H., Schouten, S., Collinson, M.E., Sluijs, A., Sinninghe Damsté, J.S., Dickens, G.R., Huber, M., Cronin, T.M., Onodera, J., Takahashi, K., Bujak, J.P., Stein, R., van der Burgh, J., Eldrett, J.S., Harding, I.C., Lotter, A.F., Sangiorgi, F., van Konijnenburg-van Cittert, H., de Leeuw, J.W., Matthiessen, J., Backman, J., Moran, K., and the Expedition 302 Scientists, 2006. Episodic fresh surface waters in the Eocene Arctic Ocean. Nature (London, U. K.), 441(7093):606-609. doi:10.1038/ nature04692

Channell, J.E.T., Hodell, D.A., Romero, O., Hillaire-Marcel, C., de Vernal, A., Stoner, J.S., Mazaud, A., and Röhl, U., 2012. A 750-k.y. detrital-layer stratigraphy for the North Atlantic (IODP Sites U1302-U1303, Orphan Knoll, Labrador Sea). Earth Planet. Sci. Lett., 317-318:218-230. doi:10.1016/j.epsl.2011.11.029

Channell, J.E.T., Sato, T., Kanamatsu, T., Stein, R., and Alvarez Zarikian, C., 2010. Expediiton 303/306 synthesis: North Atlantic climate. In Channell, J.E.T., Kanamatsu, T., Sato, T., Stein, R., Alvarez Zarikian, C.A., Malone, M.J., and the Expedition 303/306 Scientists, Proc. IODP, 303/306: College Station, TX (Integrated Ocean Drilling Program Management International, Inc.). doi:10.2204/iodp.proc.303306.214.2010
Claeys, P., Kiessling, W., and Alvarez, W., 2002. Distribution of Chicxulub ejecta at the Cretaceous-Tertiary boundary. In Koeberl, C., and MacLeod, K.G. (Eds.), Catastrophic Events and Mass Extinctions: Impacts and Beyond. Spec. Pap.-Geol. Soc. Am., 356:55-68. doi:10.1130/08137-2356-6.55

Colosimo, A.B, Bralower, T.J., and Zachos, J.C., 2006. Evidence for lysocline shoaling at the Paleocene/Eocene Thermal Maximum on Shatsky Rise, northwest Pacific. In Bralower, T.J., Premoli Silva, I., and Malone, M.J. (Eds.), Proc. ODP, Sci. Results, 198: College Station, TX (Ocean Drilling Program), 1-36. doi:10.2973/ odp.proc.sr.198.112.2006

Coxall, H.K., D'Hondt, S., and Zachos, J.C., 2006. Pelagic evolution and environmental recovery after the Cretaceous-Paleogene mass extinction. Geology, 34(4):297300. doi:10.1130/G21702.1

Coxall, H.K., and Wilson, P.A., 2011. Early Oligocene glaciation and productivity in the eastern equatorial Pacific: insights into global carbon cycling. Paleoceanography, 26(2):PA2221. doi:10.1029/2010PA002021

Coxall, H.K., Wilson, P.A., Pälike, H., Lear, C.H., and Backman, J., 2005. Rapid stepwise onset of Antarctic glaciation and deeper calcite compensation in the Pacific Ocean. Nature (London, U. K.), 433(7021):53-57. doi:10.1038/nature03135

Cramer, B.S., Wright, J.D., Kent, D.V., and Aubry, M.-P., 2003. Orbital climate forcing of $\delta^{13} \mathrm{C}$ exursions in the late Paleocene-early Eocene (Chrons C24n-C25n). Paleoceanography, 18(4):1097-1122. doi:10.1029/ 2003PA000909

Curry, W.B., Shackleton, N.J., Richter, C., et al., 1995. Proc. ODP, Init. Repts., 154: College Station, TX (Ocean Drilling Program). doi:10.2973/odp.proc.ir.154.1995

Dahlen, F.A., Suppe, J., and Davis, D., 1984. Mechanics of fold-and-thrust belts and accretionary wedges: cohesive Coulomb theory. J. Geophys. Res.: Solid Earth, 89(B12):10087-10101. doi:10.1029/JB089iB12p10087

Dansgaard, W., Johnsen, S.J., Clausen, H.B., Dahl-Jensen, D., Gundestrup, N.S., Hammer, C.U., Hvidberg, C.S., Steffensen, J.P., Sveinbjörnsdottir, A.E., Jouzel, J., and Bond, G., 1993. Evidence for general instability of past climate from a 250-kyr ice-core record. Nature (London, U. K.), 364(6434):218-220. doi:10.1038/364218a0

Davies, R., Cartwright, J., Pike, J., and Line, C., 2001. Early Oligocene initiation of North Atlantic Deep Water formation. Nature (London, U. K.), 410(6831):917-920. doi:10.1038/35073551

Davis, D., Suppe, J., and Dahlen, F.A., 1983. Mechanics of fold-and-thrust belts and accretionary wedges. J. Geophys. Res.: Solid Earth, 88(B2):1153-1172. doi:10.1029/ JB088iB02p01153

Dean, W.E., and Arthur, M.A., 1987. Inorganic and organic geochemistry of Eocene to Cretaceous strata recovered from the lower continental rise, North American Basin, Site 603, Deep Sea Drilling Project Leg 93. Init. Repts. DSDP, 93: Washington, DC (U.S. Govt. Printing Office), 1093-1137. doi:10.2973/dsdp.proc.93.146.1987

de Graciansky, P.C., and Bourbon, M., 1985. The Goban Spur of the northeast-Atlantic margin during Late Cre- 
taceous times. In de Graciansky, P.C., Poag, C.W., et al., Init. Repts. DSDP, 80: Washington, DC (U.S. Govt. Printing Office), 863-883. doi:10.2973/

dsdp.proc.80.137.1985

DeConto, R.M., Galeotti, S., Pagani, M., Tracy, D., Schafer, K., Zhang, T., Pollard, D., and Beerling, D.J., 2012. Past extreme warming events linked to massive carbon release from thawing permafrost. Nature (London, U. K.), 484(7392):87-91. doi:10.1038/nature10929

DeConto, R.M., and Pollard, D., 2003. Rapid Cenozoic glaciation of Antarctica induced by declining atmospheric $\mathrm{CO}_{2}$. Nature (London, U. K.), 421(6920):245-249. doi:10.1038/nature01290

DeConto, R.M., Pollard, D., Wilson, P.A., Palike, H., Lear, C.H., and Pagani, M., 2008. Thresholds for Cenozoic bipolar glaciation. Nature (London, U. K.), 455(7213):652-656. doi:10.1038/nature07337

D'Hondt, S., 2005. Consequences of the Cretaceous/Paleogene mass extinction for marine ecosystems. Annu. Rev. Ecol. Evol. Syst., 36(1):295-317. doi:10.1146/ annurev.ecolsys.35.021103.105715

Dickens, G.R., 2011. Down the rabbit hole: toward appropriate discussion of methane hydrate release from gas hydrate systems during the Paleocene/Eocene Thermal Maximum and other past hydrothermal events. Clim. Past, 7(3):831-846. doi:10.5194/cp-7-831-2011

Dickens, G.R., Castillo, M.M., and Walker, J.C.G., 1997. A blast of gas in the latest Paleocene: simulating firstorder effects of massive dissociation of oceanic methane hydrate. Geology, 25(3):259-262. doi:10.1130/00917613(1997)025<0259:ABOGIT>2.3.CO;2

Dillon, W.P., Nealon, J.W., Taylor, M.H., Lee, M.W., Drury, R.M., and Anton, C.H., 2000. Seafloor collapse and methane venting associated with gas hydrate on the Blake Ridge: causes and implications to seafloor stability and methane release. In Paull, C.K., and Dillon, W.P. (Eds.), Natural Gas Hydrates: Occurrence, Distribution, and Detection. Geophys. Monogr., 124:211-233. doi:10.1029/GM124p0211

Dugan, B., and Flemings, P.B., 2000. Overpressure and fluid flow in the New Jersey continental slope: implications for slope failure and cold seeps. Science, 289(5477):288-291. doi:10.1126/science.289.5477.288

Dugan, B., and Flemings, P.B., 2002. Fluid flow and stability of the US continental slope offshore New Jersey from the Pleistocene to the present. Geofluids, 2(2):137-146. doi:10.1046/j.1468-8123.2002.00032.x

Dunkley Jones, T., Bown, P.R., and Pearson, P.N., 2009. Exceptionally well preserved upper Eocene to lower Oligocene calcareous nannofossils (Prymnesiophycidae) from the Pande Formation (Kilwa Group), Tanzania. J. Syst. Palaeontol., 7(4):359-411. doi:10.1017/ S1477201909990010

Dunkley Jones, T., Bown, P.R., Pearson, P.N., Wade, B.S., Coxall, H.K., and Lear, C.H. 2008. Major shifts in calcareous phytoplankton assemblages through the EoceneOligocene transition of Tanzania and their implications for low-latitude primary production. Paleoceanography, 23(4):PA4204. doi:10.1029/2008PA001640
Dunkley Jones T., Ridgwell A., Lunt, D.J., Maslin, M.A., Schmidt, D.N., and Valdes, P.J., 2010. A Palaeogene perspective on climate sensitivity and methane hydrate instability. Philos. Trans. R. Soc., A, 368(1919):23952415. doi:10.1098/rsta.2010.0053

Edgar, K.M., Wilson, P.A., Sexton, P.F., Gibbs, S.J., Roberts, A.P., and Norris, R.D., 2010. New biostratigraphic, magnetostratigraphic and isotopic insights into the Middle Eocene Climatic Optimum in low latitudes. Palaeogeogr., Palaeoclimatol., Palaeoecol., 297(3-4):670-682. doi:10.1016/j.palaeo.2010.09.016

Edgar, K.M., Wilson, P.A., Sexton, P.F., and Suganuma, Y., 2007. No extreme bipolar glaciation during the main Eocene calcite compensation shift. Nature (London, $U$. K.), 448(7156):908-911. doi:10.1038/nature06053

Eldrett, J.S., Greenwood, D.R., Harding, I.C., and Huber, M., 2009. Increased seasonality through the Eocene to Oligocene transition in northern high latitudes. Nature (London, U. K.), 459(7249):969-973. doi:10.1038/ nature08069

Eldrett, J.S., Harding, I.C., Wilson, P.A., Butler, E., and Roberts, A.P., 2007. Continental ice in Greenland during the Eocene and Oligocene. Nature (London, U. K.), 446(7132):176-179. doi:10.1038/nature05591

Erbacher, J., Friedrich, O., Wilson, P.A., Birch, H., and Mutterlose, J., 2005. Stable organic carbon isotope stratigraphy across oceanic anoxic Event 2 of Demerara Rise, western tropical Atlantic. Geochem., Geophys., Geosyst., 6(6):Q06010. doi:10.1029/2004GC000850

Erbacher, J., Mosher, D.C., Malone, M.J., et al., 2004. Proc. ODP, Init. Repts., 207: College Station, TX (Ocean Drilling Program). doi:10.2973/odp.proc.ir.207.2004

Fagel, N., Robert, C., and Hillaire-Marcel, C., 1996. Clay mineral signature of the NW Atlantic boundary undercurrent. Mar. Geol., 130(1-2):19-28. doi:10.1016/00253227(95)00134-4

Fagel, N., Robert, C., Preda, M., and Thorez, J., 2001. Smectite composition as a tracer of deep circulation: the case of the northern North Atlantic. Mar. Geol., 172(34):309-330. doi:10.1016/S0025-3227(00)00123-7

Farley, K.A., and Eltgroth, S.F., 2003. An alternative age model for the Paleocene/Eocene Thermal Maximum using extraterrestrial ${ }^{3}$ He. Earth Planet. Sci. Lett., 208(34):135-148. doi:10.1016/S0012-821X(03)00017-7

Fisher, A.T., Wheat, C.G., Becker, K., Davis, E.E., Jannasch, H., Schroeder, D., Dixon, R., Pettigrew, T.L., Meldrum, R., McDonald, R., Nielsen, M., Fisk, M., Cowen, J., Bach, W., and Edwards, K., 2005. Scientific and technical design and deployment of long-term subseafloor observatories for hydrogeologic and related experiments, IODP Expedition 301, eastern flank of Juan de Fuca Ridge. In Fisher, A.T., Urabe, T., Klaus, A., and the Expedition 301 Scientists, Proc. IODP, 301: College Station, TX (Integrated Ocean Drilling Program Management International, Inc.). doi:10.2204/ iodp.proc.301.103.2005

Flemings, P.B., Long, H., Dugan, B., Germaine, J., John, C.M., Behrmann, J.H., Sawyer, D., and IODP Expedition 308 Scientists, 2008. Pore pressure penetrometers document high overpressure near the seafloor where multi- 
ple submarine landslides have occurred on the continental slope, offshore Louisiana, Gulf of Mexico. Earth Planet. Sci. Lett., 269(3-4):309-325. doi:10.1016/ j.epsl.2007.12.005

Flower, B.P., Zachos, J.C., and Martin, E., 1997. Latest Oligocene through early Miocene isotopic stratigraphy and deep-water paleoceanography of the western equatorial Atlantic: Sites 926 and 929. In Shackleton, N.J., Curry, W.B., Richter, C., and Bralower, T.J. (Eds.), Proc. ODP, Sci. Results, 154: College Station, TX (Ocean Drilling Program), 451-461. doi:10.2973/ odp.proc.sr.154.142.1997

Folk, R.L., 1959. Practical petrographical classification of limestones. AAPG Bull., 43(1):1-38. http://aapgbull.geoscienceworld.org/content/43/1/1.abstract

Frank, T.D., and Arthur, M.A., 1999. Tectonic forcings of Maastrichtian ocean-climate evolution. Paleoceanography, 14(2):103-117. doi:10.1029/1998PA900017

Frank, T.D., Thomas, D.J., Leckie, R.M., Arthur, M.A., Bown, P.R., Jones, K., and Lees, J.A., 2005. The Maastrichtian record from Shatsky Rise (northwest Pacific): a tropical perspective on global ecological and oceanographic changes. Paleoceanography, 20:PA1008. doi:10.1029/2004PA001052

Friedrich, O., Erbacher, J., Moriya, K., Wilson, P.A., and Kuhnert, H., 2008. Warm saline intermediate waters in the Cretaceous tropical Atlantic Ocean. Nat. Geosci., 1(7):453-457. doi:10.1038/ngeo217

Friedrich, O., Herrle, J.O., Wilson, P.A., Cooper, M.J., Erbacher, J., and Hemleben, C., 2009. Early Maastrichtian carbon cycle perturbation and cooling event: implications from the South Atlantic Ocean. Paleoceanography, 24(2):PA2211. doi:10.1029/ 2008PA001654

Friedrich, O., Norris, R.D., and Erbacher, J., 2012. Evolution of middle to Late Cretaceous oceans-a 55 m.y. record of Earth's temperature and carbon cycle. Geology, 40(2):107-110. doi:10.1130/G32701.1

Fuqua, L.M., Bralower, T.J., Arthur, M.A., and Patzkowsky, M.E., 2008. Evolution of calcareous nannoplankton and the recovery of marine food webs after the CretaceousPaleocene mass extinction. Palaios, 23(4):185-194. doi:10.2110/palo.2007.p07-004r

Galeotti, S., Krishnan, S., Pagani, M., Lanci, L., Gaudio, A., Zachos, J.C., Monechi, S., Morelli, G., and Lourens, L., 2010. Orbital chronology of early Eocene hyperthermals from the Contessa Road section, central Italy. Earth Planet. Sci. Lett., 290(1-2):192-200. doi:10.1016/ j.epsl.2009.12.021

Gersonde, R., Hodell, D.A., Blum, P., et al., 1999. Proc. ODP, Init. Repts., 177: College Station, TX (Ocean Drilling Program). doi:10.2973/odp.proc.ir.177.1999

Gibbs, S.J., Bown, P.R., Sessa, J.A., Bralower, T.J., and Wilson, P.A., 2006. Nannoplankton extinction and origination across the Paleocene-Eocene Thermal Maximum. Science, 314(5806):1770-1773. doi:10.1126/science. 1133902

Goodwin, P., Williams, R.G., Ridgwell, A., and Follows, M.J., 2009. Climate sensitivity to the carbon cycle mod- ulated by past and future changes in ocean chemistry. Nat. Geosci., 2(2):145-150. doi:10.1038/ngeo416

Gradstein, F.M., Ogg, J.G., Schmitz, M.D., and Ogg, G.M. (Eds)., 2012. The Geological Time Scale 2012: Amsterdam (Elsevier).

Griffith, E., Calhoun, M., Thomas, E., Averyt, K., Erhardt, A., Bralower, T., Lyle, M., Olivarez-Lyle, A., and Paytan, A., 2010. Export productivity and carbonate accumulation in the Pacific Basin at the transition from a greenhouse to icehouse climate (late Eocene to early Oligocene). Paleoceanography, 25(3):PA3212. doi:10.1029/2010PA001932

Haneberg, W.C., 1995. Groundwater flow and the stability of heterogeneous infinite slopes underlain by impervious substrata. In Haneberg, W.C., and Anderson, S.A. (Eds.), Clay and Shale Slope Instability. Rev. Eng. Geol., 10:63-78.

Hardas, P., and Mutterlose, J., 2006. Calcareous nannofossil biostratigraphy of the Cenomanian/Turonian boundary interval of ODP Leg 207 at the Demerara rise. In Erbacher, J., Danelian, T., and Nishi, H. (Eds.), Demerara Rise (Leg 207): Equatorial Cretaceous and Palaeogene Stratigraphy and Paleoceanography, Part I. Rev. Micropaleontol., 49(3):165-179. doi:10.1016/j.revmic.2006.04.005

Hayes, J.M., 1993. Factors controlling ${ }^{13} \mathrm{C}$ contents of sedimentary organic compounds: principles and evidence. Mar. Geol., 113(1-2):111-125. doi:10.1016/ 0025-3227(93)90153-M

Haywood, A.M., Ridgwell, A., Lunt, D.J., Hill, D.J., Pound, M.J., Dowsett, H.J., Dolan, A.M., Francis, J.E., and Williams, M., 2011. Are there pre-Quaternary geological analogues for a future greenhouse warming? Philos. Trans. R. Soc., A, 369(1938):933-956. doi:10.1098/ rsta.2010.0317

Heinze, C., Maier-Reimer, E., Winguth, A.M.E., and Archer, D., 1999. A global oceanic sediment model for longterm climate studies. Global Biogeochem. Cycles, 13(1):221-250. doi:10.1029/98GB02812

Hemming, S.R., Broecker, W.S., Sharp, W.D., Bond, G.C., Gwiazda, R.H., McManus, J.F., Klas, M., and Hajdas, I., 1998. Provenance of Heinrich layers in core V28-82, northeastern Atlantic: ${ }^{40} \mathrm{Ar} /{ }^{39} \mathrm{Ar}$ ages of ice-rafted hornblende, $\mathrm{Pb}$ isotopes in feldspar grains, and $\mathrm{Nd}-\mathrm{Sr}-\mathrm{Pb}$ isotopes in the fine sediment fraction. Earth Planet. Sci. Lett., 164(1-2):317-333. doi:10.1016/S0012821X(98)00224-6

Higgins, J.A., and Schrag, D.P., 2006. Beyond methane: towards a theory for the Paleocene-Eocene Thermal Maximum. Earth Planet. Sci. Lett., 245(3-4):523-537. doi:10.1016/j.epsl.2006.03.009

Hildebrand, A.R., Penfield, G.T., Kring, D.A., Pilkington, M., Camargo, A.Z., Jacobsen, S.B., and Boynton, W.V., 1991. Chicxulub crater: a possible Cretaceous/Tertiary boundary impact crater on the Yucatán Peninsula, Mexico. Geology, 19(9):867-871. doi:10.1130/ 0091-7613(1991)019<0867:CCAPCT >2.3.CO;2

Hilting, A.K., Kump, L.R., and Bralower, T.J., 2008. Variations in the oceanic vertical carbon isotope gradient and their implications for the Paleocene-Eocene biolog- 
ical pump. Paleoceanography, 23(3):PA3222. doi:10.1029/2007PA001458

Hohbein, M.W., Sexton, P.F., and Cartwright, J.A., 2012. Onset of North Atlantic Deep Water production coincident with inception of the Cenozoic global cooling trend. Geology, 40(3):255-258. doi:10.1130/G32461.1

Hollis, C.J., Rodgers, K.A., and Parker, R.J., 1995. Siliceous plankton bloom in the earliest Tertiary of Marlborough, New Zealand. Geology, 23(9):835-838. doi:10.1130/ 0091-7613(1995)023<0835:SPBITE $>2.3$. CO;2

Huber, B.T., 1996. Evidence for planktonic foraminifer reworking versus survivorship across the CretaceousTertiary boundary at high latitudes. In Ryder, G., Fastovsky, D.E., and Gartner, S. (Eds.), The Cretaceous-Tertiary Event and Other Catastrophes in Earth History. Spec. Pap.-Geol. Soc. Am., 307:319-334. doi:10.1130/08137-2307-8.319

Huber, B.T., Liu, C., Olsson, R.K., and Berggren, W.A., 1994. Comment on "The Cretaceous-Tertiary boundary transition in the Antarctic Ocean and its global implications," by G. Keller. Mar. Micropaleontol., 24(2):91-99. doi:10.1016/0377-8398(94)90017-5

Huber, B.T., Norris, R.D., and MacLeod, K.G., 2002. Deep sea paleotemperature record of extreme warmth during the Cretaceous. Geology, 30(2):123-126. doi:10.1130/ 0091-7613(2002)030<0123:DSPROE >2.0.CO;2

Hull, P.M., Franks, P.J.S., and Norris, R.D., 2011a. Mechanisms and models of iridium anomaly shape across the Cretaceous-Paleogene boundary. Earth Planet. Sci. Lett., 301(1-2):98-106. doi:10.1016/j.epsl.2010.10.031

Hull, P.M., and Norris, R.D., 2011. Diverse patterns of ocean export productivity change across the Cretaceous-Paleogene boundary: new insights from biogenic barium. Paleoceanography, 26(3):PA3205. doi:10.1029/ 2010PA002082

Hull, P.M., Norris, R.D., Bralower, T.J., and Schueth, J.D., $2011 b$. A role for chance in marine recovery from the end-Cretaceous extinction. Nat. Geosci., 4(12):856-860. doi:10.1038/ngeo1302

Hutchinson, D.R., Poag, C.W., and Popenoe, P., 1995. Geophysical database of the east coast of the United States: southern Atlantic margin-stratigraphy and velocity from multichannel seismic profiles. Open-File Rep.-U.S. Geol. Surv., 95-27.

Hyndman, R.D., and Davis, E.E., 1992. A mechanism for the formation of methane hydrate and seafloor bottomsimulating reflectors by vertical fluid expulsion. J. Geophys. Res.: Solid Earth, 97(B5):7025-7041. doi:10.1029/ 91JB03061

Innocent, C., Fagel, N., and Hillaire-Marcel, C., 2000. Sm$\mathrm{Nd}$ isotope systematics in deep-sea sediments: clay-size versus coarser fractions. Mar. Geol., 168(1-4):79-87. doi:10.1016/S0025-3227(00)00052-9

Jenkyns, H.C., 2010. Geochemistry of oceanic anoxic events. Geochem., Geophys., Geosyst., 11(3):Q03004. doi:10.1029/2009GC002788

Jenkyns, H.C., Matthews, A., Tsikos, H., and Erel, Y., 2007. Nitrate reduction, sulfate reduction, and sedimentary iron isotope evolution during the Cenomanian-Turo- nian oceanic anoxic event. Paleoceanography, 22(3):PA3208. doi:10.1029/2006PA001355

Jiang, S., Bralower, T.J., Patzkowsky, M.E., Kump, L.R., and Schueth, J.D., 2010. Geographic controls on nannoplankton extinction across the Cretaceous/Palaeogene boundary. Nat. Geosci., 3(4):280-285. doi:10.1038/ ngeo775

Junium, C.K., and Arthur, M.A., 2007. Nitrogen cycling during the Cretaceous, Cenomanian-Turonian oceanic anoxic Event II. Geochem., Geophys., Geosyst., 8(3):Q03002. doi:10.1029/2006GC001328

Kamikuri, S., Moore, T.C., Ogane, K., Suzuki, N., Pälike, H., and Nishi, H., 2012. Early Eocene to early Miocene radiolarian biostratigraphy for the low-latitude Pacific Ocean. Stratigraphy, 9(1):77-108. http://www.micropress.org/micropen $2 /$ articles/1/7/ 27546_articles_article_file_1785.pdf

Katz, M.E., Pak, D.K., Dickens, G.R., and Miller, K.G., 1999. The source and fate of massive carbon input during the latest Paleocene thermal maximum. Science, 286(5444):1531-1533. doi:10.1126/science.286.5444.1531

Keeling, R.F., and Stephens, B.B., 2001. Antarctic sea ice and the control of Pleistocene climate instability. Paleoceanography, 16(1):112-131. doi:10.1029/ 2000PA000529

Keller, G., 1993. The Cretaceous-Tertiary boundary transition in the Antarctic Ocean and its global implications. Mar. Micropaleontol., 21(1-3):1-45. doi:10.1016/03778398(93)90010-U

Kelly, D.C., Nielsen, T.M.J., McCarren, H.K., Zachos, J.C., and Röhl, U., 2010. Spatiotemporal patterns of carbonate sedimentation in the South Atlantic: implications for carbon cycling during the Paleocene-Eocene Thermal Maximum. Palaeogeogr., Palaeoclimatol., Palaeoecol., 293(1-2):30-40. doi:10.1016/j.palaeo.2010.04.027

Kent, D.V., Cramer, B.S., Lanci, L., Wang, D., Wright, J.D., and Van der Voo, R., 2003. A case for a comet impact trigger for the Paleocene/Eocene Thermal Maximum and carbon isotope excursion. Earth Planet. Sci. Lett., 211(1-2):13-26. doi:10.1016/S0012-821X(03)00188-2

Kirschvink, J.L., 1980. The least-squares line and plane and the analysis of palaeomagnetic data. Geophys. J. R. Astron. Soc., 62(3):699-718. doi:10.1111/j.1365246X.1980.tb02601.x

Koch, M.C., and Friedrich, O., 2012. Campanian-Maastrichtian intermediate to deep-water changes in the high latitudes: benthic foraminiferal evidence. Paleoceanography, 27(2):PA2209. doi:10.1029/ 2011PA002259

Kuroda, J., Ogawa, N.O., Tanimizu, M., Coffin, M.F., Tokuyama, H., Kitazato, H., and Ohkouchi, N., 2007. Contemporaneous massive subaerial volcanism and Late Cretaceous oceanic anoxic Event 2. Earth Planet. Sci. Lett., 256(1-2):211-223. doi:10.1016/ j.epsl.2007.01.027

Kurtz, A.C., Kump, L.R., Arthur, M.A., Zachos, J.C., and Paytan, A., 2003. Early Cenozoic decoupling of the global carbon and sulfur cycles. Paleoceanography, 18:1090. doi:10.1029/2003PA000908 
Kuypers, M.M.M., van Breugel, Y., Schouten, S., Erba, E., and Sinninghe Damsté, J.S., 2004. $\mathrm{N}_{2}$-fixing cyanobacteria supplied nutrient $\mathrm{N}$ for Cretaceous oceanic anoxic events. Geology, 32:853-856. doi:10.1130/G20458.1

Kvenvolden, K.A., 1993. Gas hydrates-geological perspective and global change. Rev. Geophys., 31(2):173-187. doi:10.1029/93RG00268

Larsen, H.C., Saunders, A.D., Clift, P.D., Beget, J., Wei, W., Spezzaferri, S., and ODP Leg 152 Scientific Party, 1994. Seven million years of glaciation in Greenland. Science, 264(5161):952-955. doi:10.1126/science.264.5161.952

Laskar, J., Robutel, P., Joutel, F., Gastineau, M., Correia, A.C.M., and Levrard, B., 2004. A long-term numerical solution for the insolation quantities of the Earth. Astron. Astrophys., 428(1):261-285. doi:10.1051/ 0004-6361:20041335

Lear, C.H., Bailey, T.R., Pearson, P.N., Coxall, H.K., and Rosenthal, Y., 2008. Cooling and ice growth across the Eocene-Oligocene transition. Geology, 36(3):251-254. doi:10.1130/G24584A.1

Lear, C.H., Elderfield, H., and Wilson, P.A., 2000. Cenozoic deep-sea temperatures and global ice volumes from $\mathrm{Mg}$ / $\mathrm{Ca}$ in benthic foraminiferal calcite. Science, 287(5451):269-272. doi:10.1126/science.287.5451.269

Lear, C.H., Rosenthal, Y., Coxall, H.K., and Wilson, P.A., 2004. Late Eocene to early Miocene ice sheet dynamics and the global carbon cycle. Paleoceanography, 19(4):PA4015-PA4025. doi:10.1029/2004PA001039

Leckie, R.M., Bralower, T.J., and Cashman, R., 2002. Oceanic anoxic events and plankton evolution: biotic response to tectonic forcing during the mid-Cretaceous. Paleoceanography, 17(3):1041. doi:10.1029/ 2001PA000623

Leon-Rodriguez, L., and Dickens, G.R., 2010. Constraints on ocean acidification associated with rapid and massive carbon injections: the early Paleogene record at Ocean Drilling Program Site 1215, equatorial Pacific Ocean. Palaeogeogr., Palaeoclimatol., Palaeoecol., 298(34):409-420. doi:10.1016/j.palaeo.2010.10.029

Liebrand, D., Lourens, L.J., Hodell, D.A., de Boer, B., van de Wal, R.S.W., and Pälike, H., 2011. Antarctic ice sheet and oceanographic response to eccentricity forcing during the early Miocene. Clim. Past, 7(3):869-880. doi:10.5194/cp-7-869-2011

Lisiecki, L.E., and Raymo, M.E., 2005. A Pliocene-Pleistocene stack of 57 globally distributed benthic $\delta^{18} \mathrm{O}$ records. Paleoceanography, 20(1):PA1003. doi:10.1029/ 2004PA001071

Liu, X., and Flemings, P., 2009. Dynamic response of oceanic hydrates to sea level drop. Geophys. Res. Lett., 36(17):L17308. doi:10.1029/2009GL039821

Liu, Z., Pagani, M., Zinniker, D., DeConto, R., Huber, M., Brinkhuis, H., Shah, S.R., Leckie, R.M., and Pearson, A., 2009. Global cooling during the Eocene-Oligocene climate transition. Science, 323(5918):1187-1190. doi:10.1126/science.1166368

Lourens, L., Hilgen, F., Shackleton, N.J., Laskar, J., and Wilson, D., 2004. The Neogene period. In Gradstein, F.M.,
Ogg, J.G., and Smith, A. (Eds.), A Geologic Time Scale 2004: Cambridge (Cambridge Univ. Press), 409-440.

Lourens, L.J., Sluijs, A., Kroon, D., Zachos, J.C., Thomas, E., Röhl, U., Bowles, J., and Raffi, I., 2005. Astronomical pacing of late Palaeocene to early Eocene global warming events. Nature (London, U. K.), 435(7045):10831087. doi:10.1038/nature03814

Lyle, M., Olivarez Lyle, A., Backman, J., and Tripati, A., 2005. Biogenic sedimentation in the Eocene equatorial Pacific-the stuttering greenhouse and Eocene carbonate compensation depth. In Lyle, M., Wilson, P.A., Janecek, T.R., et al., Proc. ODP, Init. Repts., 199: College Station, TX (Ocean Drilling Program), 1-35. doi:10.2973/odp.proc.sr.199.219.2005

Lyle, M., Wilson, P.A., Janecek, T.R., et al., 2002. Proc. ODP, Init. Repts., 199: College Station, TX (Ocean Drilling Program). doi:10.2973/odp.proc.ir.199.2002

MacLeod, K.G., Londoño, C.I., Martin, E.E., Jiménez Berrocoso, Á., and Basak, C., 2011. Changes in North Atlantic circulation at the end of the Cretaceous greenhouse interval. Nat. Geosci., 4(11):779-782. doi:10.1038/ ngeo1284

MacLeod, K.G., Martin, E.E., and Blair, S.W., 2008. Nd isotopic excursion across Cretaceous oceanic anoxic Event 2 (Cenomanian-Turonian) in the tropical North Atlantic. Geology, 36(10):811-814. doi:10.1130/G24999A.1

Marotzke, J., and Willebrand, J., 1991. Multiple equilibria of the global thermohaline circulation, J. Phys. Oceanogr., 21(9):1372-1385. doi:10.1175/15200485(1991)021<1372:MEOTGT>2.0.CO;2

Martin, E.E., MacLeod, K.G., Jiménez Berrocoso, A., and Bourbon, E., 2012. Water mass circulation on Demerara Rise during the Late Cretaceous based on Nd isotopes. Earth Planet. Sci. Lett., 327-328:111-120. doi:10.1016/ j.epsl.2012.01.037

Martini, E., 1971. Standard Tertiary and Quaternary calcareous nannoplankton zonation. In Farinacci, A. (Ed.), Proc. Second Planktonic Conf. Roma 1970: Rome (Ed. Tecnosci.), 2:739-785.

McGowran, B., 1989. Silica burp in the Eocene ocean. Geology, 17(9):857-860. doi:10.1130/

0091-7613(1989)017<0857:SBITEO >2.3.CO;2

Meinen, C.S., and Watts, D.R., 2000. Vertical structure and transport on a transect across the North Atlantic Current near $42^{\circ} \mathrm{N}$ : time series and mean. J. Geophys. Res.: Oceans, 105(C9):21869-21891. doi:10.1029/ 2000JC900097

Merico, A., Tyrrell, T., and Wilson, P.A., 2008. Eocene/Oligocene ocean de-acidification linked to Antarctic glaciation by sea-level fall. Nature (London, U. K.), 452(7190):979-982. doi:10.1038/nature06853

Michel, H.V., Asaro, F., Alvarez, W., and Alvarez, L.W., 1981. Distribution of iridium and other elements near the Cretaceous/Tertiary boundary in Hole 465A: preliminary results. In Thiede, J., and Vallier, T.L., et al., Init. Repts. DSDP, 62: Washington, DC (U.S. Govt. Printing Office), 847-849. doi:10.2973/dsdp.proc.62.139.1981

Michel, H.V., Asaro, F., Alvarez, W., and Alvarez, L.W., 1985. Elemental profile of iridium and other elements near the Cretaceous/Tertiary boundary in Hole 577B. In 
Heath, G.R., Burckle, L.H., et al., Init. Repts. DSDP, 86: Washington, DC (U.S. Govt. Printing Office), 533-538. doi:10.2973/dsdp.proc.86.121.1985

Miller, K.G., and Fairbanks, R.G., 1985. Oligocene to Miocene carbon isotope cycles and abyssal circulation changes. In Sundquist, E.J., and Broecker, W.S. (Eds.), The Carbon Cycle and Atmospheric $\mathrm{CO}_{2}$ : Natural Variations Archean to Present. Geophys. Monogr., 32:469-486. doi:10.1029/GM032p0469

Miller, K.G., Fairbanks, R.G., and Mountain, G.S., 1987. Tertiary oxygen isotope synthesis, sea level history, and continental margin erosion. Paleoceanography, 2(1):119. doi:10.1029/PA002i001p00001

Miller, K.G., Sugarman, P.J., Browning, J.V., Kominz, M.A., Hernández, J.C., Olsson, R.K., Wright, J.D., Feigenson, M.D., and Van Sickel, W., 2003. Late Cretaceous chronology of large, rapid sea-level changes: glacioeustasy during the greenhouse world. Geology, 31(7):585-588. doi:10.1130/ 0091-7613(2003)031<0585:LCCOLR>2.0.CO;2

Miller, K.G., Wright, J.D., and Browning, J.V., 2005. Visions of ice sheets in a greenhouse world. In de la Rocha, C.L., and Paytan, A. (Eds.), Ocean Chemistry over the Phanerozoic and its Links to Geological Processes. Mar. Geol., 217(3-4):215-231. doi:10.1016/j.margeo.2005.02.007

Miller, K.G., Wright, J.D., and Fairbanks, R.G., 1991. Unlocking the ice house: Oligocene-Miocene oxygen isotopes, eustasy, and margin erosion. J. Geophys. Res.: Solid Earth, 96(B4):6829-6848. doi:10.1029/90JB02015

Moran, K., Backman, J., Brinkhuis, H., Clemens, S.C., Cronin, T., Dickens, G.R., Eynaud, F., Gattacceca, J., Jakobsson, M., Jordan, R.W., Kaminski, M., King, J., Koc, N., Krylov, A., Martinez, N., Matthiessen, J., McInroy, D., Moore, T.C., Onodera, J., O’Regan, M., Pälike, H., Rea, B., Rio, D., Sakamoto, T., Smith, D.C., Stein, R., St. John, K., Suto, I., Suzuki, N., Takahashi, K., Watanabe, M., Yamamoto, M., Farrell, J., Frank, M., Kubik, P., Jokat, W., and Kristoffersen, Y., 2006. The Cenozoic palaeoenvironment of the Arctic Ocean. Nature (London, U. K.), 441(7093):601-605. doi:10.1038/nature04800

Morgan, J., Warner, M., the Chicxulub Working Group, Brittan, J., Buffler, R., Carmargo, A., Christeson, G., Denton, P., Hildebrand, A., Hobbs, R., Macintyre, H., Mackenzie, G., Maguire, P., Marin, L., Nakamura, Y., Pilkington, M., Sharpton, V., Snyder, D., Suarez, G., and Trejo, A., 1997. Size and morphology of the Chicxulub impact crater. Nature (London, U. K.), 390(6659):472476. doi:10.1038/37291

Mort, H.P., Adatte, T., Föllmi, K.B., Keller, G., Steinmann, P., Matera, V., Berner, Z., and Stüben, D., 2007. Phosphorus and the roles of productivity and nutrient recycling during oceanic anoxic Event 2. Geology, 35(6):483486. doi:10.1130/G23475A.1

Mountain, G.S., and Miller, K.G., 1992. Seismic and geologic evidence for early Paleogene deepwater circulation in the western North Atlantic. Paleoceanography, 7(4):423-439. doi:10.1029/92PA01268

Mountain, G.S., and Tucholke, B.E., 1985. Mesozoic and Cenozoic geology of the U.S. Atlantic continental slope and rise. In Poag, C.W. (Ed.), Geologic Evolution of the
United States Atlantic Margin: New York (Van Nostrand Reinhold), 293-341.

Muttoni, G., and Kent, D.V., 2007. Widespread formation of cherts during the early Eocene climatic optimum. Palaeogeogr., Paleoclimatol., Palaeoecol., 253(3-4):348362. doi:10.1016/j.palaeo.2007.06.008

National Research Council, 2011. Understanding Earth's Deep Past: Lessons for Our Climate Future: Washington DC (National Academies Press).

Norris, R.D., 1996. Symbiosis as an evolutionary innovation in the radiation of Paleocene planktic foraminifera. Paleobiology, 22(4):461-480. http://www.jstor.org/stable $/ 2401200$

Norris, R.D., 2001. Impact of K-T boundary events on marine life. In Briggs, D.E.G., and Crowther, P.R. (Eds.), Palaeobiology II: Oxford (Blackwell Science Ltd.), 229231. doi:10.1002/9780470999295.ch49

Norris, R.D., Huber, B.T., and Self-Trail, J., 1999. Synchroneity of the K-T oceanic mass extinction and meteorite impact: Blake Nose, western North Atlantic. Geology, 27(5):419-422. doi:10.1130/00917613(1999)027<0419:SOTKTO>2.3.CO;2

Norris, R.D., Klaus, A., and Kroon, D., 2001a. Mid-Eocene deep water, the Late Palaeocene Thermal Maximum and continental slope mass wasting during the CretaceousPalaeogene impact. In Kroon, D., Norris, R.D., and Klaus, A. (Eds.), Western North Atlantic Paleogene and Cretaceous Paleoceanography. Geol. Soc. Spec. Publ., 183(1):23-48. doi:10.1144/GSL.SP.2001.183.01.02

Norris, R.D., Kroon, D., Huber, B.T., and Erbacher, J., 2001b. Cretaceous-Palaeogene ocean and climate change in the subtropical North Atlantic. In Kroon, D., Norris, R.D., and Klaus, A. (Eds.), Western North Atlantic Paleogene and Cretaceous Paleoceanography, Geol. Soc. Spec. Publ., 183(1):1-22. doi:10.1144/ GSL.SP.2001.183.01.01

Norris, R.D., Kroon, D., Klaus, A., et al., 1998. Proc. ODP, Init. Repts., 171B: College Station, TX (Ocean Drilling Program). doi:10.2973/odp.proc.ir.171B.1998

Norris, R.D., and Röhl, U., 1999. Carbon cycling and chronology of climate warming during the Palaeocene/ Eocene transition. Nature (London, U. K.), 401(6755):775-778. doi:10.1038/44545

Norris, R.D., and Wilson, P.A., 1998. Low-latitude sea-surface temperatures for the mid-Cretaceous and the evolution of planktic foraminifera. Geology, 26(9):823-826. doi:10.1130/00917613(1998)026<0823:LLSSTF >2.3.CO;2

Norris, R.D., Wilson, P.A., Blum, P., Fehr, A., Agnini, C., Bornemann, A., Boulila, S., Bown, P.R., Cournede, C., Friedrich, O., Ghosh, A.K., Hollis, C.J., Hull, P.M., Jo, K., Junium, C.K., Kaneko, M., Liebrand, D., Lippert, P.C., Liu, Z., Matsui, H., Moriya, K., Nishi, H., Opdyke, B.N., Penman, D., Romans, B., Scher, H.D., Sexton, P., Takagi, H., Turner, S.K., Whiteside, J.H., Yamaguchi, T., and Yamamoto, Y., 2014a. Site U1403. In Norris, R.D., Wilson, P.A., Blum, P., and the Expedition 342 Scientists, Proc. IODP, 342: College Station, TX (Integrated Ocean Drilling Program). doi:10.2204/ iodp.proc.342.104.2014 
Norris, R.D., Wilson, P.A., Blum, P., Fehr, A., Agnini, C., Bornemann, A., Boulila, S., Bown, P.R., Cournede, C., Friedrich, O., Ghosh, A.K., Hollis, C.J., Hull, P.M., Jo, K., Junium, C.K., Kaneko, M., Liebrand, D., Lippert, P.C., Liu, Z., Matsui, H., Moriya, K., Nishi, H., Opdyke, B.N., Penman, D., Romans, B., Scher, H.D., Sexton, P., Takagi, H., Turner, S.K., Whiteside, J.H., Yamaguchi, T., and Yamamoto, Y., 2014b. Site U1411. In Norris, R.D., Wilson, P.A., Blum, P., and the Expedition 342 Scientists, Proc. IODP, 342: College Station, TX (Integrated Ocean Drilling Program). doi:10.2204/

iodp.proc.342.112.2014

Nuñes, F., and Norris, R.D., 2006. Abrupt reversal in ocean overturning during the Palaeocene/Eocene warm period. Nature (London, U. K.), 439(7072):60-63. doi:10.1038/nature04386

Officer, C.B., and Drake, C.L., 1983. The Cretaceous-Tertiary transition. Science, 219(4591):1383-1390. doi:10.1126/science.219.4591.1383

Oppo, D.W., and Lehman, S.J., 1993. Mid-depth circulation of the subpolar North Atlantic during the Last Glacial Maximum. Science, 259(5098):1148-1152. doi:10.1126/science.259.5098.1148

Oppo, D.W., Raymo, M.E., Lohmann, G.P., Mix, A.C., Wright, J.D., and Prell, W.L., 1995. A $\delta^{13} \mathrm{C}$ record of upper North Atlantic Deep Water during the past 2.6 million years. Paleoceanography, 10(3):373-394. doi:10.1029/95PA00332

Pagani, M., Caldeira, K. Archer, D., and Zachos, J.C., $2006 a$. ATMOSPHERE: an ancient carbon mystery. Science, 314(5805):1556-1557. doi:10.1126/science.1136110

Pagani, M., Huber, M., Liu, Z., Bohaty, S.M., Henderiks, J., Sijp, W., Krishnan, S., and DeConto, R.M., 2011. The role of carbon dioxide during the onset of Antarctic glaciation. Science, 334(6060):1261-1264. doi:10.1126/science.1203909

Pagani, M., Pedentchouk, N., Huber, M., Sluijs, A., Schouten, S., Brinkhuis, H., Sinninghe Damsté, J.S., Dickens, G.R., and Expedition 302 Scientists, 2006b. Arctic hydrology during global warming at the Palaeocene/Eocene Thermal Maximum. Nature (London, U. K.), 443(7103):671-675. doi:10.1038/nature05043

Pagani, M., Zachos, J.C., Freeman, K.H., Tipple, B., and Bohaty, S., 2005. Marked decline in atmospheric carbon dioxide concentrations during the Paleogene. Science, 309(5734):600-603. doi:10.1126/science.1110063

Pälike, H., Frazier, J., and Zachos, J.C., 2006a. Extended orbitally forced palaeoclimatic records from the equatorial Atlantic Ceara Rise. Quat. Sci. Rev., 25(23-24):31383149. doi:10.1016/j.quascirev.2006.02.011

Pälike, H., Laskar, J., and Shackleton, N.J., 2004. Geologic constraints of the chaotic diffusion of the solar system. Geology, 32(11)929-932. doi:10.1130/G20750.1

Pälike, H., Lyle, M.W., Nishi, H., Raffi, I., Ridgwell, A., Gamage, K., Klaus, A., Acton, G., Anderson, L., Backman, J., Baldauf, J., Beltran, C., Bohaty, S.M., Bown, P., Busch, W., Channell, J.E.T., Chun, C.O.J., Delaney, M., Dewangan, P., Dunkley Jones, T., Edgar, K.M., Evans, H., Fitch, P., Foster, G,L., Gussone, N., Hasegawa, H., Hathorne, E.C., Hayashi, H., Herrle, J.O., Holbourn, A.,
Hovan, S., Hyeong, K., Iijima, K., Ito, T., Kamikuri, S., Kimoto, K., Kuroda, J., Leon-Rodriguez, L., Malinverno, A., Moore, T.C., Jr., Murphy, B.H., Murphy, D.P., Nakamura, H., Ogane, K., Ohneiser, C., Richter, C., Robinson, R., Rohling, E.J., Romero, O., Sawada, K., Scher, H., Schneider, L., Sluijs, A., Takata, H., Tian, J., Tsujimoto, A., Wade, B.S., Westerhold, T., Wilkens, R., Williams, T., Wilson, P.A., Yamamoto, Y., Yamamoto, S., Yamazaki, T., and Zeebe, R.E., 2012. A Cenozoic record of the equatorial Pacific carbonate compensation depth. Nature (London, U. K.), 488(7413):609-614. doi:10.1038/ nature 11360

Pälike, H., Nishi, H., Lyle, M., Raffi, I., Gamage, K., Klaus, A., and the Expedition 320/321 Scientists, 2010. Expedition 320/321 summary. In Pälike, H., Lyle, M., Nishi, H., Raffi, I., Gamage, K., Klaus, A., and the Expedition 320/ 321 Scientists, Proc. IODP, 320/321: Tokyo (Integrated Ocean Drilling Program Management International, Inc.). doi:10.2204/iodp.proc.320321.101.2010

Pälike, H., Norris, R.D., Herrle, J.O., Wilson, P.A., Coxall, H.K., Lear, C.H., Shackleton, N.J., Tripati, A.K., and Wade, B.S., 2006b. The heartbeat of the Oligocene climate system. Science, 314(5807):1894-1898. doi:10.1126/science.1133822

Pälike, H., and Shackleton, N.J., 2000. Constraints on astronomical parameters from the geological record for the last 25 Myr. Earth Planet. Sci. Lett., 182(1):1-14. doi:10.1016/S0012-821X(00)00229-6

Pälike, H., Shackelton, N.J., and Röhl, U., 2001. Astronomical forcing in late Eocene marine sediments. Earth Planet. Sci. Lett., 193(3-4):589-602. doi:10.1016/S0012821X(01)00501-5

Panchuk, K., Ridgwell, A., and Kump, L.R., 2008. Sedimentary response to Paleocene-Eocene Thermal Maximum carbon release: a model-data comparison. Geology, 36(4):315-318. doi:10.1130/G24474A.1

Paul, H.A., Zachos, J.C., Flower, B.P., and Tripati, A., 2000. Orbitally induced climate and geochemical variability across the Oligocene/Miocene boundary. Paleoceanography, 15(5):471-485. doi:10.1029/1999PA000443

Pearson, P.N., Ditchfield, P.W., Singano, J., HarcourtBrown, K.G., Nicholas, C.J., Olsson, R.K., Shackleton, N.J., and Hall, M.A., 2001. Warm tropical sea surface temperatures in the Late Cretaceous and Eocene epochs. Nature (London, U. K.), 413(6855):481-487. doi:10.1038/35097000

Pearson, P.N., Foster, G.L., and Wade, B.S., 2009. Atmospheric carbon dioxide through the Eocene-Oligocene climate transition. Nature (London, U. K.), 461(7267):1110-1113. doi:10.1038/nature08447

Pearson, P.N., McMillan, I.K., Wade, B.S., Dunkley Jones, T., Coxall, H.K., Bown, P.R., and Lear, C.H., 2008. Extinction and environmental change across the Eocene-Oligocene boundary in Tanzania. Geology, 36(2):179-182. doi:10.1130/G24308A.1

Pekar, S.F., Hucks, A., Fuller, M., and Li, S., 2005. Glacioeustatic changes in the early and middle Eocene (51-42 $\mathrm{Ma}$ ): shallow-water stratigraphy from ODP Leg 189 Site 1171 (South Tasman Rise) and deep-sea $\delta^{18} \mathrm{O}$ records. 
Geol. Soc. Am. Bull., 117(7-8):1081-1093. doi:10.1130/ B25486.1

Peterson, L.C., and Backman, J., 1990. Late Cenozoic carbonate accumulation and the history of the carbonate compensation depth in the western equatorial Indian Ocean. In Duncan, R.A., Backman, J., Peterson, L.C., et al., Proc. ODP, Sci. Results, 115: College Station, TX (Ocean Drilling Program), 467-507. doi:10.2973/ odp.proc.sr.115.163.1990

Peterson, L.C., Murray, D.W., Ehrmann, W.U., and Hempel, P., 1992. Cenozoic carbonate accumulation and compensation depth changes in the Indian Ocean. In Duncan, R.A., Rea, D.K., Kidd, R.B., von Rad, U., and Weissel, J.K. (Eds.), Synthesis of Results from Scientific Drilling in the Indian Ocean. Geophys. Monogr., 70:311333. doi:10.1029/GM070p0311

Petrizzo, M.R., 2005. An early late Paleocene event on Shatsky Rise, northwest Pacific Ocean (ODP Leg 198): evidence from planktonic foraminiferal assemblages. In Bralower, T.J., Premoli Silva, I., and Malone, M.J. (Eds.), Proc. ODP, Sci. Results, 198: College Station, TX (Ocean Drilling Program), 1-29. doi:10.2973/ odp.proc.sr.198.102.2005

Pickart, R.S., McKee, T.K., Torres, D.J., and Harrington, S.A., 1999. Mean structure and interannual variability of the slopewater system south of Newfoundland. J. Phys. Oceanogr., 29(10):2541-2558. doi:10.1175/15200485(1999)029<2541:MSAIVO>2.0.CO;2

Pollard, D., and DeConto, R.M., 2005. Hysteresis in Cenozoic Antarctic ice-sheet variations. Global Planet. Change, 45(1-3):9-21. doi:10.1016/j.gloplacha.2004.09.011

Pospichal, J.J., 1994. Calcareous nannofossils at the K-T boundary, El Kef: no evidence for stepwise, gradual, or sequential extinctions. Geology, 22(2):99-102. doi:10.1130/00917613(1994)022<0099:CNATKT >2.3.CO;2

Prins, M.A., Bouwer, L.M., Beets, C.J., Troelstra, S.R., Weltje, G.J., Kruk, R.W., Kuijpers, A., and Vroon, P.Z., 2002. Ocean circulation and iceberg discharge in the glacial North Atlantic: inferences from unmixing of sediment size distributions. Geology, 30(6):555-558. doi:10.1130/00917613(2002)030<0555:OCAIDI>2.0.CO;2

Quillévéré, F., Aubry, M.-P., Norris, R.D., and Berggren, W.A., 2002. Paleocene oceanography of the eastern subtropical Indian Ocean: an integrated magnetobiostratigraphic and stable isotope study of ODP Hole 761B (Wombat Plateau). Palaeogeogr., Palaeoecol., Palaeoclimatol., 184(3-4):371-405. doi:10.1016/S00310182(02)00275-4

Quillévéré, F., Norris, R.D., Kroon, D., and Wilson, P.A., 2008. Transient ocean warming and shifts in carbon reservoirs during the early Danian. Earth Planet. Sci. Lett., 265(3-4):600-615. doi:10.1016/j.epsl.2007.10.040

Quillévéré, F., Norris, R.D., Moussa, I., and Berggren, W.A., 2001. Role of photosymbiosis and biogeography in the diversification of early Paleogene acarininids (planktonic foraminifera). Paleobiology, 27(2):311-326.
doi:10.1666/0094-8373(2001)027<0311:ROP$\mathrm{ABI}>2.0 . \mathrm{CO} ; 2$

Racki, G., and Cordey, F., 2000. Radiolarian palaeoecology and radiolarites: is the present the key to the past? Earth-Sci. Rev., 52(1-3):83-120 doi:10.1016/S00128252(00)00024-6

Raffi, I., Backman, J., Fornaciari, E., Pälike, H., Rio, D., Lourens, L., and Hilgen, F., 2006. A review of calcareous nannofossil astrobiochronology encompassing the past 25 million years. Quat. Sci. Rev., 25(23-24):3113-3137. doi:10.1016/j.quascirev.2006.07.007

Rahmstorf, S., 1995. Bifurcations of the Atlantic thermohaline circulation in response to changes in the hydrological cycle. Nature (London, U. K.), 378(6553):145-149. doi:10.1038/378145a0

Ravizza, G., and Peucker-Ehrenbrink, B., 2003. Chemostratigraphic evidence of Deccan volcanism from the marine osmium isotope record. Science, 302(5649):1392-1395. doi:10.1126/science.1089209

Ridgwell, A., 2007. Interpreting transient carbonate compensation depth changes by marine sediment core modeling. Paleoceanography, 22(4):PA4102. doi:10.1029/2006PA001372

Robinson, N., Ravizza, G., Coccioni, R., Peucker-Ehrenbrink, B., and Norris, R., 2009. A high-resolution marine ${ }^{187} \mathrm{Os} /{ }^{188}$ Os record for the late Maastrichtian: distinguishing the chemical fingerprints of Deccan volcanism and the KP impact event. Earth Planet. Sci. Lett., 281(34):159-168. doi:10.1016/j.epsl.2009.02.019

Robinson, S.A., Murphy, D.P., Vance, D., and Thomas, D.J., 2010. Formation of "Southern Component Water" in the Late Cretaceous: evidence from Nd-isotopes. Geology, 38(10):871-874. doi:10.1130/G31165.1

Rudnicki, M.D., Wilson, P.A., and Anderson, W.T., 2001. Numerical models of diagenesis, sediment properties, and pore fluid chemistry on a paleoceanographic transect: Blake Nose, Ocean Drilling Program Leg 171B. Paleoceanography, 16(6):563-575. doi:10.1029/ 2000PA000551

Ruppel, C., 1997. Anomalously cold temperatures observed at the base of the gas hydrate stability zone on the U.S. Atlantic passive margin. Geology, 25(8):699-702. doi:10.1130/00917613(1997)025<0699:ACTOAT>2.3.CO;2

Saffer, D., McNeill, L., Byrne, T., Araki, E., Toczko, S., Eguchi, N., Takahashi, K., and the Expedition 319 Scientists, 2010. Proc. IODP, 319: Tokyo (Integrated Ocean Drilling Program management International, Inc.). doi:10.2204/iodp.proc.319.2010

Saffer, D.M., and Bekins, B.A., 2002. Hydrologic controls on the morphology and mechanics of accretionary wedges. Geology, 30(3):271-274. doi:10.1130/00917613(2002)030<0271:HCOTMA >2.0.CO;2

Sageman, B.B., Meyers, S.R., and Arthur, M.A., 2006. Orbital time scale and new $\mathrm{C}$ isotope record for Cenomanian/Turonian boundary stratotype. Geology, 34(2):125-128. doi:10.1130/G22074.1

Sanfilippo, A., and Blome, C.D., 2001. Biostratigraphic implications of mid-latitude Paleocene-Eocene radiolarian faunas from Hole 1051A, ODP Leg 171B, Blake 
Nose, western North Atlantic. In Kroon, D., Norris, R.D., and Klaus, A. (Eds.), Western North Atlantic Palaeogene and Cretaceous Palaeoceanography. Geol. Soc. Spec. Publ., 183(1):185-224. doi:10.1144/GSL.SP.2001.183.01.10

Scher, H.D., Bohaty, S.M., Zachos, J.C., and Delaney, M.L., 2011. Two-stepping into the icehouse: East Antarctic weathering during progressive ice-sheet expansion at the Eocene-Oligocene transition. Geology, 39(4):383386. doi:10.1130/G31726.1

Schlanger, S.O., Arthur, M.A., Jenkyns, H.C., and Scholle, P.A., 1987. The Cenomanian-Turonian oceanic anoxic event, I. Stratigraphy and distribution of organic carbon-rich beds and the marine $\delta^{13} \mathrm{C}$ excursion. In Brooks, J., and Fleet, A.J. (Eds.), Marine Petroleum Source Rocks. Geol. Soc. Spec. Publ., 26(1):371-399. doi:10.1144/ GSL.SP.1987.026.01.24

Schouten, S., Hopmans, E.C., Forster, A., van Breugel, Y., Kuypers, M.M.M., and Sinninghe Damsté, J.S., 2003. Extremely high sea-surface temperatures at low latitudes during the middle Cretaceous as revealed by archaeal membrane lipids. Geology, 31(12):1069-1072. doi:10.1130/G19876.1

Schulte, P., Alegret, L., Arenillas, I., Arz, J.A., Barton, P.J., Bown, P.R., Bralower, T.J., Christeson, G.L., Claeys, P., Cockell, C.S., Collins, G.S., Deutsch, A., Goldin, T.J., Goto, K., Grajales-Nishimura, J.M., Grieve, R.A.F., Gulick, S.P.S., Johnson, K.R., Kiessling, W., Koeberl, C., Kring, D.A., MacLeod, K.G., Matsui, T., Melosh, J., Montanari, A., Morgan, J.V., Neal, C.R., Nichols, D.J., Norris, R.D., Pierazzo, E., Ravizza, G., Rebolledo-Vieyra, M., Reimold, W.U., Robin, E., Salge, T., Speijer, R.P., Sweet, A.R., Urrutia-Fucugauchi, J., Vajda, V., Whalen, M.T., and Willumsen, P.S., 2010. The Chicxulub asteroid impact and mass extinction at the Cretaceous-Paleogene boundary. Science, 327:1214-1218. doi:10.1126/ science. 1177265

Screaton, E., Saffer, D., Henry, P., and Hunze, S., 2002. Porosity loss within the underthrust sediments of the Nankai accretionary complex: implications for overpressures. Geology, 30(1):19-22. doi:10.1130/00917613(2002)030<0019:PLWTUS>2.0.CO;2

Sepkoski, J.J., Jr., Bambach, R.K., Raup, D.M., and Valentine, J.W., 1981. Phanerozoic marine diversity and the fossil record. Nature (London, U. K.), 293(5832):435-437. doi: $10.1038 / 293435 \mathrm{a} 0$

Sexton, P.F., and Norris, R.D., 2008. Dispersal and biogeography of marine plankton: long-distance dispersal of the foraminifer Truncorotalia truncatulinoides. Geology, 36(11):899-902. doi:10.1130/G25232A.1

Sexton, P.F., Norris, R.D., Wilson, P.A., Pälike, H., Westerhold, T., Röhl, U., Bolton, C.T., and Gibbs, S., 2011. Eocene global warming events driven by ventilation of oceanic dissolved organic carbon. Nature (London, U. K.), 471(7338):349-352. doi:10.1038/nature09826

Sexton, P.F., and Wilson, P.A., 2009. Preservation of benthic foraminifera and reliability of deep-sea temperature records: the importance of sedimentation rates, lithology, and the need to examine test wall structure. Paleoceanography, 24(2):PA2208. doi:10.1029/ 2008PA001650
Sexton, P.F., Wilson, P.A., and Norris, R.D., 2006a. Testing the Cenozoic multisite composite $\delta^{18} \mathrm{O}$ and $\delta^{13} \mathrm{C}$ curves: new monospecific Eocene records from a single locality, Demerara Rise (Ocean Drilling Program Leg 207). Paleoceanography, 21(2):PA2019. doi:10.1029/ 2005PA001253

Sexton, P.F., Wilson, P.A., and Pearson, P.N., 2006b. Microstructural and geochemical perspectives on planktic foraminiferal preservation: "glassy" versus "frosty." Geochem., Geophys., Geosyst., 7(12):Q12P19. doi:10.1029/2006GC001291

Shackleton, N.J., Backman, J., Zimmerman, H., Kent, D.V., Hall, M.A., Roberts, D.G., Schnitker, D., Baldauf, J.G., Desprairies, A., Homrighausen, R., Huddlestun, P., Keene, J.B., Kaltenback, A.J., Krumsiek, K.A.O., Morton, A.C., Murray, J.W., and Westberg-Smith, J., 1984. Oxygen isotope calibration of the onset of ice rafting and history of glaciation in the North Atlantic region. Nature (London, U. K.), 307(5952):620-623. doi:10.1038/307620a0

Sigurdsson, H., Leckie, R.M., Acton, G.D., et al., 1997. Proc. ODP, Init. Repts., 165: College Station, TX (Ocean Drilling Program). doi:10.2973/odp.proc.ir.165.1997

Simoneit, B.R.T., 1986. Cyclic terpenoids of the geosphere. In Johns, R.B. (Ed.), Biological Markers in the Sedimentary Record: Amsterdam (Elsevier), 43-99.

Sluijs, A., Schouten, S., Pagani, M., Woltering, M., Brinkhuis, H., Sinninghe Damsté, J.S., Dickens, G.R., Huber, M., Reichart, G.-J., Stein, R., Matthiessen, J., Lourens, L.J., Pedentchouk, N., Backman, J., Moran, K., and the Expedition 302 Scientists, 2006. Subtropical Arctic Ocean temperatures during the Palaeocene/Eocene Thermal Maximum. Nature (London, U. K.), 441(7093):610-613. doi:10.1038/nature04668

Stickley, C.E., St. John, K., Koç, N., Jordan, R.W., Passchier, S., Pearce, R.B., and Kearns, L.E., 2009. Evidence for middle Eocene Arctic sea ice from diatoms and icerafted debris. Nature (London, U. K.), 460(7253):376-379. doi:10.1038/nature08163

Stommel, H., and Arons, A.B., 1960. On the abyssal circulation of the world ocean-I. Stationary planetary flow patterns on a sphere. Deep Sea Res., 6:140-154. doi:10.1016/0146-6313(59)90065-6

Svensen, H., Planke, S., Malthe-Sørenssen, A., Jamtveit, B., Myklebust, R., Eidem, T.R., and Rey, S.S., 2004. Release of methane from a volcanic basin as a mechanism for initial Eocene global warming. Nature (London, U. K.), 429(6991):542-545. doi:10.1038/nature02566

Terzaghi, K., 1950. Mechanism of landslides. In Paige, S. (Ed.), Application of Geology to Engineering Practice: Berkeley Volume: Baltimore (Geol. Soc. Am.), 83-123.

Thomas, D.J., Bralower, T.J., and Jones, C.E., 2003. Neodymium isotopic reconstruction of late Paleocene-early Eocene thermohaline circulation. Earth Planet. Sci. Lett., 209(3-4):309-322. doi:10.1016/

S0012-821X(03)00096-7

Toffanin, F., Agnini, C., Fornaciari, E., Rio, D., Giusberti, L., Luciani, V., Spofforth, D.J.A., and Pälike, H., 2011. Changes in calcareous nannofossil assemblages during the Middle Eocene Climatic Optimum: clues from the 
central-western Tethys (Alano section, NE Italy). Mar. Micropaleontol., 81(1-2):22-31. doi:10.1016/j.marmicro.2011.07.002

Toggweiler, J.R., and Samuels, B., 1995. Effect of Drake Passage on the global thermohaline circulation. Deep-Sea Res., Part I, 42(4):477-500. doi:10.1016/ 0967-0637(95)00012-U

Toon, O.B., Zahnle, K., Morrison, D., Turco, R.P., and Covey, C., 1997. Environmental perturbations caused by the impacts of asteroids and comets. Rev. Geophys., 35(1):41-78. doi:10.1029/96RG03038

Tripati, A., Backman, J., Elderfield, H., and Ferretti, P., 2005. Eocene bipolar glaciation associated with global carbon cycle changes. Nature (London, U. K.), 436(7049):341-346. doi:10.1038/nature03874

Tripati, A., and Elderfield, H., 2005. Deep-sea temperature and circulation changes at the Paleocene-Eocene Thermal Maximum. Science, 308(5730):1894-1898. doi:10.1126/science.1109202

Tripati, A.K., Eagle, R.A., Morton, A., Dowdeswell, J.A., Atkinson, K.L., Bahé, Y., Dawber, C.F., Khadun, E., Shaw, R.M.H., Shorttle, O., and Thanabalasundaram, L., 2008. Evidence for glaciation in the northern hemisphere back to $44 \mathrm{Ma}$ from ice-rafted debris in the Greenland Sea. Earth Planet. Sci. Lett., 265(1-2):112-122. doi:10.1016/j.epsl.2007.09.045

Tsikos, H., Jenkyns, H.C., Walsworth-Bell, B., Petrizzo, M.R., Forster, A., Kolonic, S., Erba, E., Premoli Silva, I., Baas, M., Wagner, T., and Sinninghe-Damsté, J.S., 2004. Carbon-isotope stratigraphy recorded by the Cenomanian-Turonian oceanic anoxic event: correlation and implication based on three localities. J. Geol. Soc., 161(4):711-719. doi:10.1144/0016-764903-077

Tucholke, B.E., 1979. Relationships between acoustic stratigraphy and lithostratigraphy in the western North Atlantic Basin. In Tucholke, B.E., Vogt, P.R., et al., Init. Repts. DSDP, 43: Washington, DC (U.S. Govt. Printing Office), 827-846. doi:10.2973/dsdp.proc.43.141.1979

Tucholke, B.E., and Ludwig, W.J., 1982. Structure and origin of the J Anomaly Ridge, western North Atlantic Ocean. J. Geophys. Res.: Solid Earth, 87(B11):9389-9407. doi:10.1029/JB087iB11p09389

Tucholke, B.E., and Mountain, G.S., 1986. Tertiary paleoceanography of the western North Atlantic Ocean. In Vogt, P.R., and Tucholke, B.E. (Eds.), The Geology of North America (Vol. M): The Western North Atlantic Region: Boulder (Geol. Soc. Am.), 631-650.

Tucholke, B.E., and Vogt, P.R., 1979. Western North Atlantic: sedimentary evolution and aspects of tectonic history. In Tucholke, B.E., Vogt, P.R., et al., Init. Repts. DSDP, 43: Washington, DC (U.S. Govt. Printing Office), 791825. doi:10.2973/dsdp.proc.43.140.1979

Tucholke, B.E., Vogt, P.R., et al., 1979. Init. Repts. DSDP, 43: Washington, DC (U.S. Govt. Printing Office). doi:10.2973/dsdp.proc.43.1979

Turgeon, S.C., and Creaser, R.A., 2008. Cretaceous oceanic anoxic Event 2 triggered by a massive magmatic episode. Nature (London, U. K.), 454(7202):323-326. doi:10.1038/nature07076 van Andel, T.H., 1975. Mesozoic/Cenozoic calcite compensation depth and the global distribution of calcareous sediments. Earth Planet. Sci. Lett., 26(2):187-194. doi:10.1016/0012-821X(75)90086-2

van Hinsbergen, D.J.J., Steinberger, B., Doubrovine, P.V., and Gassmöller, R., 2011. Acceleration and deceleration of India-Asia convergence since the Cretaceous: roles of mantle plumes and continental collision. J. Geophys. Res.: Solid Earth, 116(B6):B06101. doi:10.1029/ 2010JB008051

Via, R.K., and Thomas, D.J., 2006. Evolution of Atlantic thermohaline circulation: early Oligocene onset of deep-water production in the North Atlantic. Geology, 34(6):441-444. doi:10.1130/G22545.1

Voigt, S., Erbacher, J., Mutterlose, J., Weiss, W., Westerhold, T., Wiese, F., Wilmsen, M., and Wonik, T., 2008. The Cenomanian-Turonian of the Wunstorf section (north Germany): global stratigraphic reference section and new orbital time scale for oceanic anoxic Event 2. Newsl. Stratigr., 43(1):65-89. doi:10.1127/0078-0421/ 2008/0043-0065

Voigt, S., Friedrich, O., Norris, R.D., and Schönfeld, J., 2010. Campanian-Maastrichtian carbon isotope stratigraphy: shelf-ocean correlation between the European shelf sea and the tropical Pacific Ocean. Newsl. Stratigr., 44(1):57-72. doi:10.1127/0078-0421/2010/0004

Volkman, J.K., Burton, H.R., Everitt, D.A., and Allen, D.I., 1988. Pigment and lipid compositions of algal and bacterial communities in Ace Lake, Vestfold Hills, Antarctica. Hydrobiologia, 165(1):41-57. doi:10.1007/ BF00025573

Wade, B.S., Houben, A.J.P., Quaijtaal, W., Schouten, S., Rosenthal, Y., Miller, K.G., Katz, M.E., Wright, J.D., and Brinkhuis, H., 2012. Multiproxy record of abrupt seasurface cooling across the Eocene-Oligocene transition in the Gulf of Mexico. Geology, 40(2):159-162. doi:10.1130/G32577.1

Wade, B.S., and Pälike, H., 2004. Oligocene climate dynamics. Paleoceanography, 19(4):PA4019. doi:10.1029/2004PA001042

Wade, B.S., Pearson, P.N., Berggren, W.A., and Pälike, H., 2011. Review and revision of Cenozoic tropical planktonic foraminiferal biostratigraphy and calibration to the geomagnetic polarity and astronomical time scale. Earth-Sci. Rev., 104(1-3):111-142. doi:10.1016/j.earscirev.2010.09.003

Weltje, G.J., 1997. End-member modeling of compositional data: numerical-statistical algorithms for solving the explicit mixing problem. Math. Geol., 29(4):503549. doi:10.1007/BF02775085

Weltje, G.J., and Prins, M.A., 2003. Muddled or mixed? Inferring palaeoclimate from size distributions of deepsea clastics. Sediment. Geol., 162(1-2):39-62. doi:10.1016/S0037-0738(03)00235-5

Westerhold, T., and Röhl, U., 2009. High resolution cyclostratigraphy of the early Eocene-new insights into the origin of the Cenozoic cooling trend. Clim. Past, 5(3):309-327. doi:10.5194/cp-5-309-2009

Westerhold, T., Röhl, U., Donner, B., McCarren, H.K., and Zachos, J.C., 2011. A complete high-resolution Paleo- 
cene benthic stable isotope record for the central Pacific (ODP Site 1209). Paleoceanography, 26(2):PA2216. doi:10.1029/2010PA002092

Westerhold, T., Röhl, U., Raffi, I., Fornaciari, E., Monechi, S., Reale, V., Bowles, J., and Evans, H.F., 2008. Astronomical calibration of the Paleocene time. Palaeogeogr., Palaeoclimatol., Palaeoecol., 257(4):377-403. doi:10.1016/j.palaeo.2007.09.016

Wilson, P.A., and Norris, R.D., 2001. Warm tropical ocean surface and global anoxia during the mid-Cretaceous period. Nature (London, U. K.), 412(6845):425-429. doi:10.1038/35086553

Wright, J.D., and Miller, K.G., 1993. Southern Ocean influences on late Eocene to Miocene deepwater circulation. In Kennett, J.P., and Warnke, D.A. (Eds.), The Antarctic Paleoenvironment: A Perspective on Global Change. Antarct. Res. Ser., 60:1-25.

Wright, J.D., Miller, K.G., and Fairbanks, R.G., 1992. Early and middle Miocene stable isotopes: implications for deepwater circulation and climate. Paleoceanography, 7(3):357-389. doi:10.1029/92PA00760

Zachos, J.C., Dickens, G.R., and Zeebe, R.E., 2008. An early Cenozoic perspective on greenhouse warming and carbon-cycle dynamics. Nature (London, U. K.), 451(7176):279-283. doi:10.1038/nature06588

Zachos, J.C., Flower, B.P., and Paul, H., 1997. Orbitally paced climate oscillations across the Oligocene/Mio- cene boundary. Nature (London, U. K.), 388(6642):567570. doi:10.1038/41528

Zachos, J.C., Kroon, D., Blum, P., et al., 2004. Proc. ODP, Init. Repts., 208: College Station, TX (Ocean Drilling Program. doi:10.2973/odp.proc.ir.208.2004

Zachos, J.C., McCarren, H., Murphy, B., Röhl, U., and Westerhold, T., 2010. Tempo and scale of late Paleocene and early Eocene carbon isotope cycles: implications for the origin of hyperthermals. Earth Planet. Sci. Lett., 299(1-2):242-249. doi:10.1016/j.epsl.2010.09.004

Zachos, J.C., Pagani, M., Sloan, L., Thomas, E., and Billups, K., 2001. Trends, rhythms, and aberrations in global climate 65 Ma to present. Science, 292(5517):686-693. doi:10.1126/science.1059412

Zachos, J.C., Röhl, U., Schellenberg, S.A., Sluijs, A., Hodell, D.A., Kelly, D.C., Thomas, E., Nicolo, M., Raffi, I., Lourens, L.J., McCarren, H., and Kroon, D., 2005. Rapid acidification of the ocean during the Paleocene-Eocene Thermal Maximum. Science, 308(5728):1611-1615. doi:10.1126/science.1109004

Zeebe, R.E., and Zachos, J.C., 2007. Reversed deep-sea carbonate ion basin gradient during Paleocene-Eocene Thermal Maximum. Paleoceanography, 22(3):PA3201. doi:10.1029/2006PA001395

Publication: 3 March 2014 MS 342-101 
Figure F1. Single-channel seismic KNR179-1 Line 7 showing a section through J-Anomaly Ridge. Note the thinning of the transparent Eocene reflector package below $\sim 6.25 \mathrm{~s}$ two-way traveltime $(\sim 4.8 \mathrm{~km})$. Drilling during Expedition 342 found that the Eocene package is composed of lower Miocene and Oligocene sediment overlying Eocene sediment. In addition, part of the Paleocene-Campanian seismic unit also includes pre-Campanian rock, very likely extending into the Albian. For location, see Figure F8.

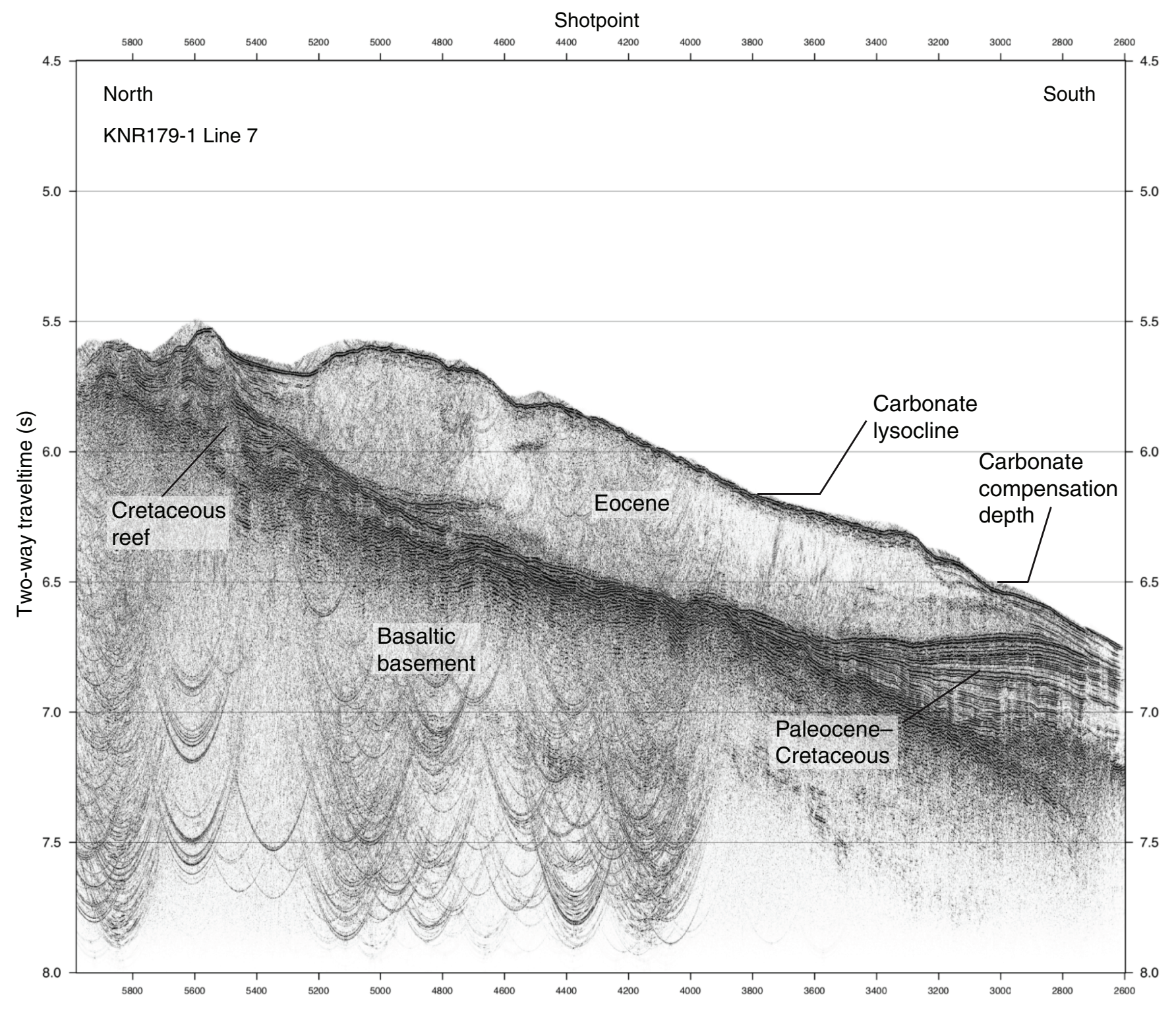


Figure F2. Subsidence estimates for North Atlantic DSDP records with an interpretation of the carbonate compensation depth (CCD) history from Tucholke and Voigt (1984). Red dashed lines report the calculated subsidence history of the base of J-Anomaly Ridge, DSDP Site 384 on the crest of J-Anomaly Ridge, and the tops of the Southeast Newfoundland Ridge (SENR) seamounts. In contrast to this CCD reconstruction, our seismic data suggest that carbonate sediments extend nearly to the base of J-Anomaly Ridge during the Paleogene (yellow area), see Figure F1.

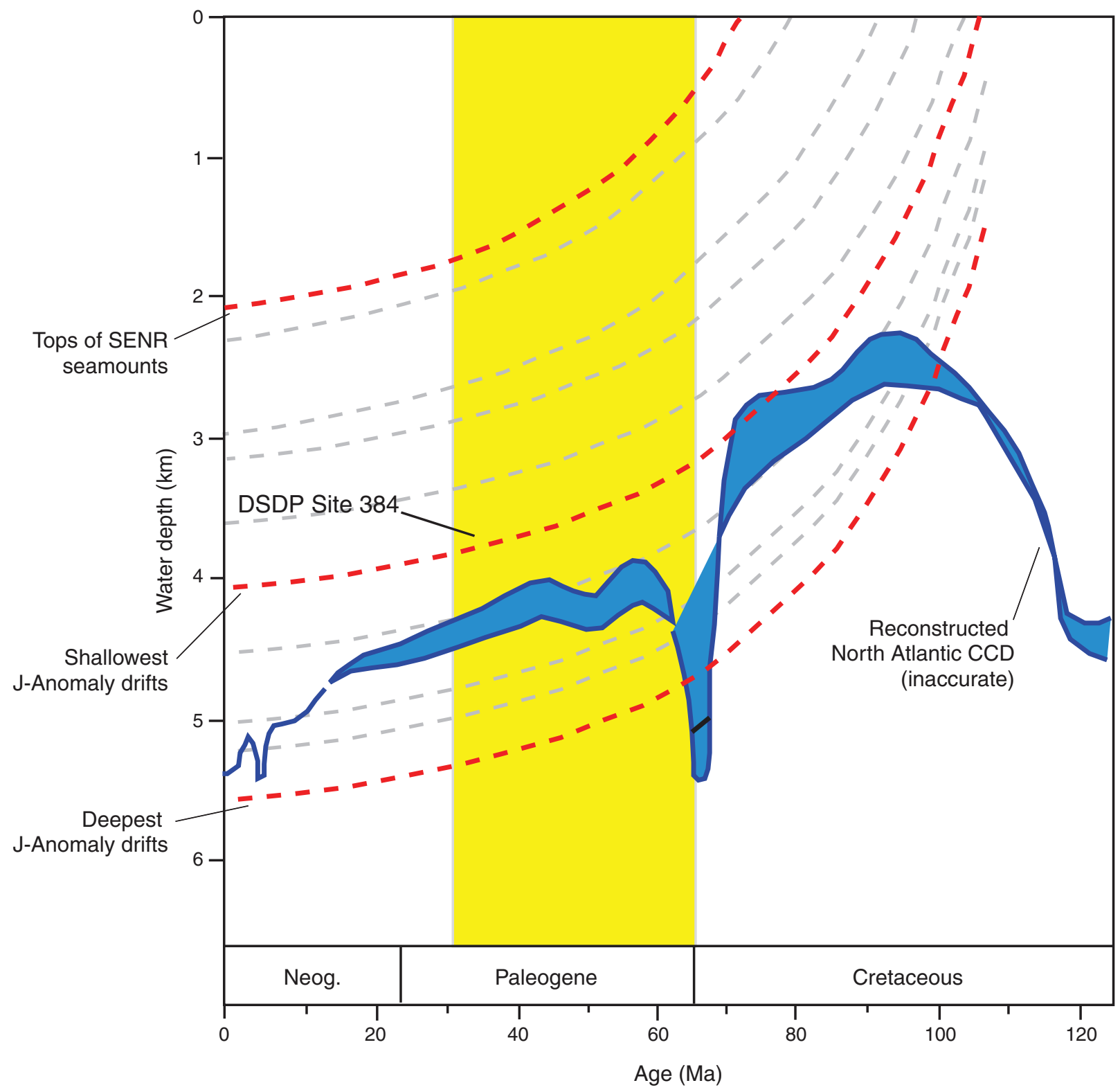


Figure F3. Record of the Eocene-Oligocene transition from the central equatorial Pacific at ODP Site 1218. Note the stair-step transition into Oligocene glacial climates for all records. From Coxall et al., 2005. VPDB = Vienna Peedee belemnite, MAR = mass accumulation rate, Oi-1 = Oligocene Isotope Event 1.

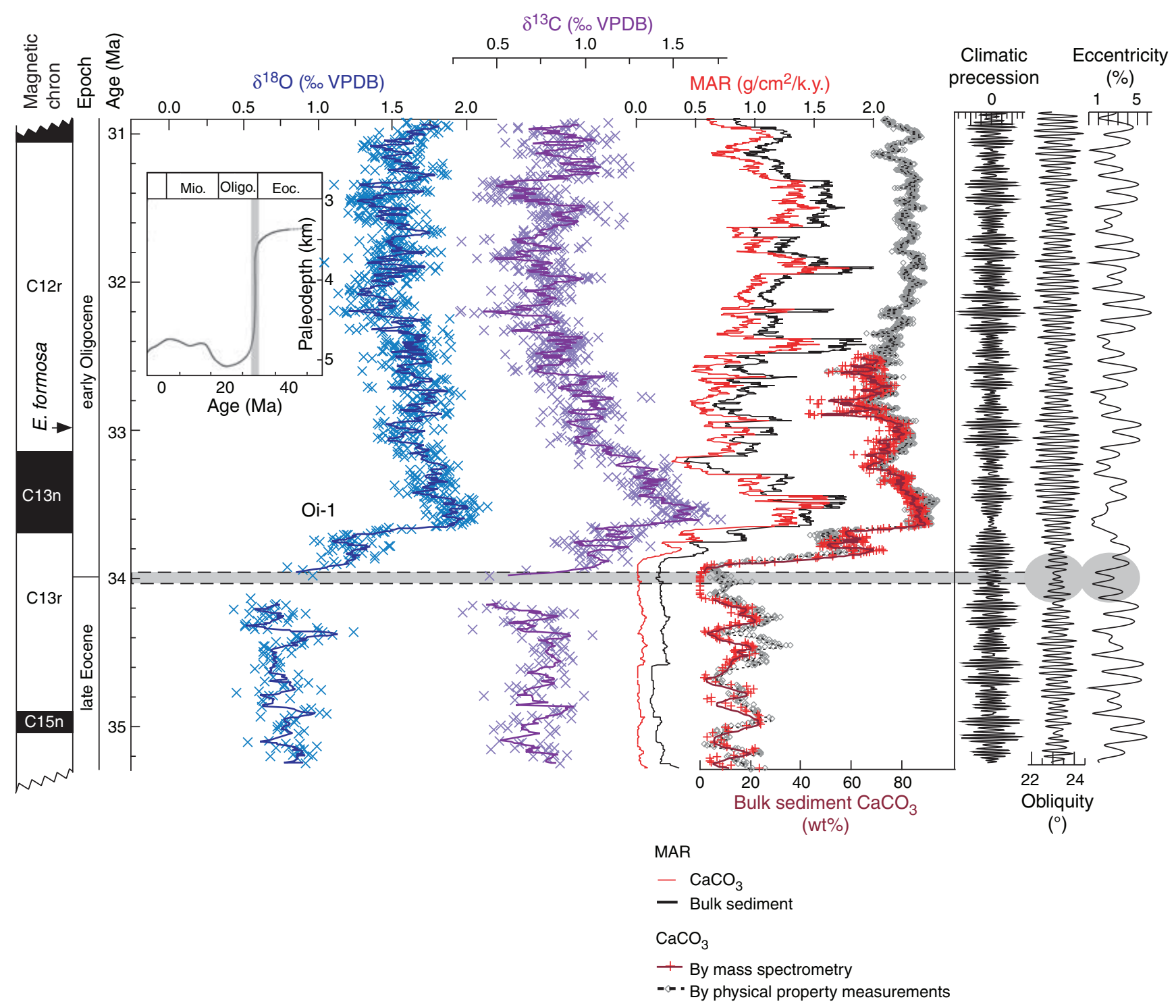


Figure F4. Location of Southeast Newfoundland Ridge and J-Anomaly Ridge relative to the flow paths of the Deep Western Boundary Current that originates in the Nordic seas and the Gulf Stream originating from the Caribbean. DSDP Site 384 is the primary deep bore hole providing stratigraphic control for Expedition 342 seismic records.

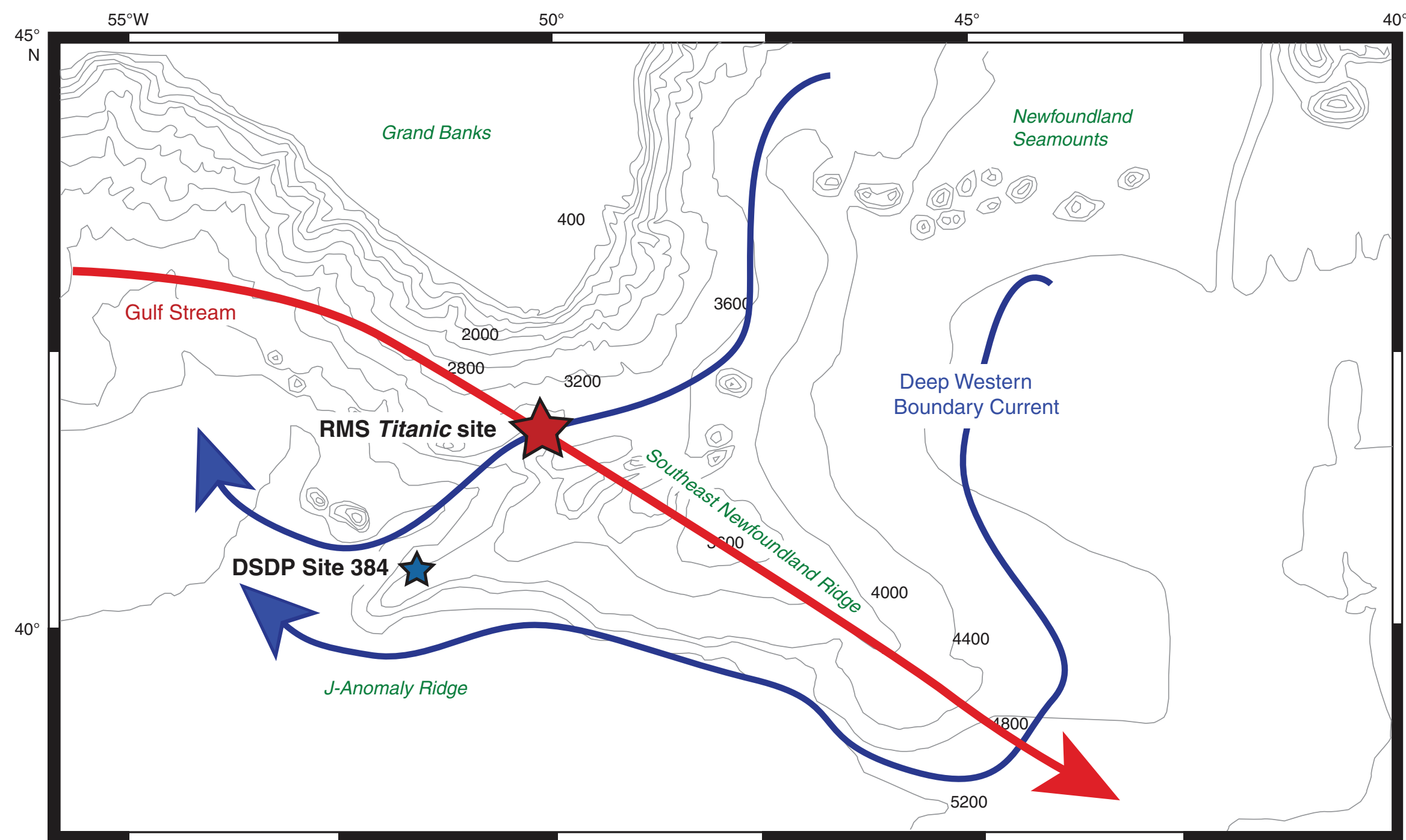


Figure F5. Compilation of benthic $\delta^{13} \mathrm{C}$ data through the Paleocene/Eocene Thermal Maximum (PETM). Northern hemisphere sites typically show more positive $\delta^{13} \mathrm{C}$ in the core of the PETM than Southern Ocean sites, indicating most deep water was formed in the northern basins. Before and after the PETM, however, the $\delta^{13} \mathrm{C}$ gradient shows the opposite pattern, indicating southern sources of deep water. From Nuñes and Norris (2006). VPDB = Vienna Peedee belemnite.

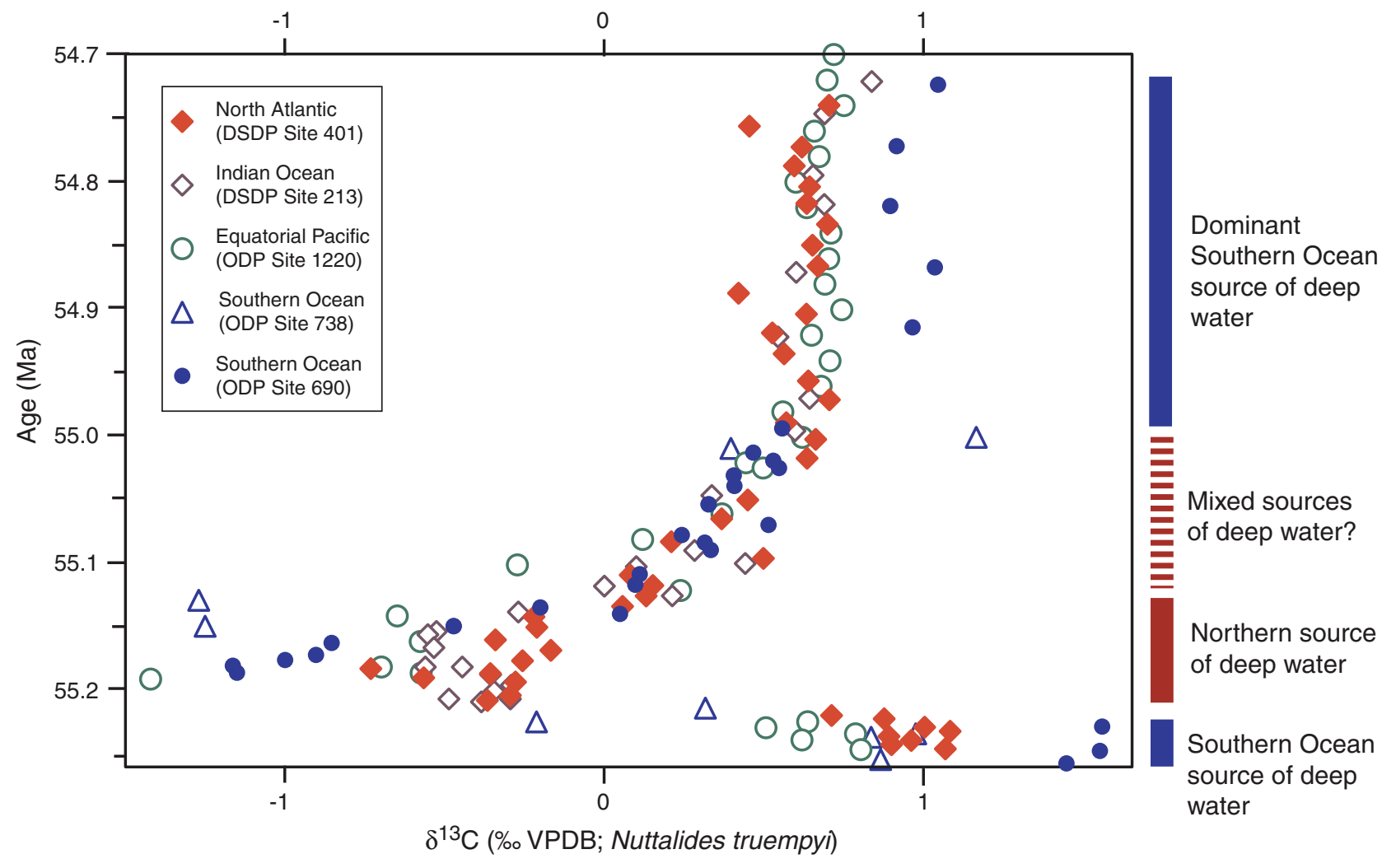


Figure F6. Hypothesized seismic and sedimentary stratigraphy of J-Anomaly Ridge and adjacent Southeast Newfoundland Ridge. Sedimentary stratigraphy based on the cored record at DSDP Site 384, whereas the seismic stratigraphy is based on seismic ties between single-channel seismic reflection profiles and Site 384. Note, site was drilled without coring the upper $\sim 55 \mathrm{~m}$.
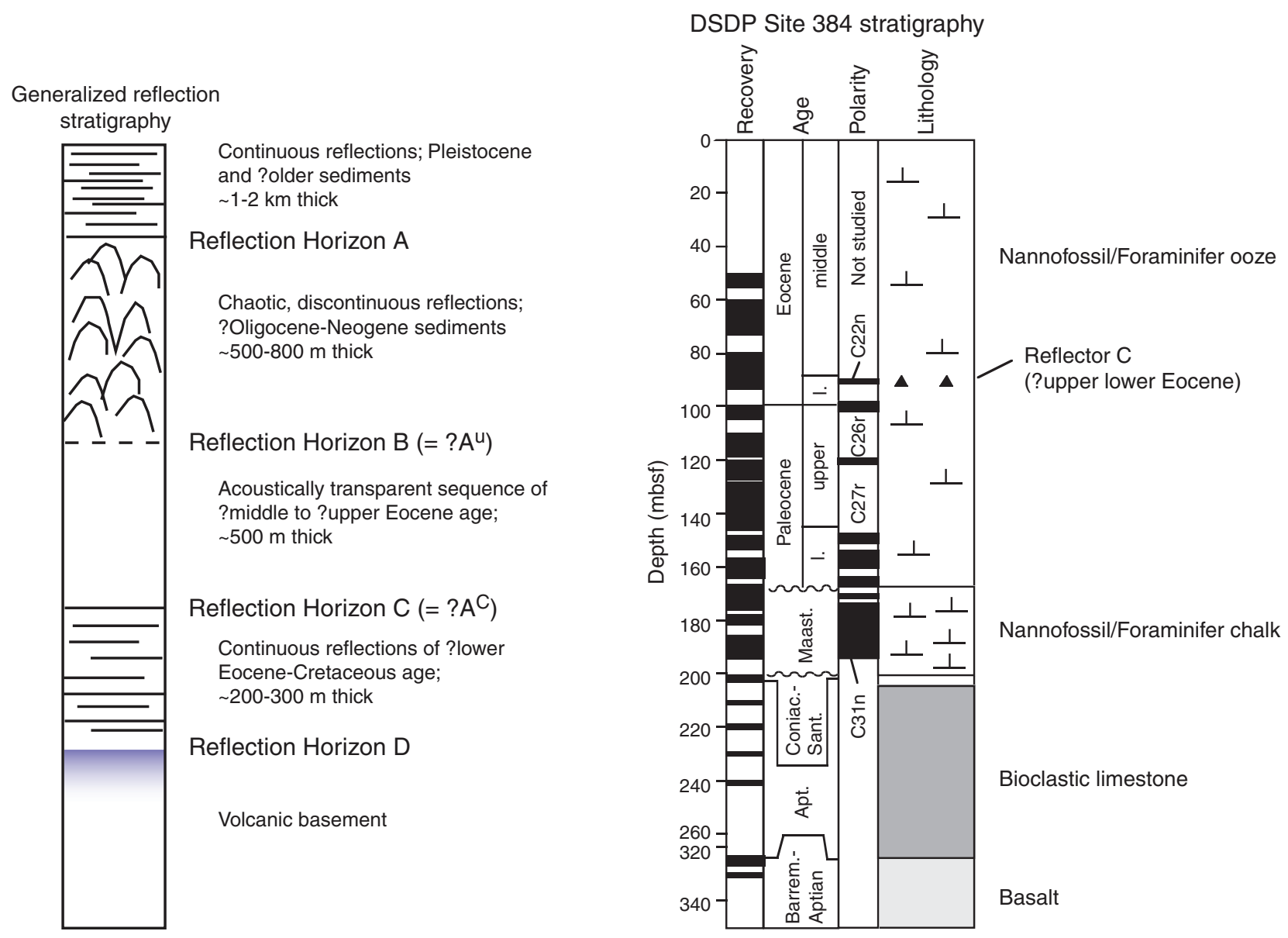
Figure F7. A. Operational area of Expedition 342. Red circles indicate Expedition 342 drill sites and the white box indicates the area of the multibeam bathymetry survey shown in B. The expedition left from Bermuda (not on map) and ended in St. Johns, Newfoundland. (Continued on next page.)

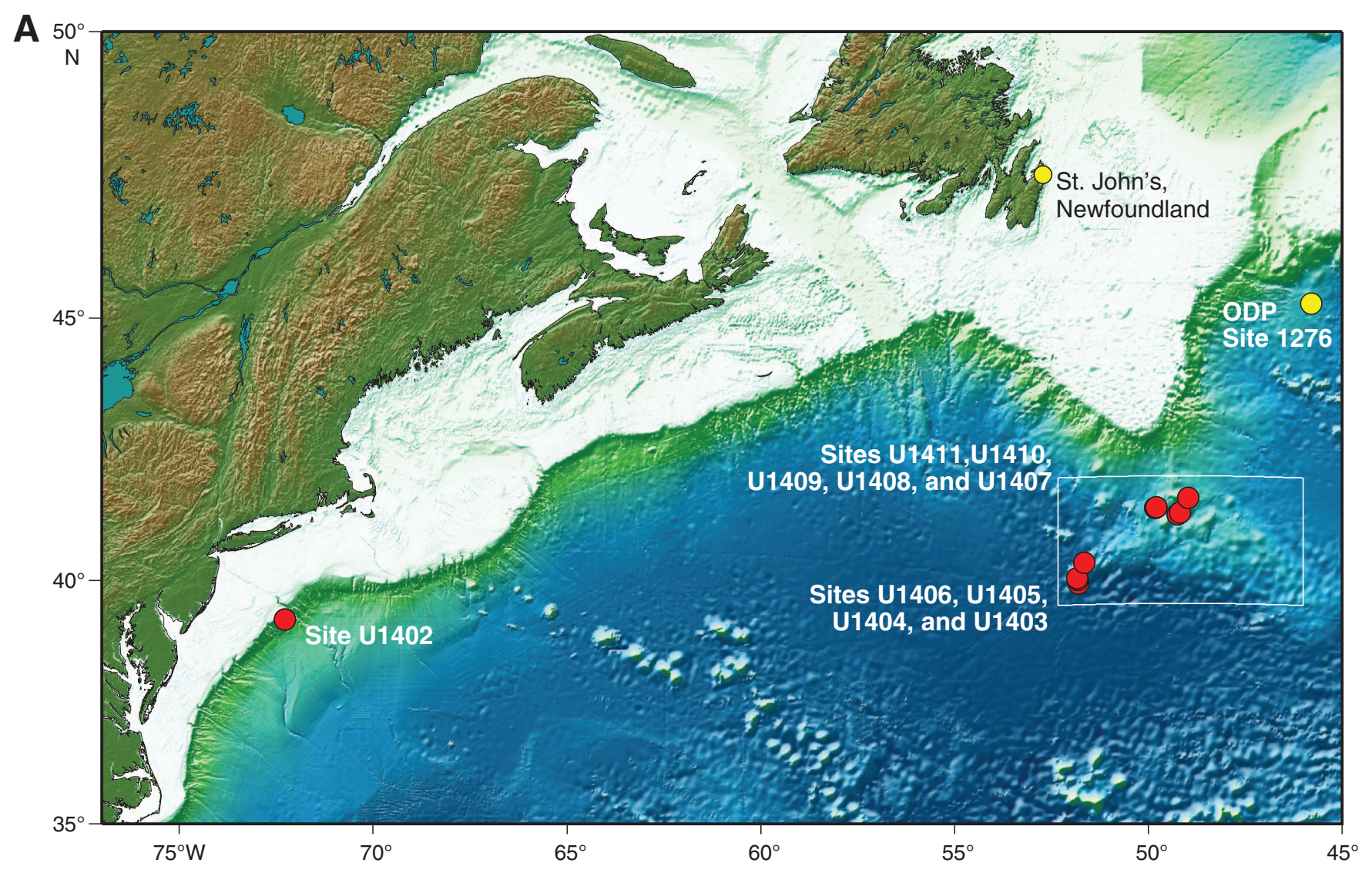


Figure F7 (continued). B. Multibeam bathymetry for Expedition 342 survey area (collected by the R/V Knorr [Knorr179-1]).

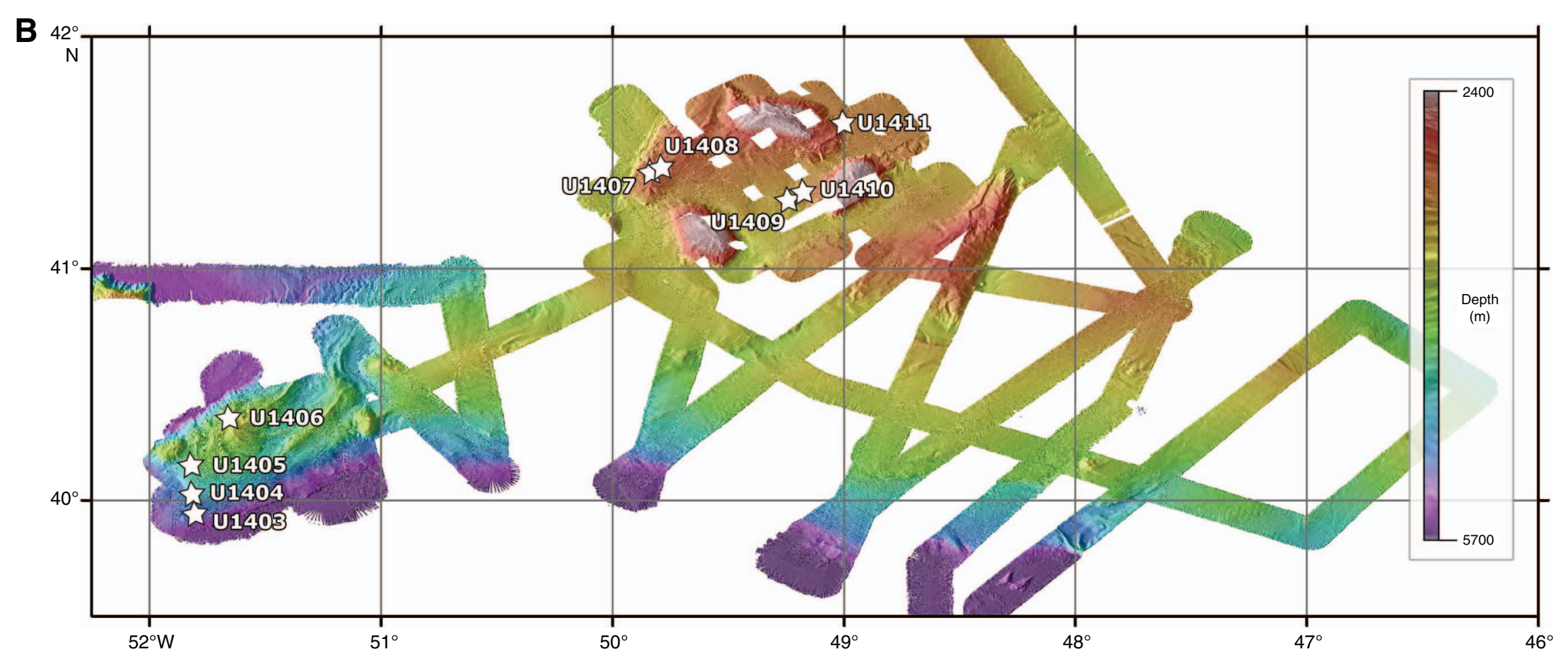


Figure F8. Track map for the Newfoundland ridges. Red lines are single-channel seismic (SCS) lines collected during the site survey Cruise Knorr179-1. Black dotted and dashed lines are other seismic profiles available to support Expedition 342 drilling. DSDP Site 384 (red star) provides stratigraphic control for interpretation of the seismic data set. Seismic details of green lines are shown in Figures F1 and F9. Black stars are locations of piston cores in the area. MCS = multichannel seismic.

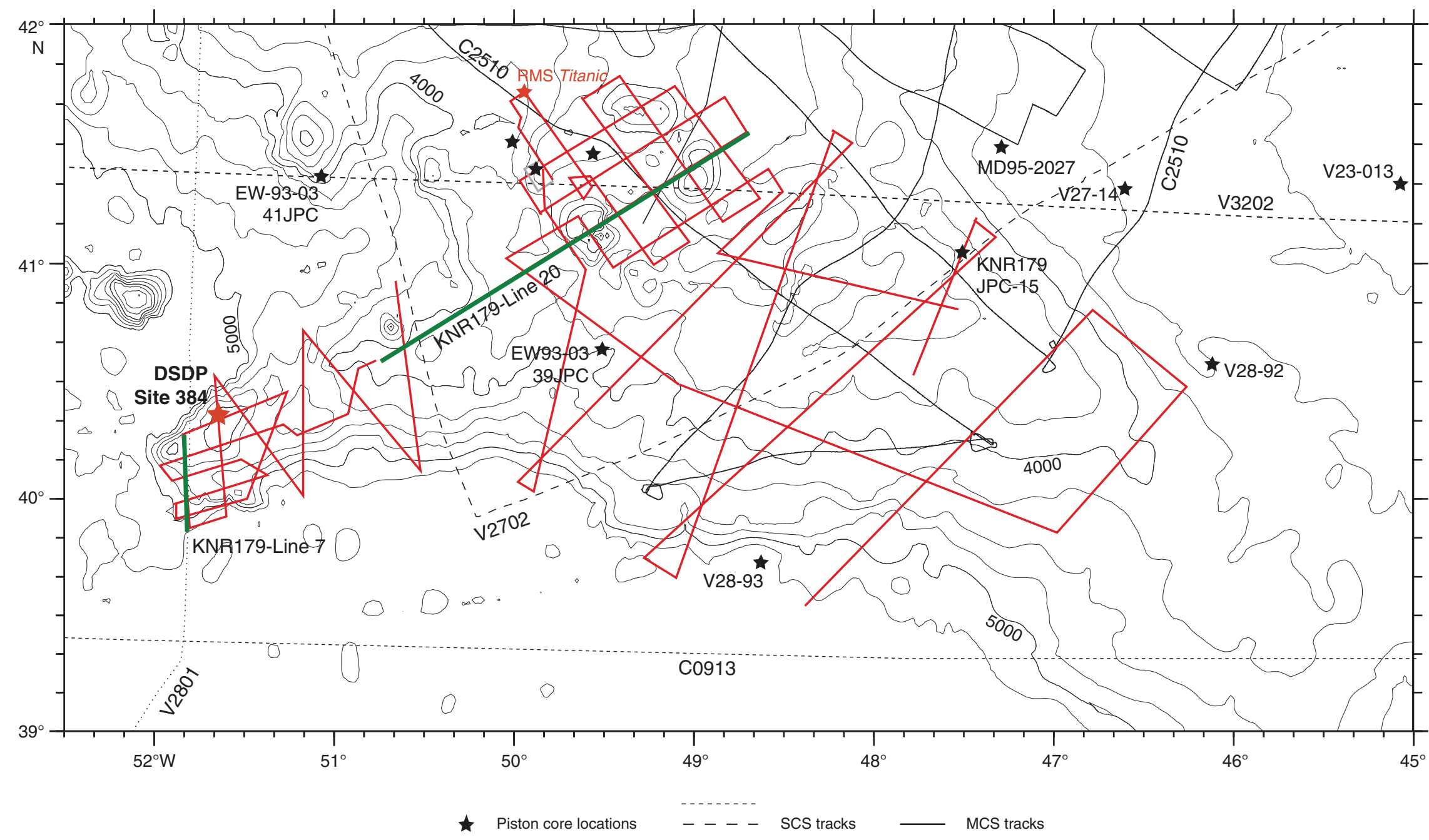


Figure F9. Portion of single-channel seismic KNR179-1 Line 20 showing the $>1 \mathrm{~km}$ thick package of mudwave-dominated sediment of likely Oligocene to Pliocene age on J-Anomaly Ridge and the complex pattern of drifts and pelagic caps on and around the seamounts on the crest of Southeast Newfoundland Ridge. For location, see Figure F8.

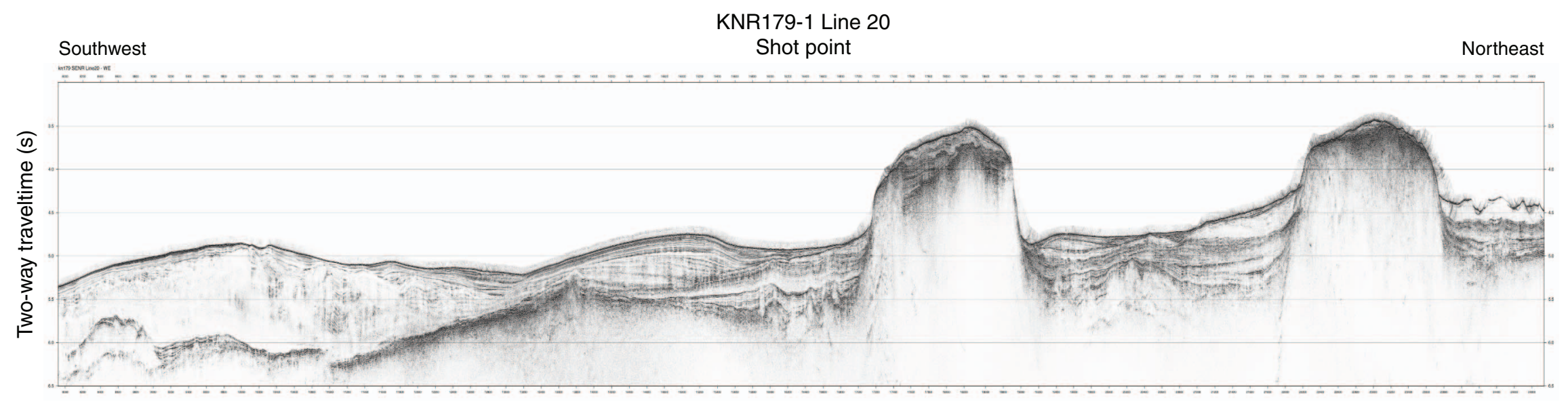


Figure F10. Interpreted seismic records from (A) Southeast Newfoundland Ridge seamount area, (B) Southeast Newfoundland Ridge eastern end, and (C) J-Anomaly Ridge. The approximate age range of the various seismic units are shown in different colors. Note the large variation in thickness and distribution of drift packages.

A Northwest

Southeast
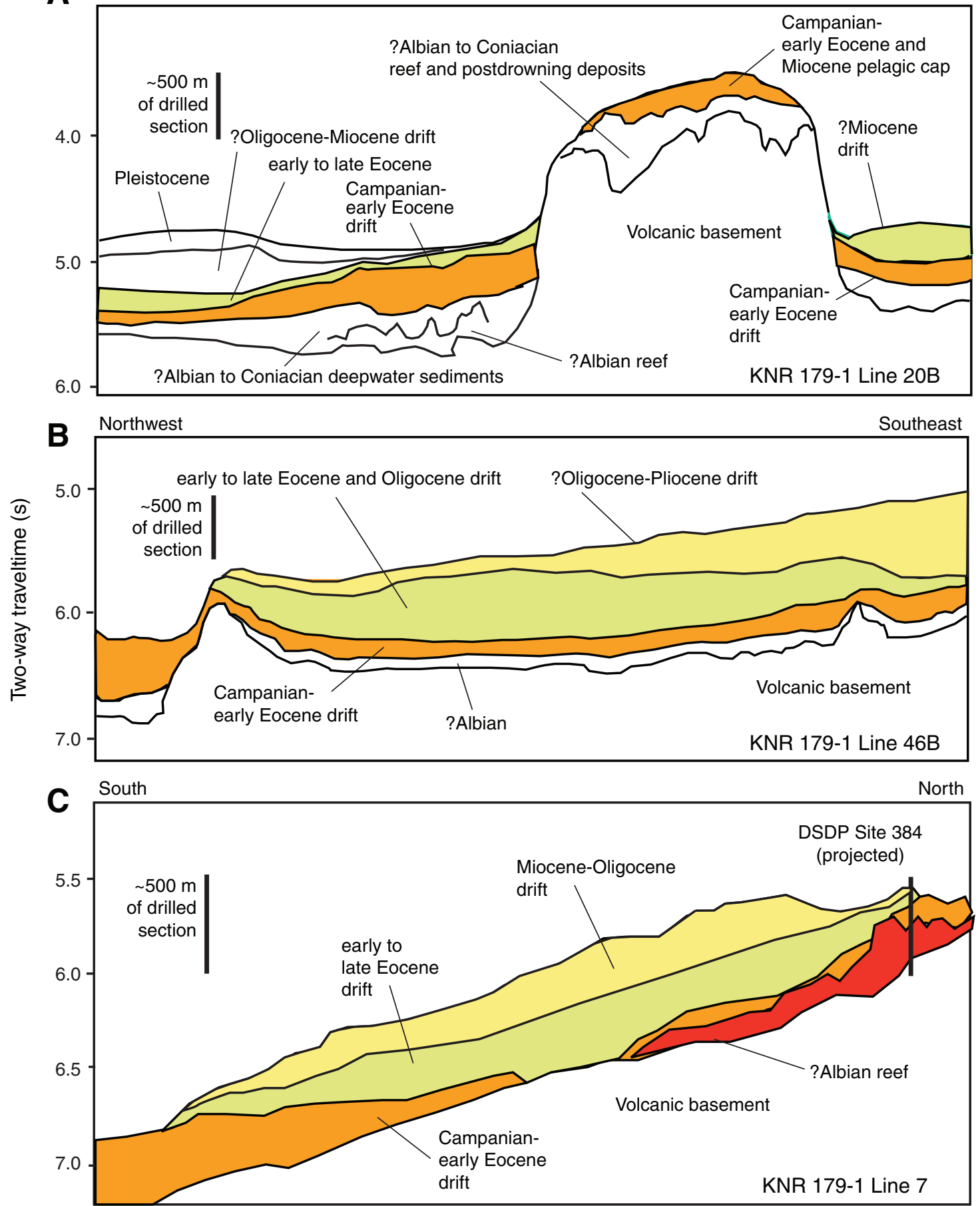
Figure F11. Multibeam bathymetric map of J-Anomaly Ridge based on the site survey by the R/V Knorr (KNR179-1). The major features are a series of largely buried seamounts surrounded by sinuous drifts of clay and nannofossil ooze, mostly of Oligocene and Miocene age, built on top of Eocene sediment drifts. Also shown are Expedition 342 drill sites on the large, smooth, pillow-like surface of the J-Anomaly sediment drift.

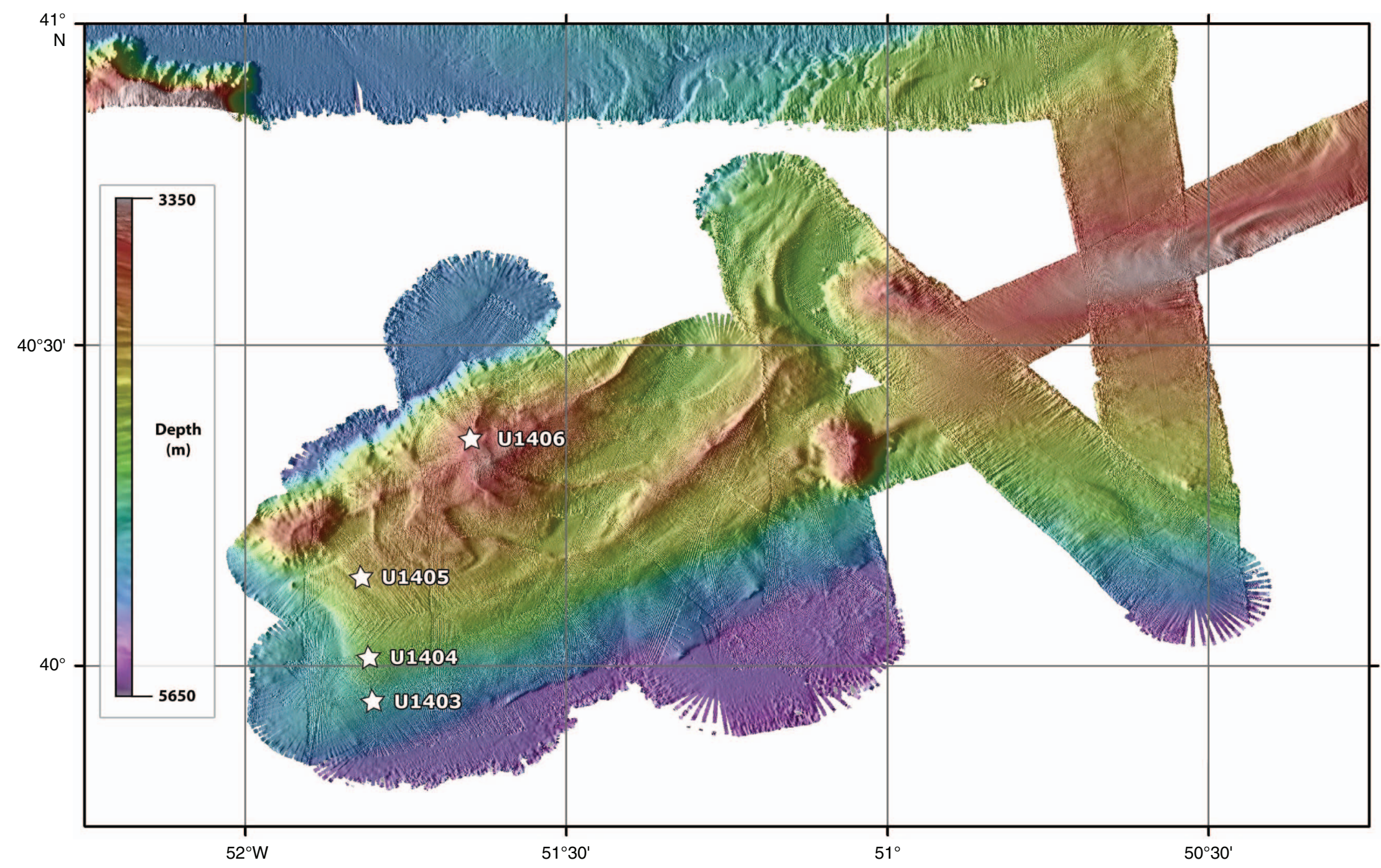


Figure F12. Multibeam bathymetric map of the seamount area of Southeast Newfoundland Ridge based on the site survey by the R/V Knorr (KNR179-1). Note the moat formed adjacent to the most distant seamount reflecting the long-term channeling of flow around the seamounts. Also note the partly sedimented seamount in the foreground, with basement exposures cropping out near the crest of the seamount and on its flanks. Expedition 342 drill sites (stars) were positioned on drifts developed as narrow piles of clay and nannofossil ooze either adjacent to the flow channels between seamounts (Sites U1409-U1411) or on ridge crests (Site U1407 and U1408).

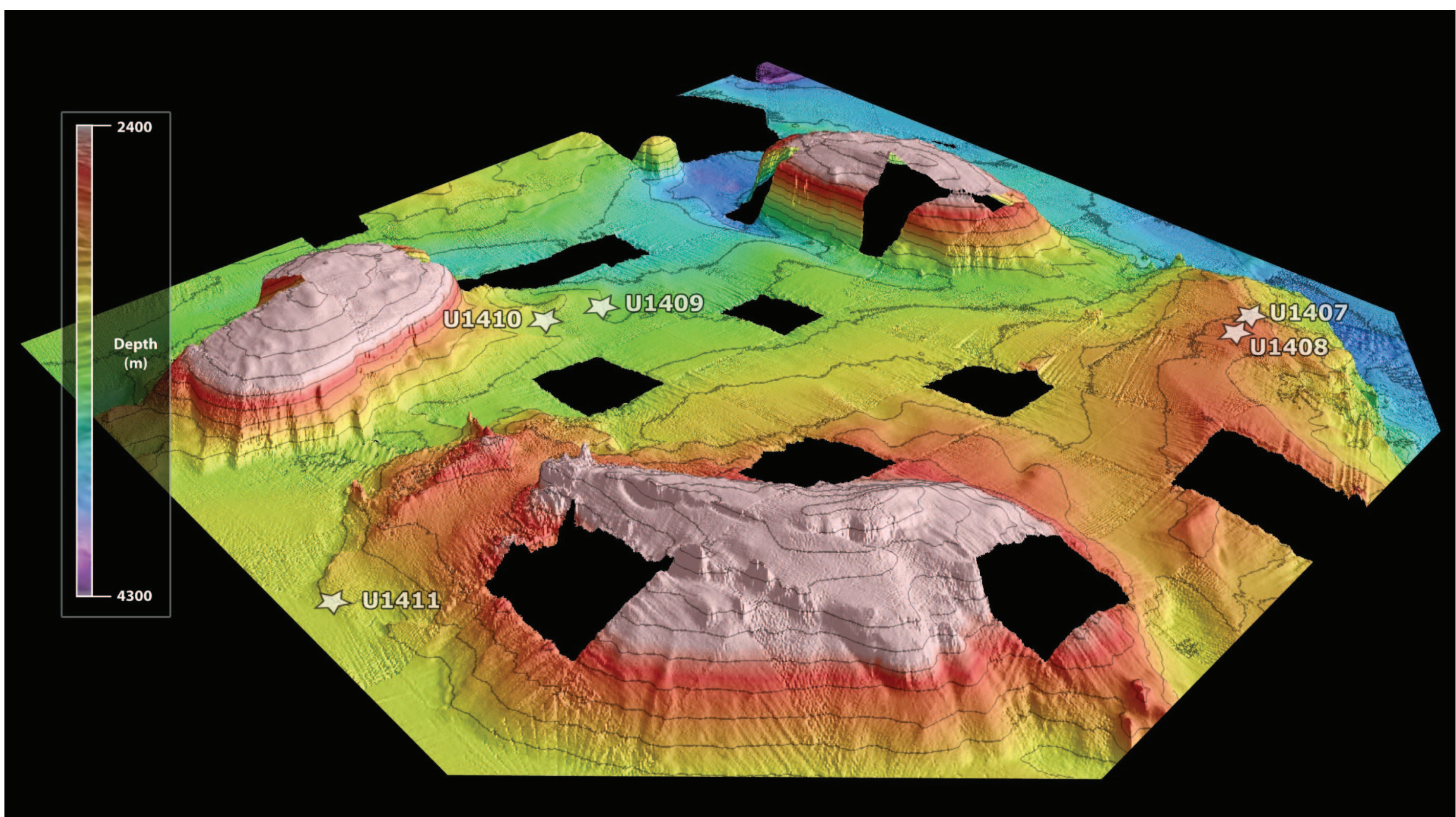


Figure F13. Schematics of past deployments of penetrometers with the colleted delivery system. A, B. Drill string pushes probe into formation. C. Successful deployment in which probe stays in ground and bottom-hole assembly slides upward as drill string is raised. D. Unsuccessful deployment in which partial coupling occurs between drill string and colleted delivery system, partially pulling tool out of hole. E. Good penetration record characterized by abrupt increase in pressure, followed by slow dissipation of pressure while tool is left in ground. F. Poor penetration record characterized by sharp drop in pore pressure during pullout, resulting in subhydrostatic pressure that gradually builds back to formation pressure. G. Pressure and temperature response during an unsuccessful deployment. When the drill string is raised (bit depth decreases), pore pressures drop abruptly and temperature rises because the probe is being pulled out of the formation.

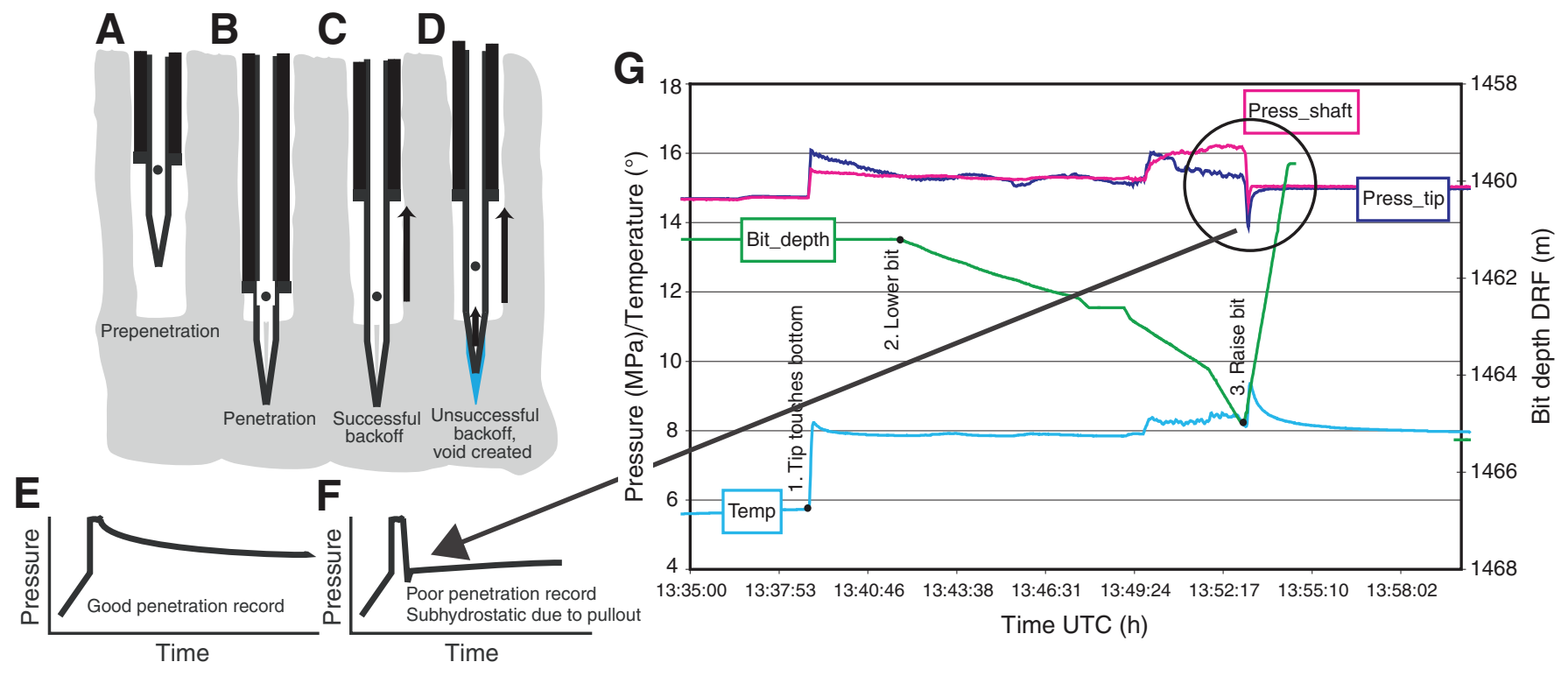


Figure F14. Diagrams of Motion Decoupled Hydraulic Delivery System (MDHDS) deployment stages, Expedition 342. A. The MDHDS reaches the bottom-hole assembly. B. The electronic release system (ERS) releases the MDHDS and lifts $3 \mathrm{~m}$. C. Upon release of the penetrometer, full circulation is achieved at a stroke of $2.9 \mathrm{~m}$. D. The MDHDS is raised $2 \mathrm{~m}$, placing it in mid-stroke for maximum heave accommodation. E. Once the test is complete, the ERS is lowered and latches onto the release system fishing neck. F. The entire unit is brought to the surface.
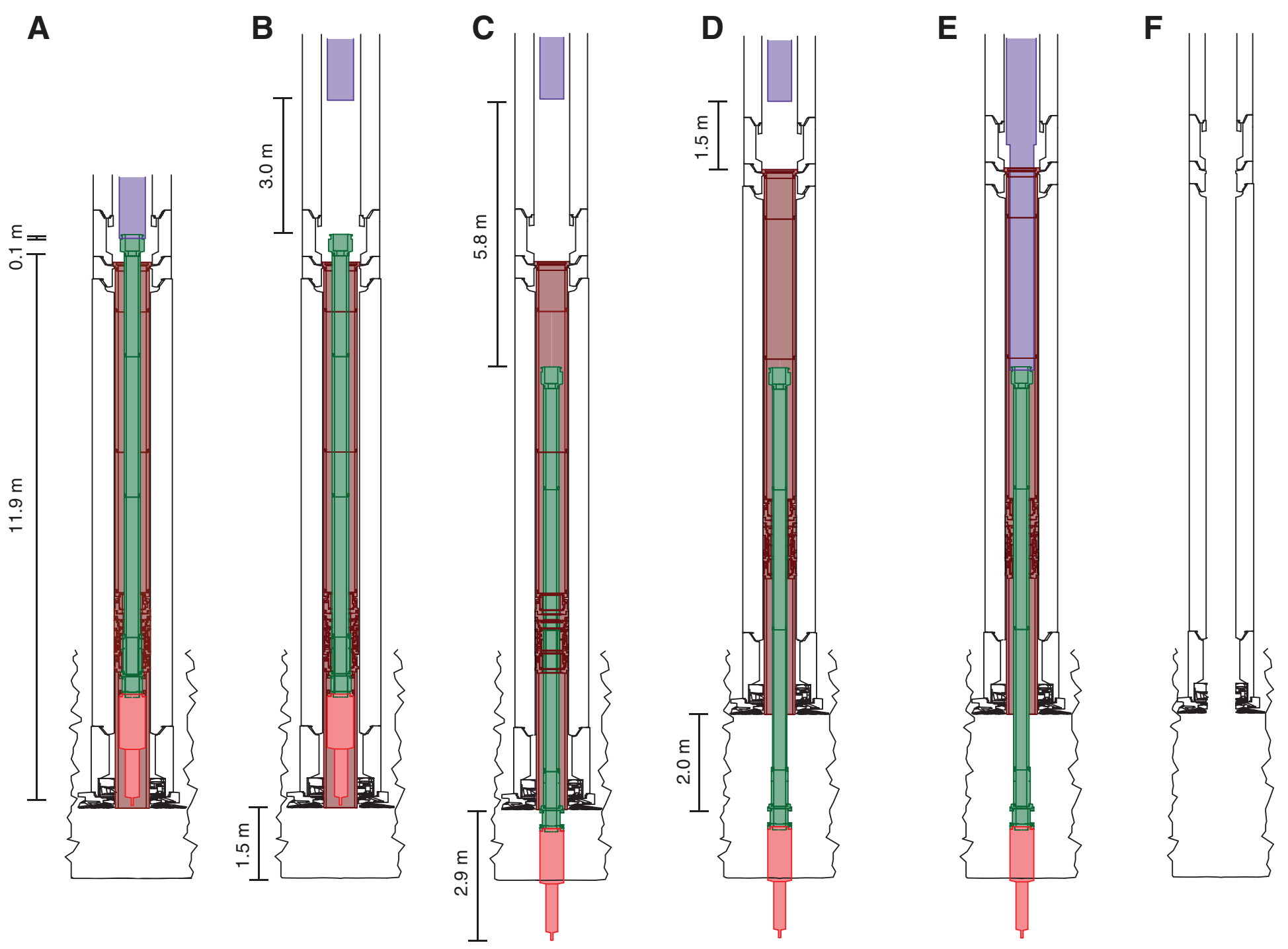
Figure F15. Bathymetric map showing the two main drill site areas of Expedition 342. Approximate pathways of modern Deep Western Boundary Current (DWBC) are also shown.

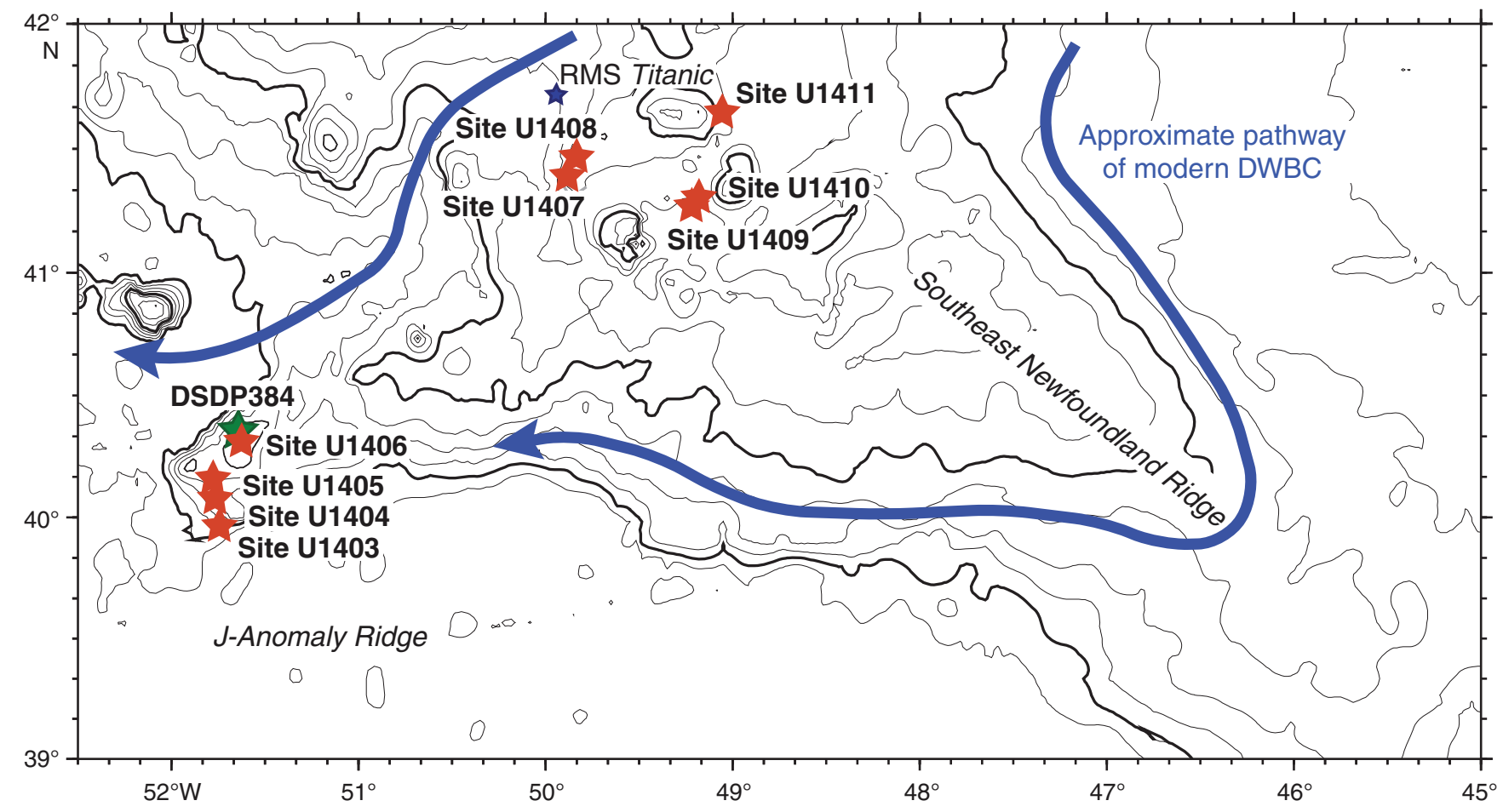


Figure F16. A. Perspective bathymetric map (view to the northwest) of J-Anomaly Ridge with locations of Sites U1403-U1406. B. Bathymetric map and seismic reflection trackline survey of the westernmost part of J-Anomaly Ridge with locations and water depths of Sites U1403-U1406. C. Perspective image of seismic reflection Lines 7 and 5 (view to the east-northeast) with positions, water depth, and approximate penetrated depths of Sites U1403-U1406 and DSDP Site 384.

\section{C}

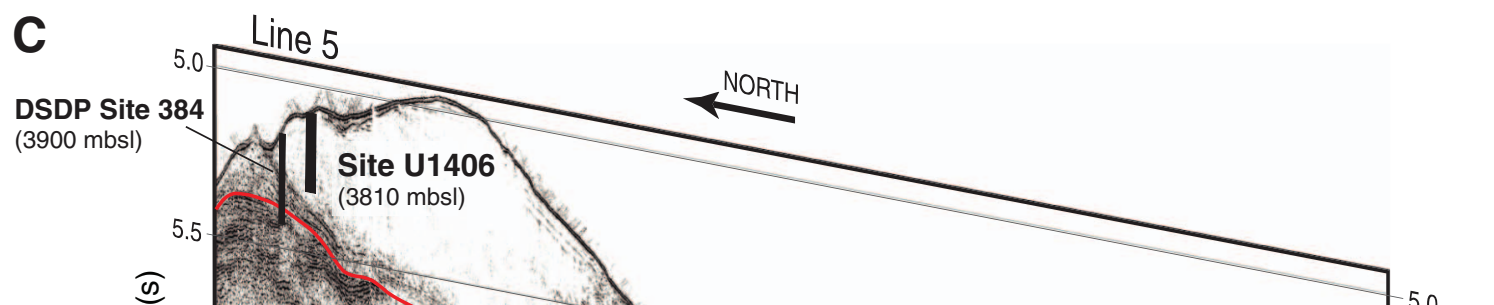

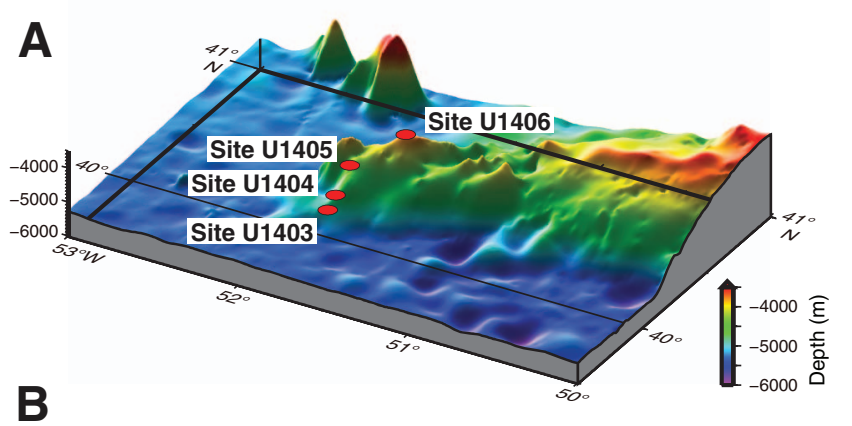

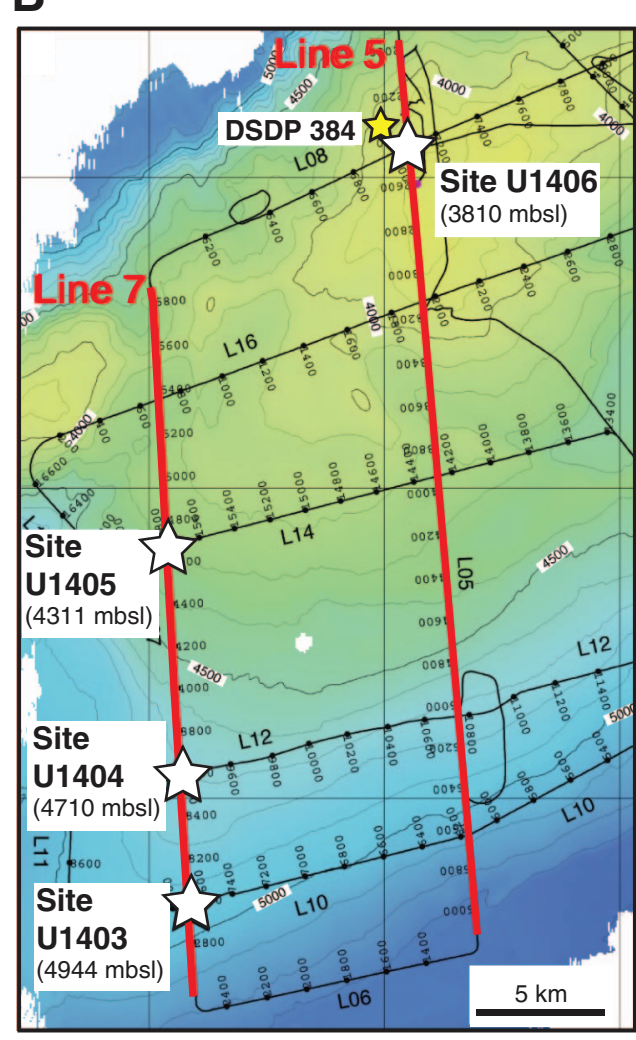

\section{B}

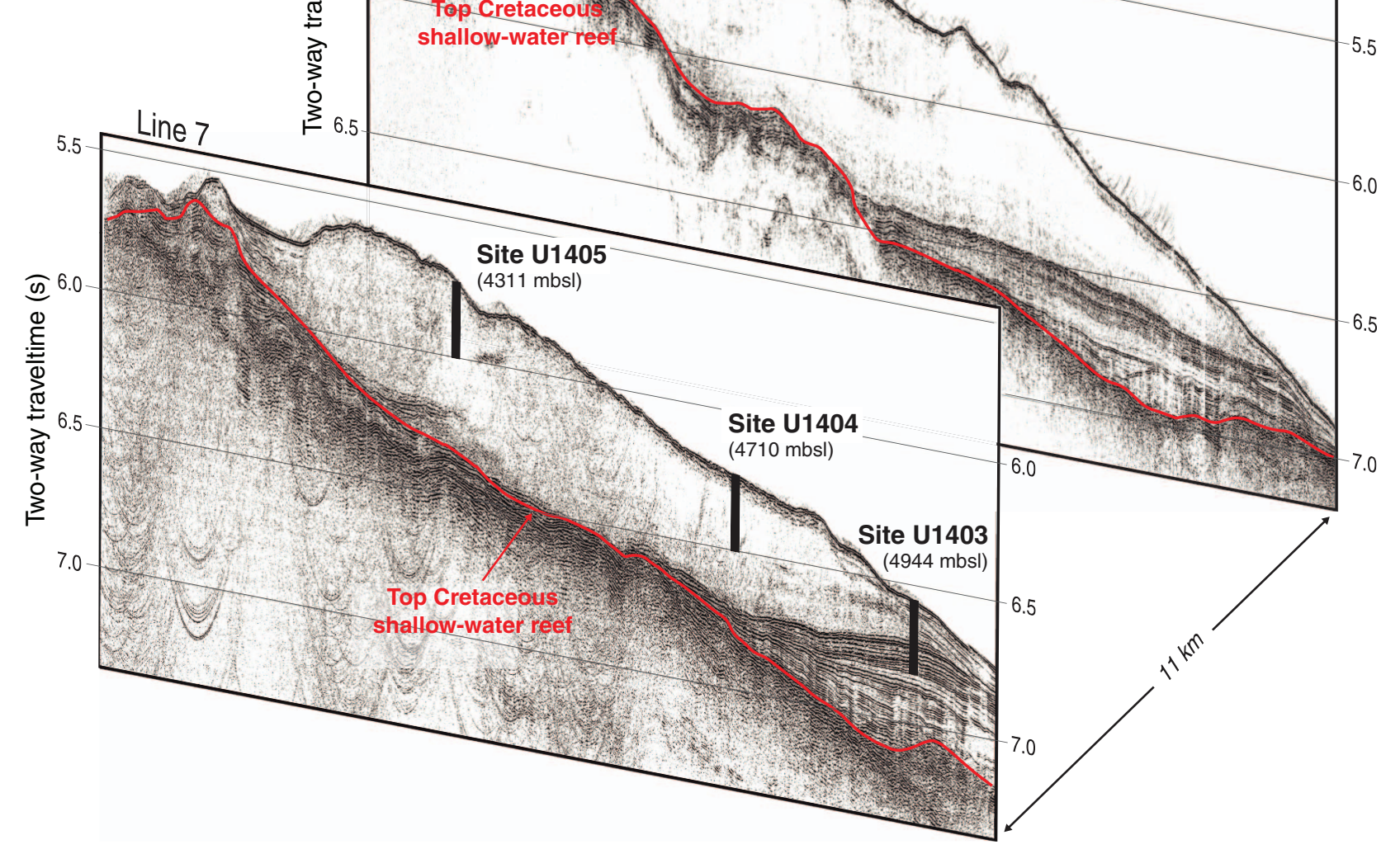


Figure F17. Generalized Paleogene to early Neogene history of drift sedimentation at J-Anomaly Ridge and Southeast Newfoundland Ridge with images of the acoustic expression (right side of figure) of each major lithostratigraphic unit. Sedimentation rates refer to maximum linear sedimentation rate as determined from agedepth plots combined from the multiple sites in each of the two areas. Hatched areas represent hiatuses or intervals where age cannot be determined. Onset of drift sedimentation interpreted from combination of oldest occurrence of distinctive greenish gray clay-rich lithology and relatively high sedimentation rates.

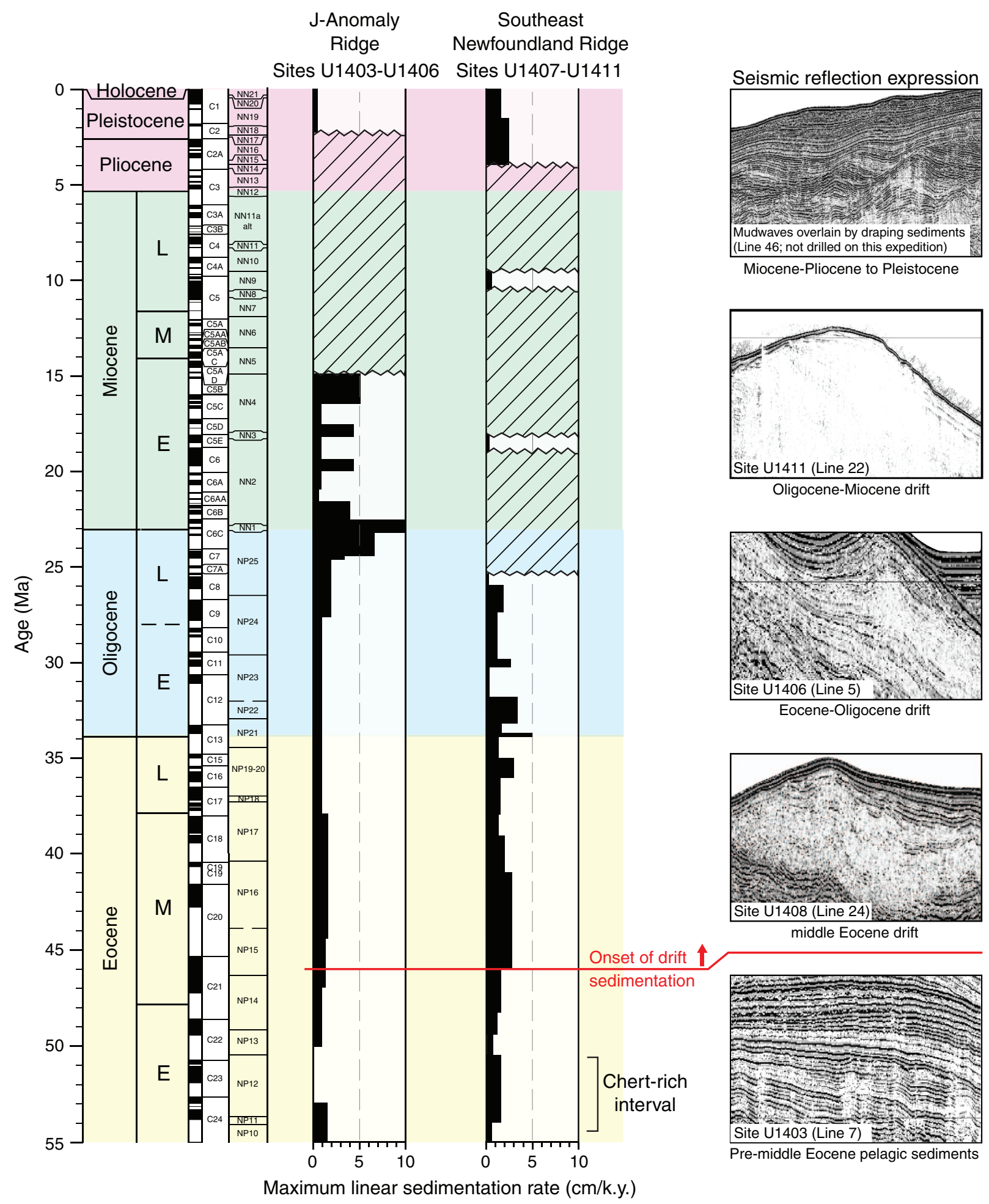




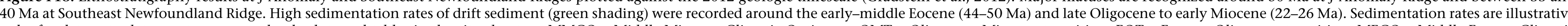

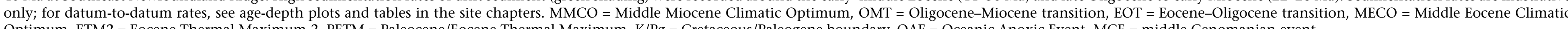
Optimum, ETM2 = Eocene Thermal Maximum 2, PETM = Paleocene/Eocene Thermal Maximum, K/Pg = Cretaceous/Paleogene boundary, OAE = Oceanic Anoxic Event, MCE = middle Cenomanian event.

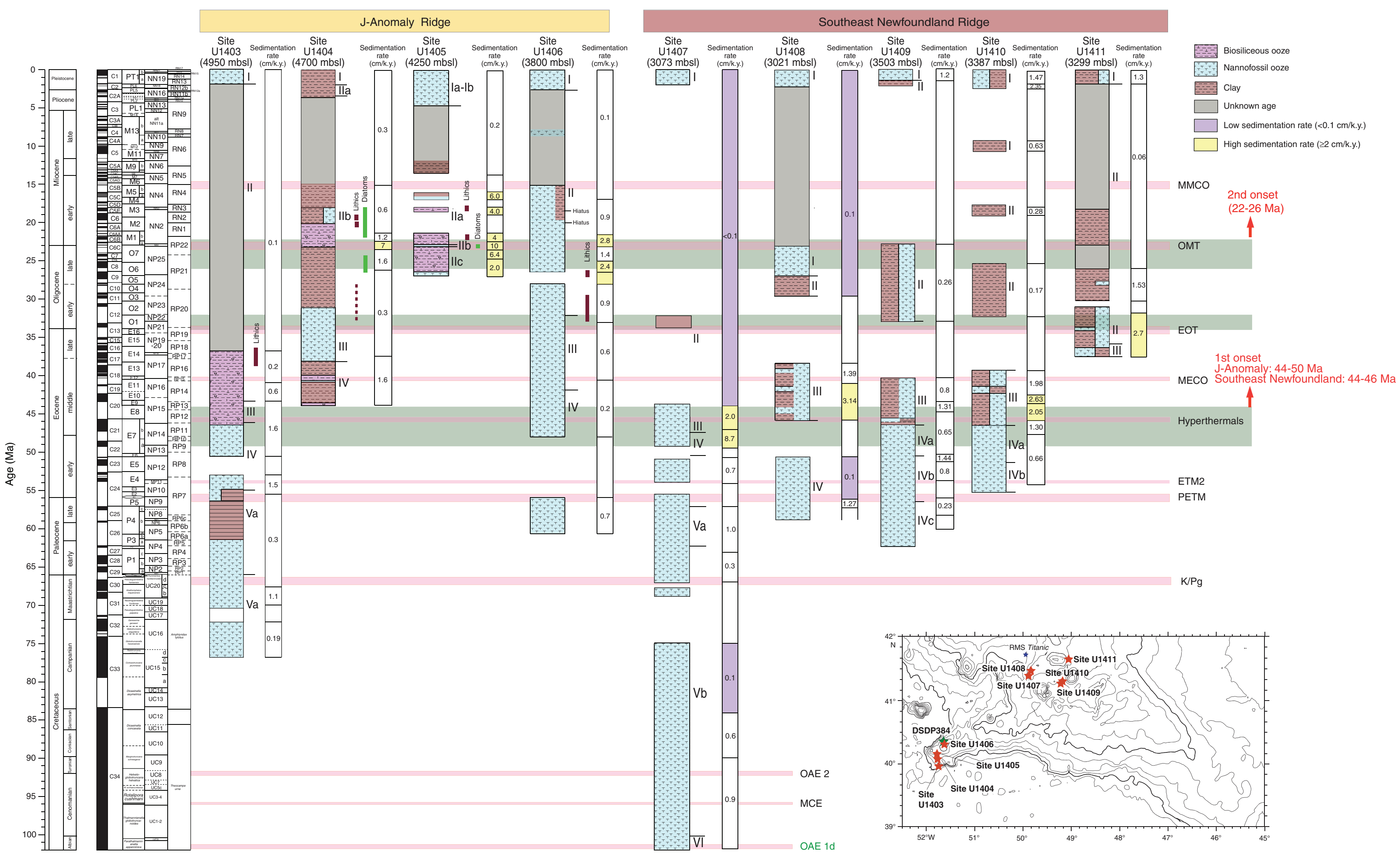


Figure F19. Magnetic susceptibility records at J-Anomaly and Southeast Newfoundland Ridges, Sites U1403U1411. Shaded areas follow stratigraphic color scheme in Figure F17.

Magnetic susceptibility (IU)
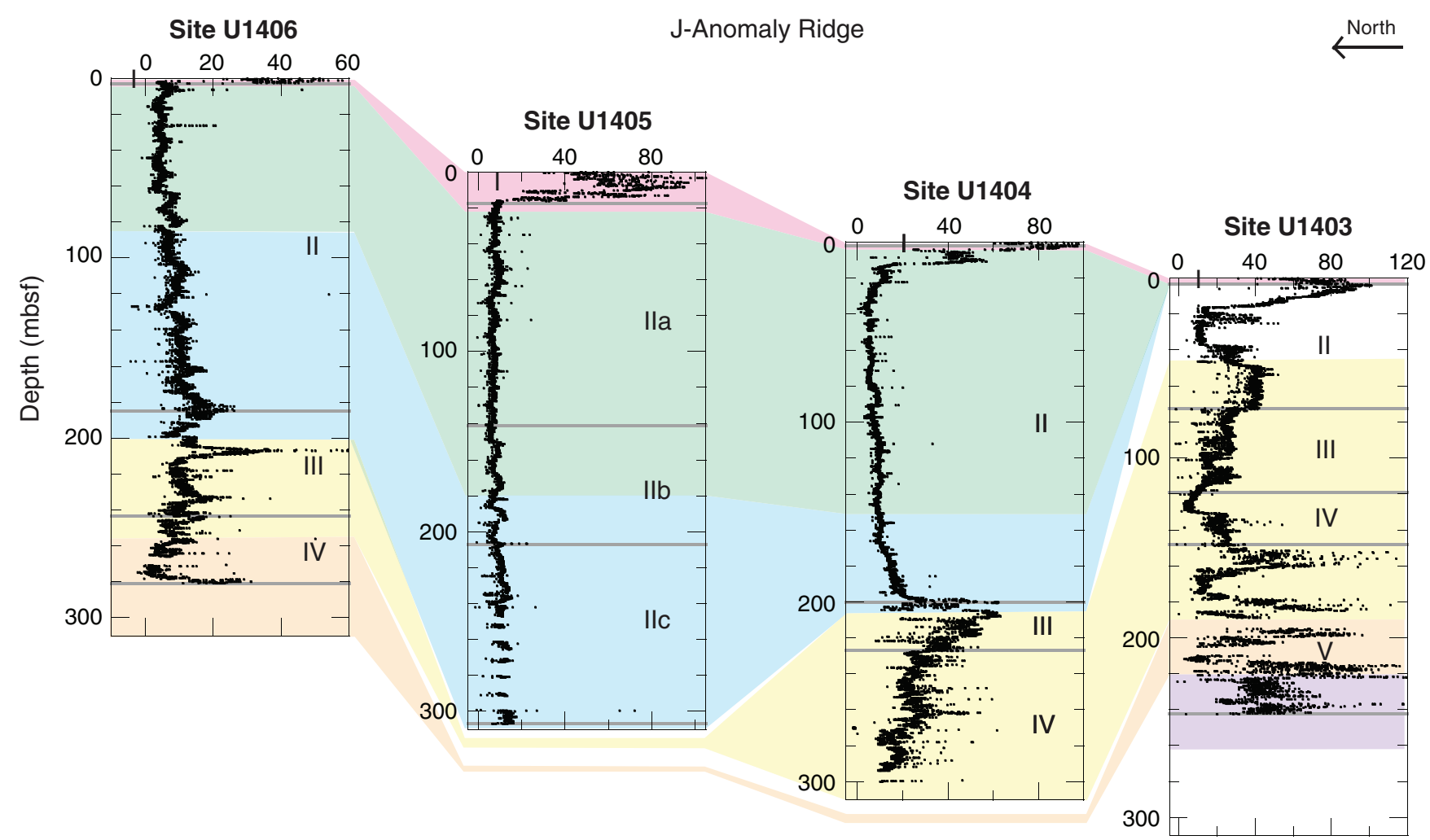

J-Anomaly Ridge

$\longleftarrow$

Southeast Newfoundland Ridge

Northeast
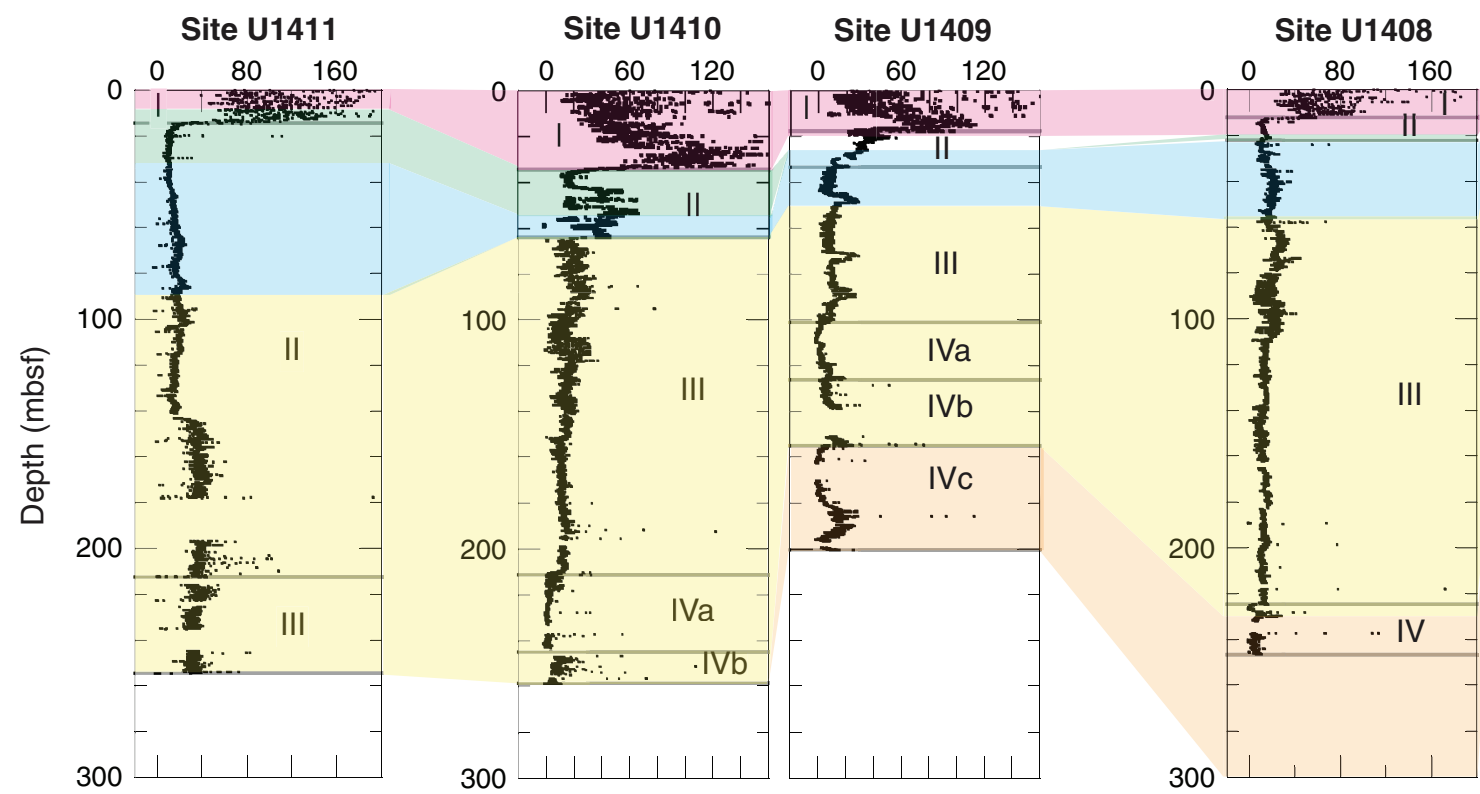

Site U1407

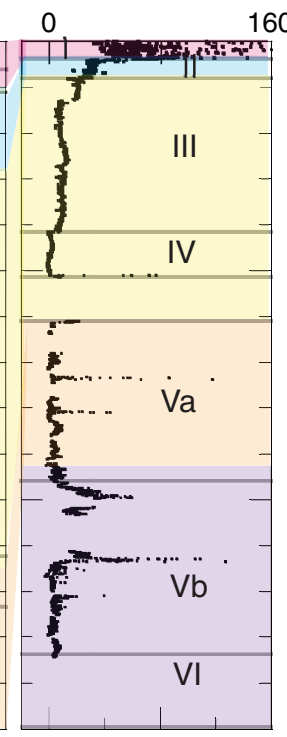


Figure F20. Bulk density records at J-Anomaly and Southeast Newfoundland Ridges, Sites U1403-U1411. Black circles = discrete moisture and density measurements, gray lines = gamma ray attenuation core logging measurements converted to bulk density. Shaded areas follow stratigraphic color scheme in Figure F17.

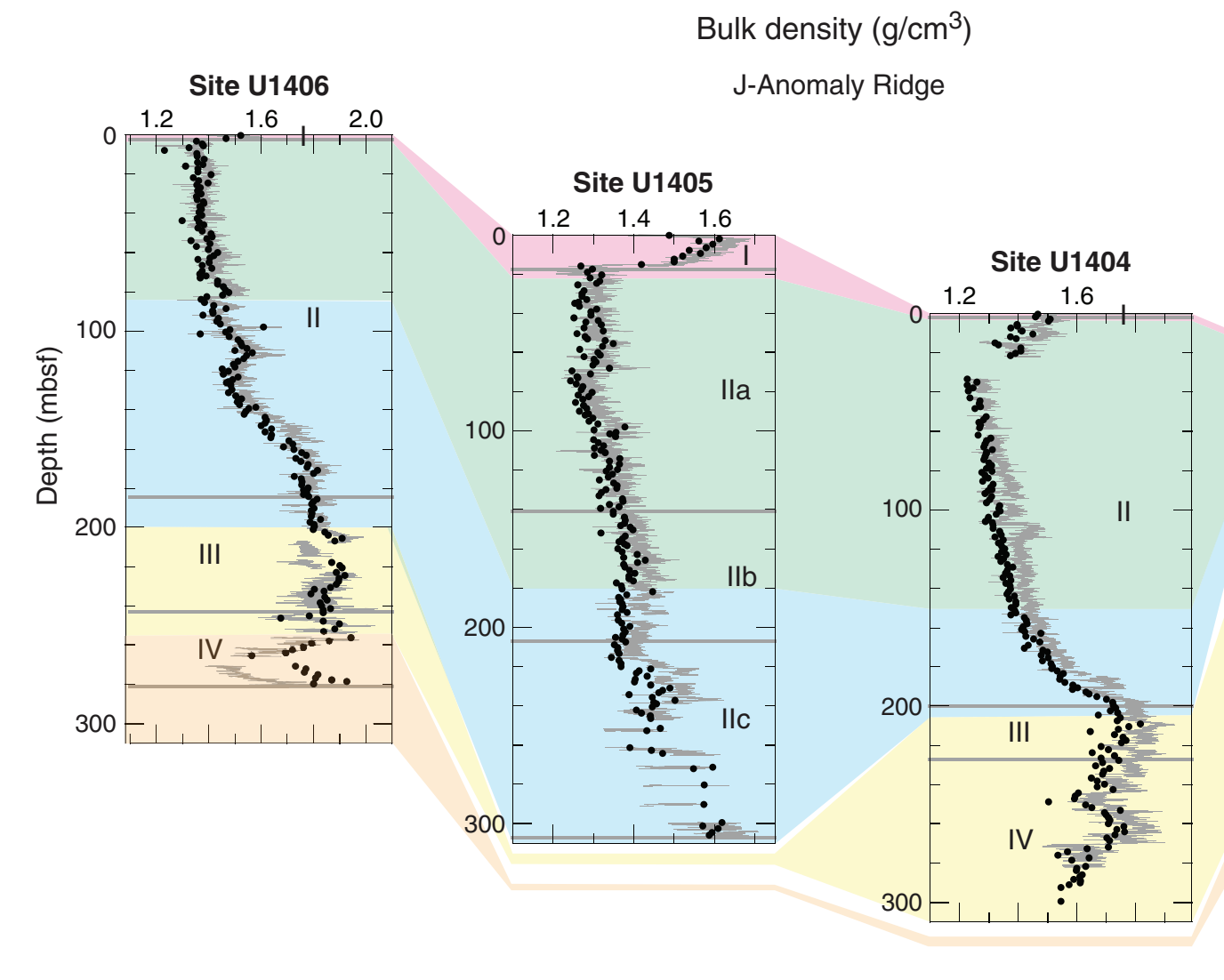

Bulk density $\left(\mathrm{g} / \mathrm{cm}^{3}\right)$

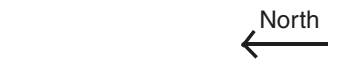

Southeast Newfoundland Ridge
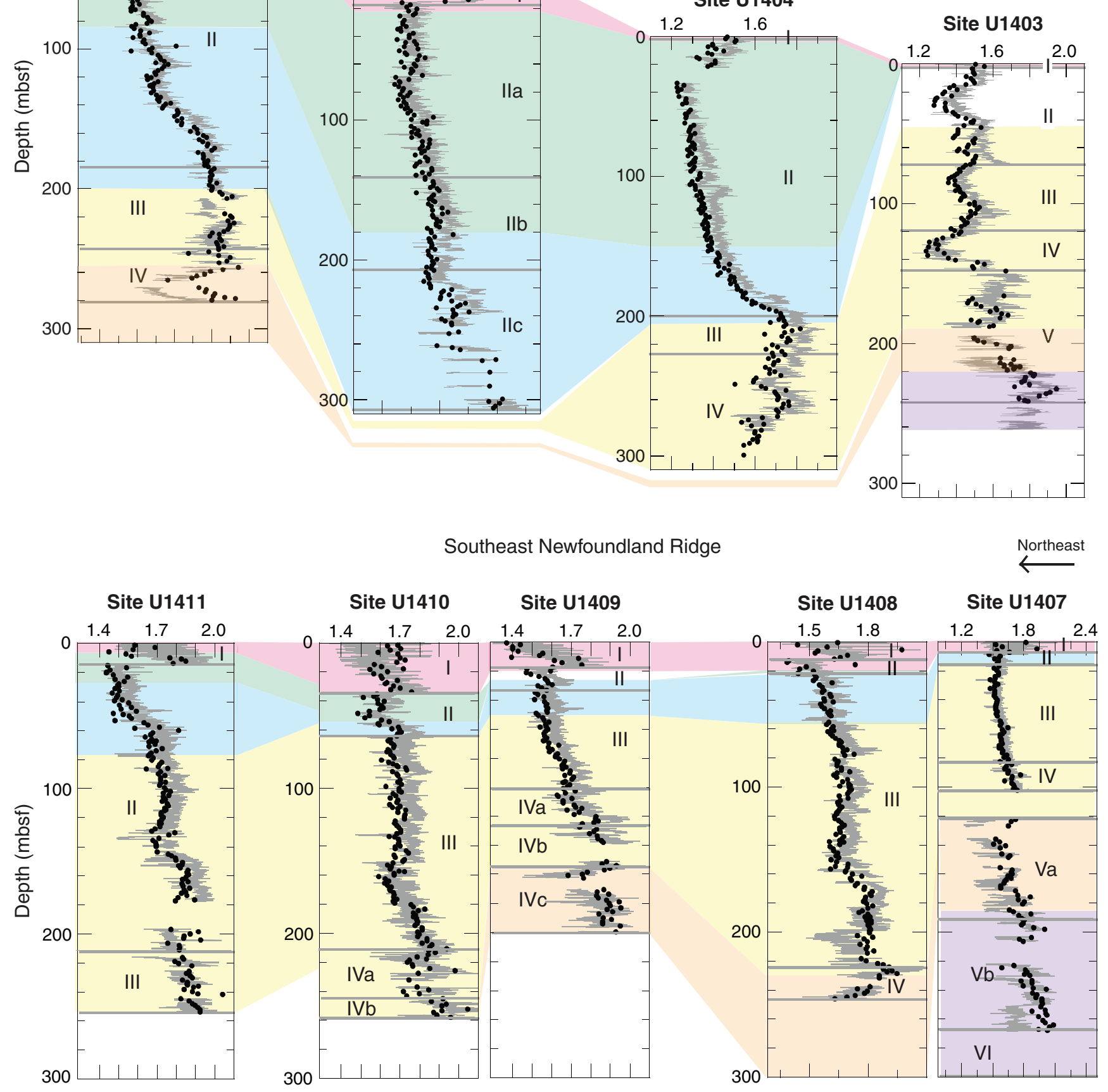

Site U1407

Northeast

$\longleftarrow$ 
Figure F21. Natural gamma radiation (NGR) records at J-Anomaly and Southeast Newfoundland Ridges, Sites U1403-U1411. Shaded areas follow stratigraphic color scheme in Figure F17.

NGR (cps)

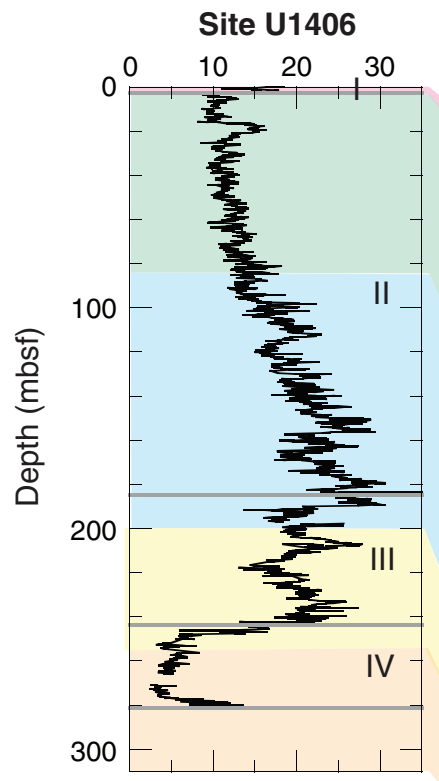

J-Anomaly Ridge

$\longleftarrow^{\text {North }}$

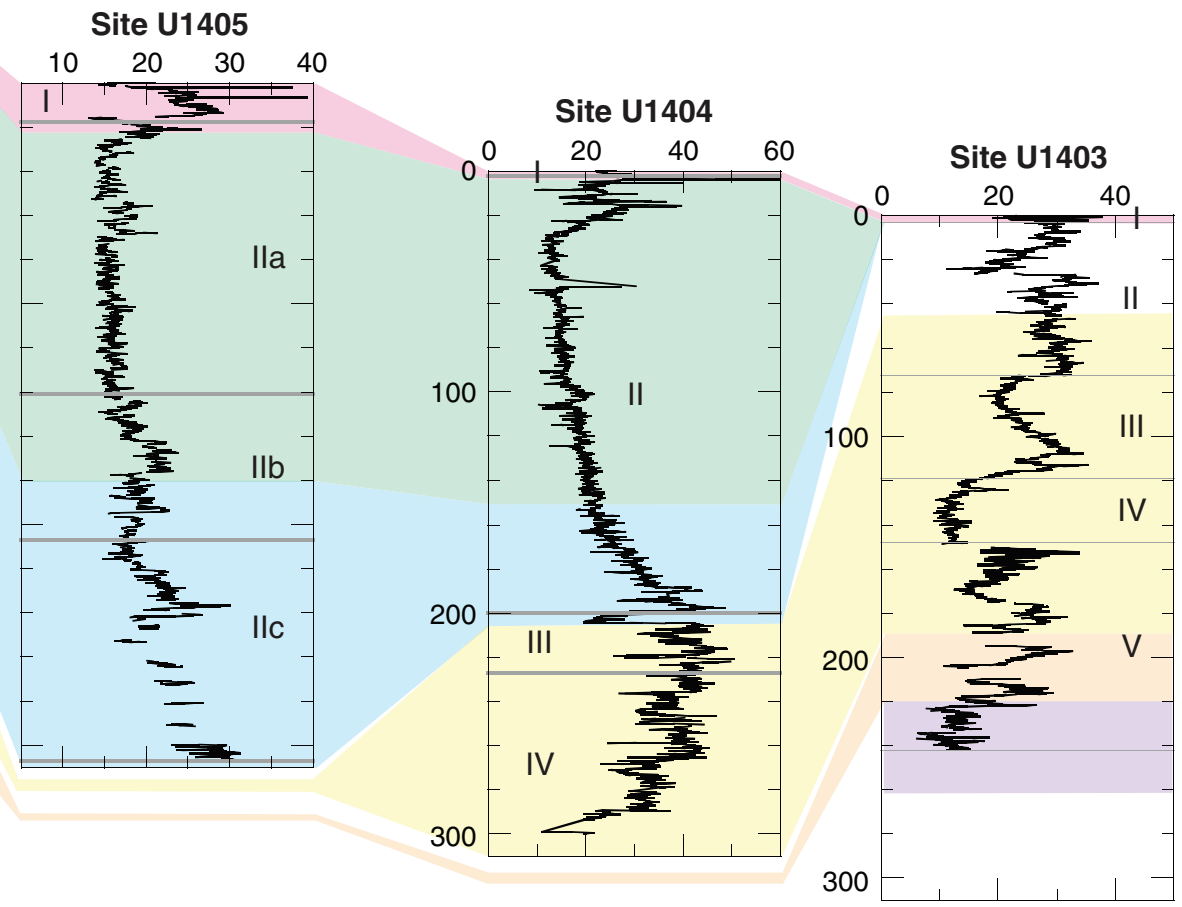

Southeast Newfoundland Ridge

Northeast
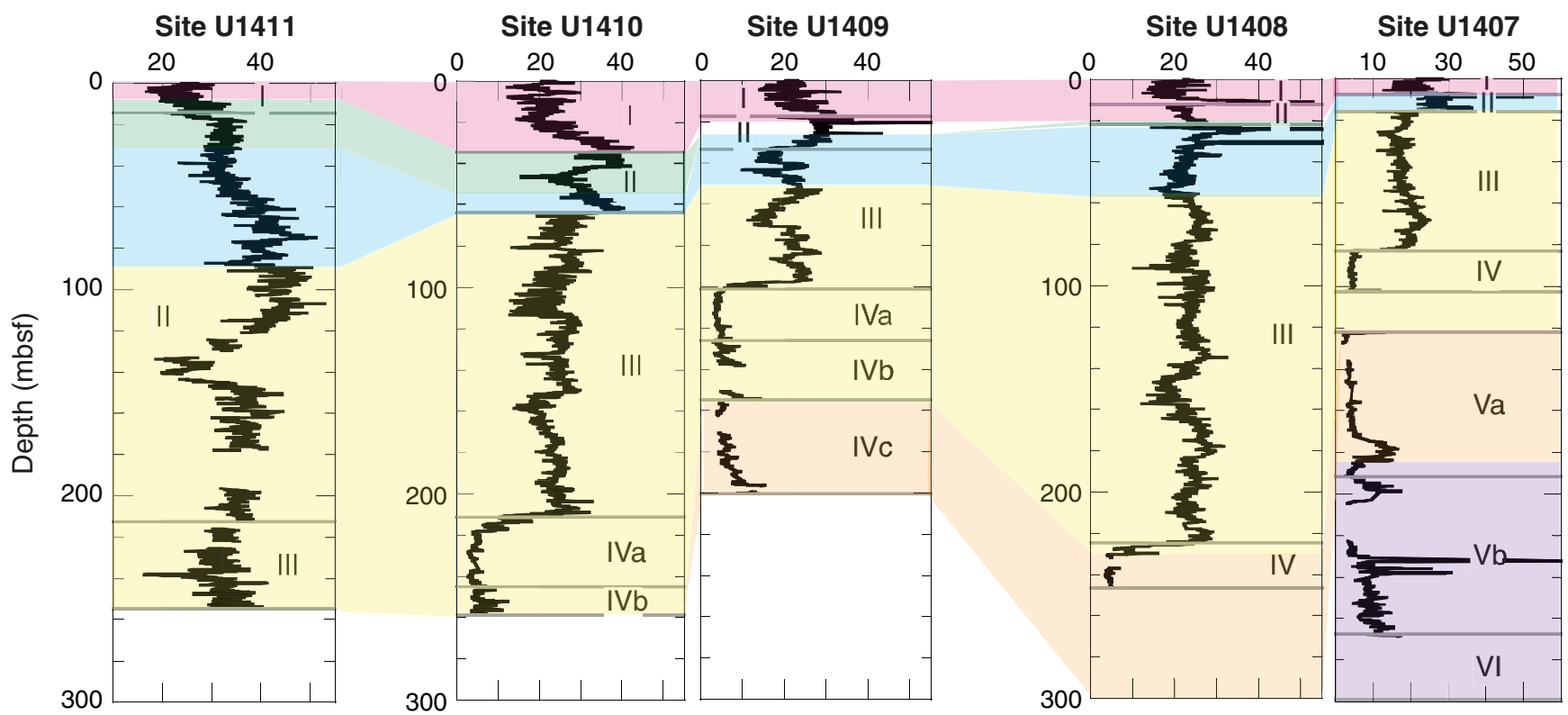
Figure F22. Color reflectance lightness records at J-Anomaly and Southeast Newfoundland Ridges, Sites U1403-U1411. Shaded areas follow stratigraphic color scheme in Figure F17.

Color reflectance $\mathrm{L}^{*}$

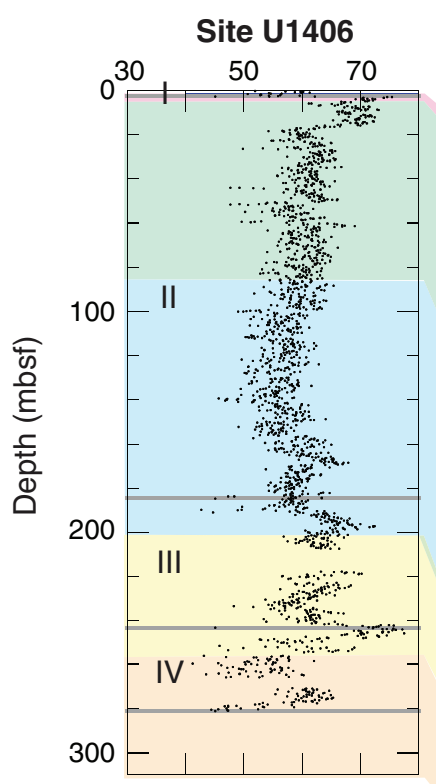

J-Anomaly Ridge
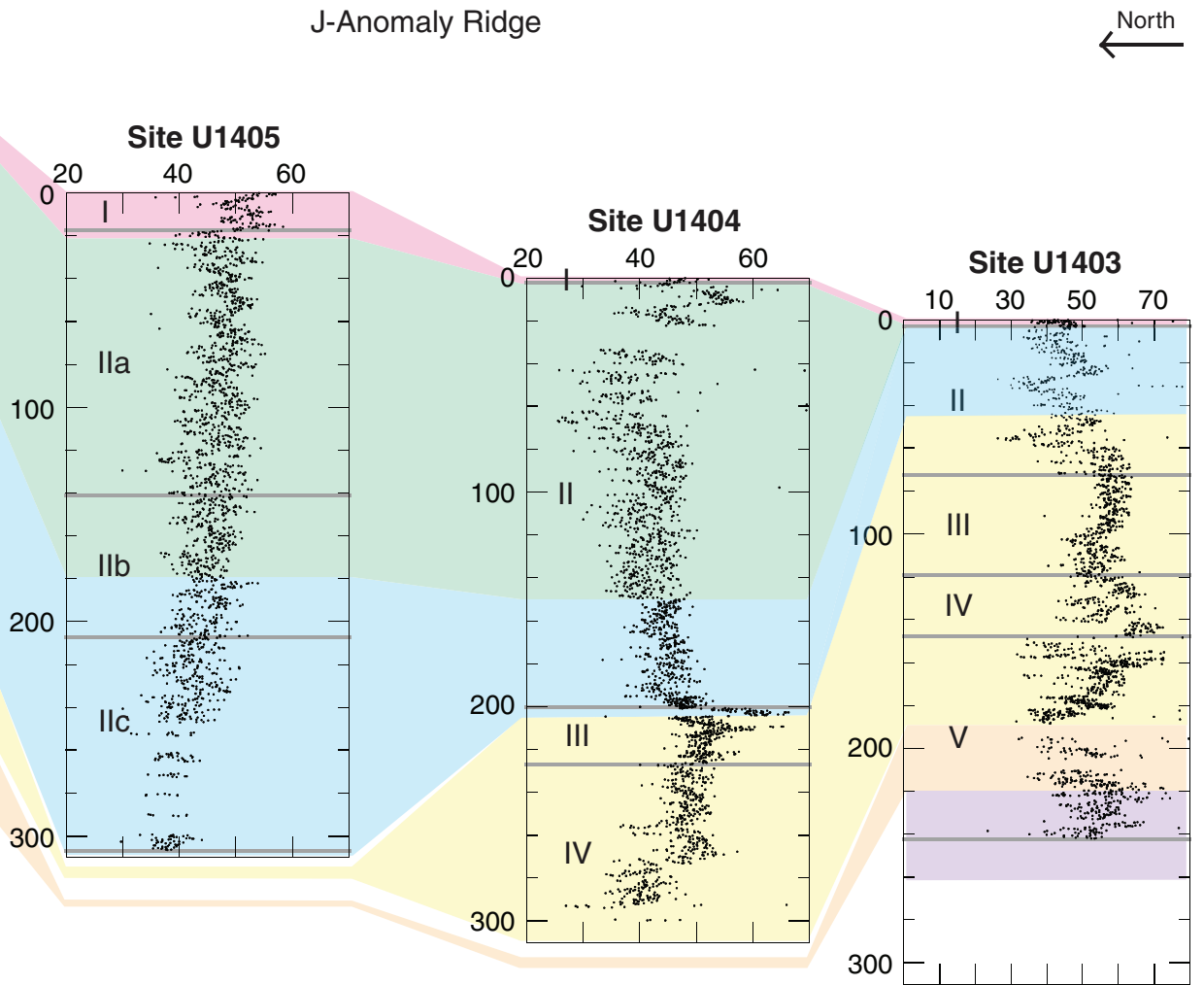

Southeast Newfoundland Ridge

$\stackrel{\text { Northeast }}{\longleftarrow}$
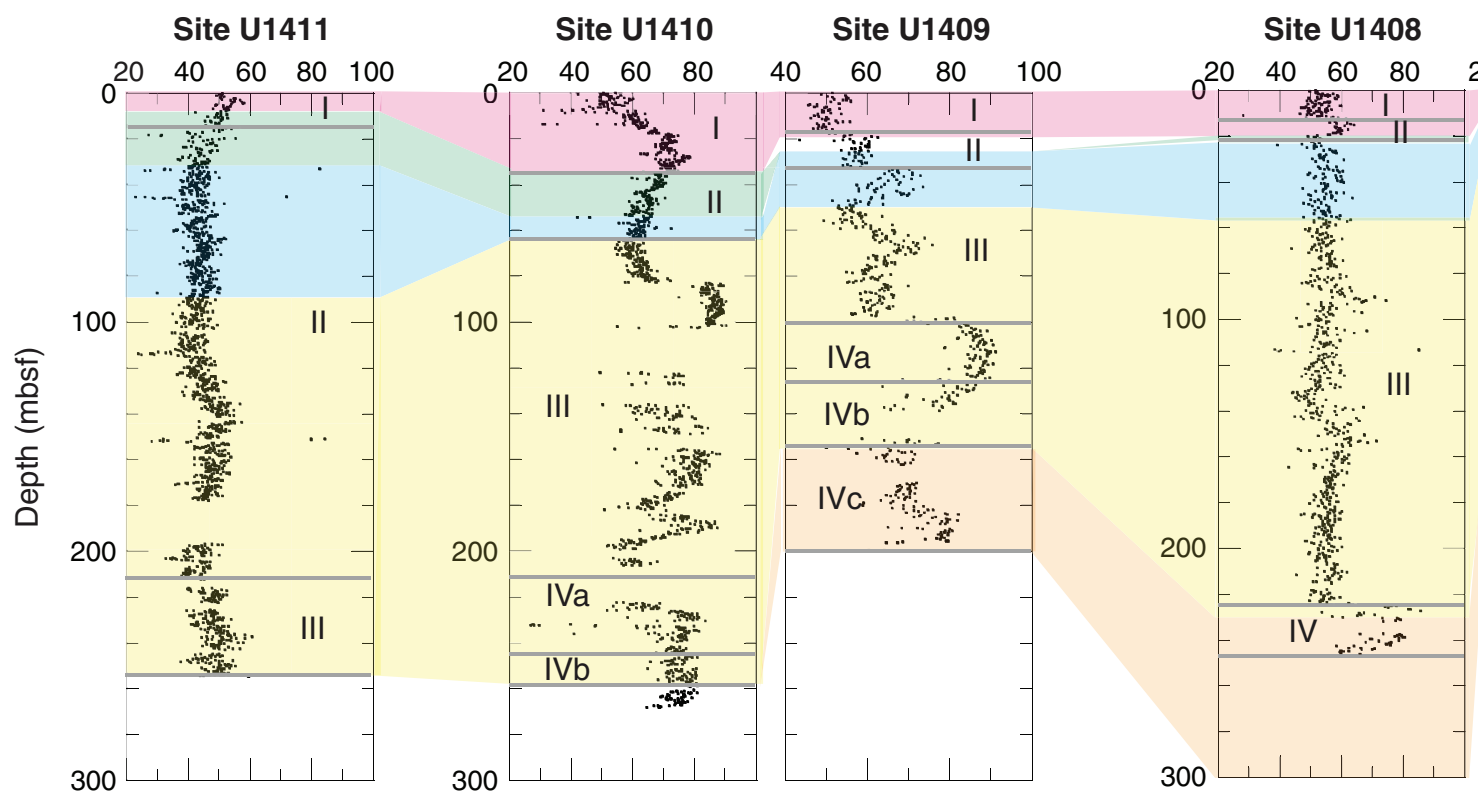

Site U1407

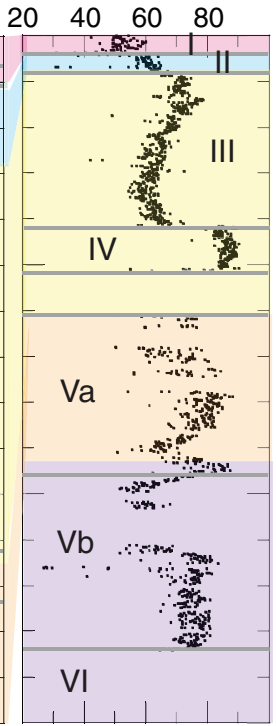




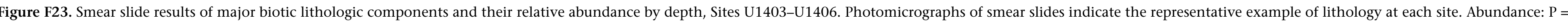
poor, $\mathrm{F}$ = few, $\mathrm{C}=$ common, $\mathrm{A}=$ abundant, $\mathrm{VA}$ = very abundant
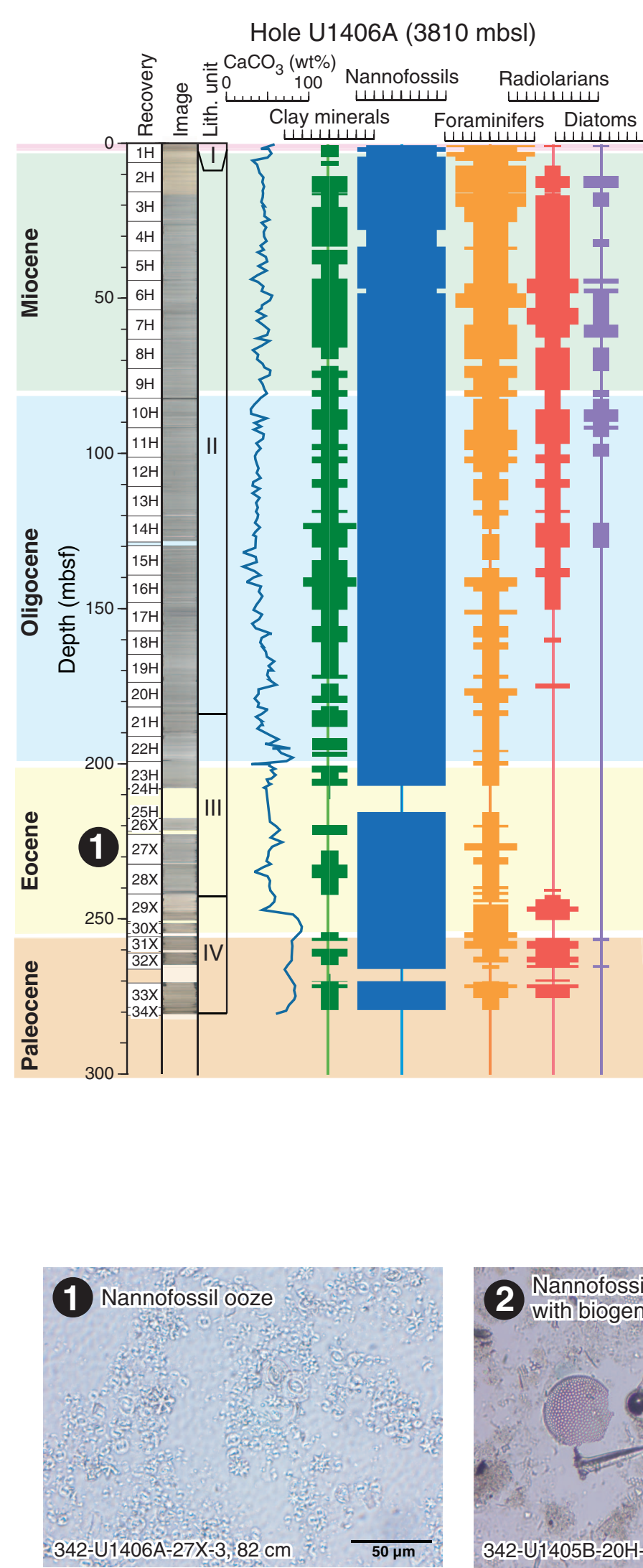

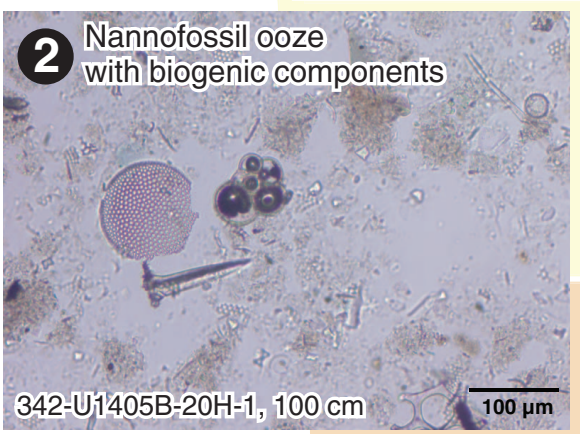

Hole U1405A (4250 mbsl)

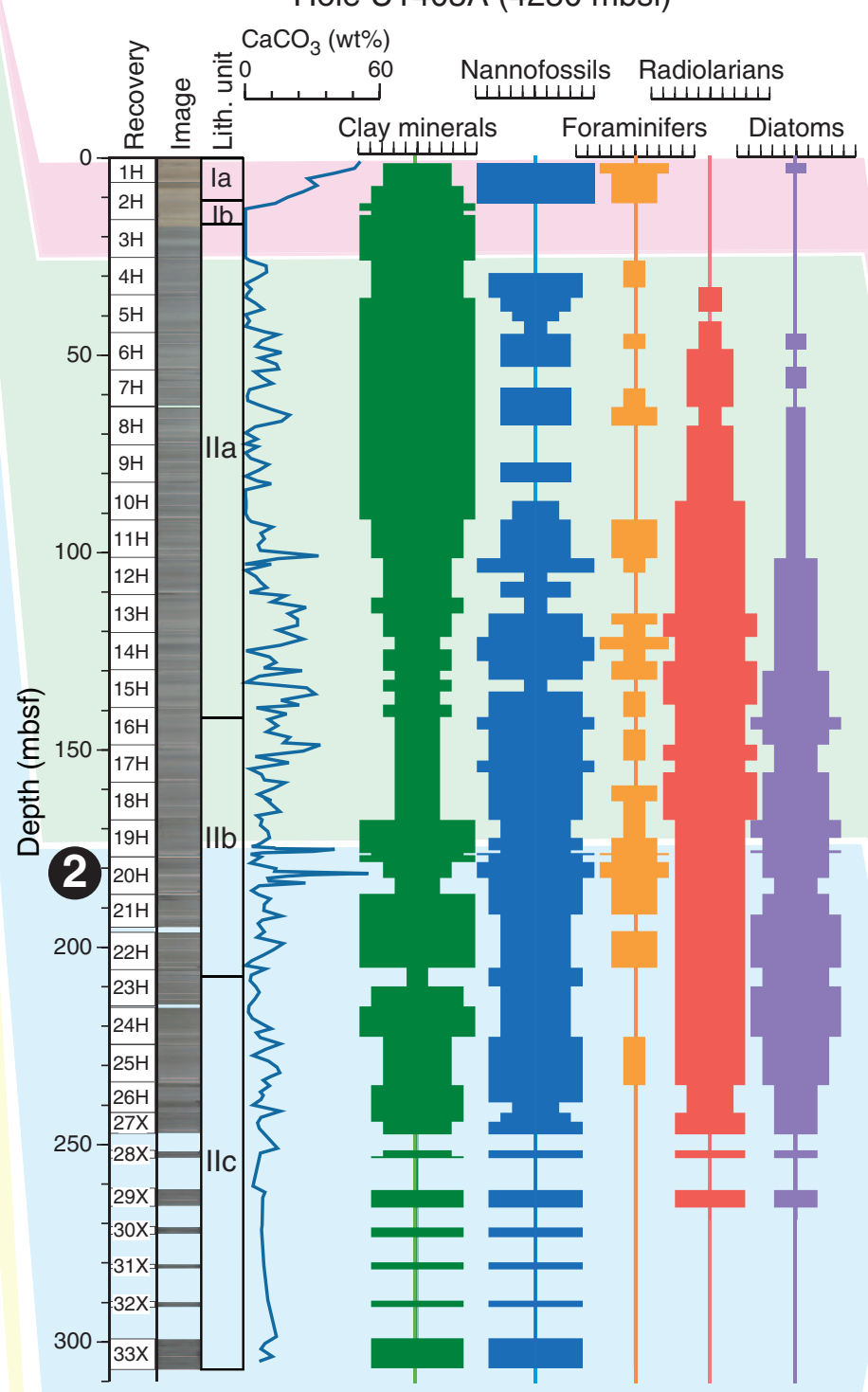

\section{3}

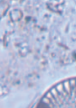

6

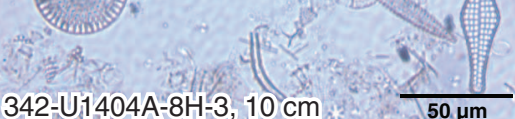

342-U1403B-7H-2, $109 \mathrm{~cm} \quad \overline{50 ~ \mu m ~}$

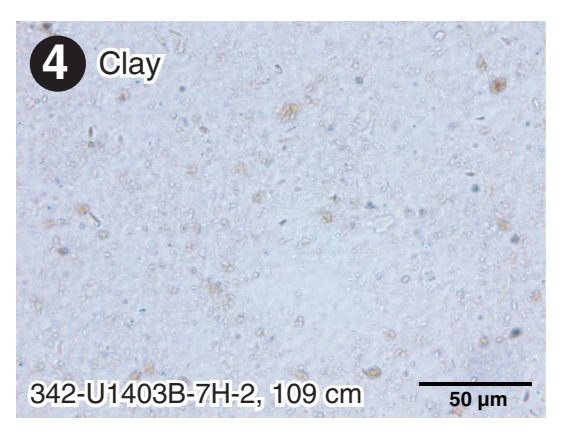

Hole U1404A (4700 mbsl)
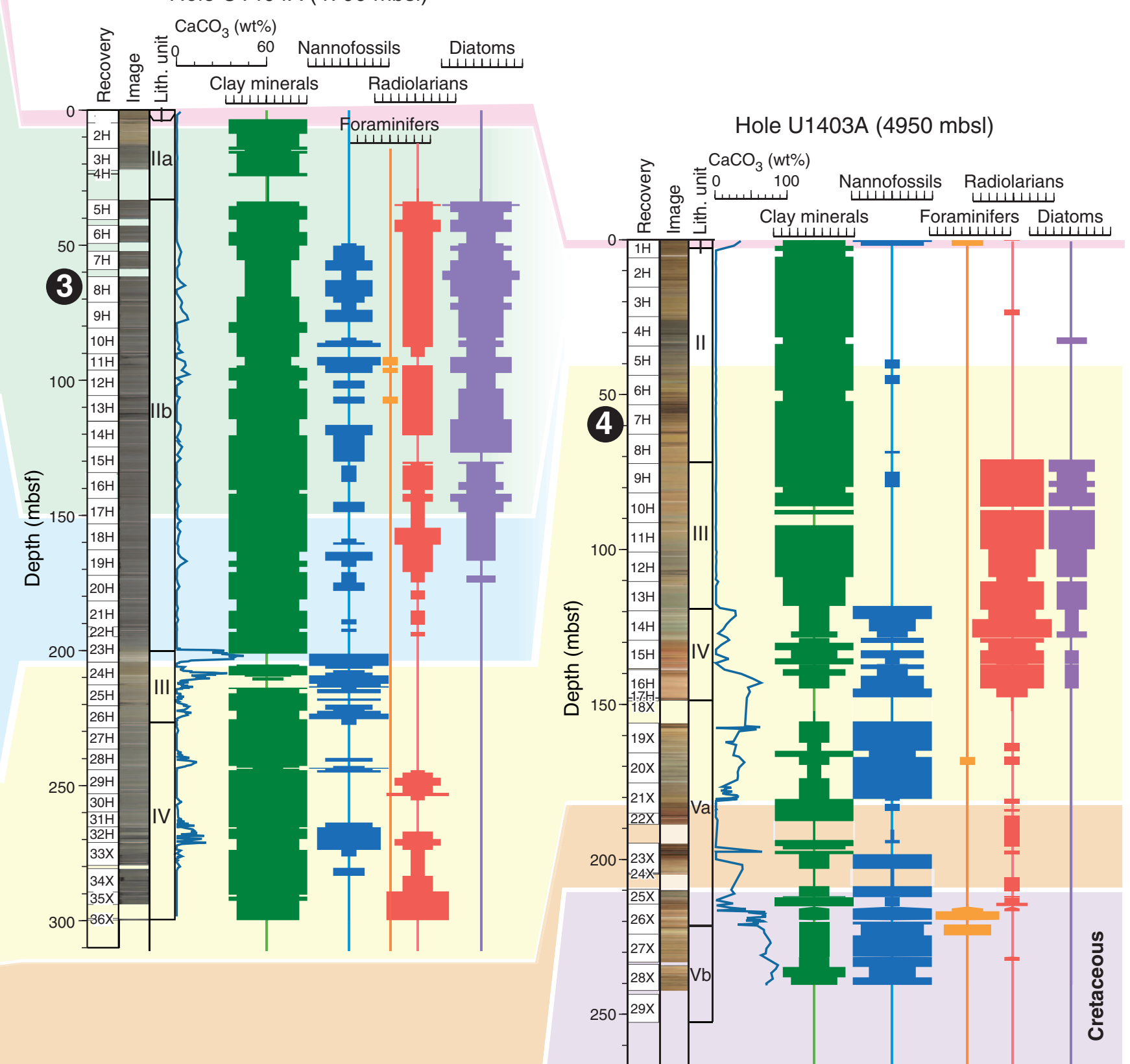
作 poor, $\mathrm{F}=$ few, $\mathrm{C}=$ common, $\mathrm{A}$ = abundant, $\mathrm{VA}$ = very abundant

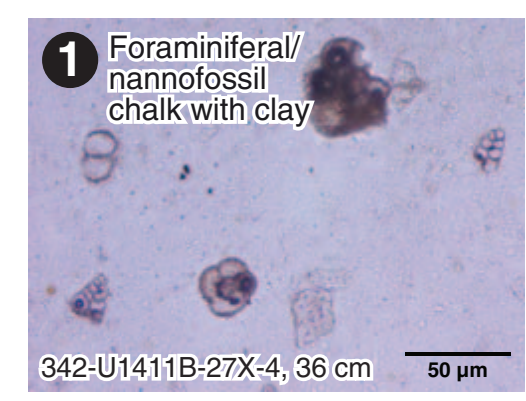

Hole U1411B (3300 mbsl)

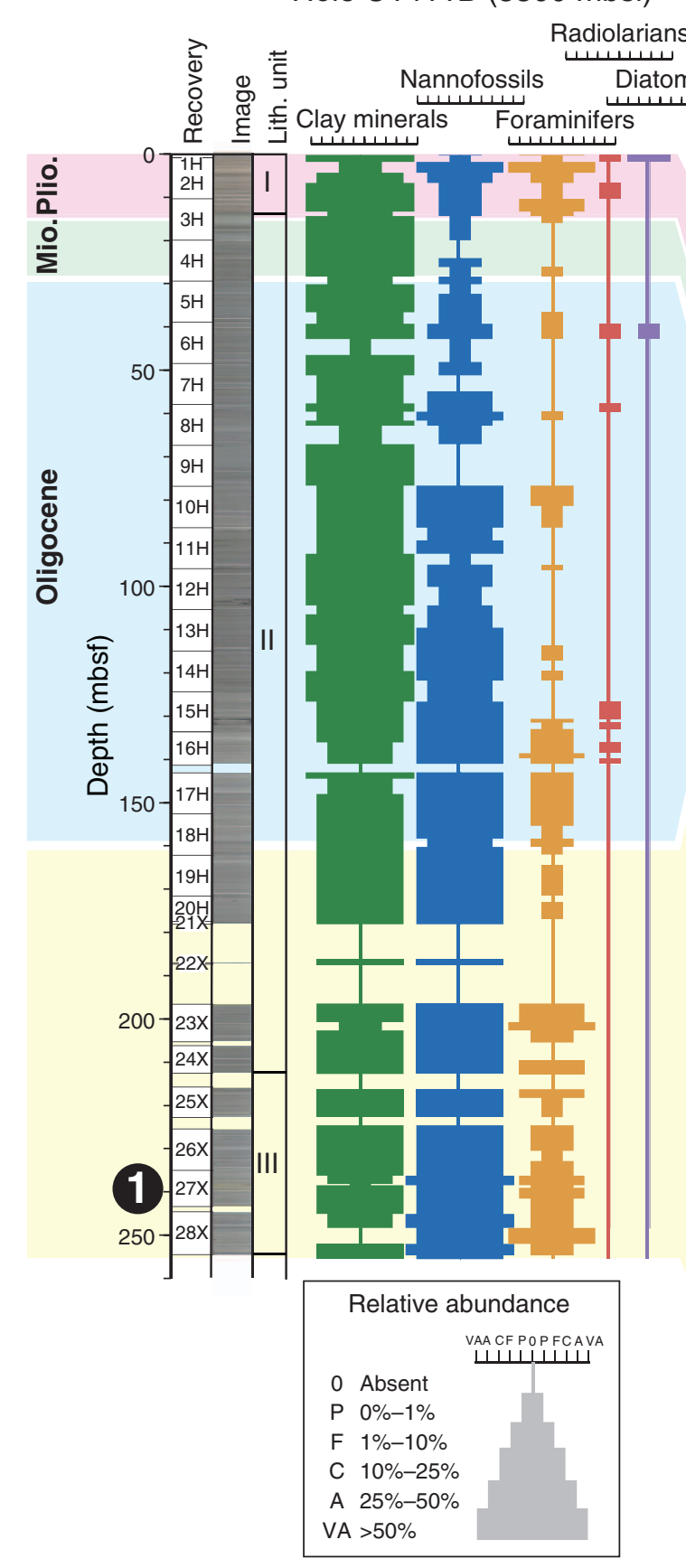

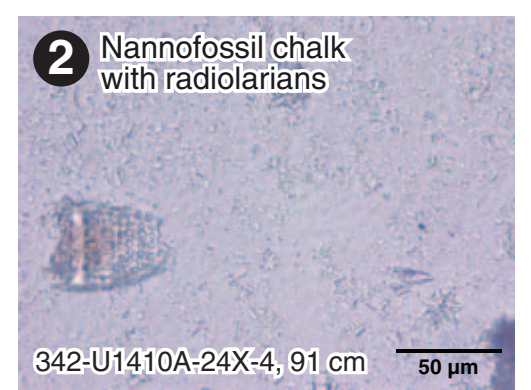
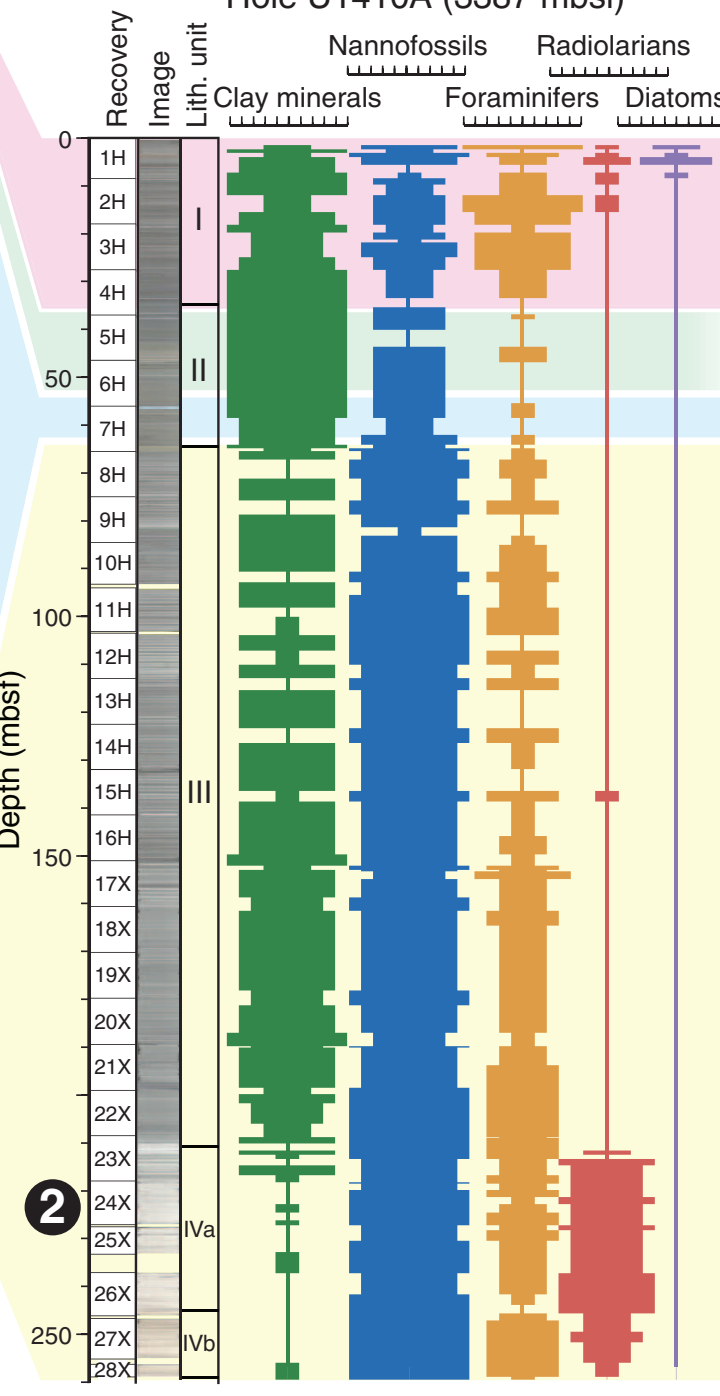

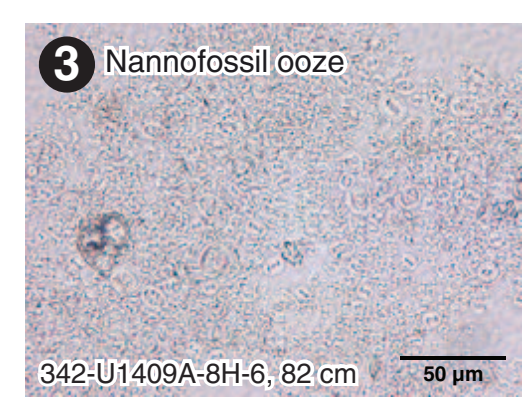

le U1409A (3500 mbsl)

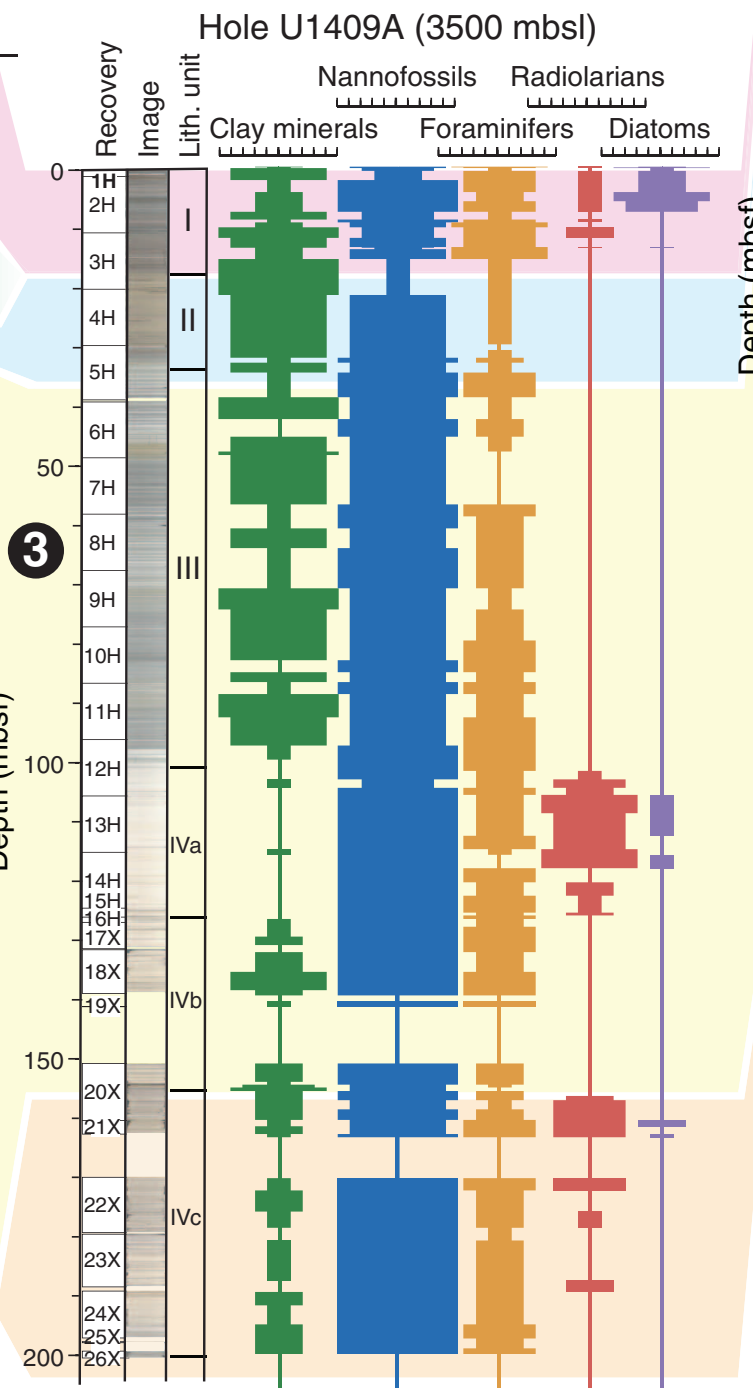

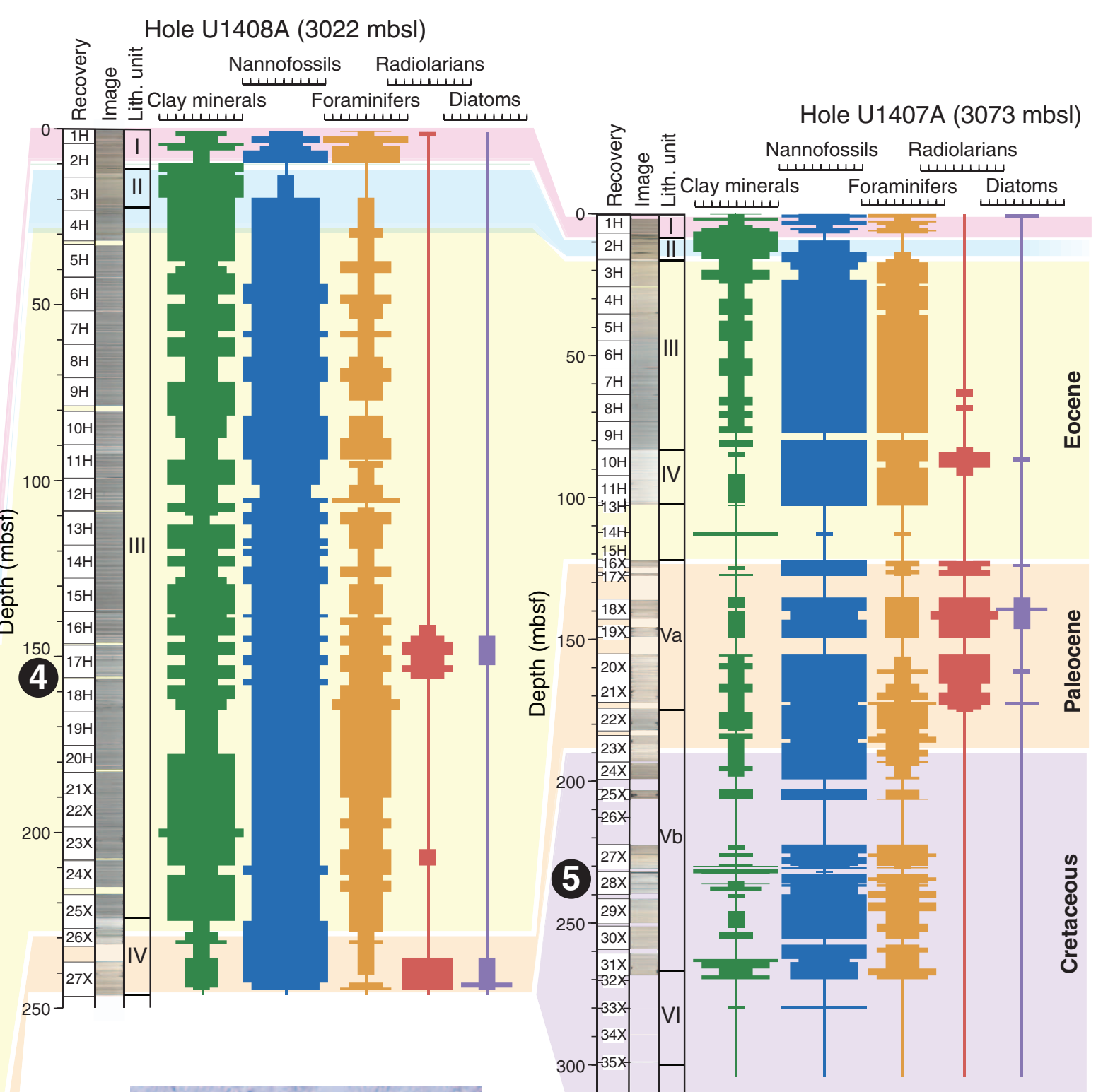

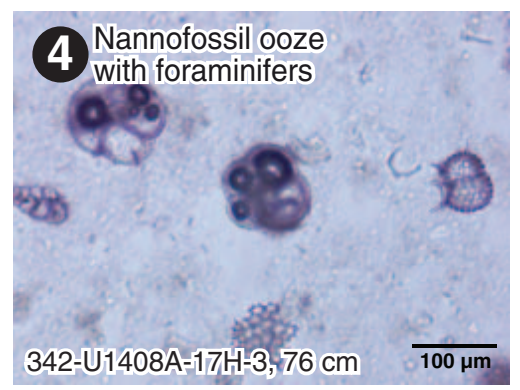

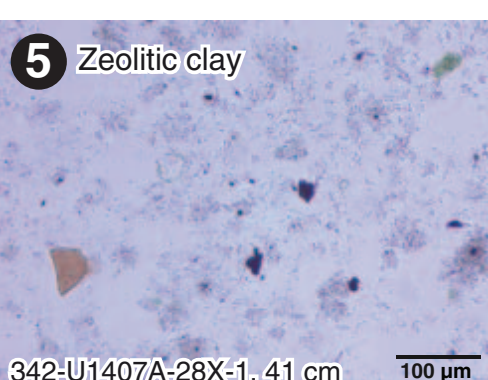




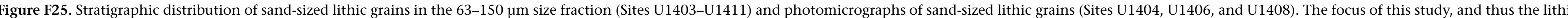

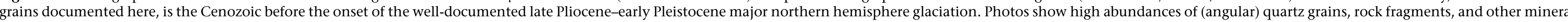

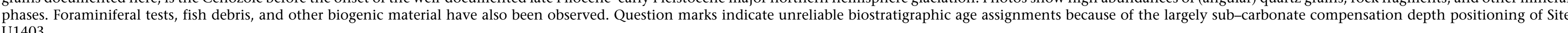
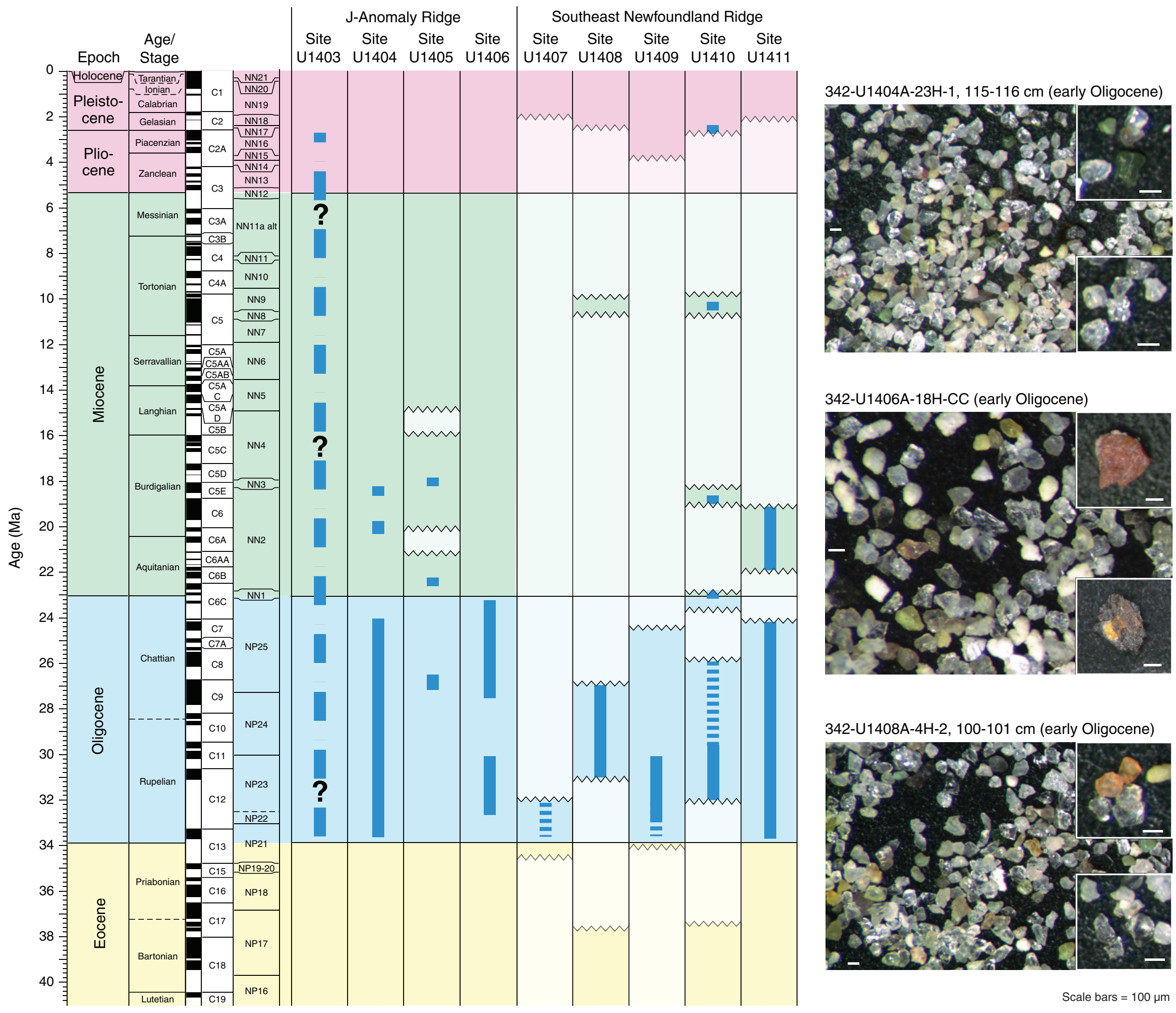
Figure F26. Representative lithologies from section-half surfaces and smear slides of (A) the putative impact ejecta horizon of the Chesapeake Bay impact deposit, (B) a glauconite nodule, (C) a vein of native copper, and (D) quartz silt blebs representing possible ice-rafted debris, Sites U1403, U1404, U1406, and U1410.
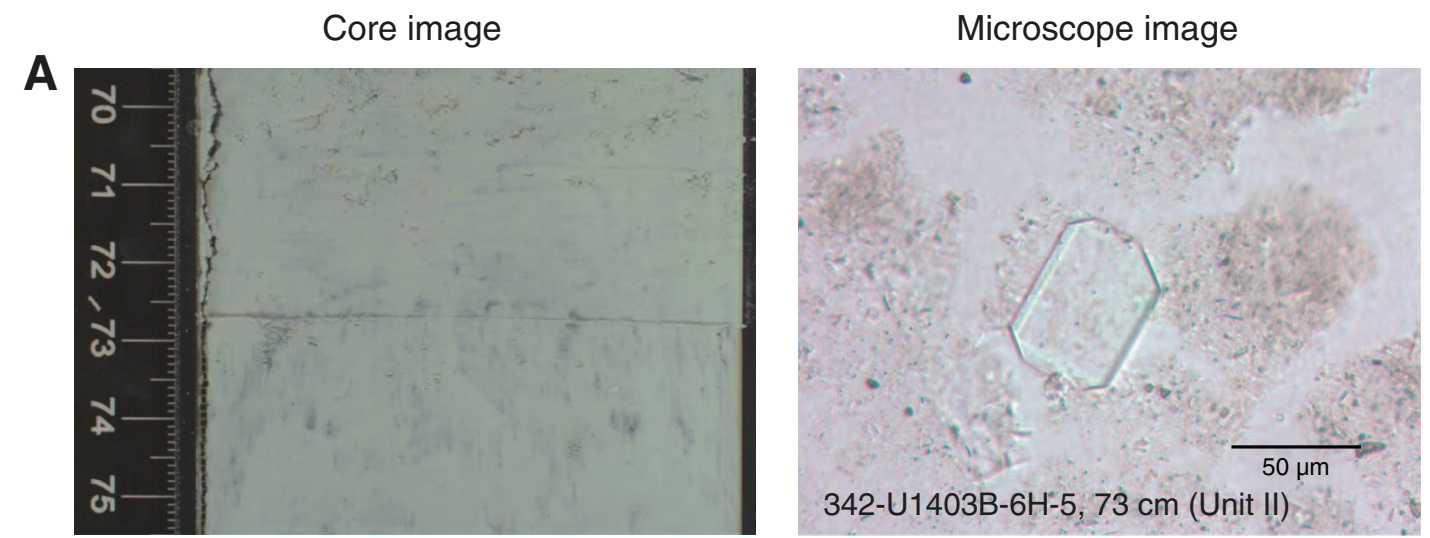

Chesapeak Bay impact ejecta
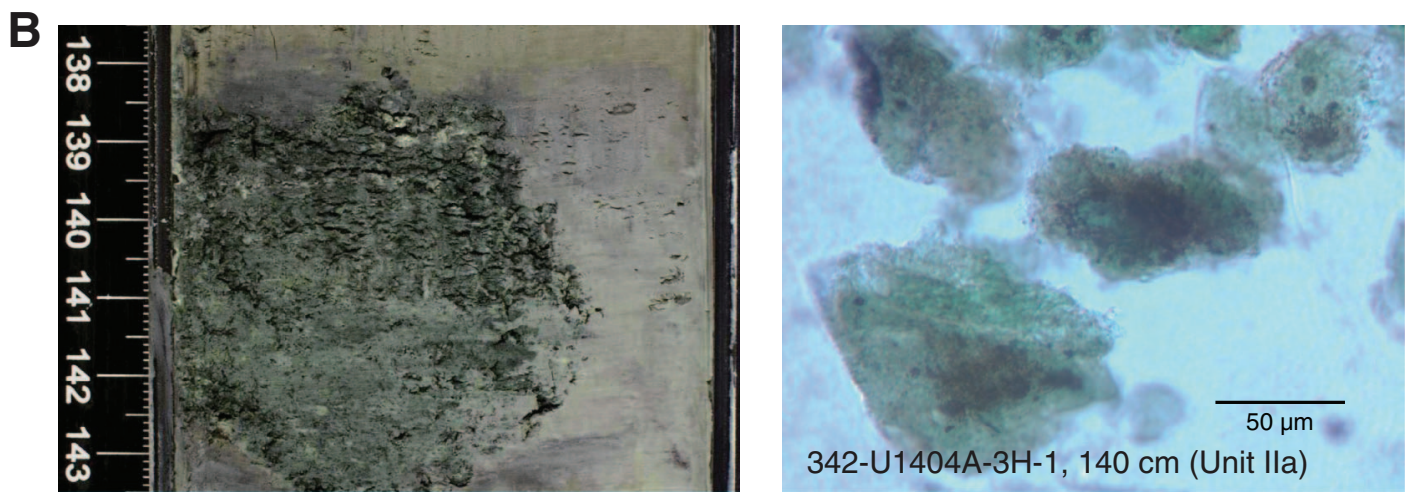

Glauconitic layer
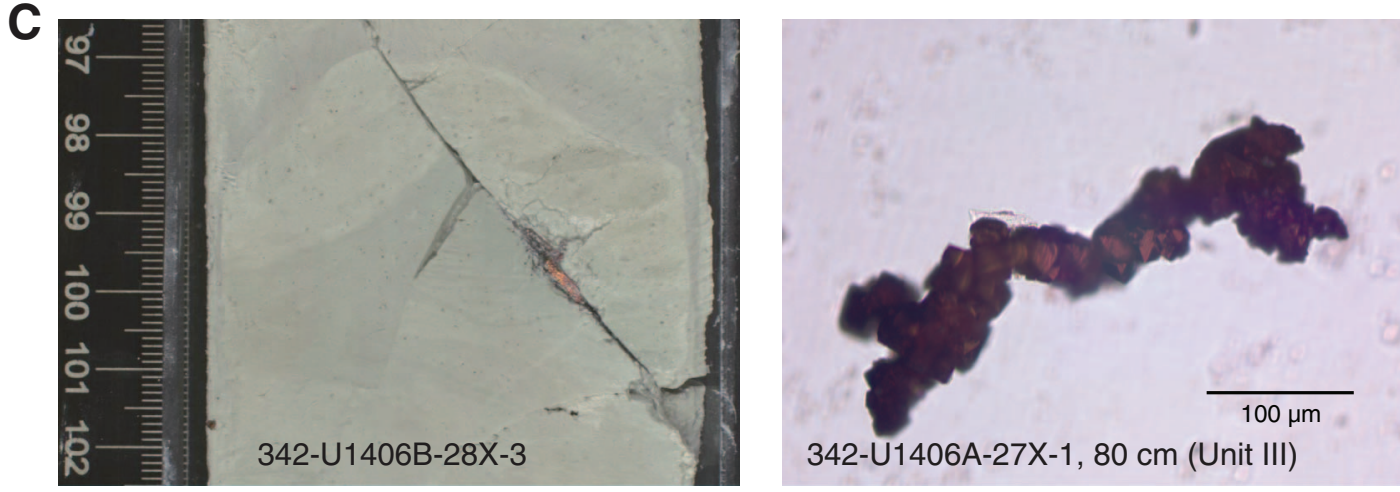

Copper

D
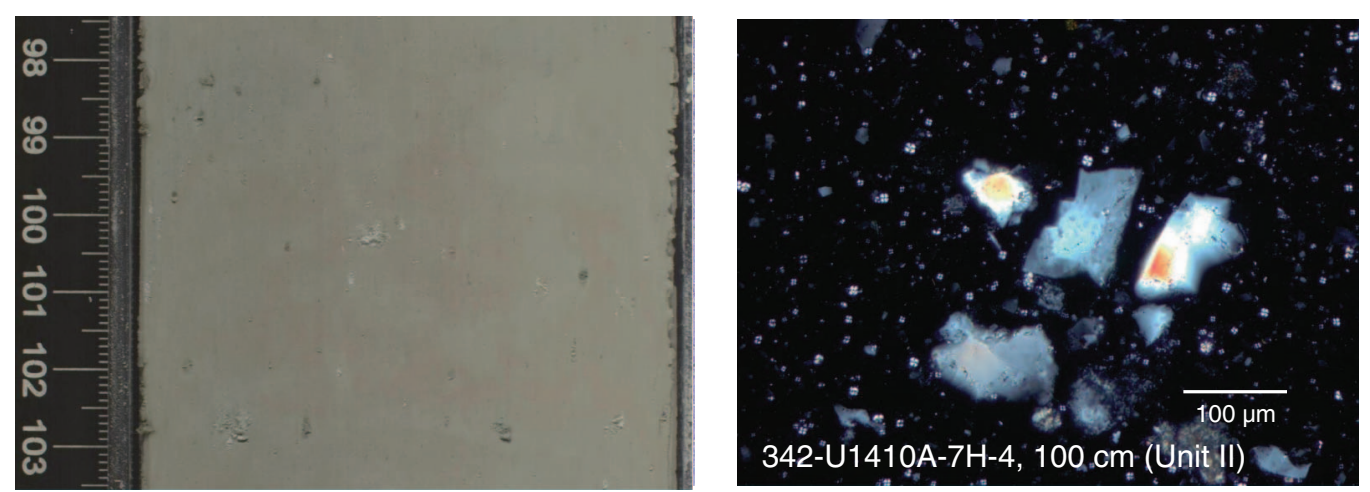

Silt bleb 
Figure F27. Core images, magnetic susceptibility, and smear slide photomicrographs of a Paleocene vitric volcanic ash bed, Site U1409.

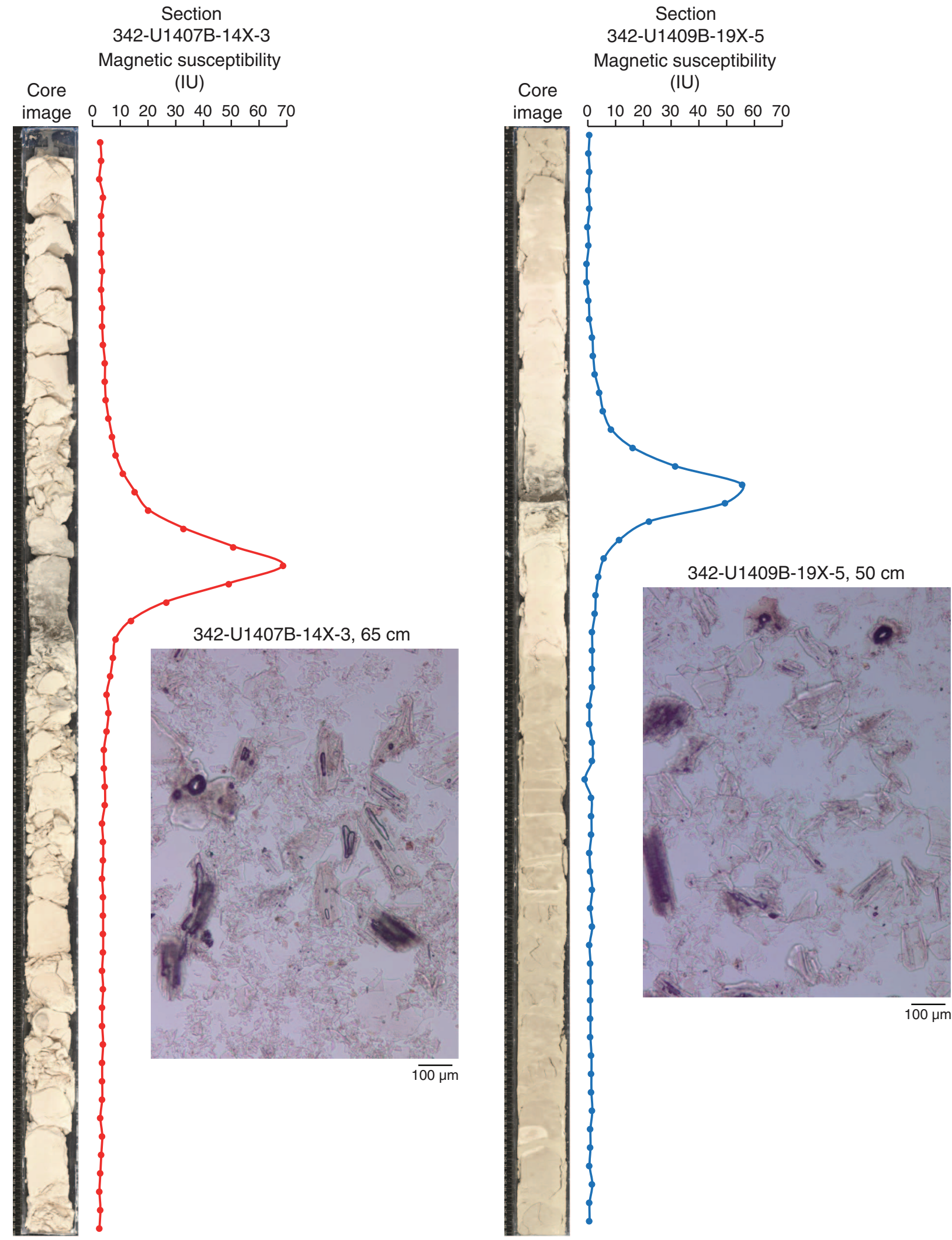


Figure 28. Pore water components associated with organic matter consumption in sediment columns along J-Anomaly Ridge depth transect, Sites U1403-U1406.
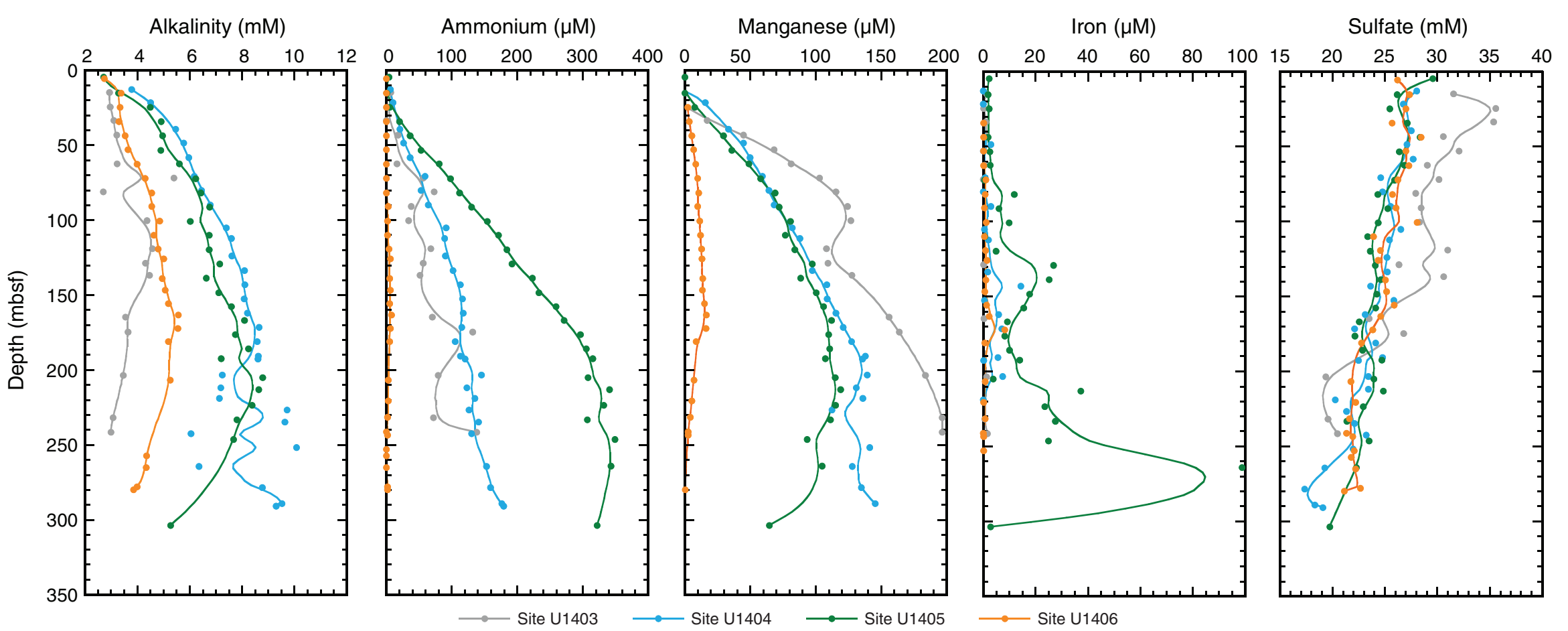
Figure F29. Carbonate, total organic carbon (TOC), and total nitrogen (TN) depth profiles from J-Anomaly Ridge Sites U1403-U1406. A common feature is that organic matter peaks in early Miocene sediment (green shading). E/O = Eocene/Oligocene boundary, PETM $=$ Paleocene/Eocene Thermal Maximum, K/Pg = Cretaceous/Paleocene boundary.

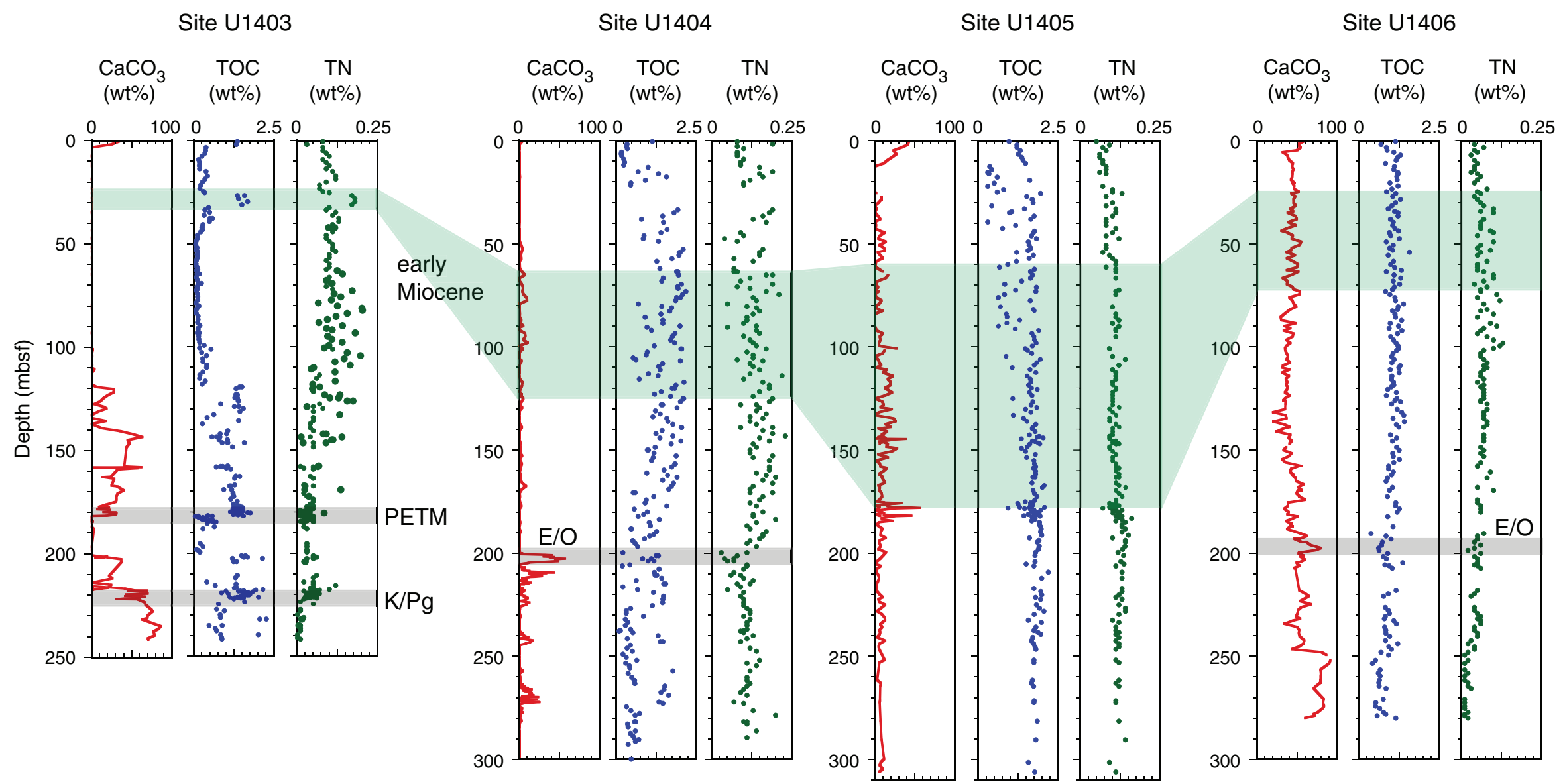


Figure F30. Calcium, magnesium, and strontium in interstitial water along the J-Anomaly Ridge depth transect, Sites U1403-U1406.
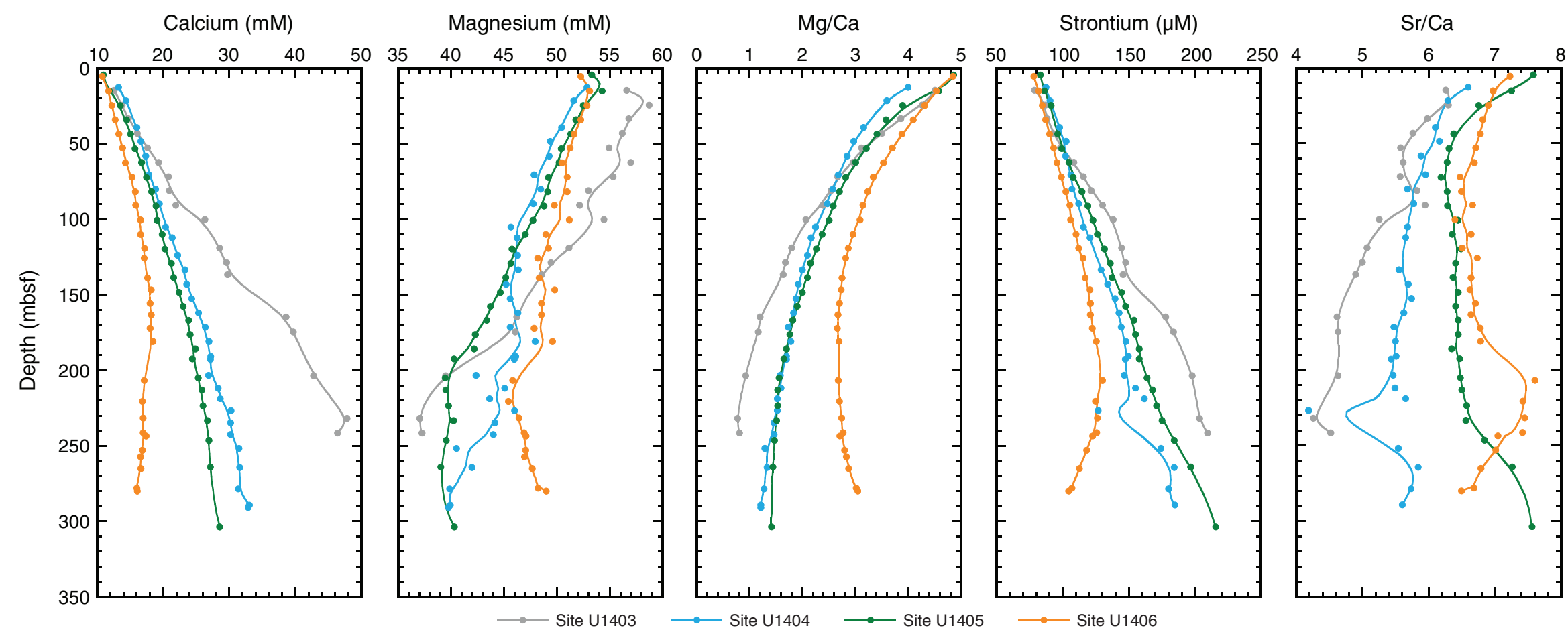

$\longrightarrow$ Site U1404

$\longrightarrow$ Site U1406 
Figure F31. Interstitial water components associated with organic matter consumption along the Southeast Newfoundland Ridge depth transect, Sites U1407-U1410.
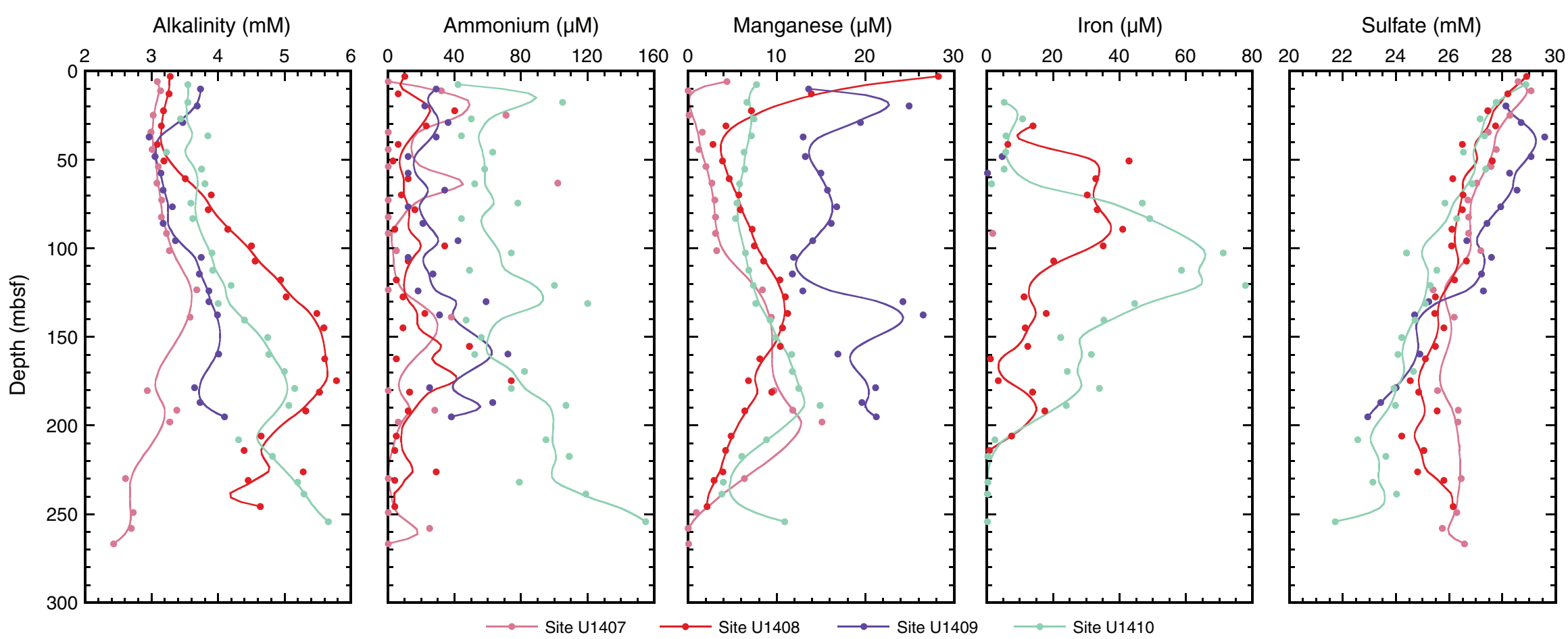

Site U1407

$\longrightarrow$ Site U1408

Site U1410 
Figure F32. Calcium and magnesium in sediment columns along the Southeast Newfoundland Ridge depth transect, Sites U1407-U1410.

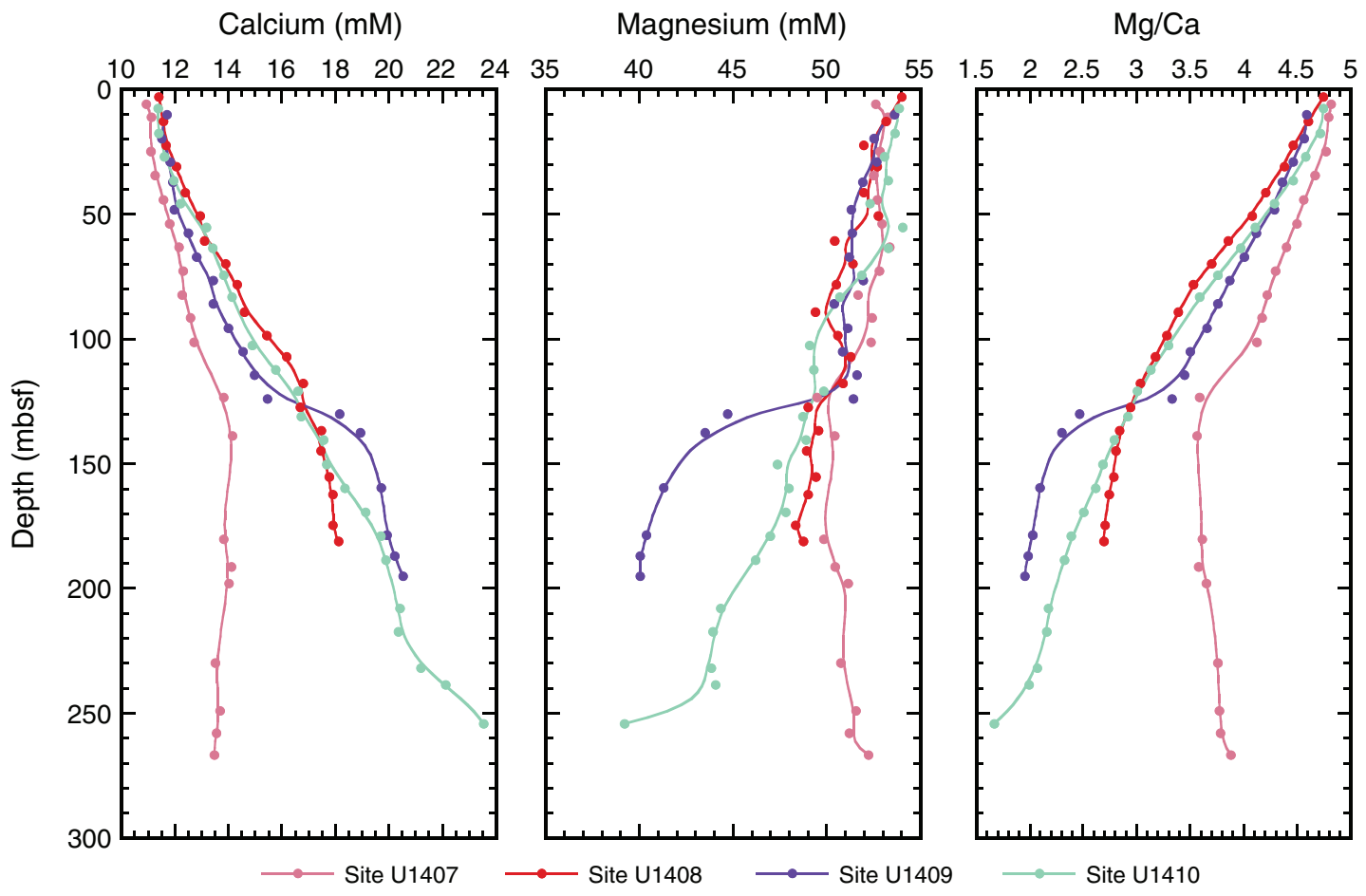




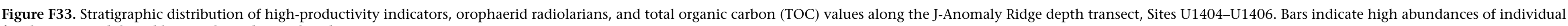
fossil groups and dotted lines indicate lower abundances.
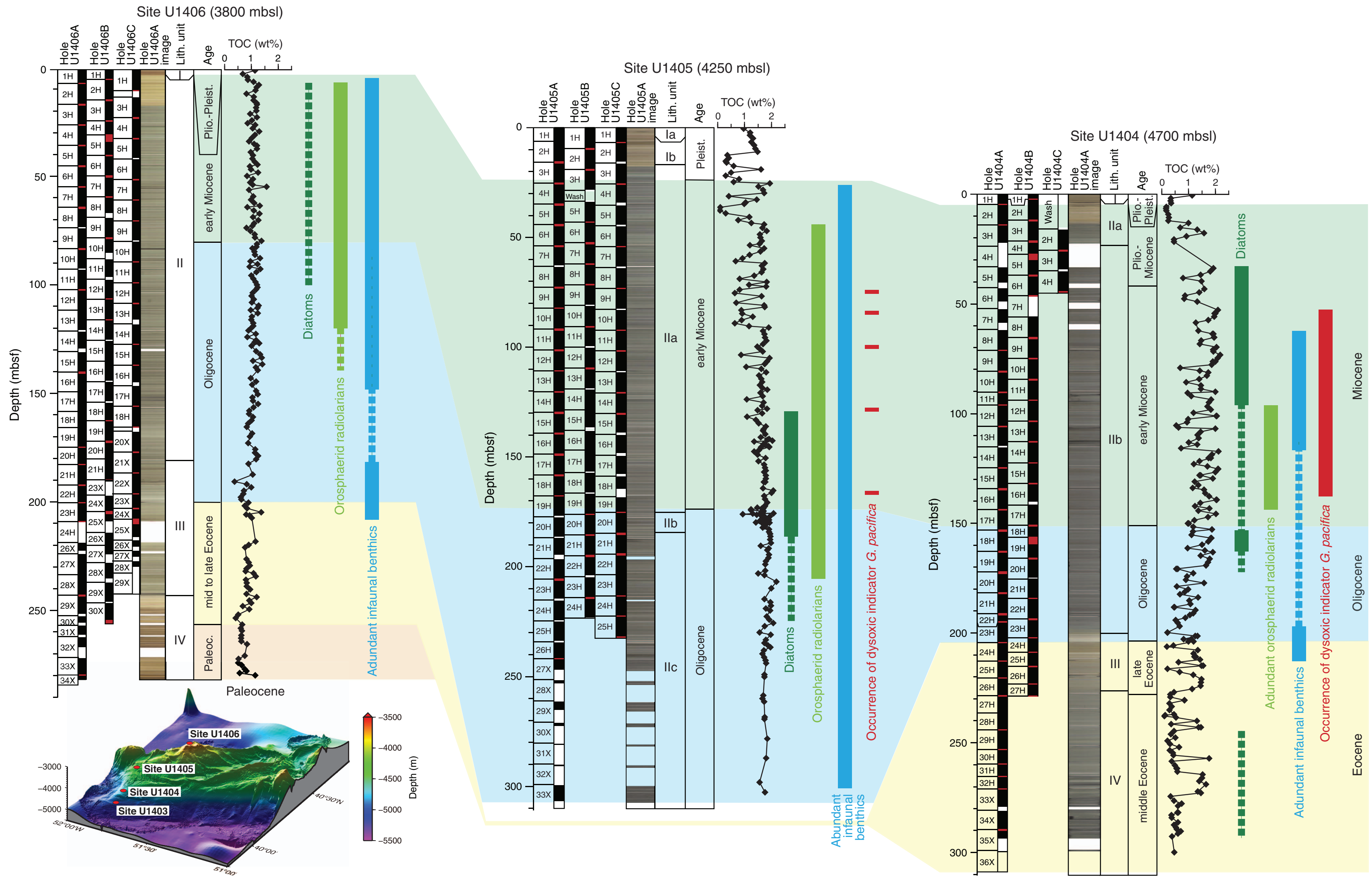


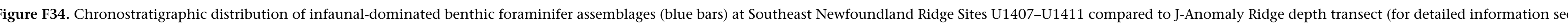
Fig. F33). Images show infaunal- and epifaunal-dominated benthic foraminiferal assemblages of selected time intervals. MECO = Middle Eocene Climate Optimum. Scale bars = $1 \mathrm{~mm}$.

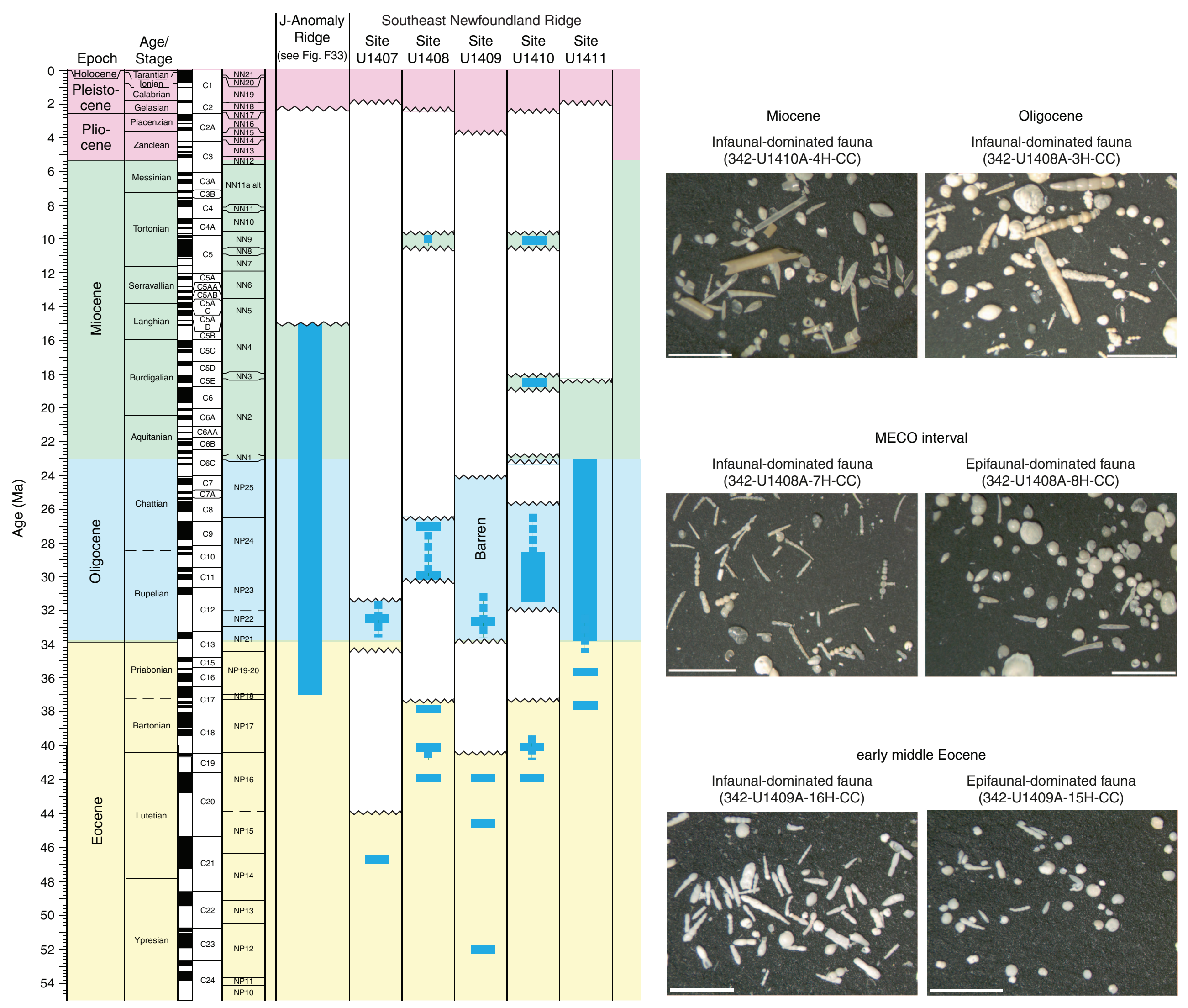


Figure F35. Carbonate, total organic carbon (TOC), and total nitrogen (TN) depth profiles at Southeast Newfoundland Ridge Sites U1407-U1410. Organic matter increases substantially around the middle/late Eocene boundary (yellow shading), whereas carbonate content decreases in the same interval. PETM = Paleocene/Eocene Thermal Maximum, OAE 2 = Oceanic Anoxic Event 2. The numbers next to OAE 2 indicate maximum identified TOC and TN values (out of scale).

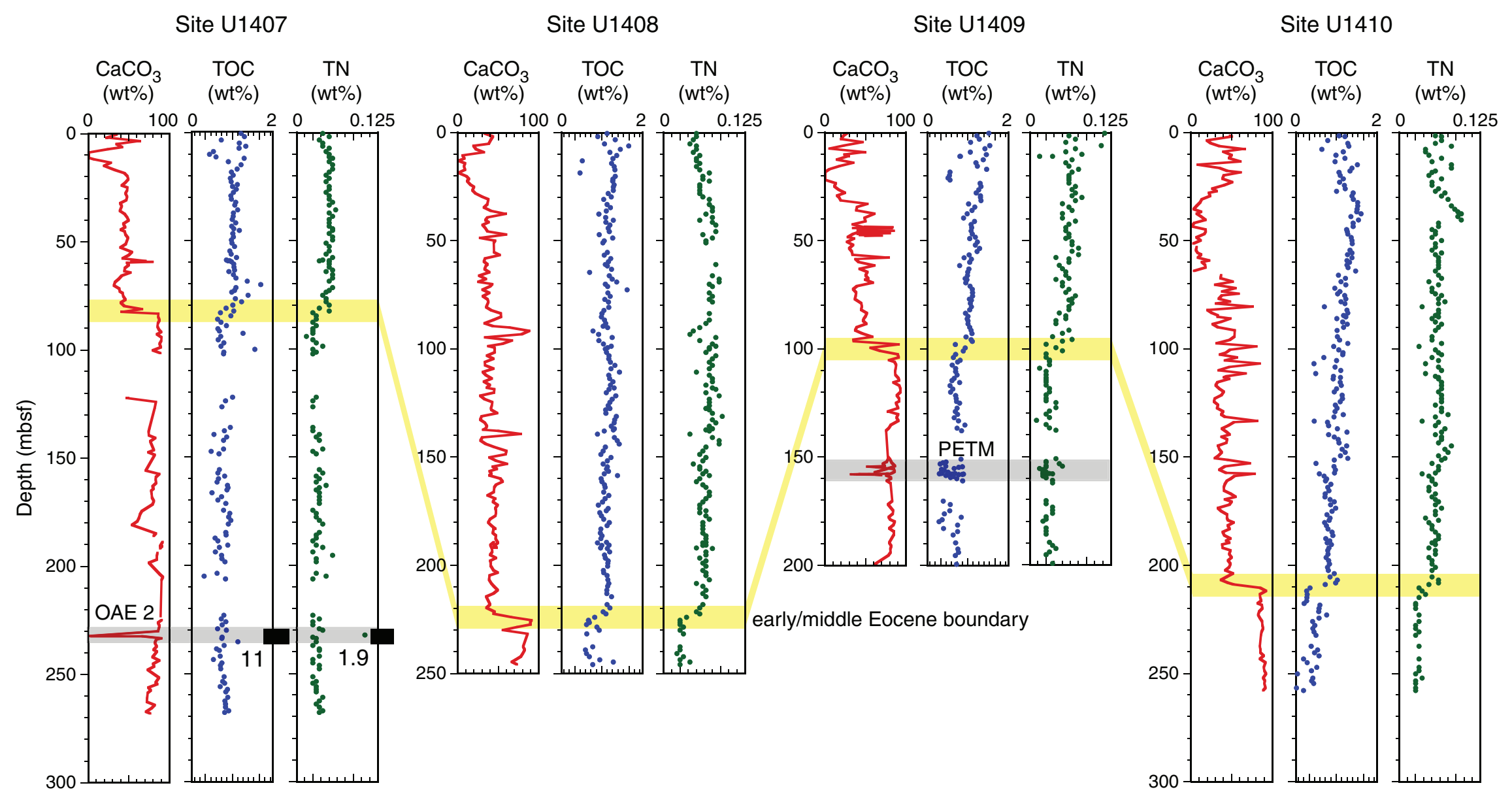


Figure F36. Exceptionally well preserved microfossils from J-Anomaly Ridge Sites U1403, U1405, and U1406. Examples include glassy planktonic and benthic foraminifers and fragile and dissolution-susceptible nannofossils. Top row: lower Miocene (Zone M1b) planktonic foraminifers revealing semiglassy taphonomy and even the presence of relict spines within the umbilici (Samples 342-U1405A-13H-6, 100-102 cm; 15H-2, 100-102 $\mathrm{cm}$; 15H-CC; and 16H-CC). Second row: benthic foraminifers (Samples 342-U1405A-15H-6, 100-102 cm; 19H$6,100-102 \mathrm{~cm} ; 15 \mathrm{H}-2,100-102 \mathrm{~cm} ; 14 \mathrm{H}-6,70-72 \mathrm{~cm}$; and 15H-6, 100-102 cm). Third row: calcareous nannofossils. Fourth row: radiolarians (all images at the same magnification).

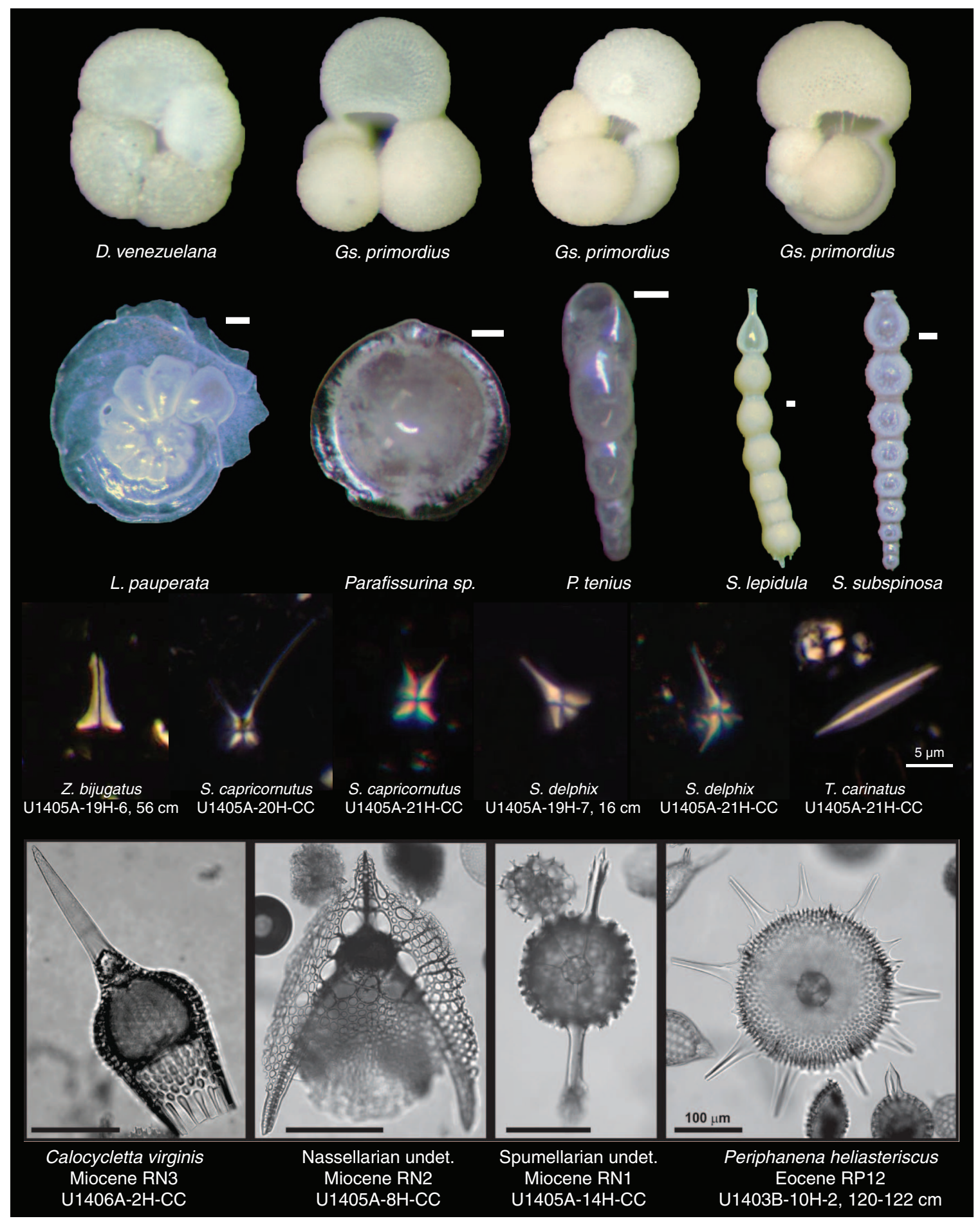


Figure F37. Exceptionally well preserved calcareous nannofossils, Expedition 342 . The majority of taxa shown are rarely seen in deep-sea carbonate oozes because of their fragility and susceptibility to dissolution and overgrowth (e.g., holococcoliths and Blackites species). Asterisk = taxa previously described from the Tanzanian microfossil lagerstätte only (e.g., Bown, 2005b; Bown et al., 2008). All images are at the same magnification.

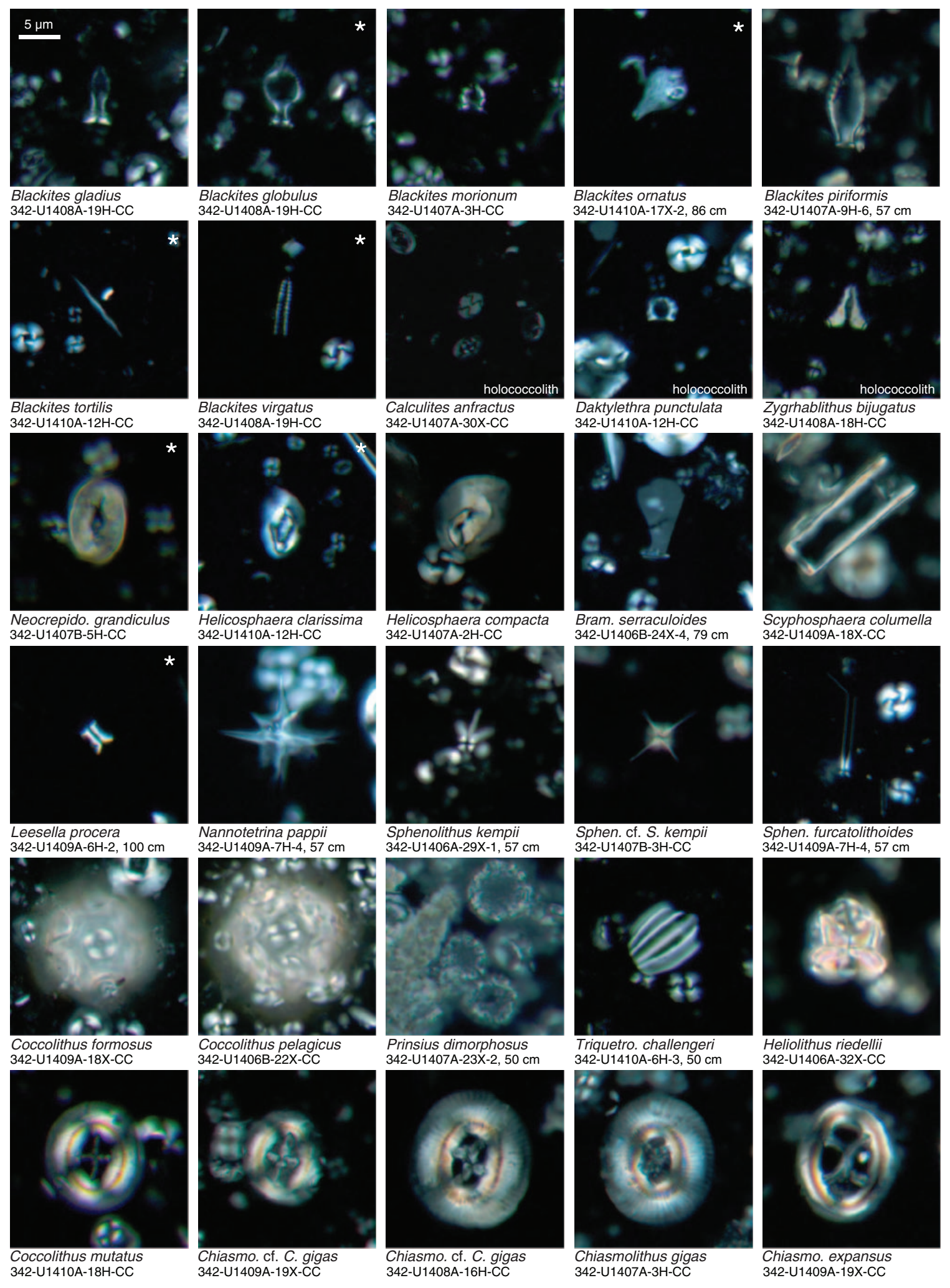




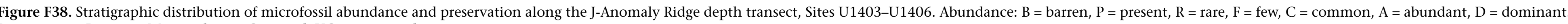
Preservation: $\mathrm{P}=$ poor, $\mathrm{M}$ = moderate, $\mathrm{G}=$ good, $\mathrm{VG}=$ very good.

Site U1406 (3800 mbsl)
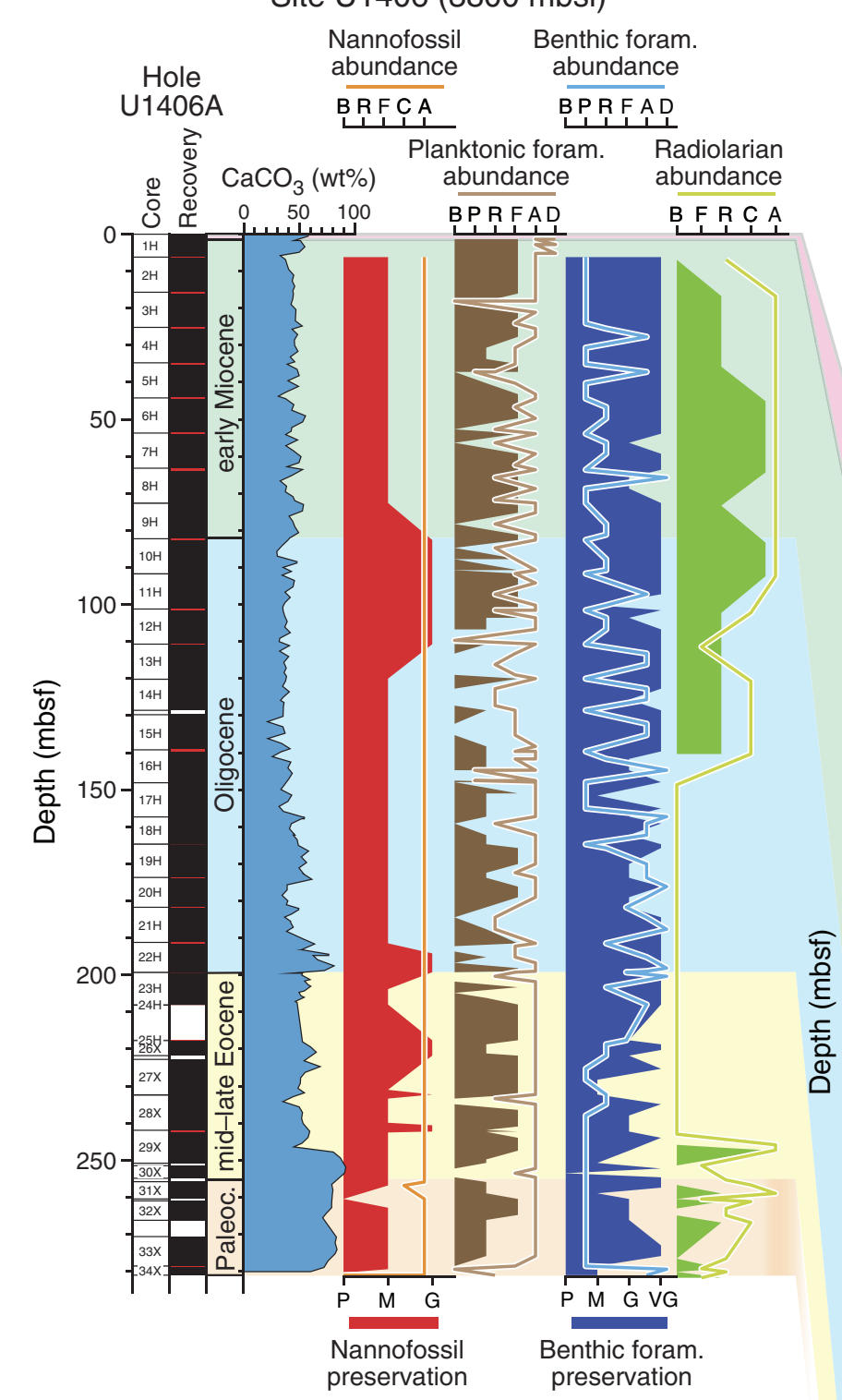

$\begin{array}{cc}P M G G & P \\ \text { Planktonic foram. } & \begin{array}{c}P \text { M } \\ \text { Radiolarian } \\ \text { preservation }\end{array} \\ \text { preservation }\end{array}$

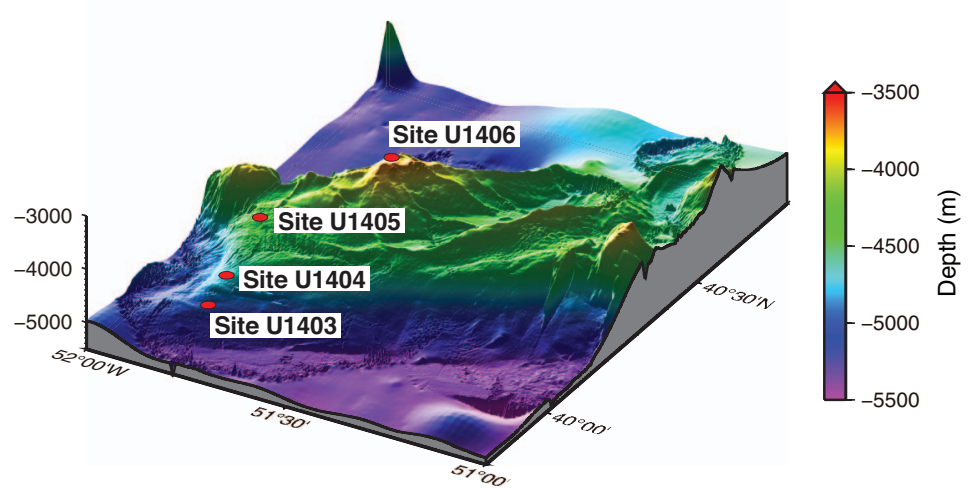

Site U1405 (4300 mbsl)

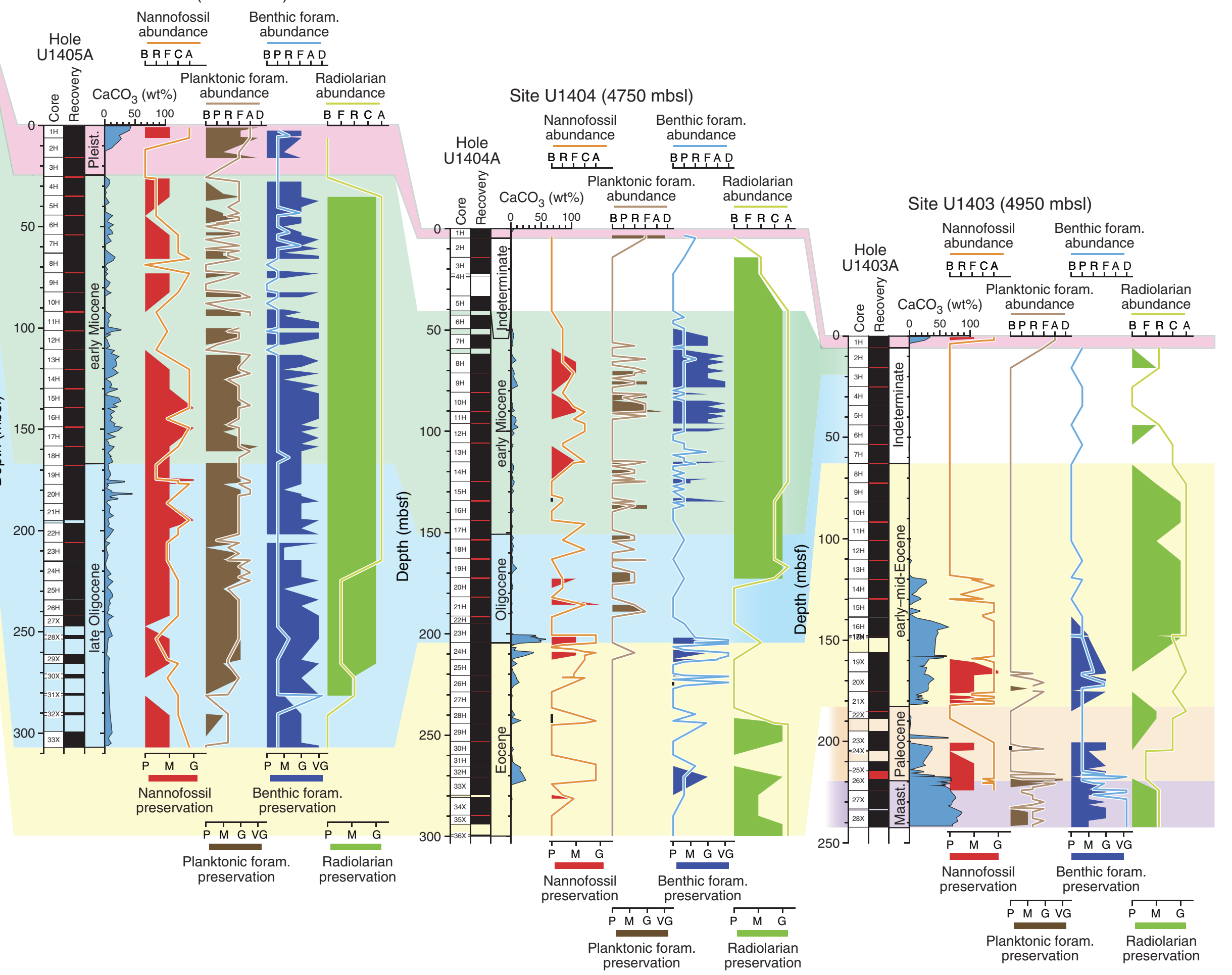




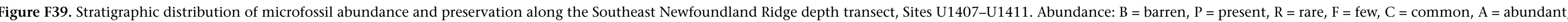
$\mathrm{D}=$ dominant. Preservation: $\mathrm{P}=$ poor, $\mathrm{M}=$ moderate, $\mathrm{G}=$ good, $\mathrm{VG}=$ very good.

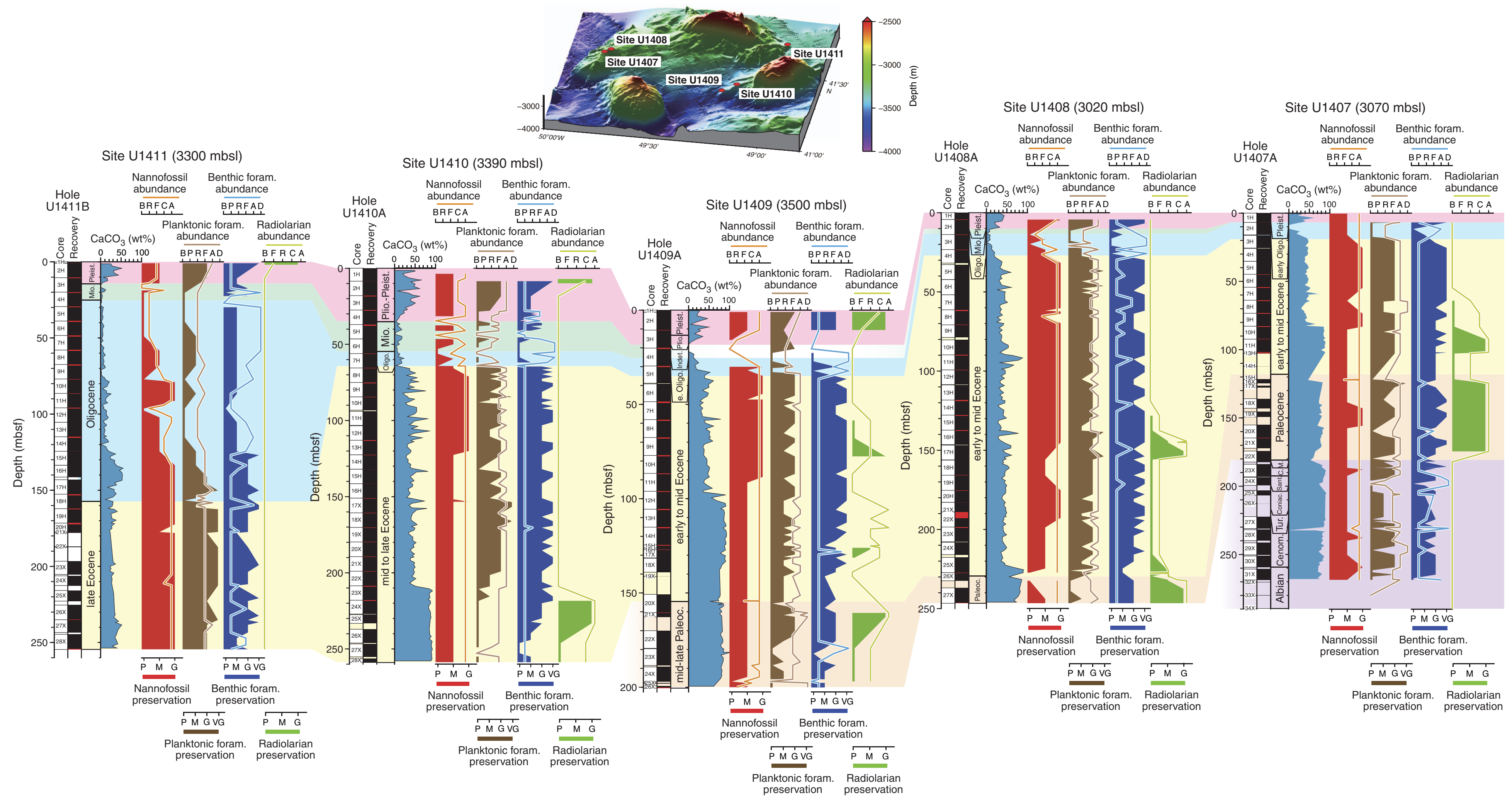




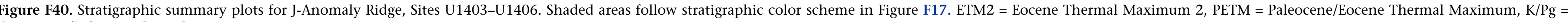
Cretaceous/Paleogene boundary.

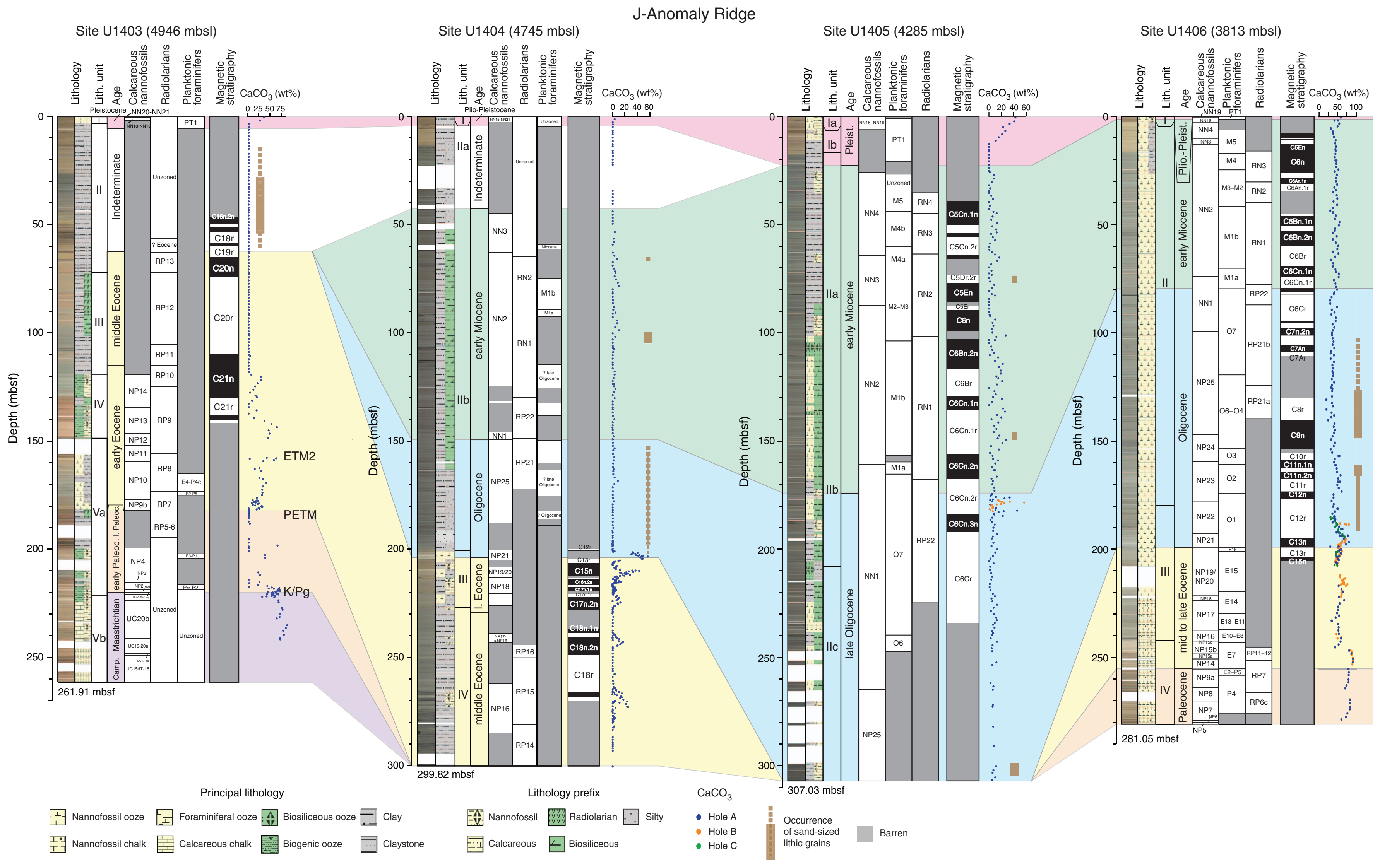


Figure F41. Stratigraphic summary plots for Southeast Newfoundland Ridge, Sites U1407-U1411. Shaded areas follow stratigraphic color scheme in Figure F17. OAE $2=$ oceanic anoxic Event 2.

Southeast Newfoundland Ridge

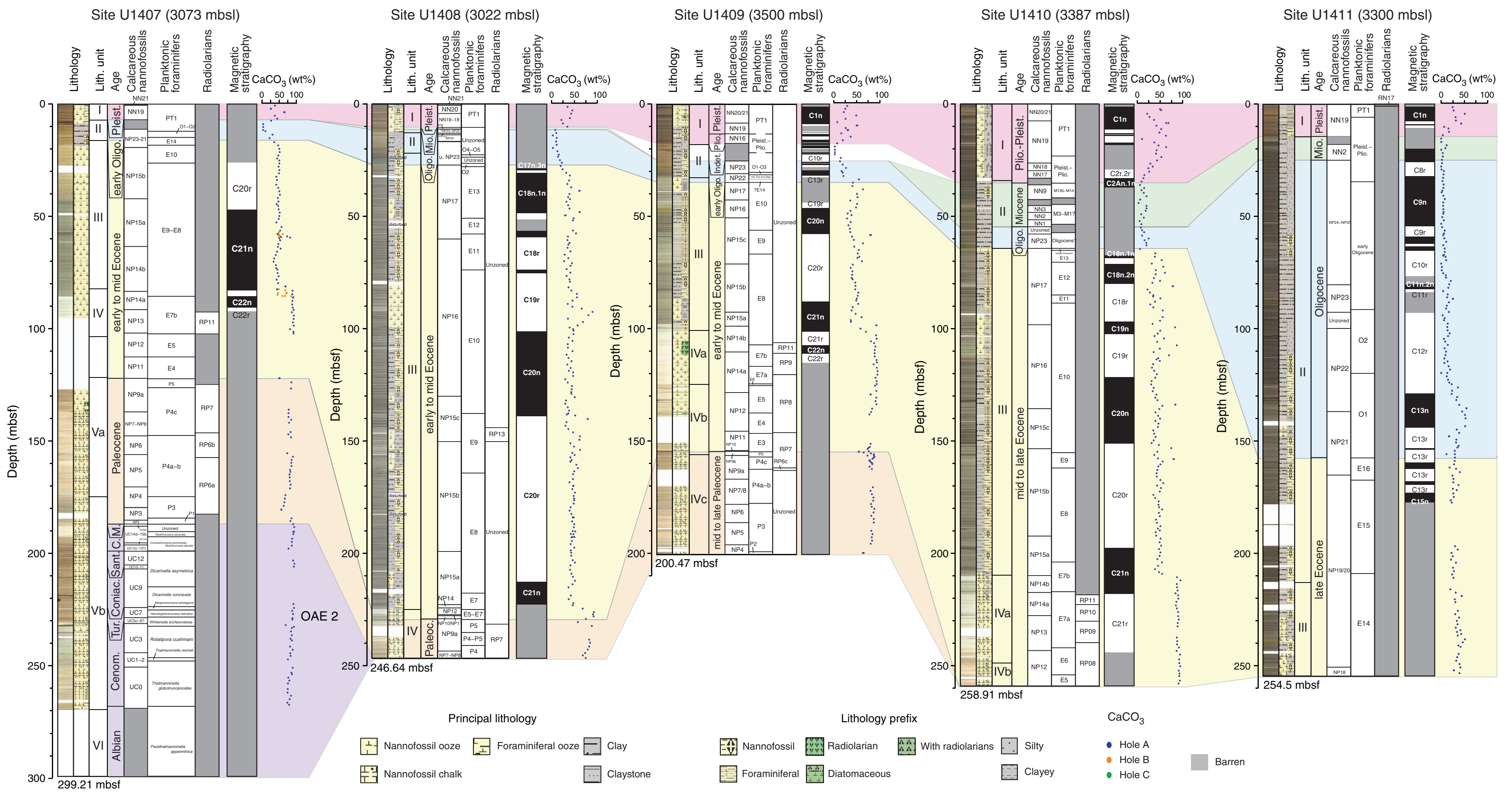


Figure F42. Calcareous nannofossil taxa used as standard (Martini, 1971) or additional Eocene marker species, Expedition 342.

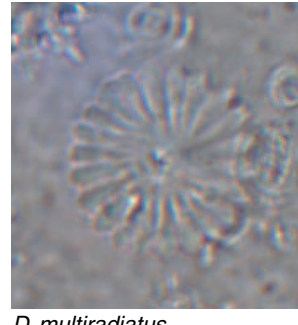

342-U1403A-20X-1, $78 \mathrm{~cm}$

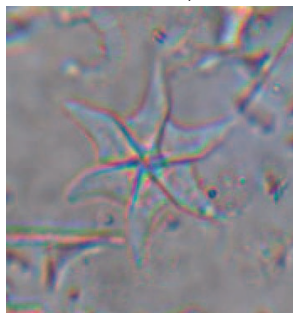

D. lodoensis

342-U1403A-15H-CC

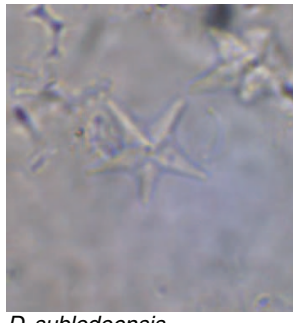

D. sublodoensis

342-U1403A-15H-1, $39 \mathrm{~cm}$

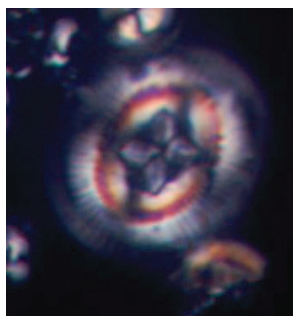

C. gigas

342-U1408A-17H-5, $110 \mathrm{~cm}$

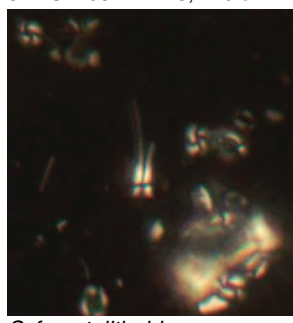

S. furcatolithoides

342-U1408A-11H-6, $90 \mathrm{~cm}$

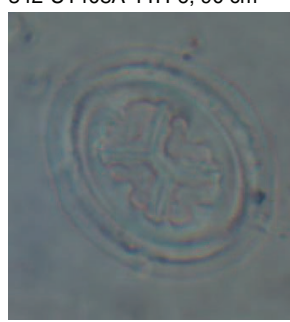

C. grandis

$342-\mathrm{U} 1408 \mathrm{~A}-8 \mathrm{H}-6,90 \mathrm{~cm}$
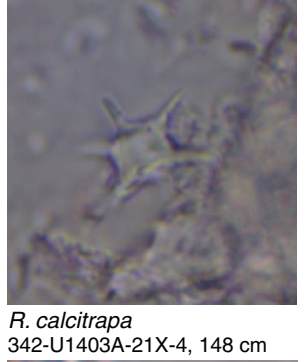

342-U1403A-21X-4, $148 \mathrm{~cm}$

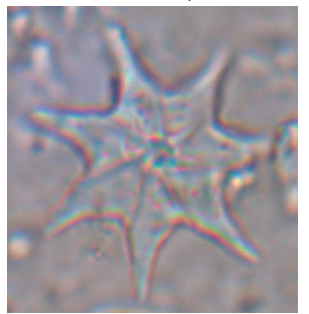

D. lodoensis

342-U1403A-15H-2, $90 \mathrm{~cm}$

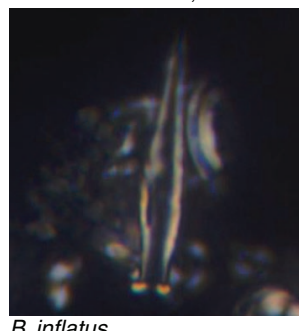

B. inflatus

342-U1410A-23H-2, $67 \mathrm{~cm}$

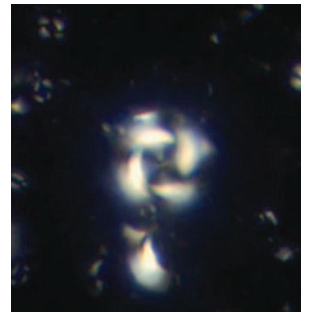

C. reticulatum

342-U1408A-10H-CC

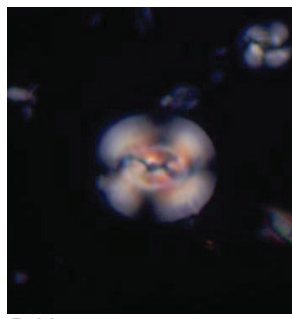

D. bisectus

342-U1408A-7H-6, $100 \mathrm{~cm}$

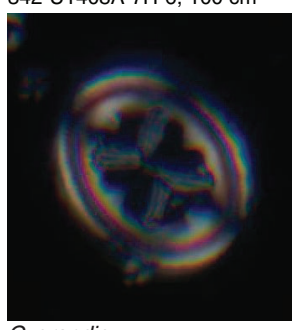

C. grandis

342-U1408A-8H-6, $90 \mathrm{~cm}$

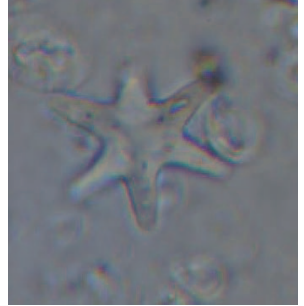

T. bramlettei

342-U1403A-20X-1, $78 \mathrm{~cm}$

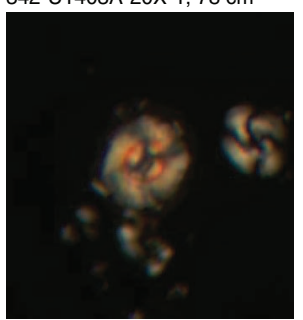

C. crassus

342-U1407A-10H-4, $100 \mathrm{~cm}$

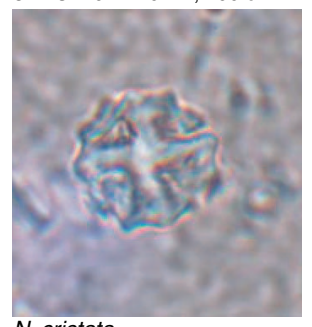

N. cristata

342-U1408A-17H-CC

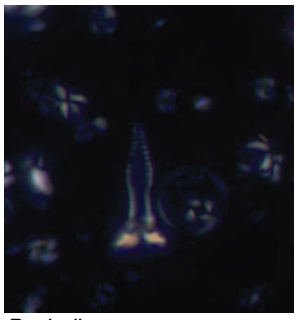

B. gladius

342-U1408A-12H-CC

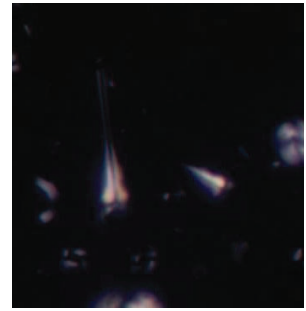

S. predistentus

342-U1408A-7H-2, $100 \mathrm{~cm}$

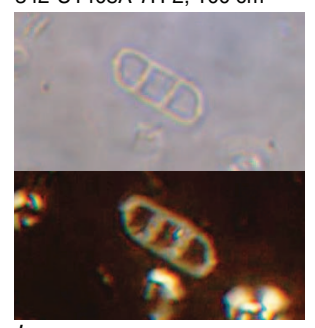

I. recurvus

342-U1406A-21H-CC

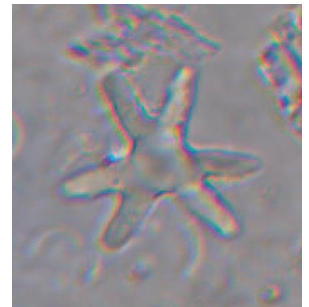

T. contortus

342-U1403A-19X-4, $38 \mathrm{~cm}$

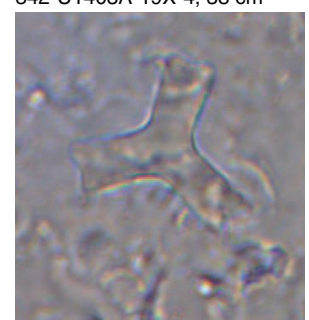

T. orthostylus

342-U1403A-19X-3, $38 \mathrm{~cm}$

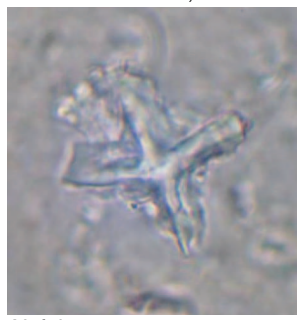

N. fulgens

342-U1408A-18H-CC

N. fulgens

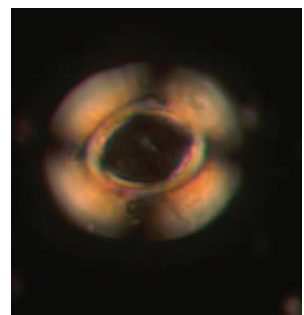

B. umbilicus

342-U1408A-4H-CC

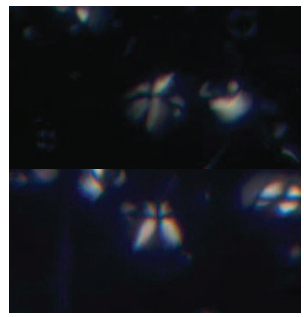

S. spiniger

342-U1408A-8H-1, $100 \mathrm{~cm}$

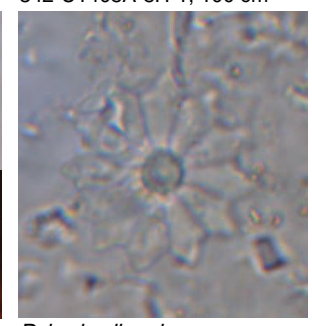

D. barbadiensis

342-U1403A-15H-2, $90 \mathrm{~cm}$

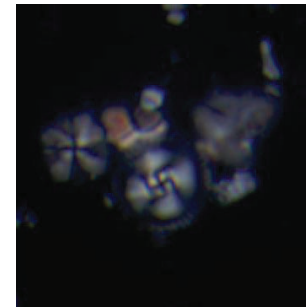

D. kuepperi/G. gammation 342-U1407A-11H-CC

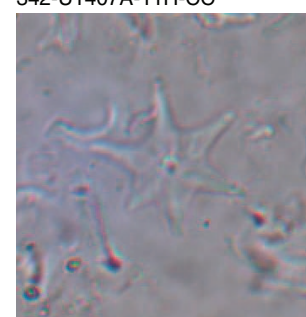

D. sublodoensis

342-U1403A-15H-1, $39 \mathrm{~cm}$

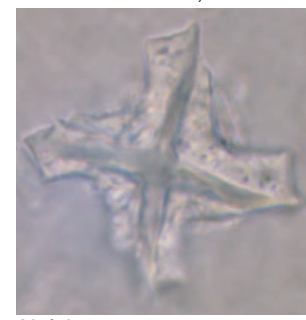

342-U1407A-5H-4, $110 \mathrm{~cm}$

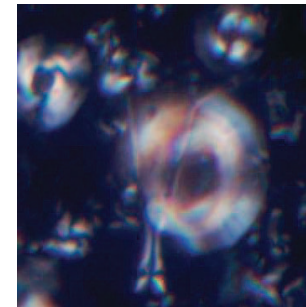

S. furcatolithoides 342-U1408A-5H-CC

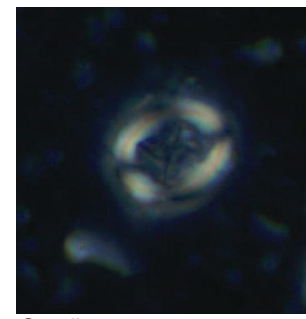

C. solitus

342-U1403A-14H-CC

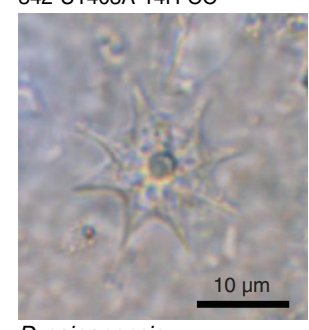

D. saipanensis

342-U1408A-7H-6, $100 \mathrm{~cm}$ 
Figure F43. Downhole paleomagnetic inclination for J-Anomaly Ridge Sites U1403-U1406. Interpreted magnetostratigraphies: black = normal, white $=$ reversed chron, gray $=$ unidentified. Small circles $=$ pass-through superconducting rock magnetometer measurement data after 20 mT alternating field demagnetization from archive-half sections. PCA = direction determined by principal component analysis (Kirschvink, 1980).
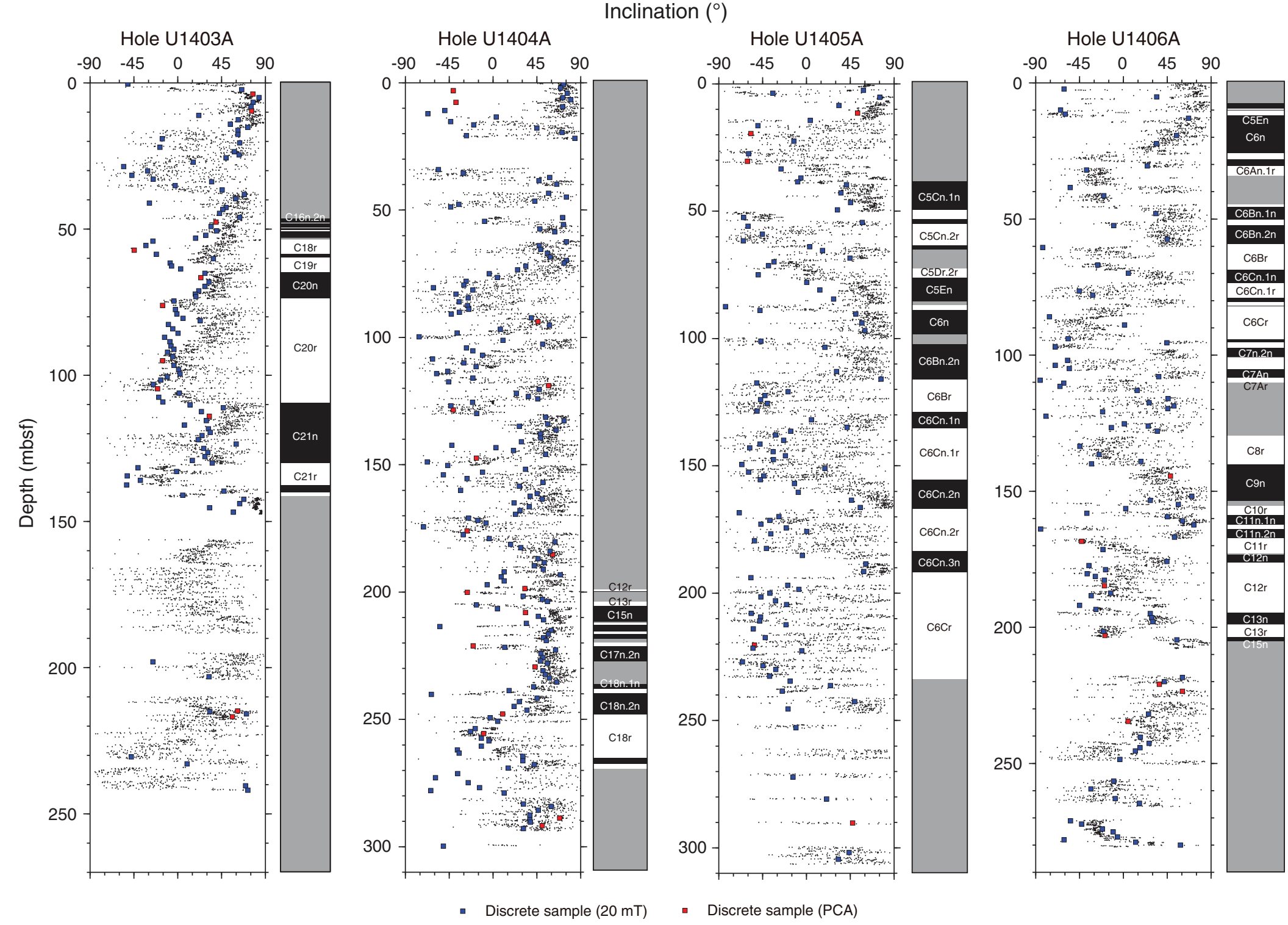
Figure F44. Downhole magnetization intensity after $20 \mathrm{mT}$ demagnetization for J-Anomaly Ridge Sites U1403-U1406. Interpreted magnetostratigraphies: black $=$ normal, white $=$ reversed chron, gray $=$ unidentified. Small circles $=$ pass-through superconducting rock magnetometer measurement data after $20 \mathrm{mT}$ alternating field demagnetization from archive-half sections. PCA = direction determined by principal component analysis (Kirschvink, 1980).
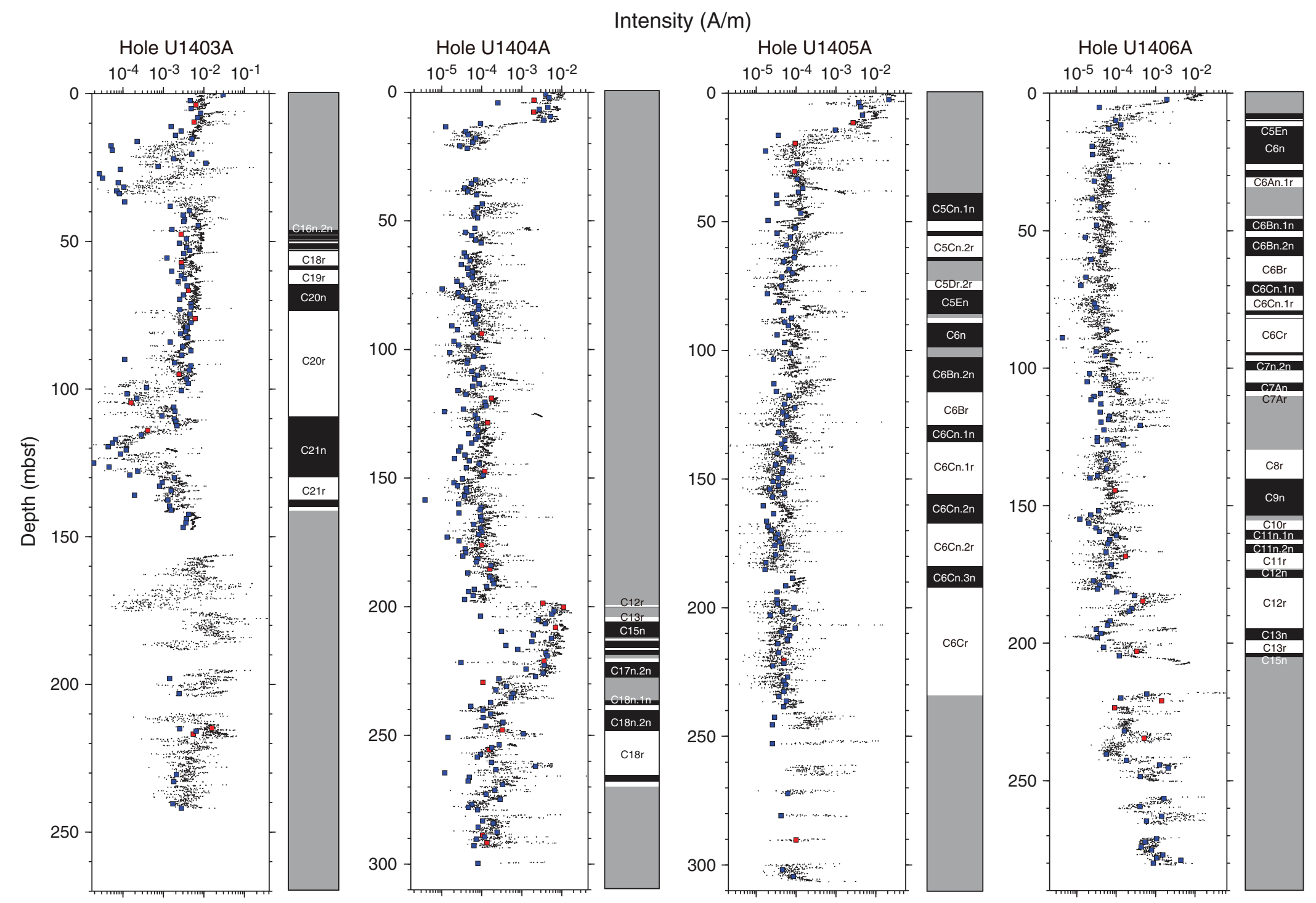

- Discrete sample $(20 \mathrm{mT})$

- Discrete sample (PCA) 
Figure F45. Downhole paleomagnetic inclination for Southeast Newfoundland Ridge Sites U1407-U1411. Interpreted magnetostratigraphies: black $=$ normal, white $=$ reversed chron, gray $=$ unidentified. Small circles $=$ pass-through superconducting rock magnetometer measurement data after $20 \mathrm{mT}$ alternating field demagnetization from archive-half sections. PCA $=$ direction determined by principal component analysis (Kirschvink, 1980).
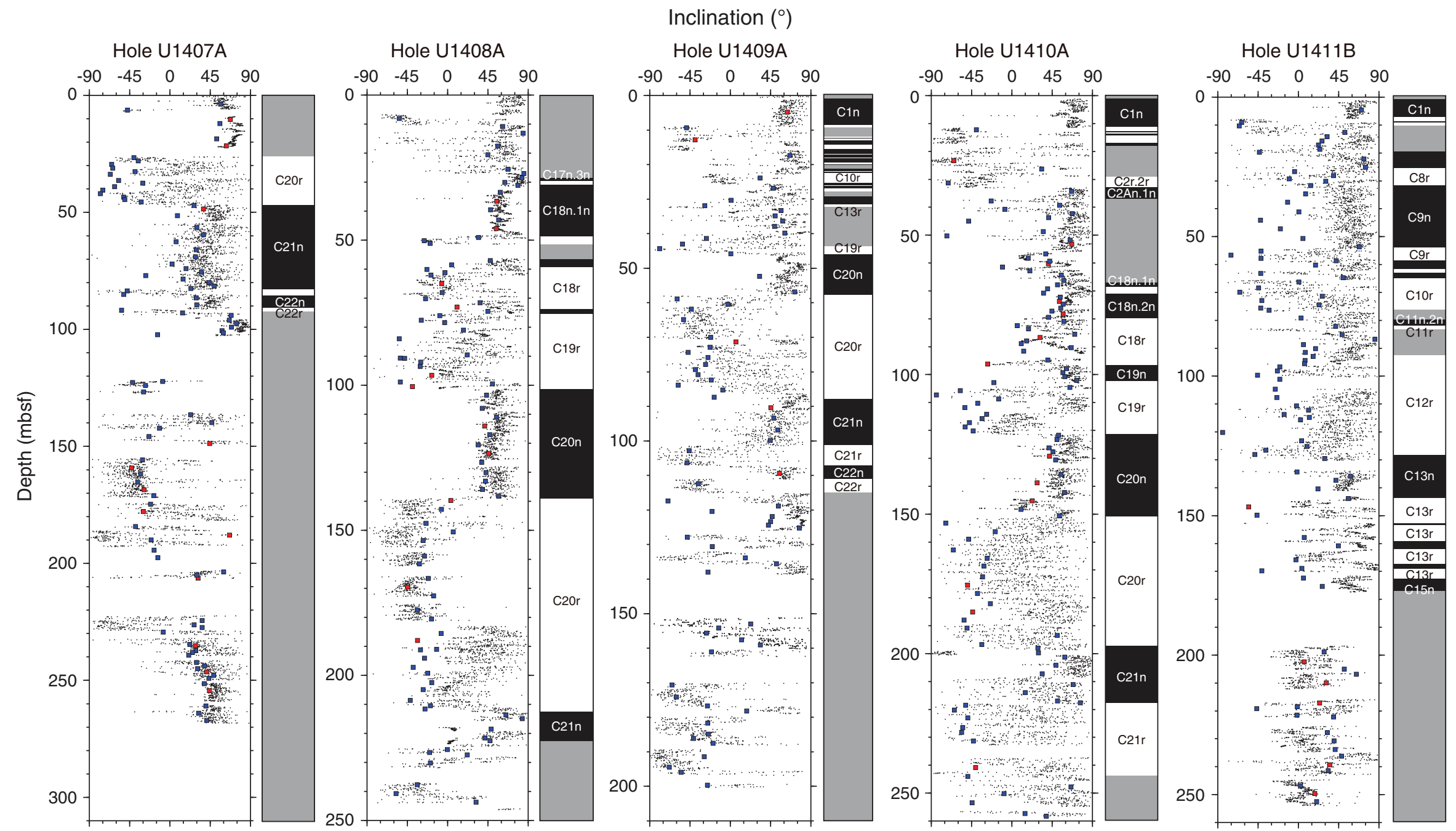

- Discrete sample (20 mT) - Discrete sample (PCA) 
Figure F46. Downhole magnetization intensity after $20 \mathrm{mT}$ demagnetization for Southeast Newfoundland Ridge Sites U1407-U1411. Interpreted magnetostratigraphies: black $=$ normal, white $=$ reversed chron, gray $=$ unidentified. Small circles $=$ pass-through superconducting rock magnetometer measurement data after $20 \mathrm{mT}$ alternating field demagnetization from archive-half sections. PCA = direction determined by principal component analysis (Kirschvink, 1980).
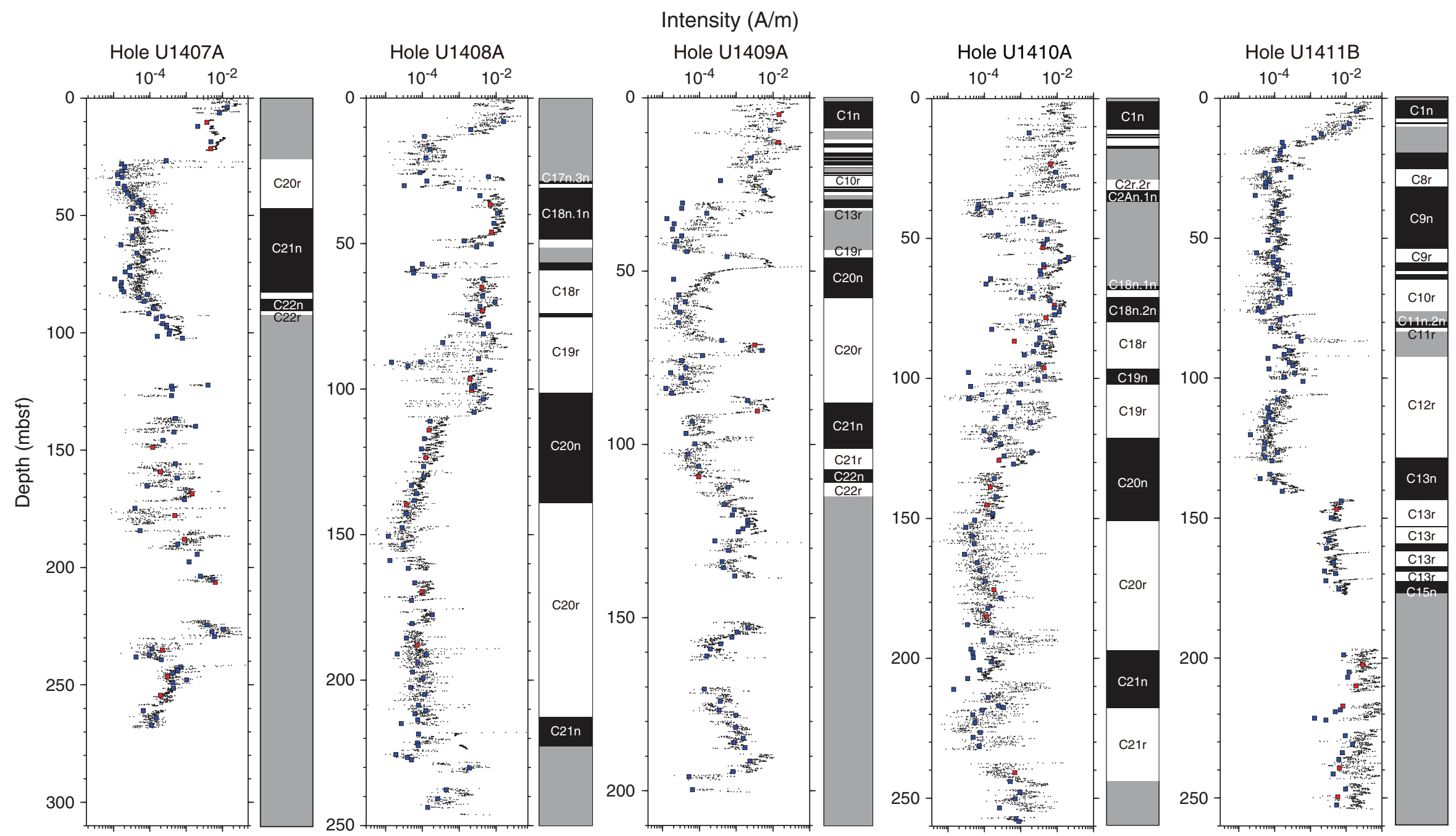

- Discrete sample (20 mT)

- Discrete sample (PCA) 
Figure F47. Plate kinematic reconstructions for the North Atlantic region at 0, 20, 40, 60, and 70 Ma. Reconstructions were made using Gplates freeware (gplates.org) and the Model A kinematic model of van Hinsbergen et al. (2011).
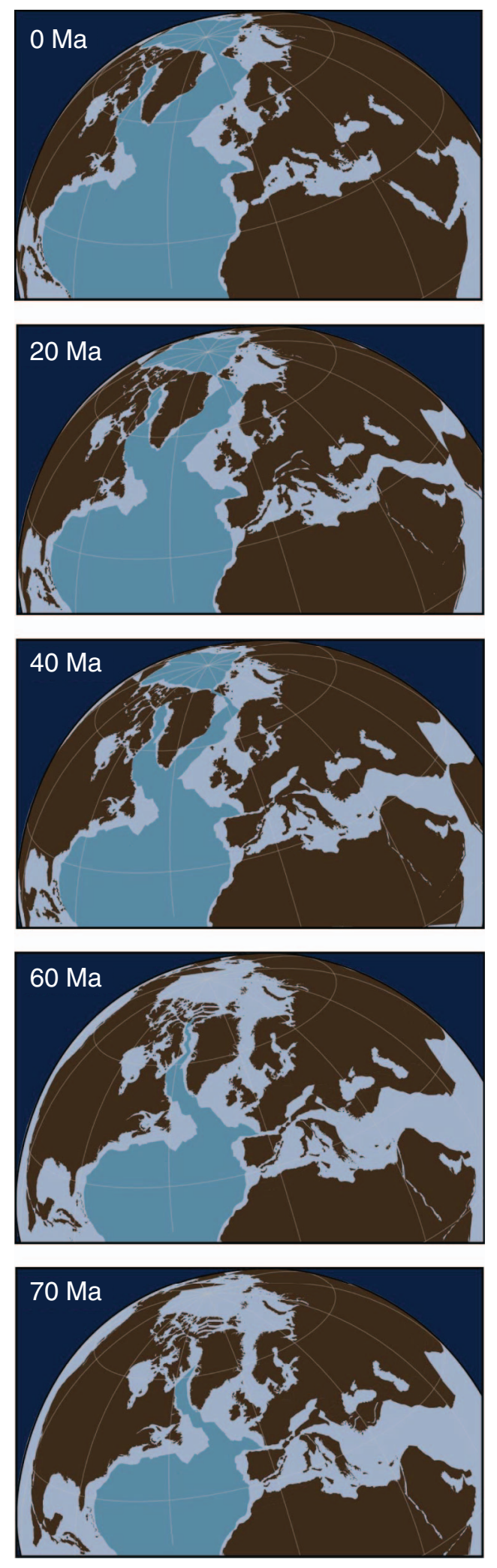
Figure F48. Color reflectance $\left(L^{*}\right)$ variations, Hole U1405A. A. Band-pass gaussian filter output highlighting a $16.7 \mathrm{~m}$ cyclicity. B. Expanded view of shaded area in A with band-pass gaussian filter output highlighting a $4.3 \mathrm{~m}$ cyclicity. C. Power spectrum of A with red noise modeling. Only periods (in meters) of peaks exceeding 99\% confidence level (CL) are shown. The two gray-shaded areas indicate frequency pass bands filtered to isolate the 16.7 and $4.3 \mathrm{~m}$ cyclicities shown in A and B, respectively. Note that only the low-frequency portion of the spectrum (0-2 cycles/m) is plotted to highlight the prominent 16.7 and $4.3 \mathrm{~m}$ cyclicities with the smaller $0.73 \mathrm{~m}$ cyclicity (see text for discussion).
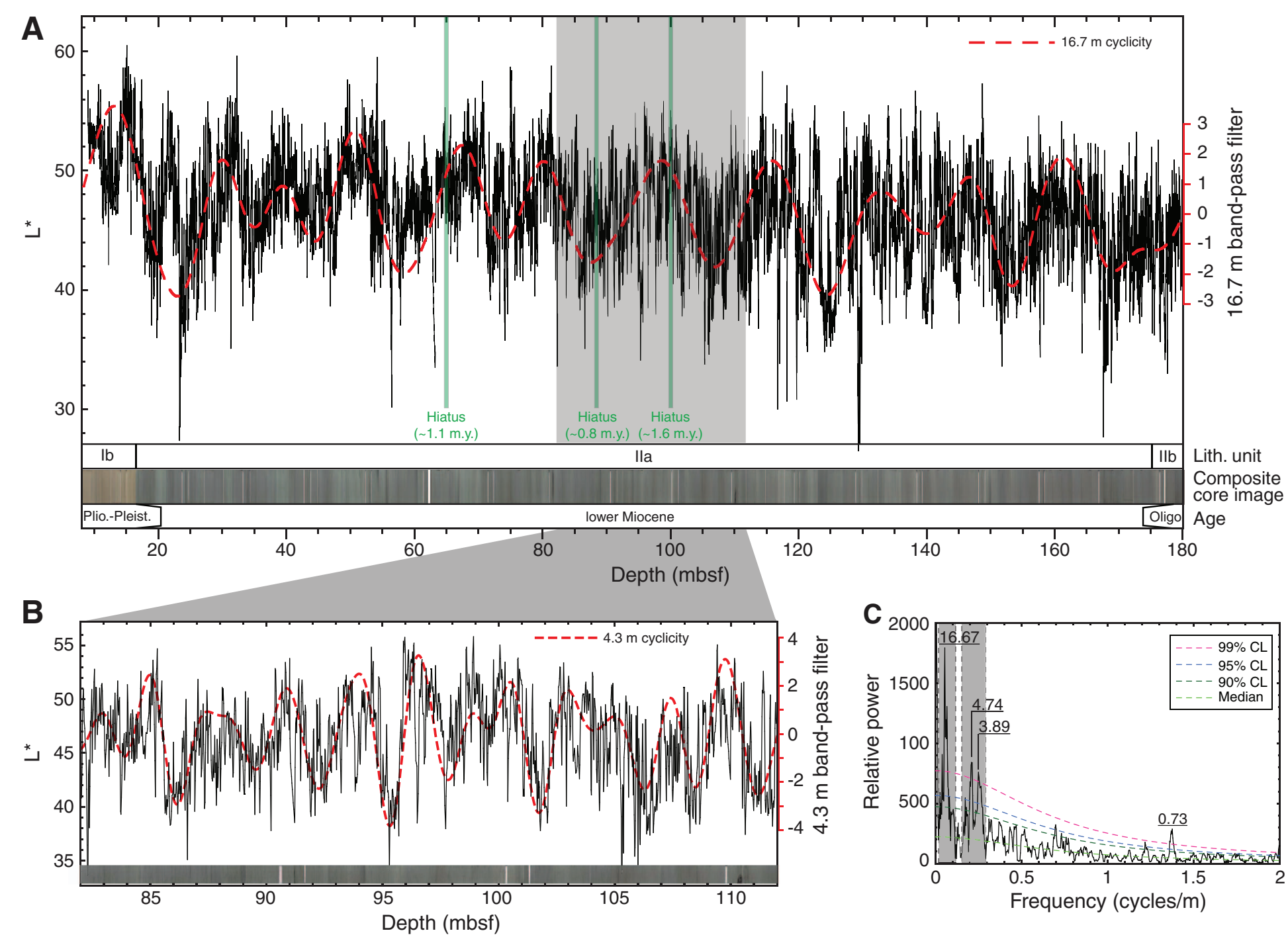
Figure F49. Changes in carbonate content in alternating light greenish gray nannofossil clay and carbonaterich white nannofossil ooze, Core 342-U1409C-6H. The low-resolution carbonate record mirrors the color reflectance $\left(L^{*}\right)$ curve, suggesting a strong cyclic signal.

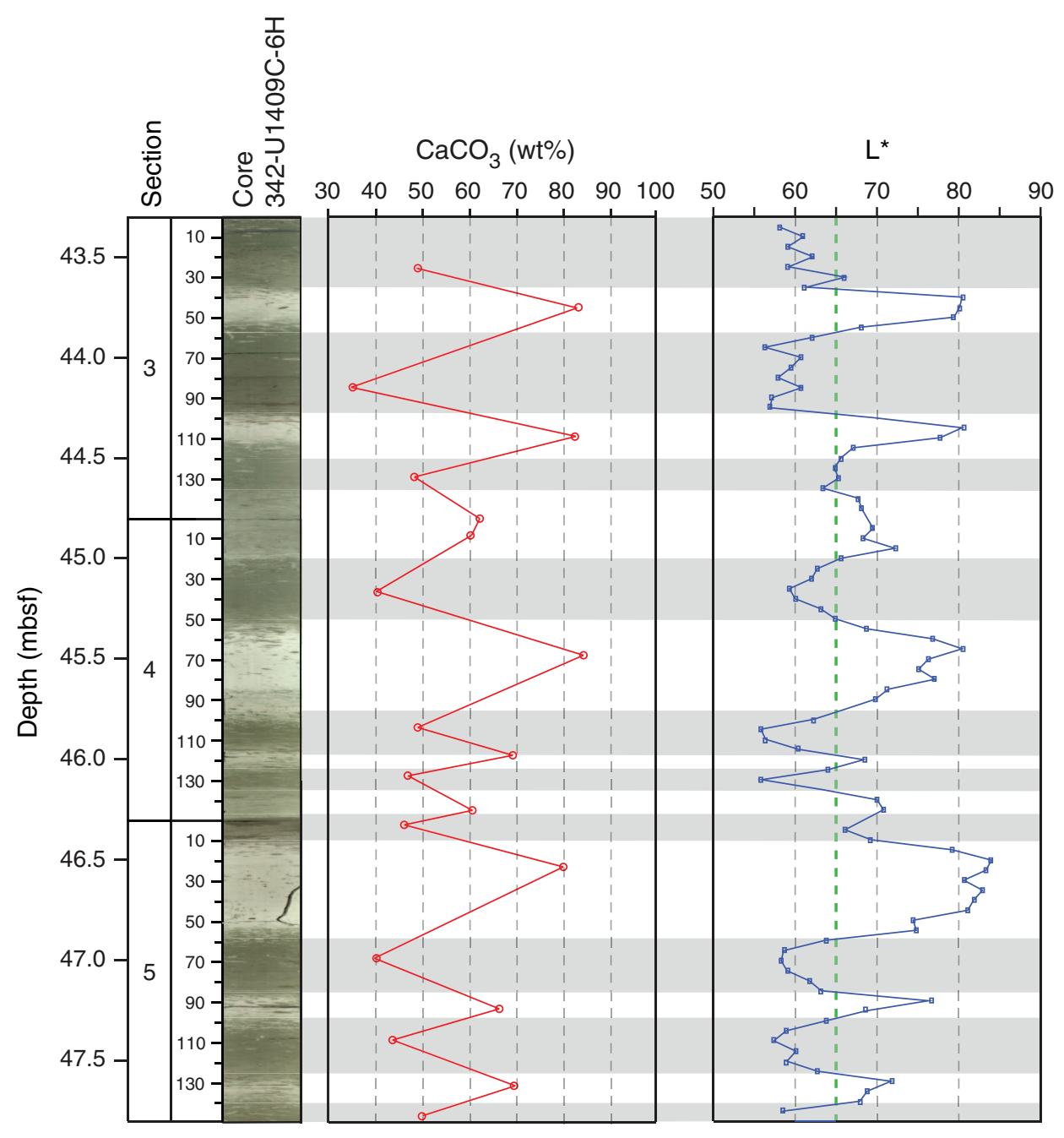


Figure F50. Plots of color reflectance $\left(\mathrm{L}^{*}\right)$ and carbonate content variations, Sites U1408-U1410. The three holes are anchored at the early/middle Eocene boundary. High-resolution $(5 \mathrm{~cm}) \mathrm{L}^{*}$ data are smoothed with a five-point moving average and then fitted to a $10 \%$ weighted average of the smoothed series (dashed lines). Low-resolution (mean sampling $=1.4 \mathrm{~m}$ ) carbonate data are fitted to a $9 \%$ weighted average of the series (dashed lines). Note the correspondence between $\mathrm{L}^{*}$ and carbonate at long-term variations within the lower-middle Eocene; these data types also correlate at the scale of 0.5 to $0.6 \mathrm{~m}$ wavelengths (top middle panel, see text for discussion). Numbers 1-5 are correlatable intervals between holes based on long-term variations of $\mathrm{L}^{*}$ and carbonate data. Note that all scales are the same for the three holes. Power spectrum plot is for 33-71 mbsf in Hole U1409A. CL = confidence level.

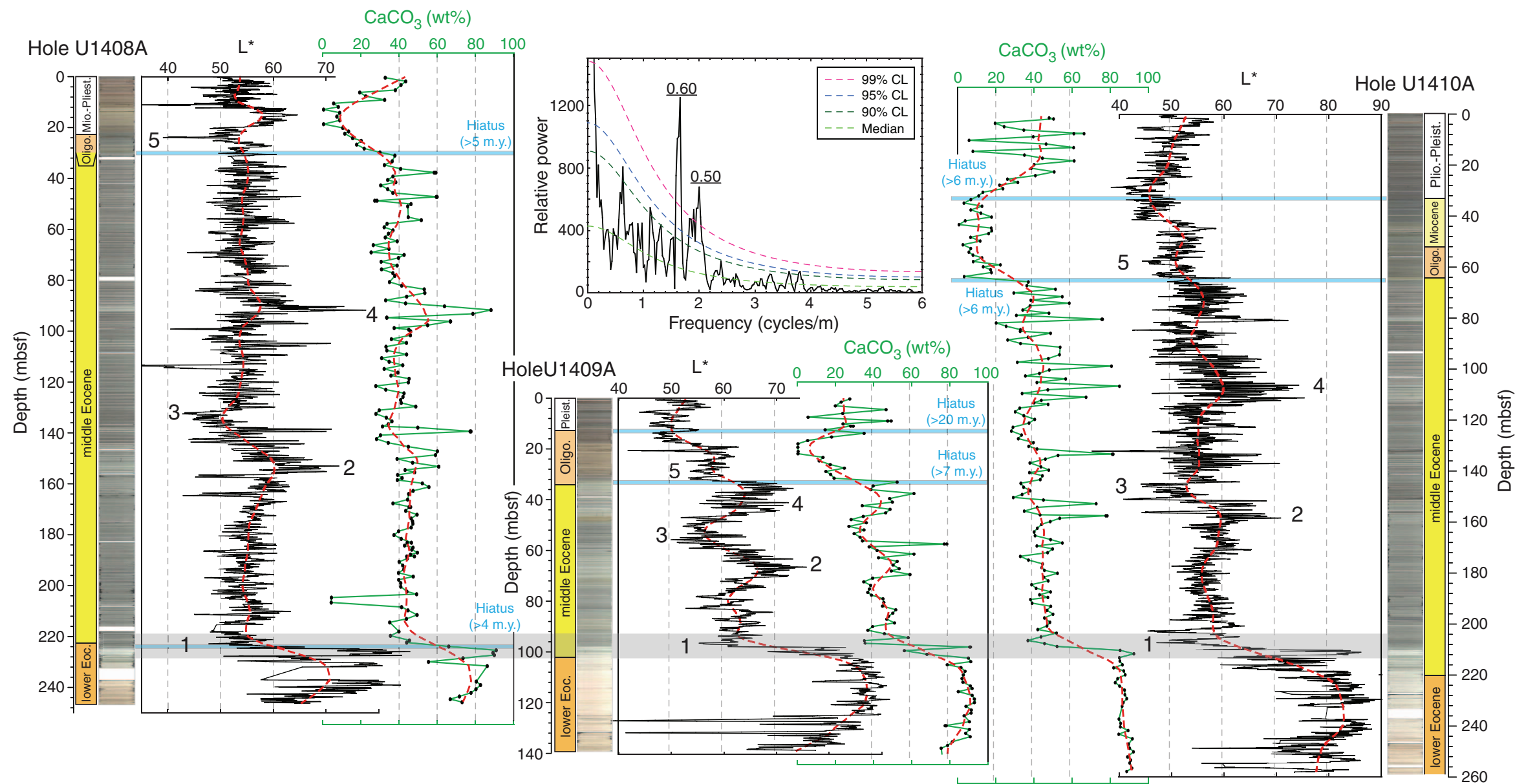


Figure F51. Middle Eocene cyclicity in lithology, magnetic susceptibility, color reflectance $\left(\mathrm{L}^{*}\right)$, and natural gamma radiation (NGR). All show well-expressed cyclicity over this interval. Gray area indicates low contrast of greenish-white color variations, which documents with high-fidelity weaker precession cycles modulated by low-amplitude 100 k.y. eccentricity cycle.

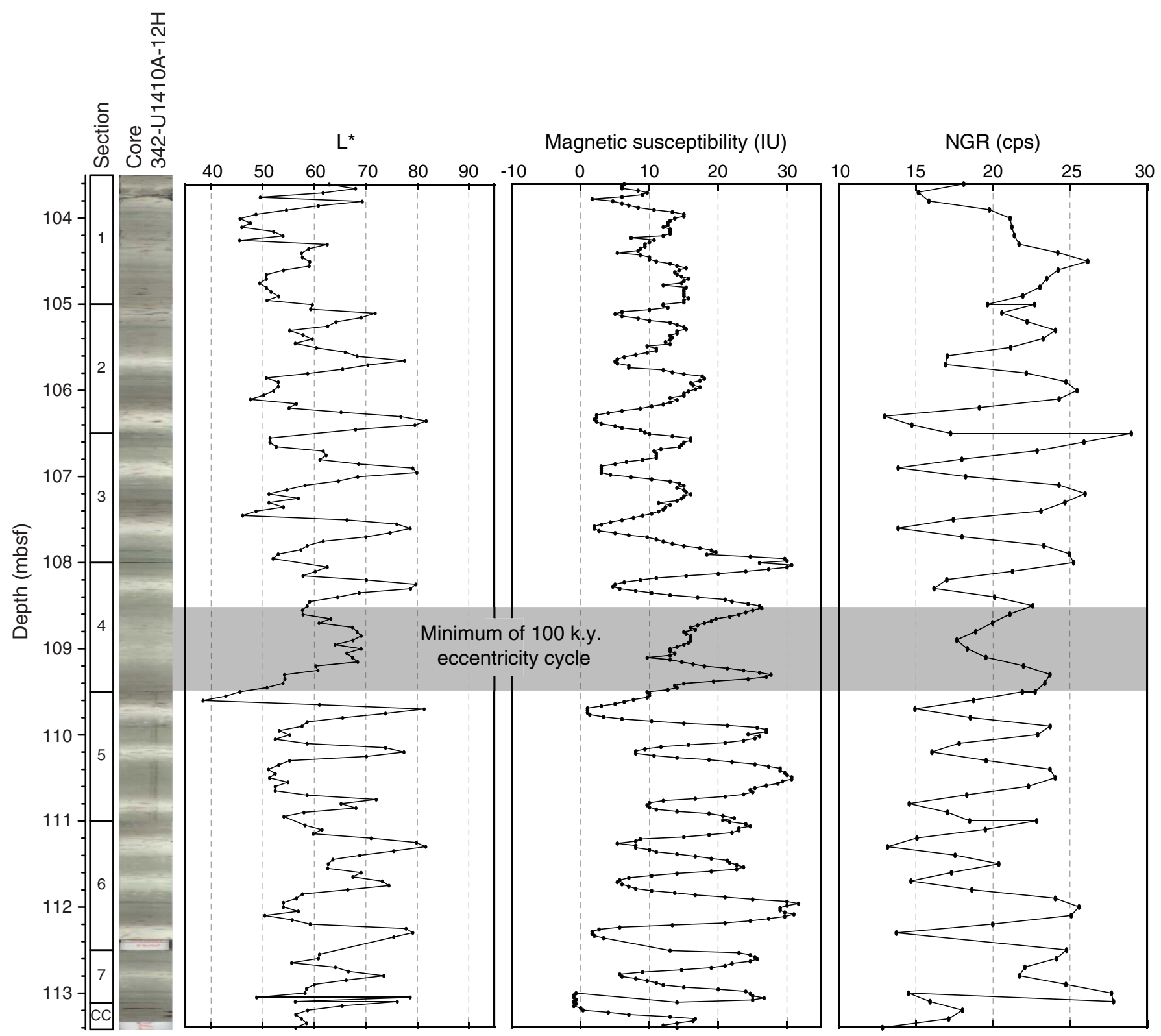


Figure F52. Magnetic susceptibility and carbonate content variations spanning the Eocene Thermal Maximum 2 (ETM2) and the Paleocene/Eocene Thermal Maximum (PETM) hyperthermal events, Holes U1403A and U1403B. A fifth-order polynomial fit is shown to indicate a parabolic trend bounding the two events. A $\sim 5 \mathrm{~m}$ cyclicity is also shown in Hole U1403A.

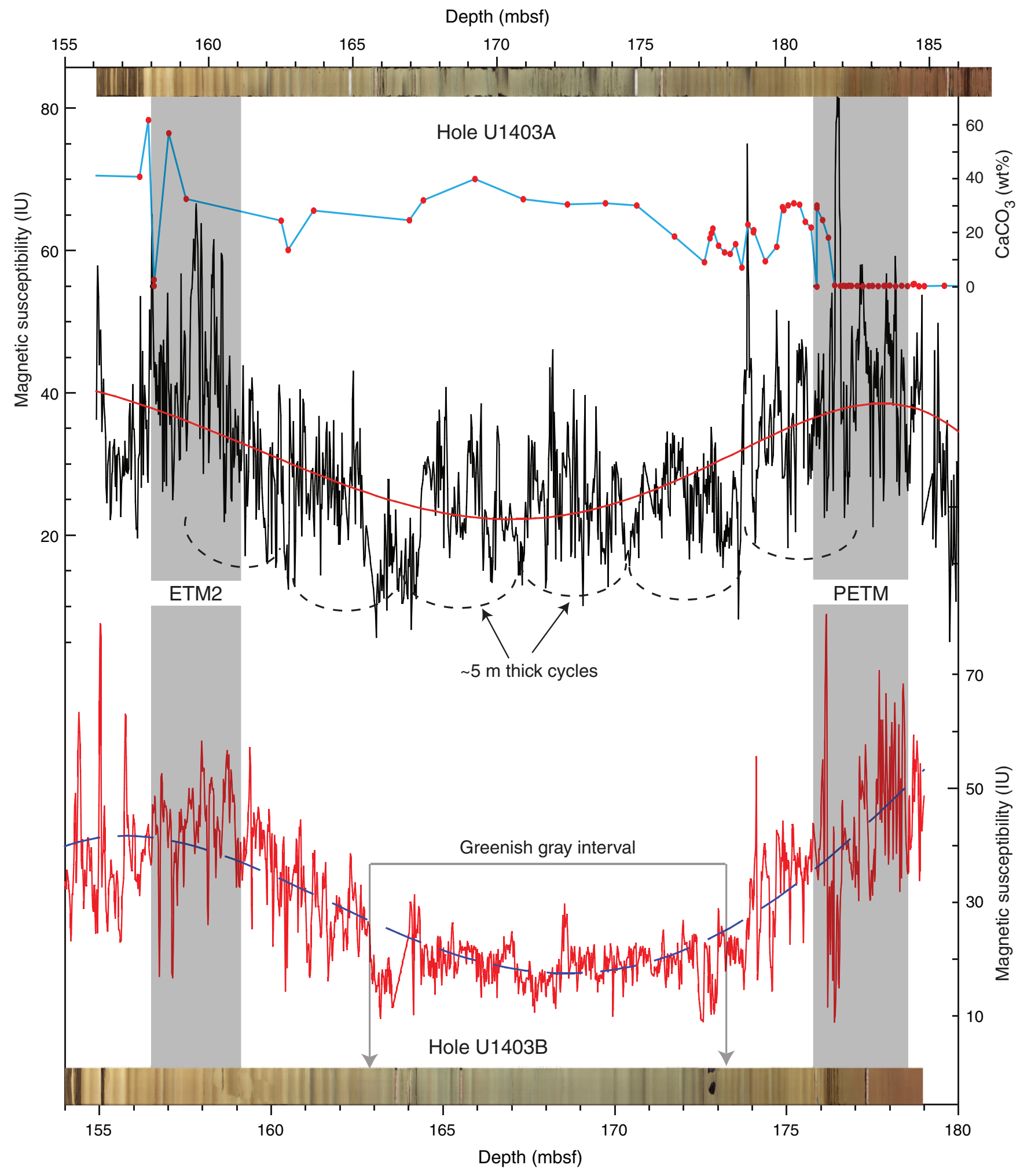


Figure F53. Age-depth models, Sites U1403-U1411. A. Biostratigraphic and paleomagnetic datums and sedimentation rate curves for J-Anomaly Ridge (JA) Holes U1403A-U1406A. B. Biostratigraphic and paleomagnetic datums and sedimentation rate curves for Southeast Newfoundland Ridge (SENR) Holes U1407AU1411A. C. Sedimentation rate curves for all sites. Maximum sedimentation rates are shown for each hole in $\mathrm{A}$ and $\mathrm{B}$.
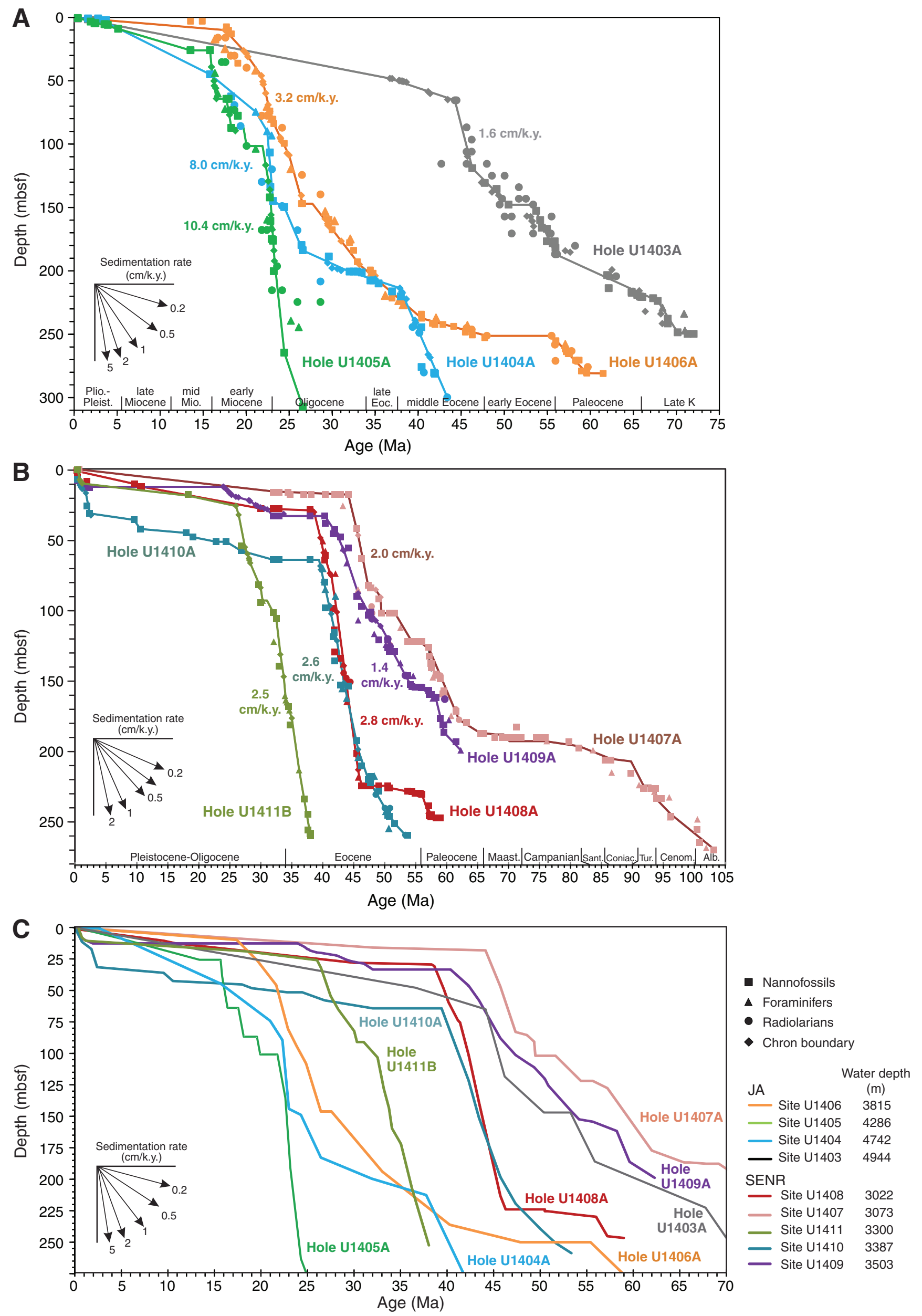
Figure F54. Mass accumulation rate (MAR) for Paleogene sequences of J-Anomaly Ridge Sites U1403, U1404, and U1406. Black lines = total MAR, blue lines = carbonate accumulation rates, red lines = noncarbonate accumulation rates. Gray shading indicates time intervals of drift deposition on the ridge crest, and orange shading indicates intervals of drift deposition on the ridge flank.
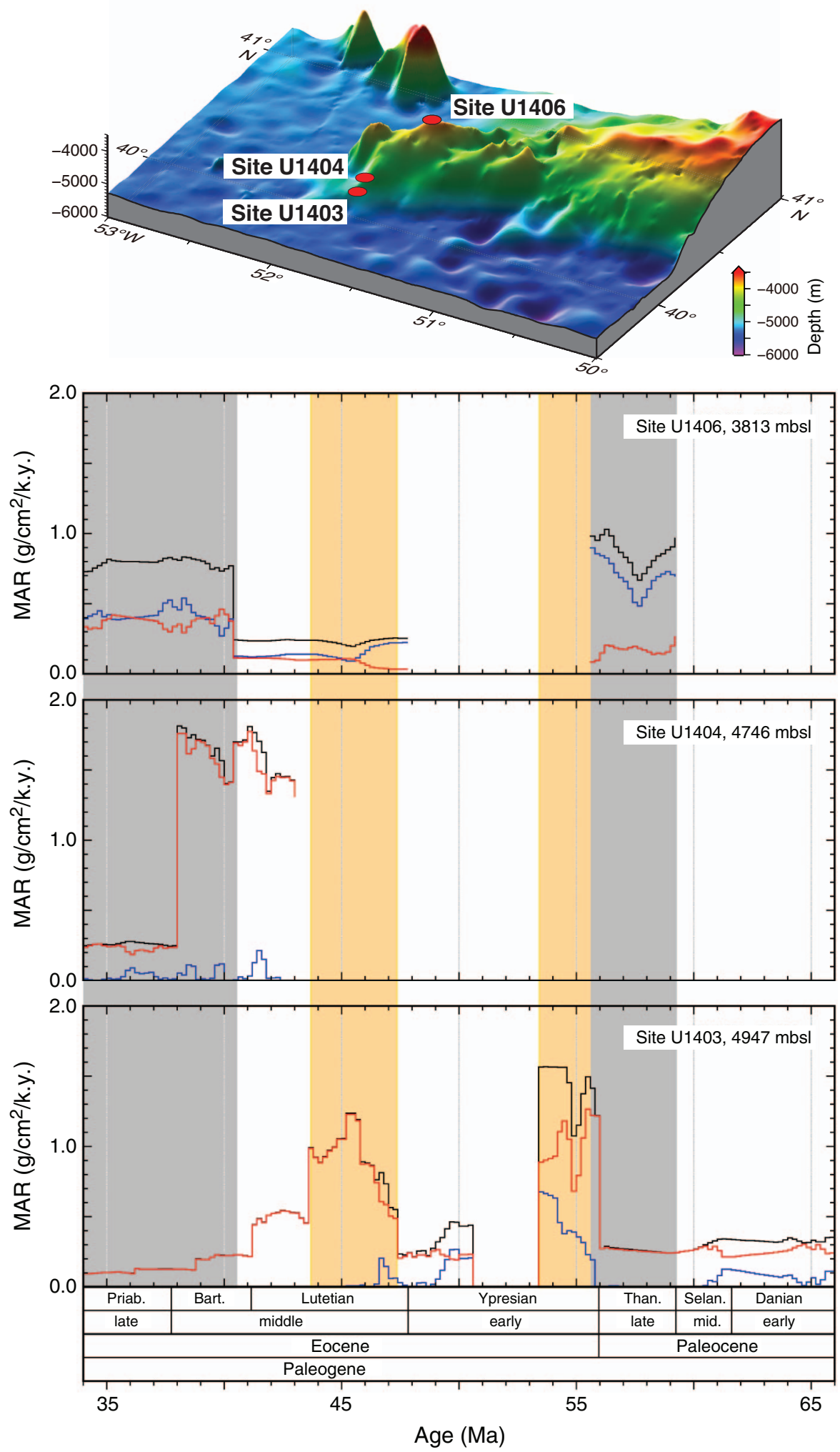
Figure F55. Mass accumulation rate (MAR) for Oligocene-Miocene sequences of J-Anomaly Ridge Sites U1404U1406. Black lines = total MAR, blue lines $=$ carbonate accumulation rates, red lines = noncarbonate accumulation rates. Orange shading indicates intervals of drift deposition on the ridge.
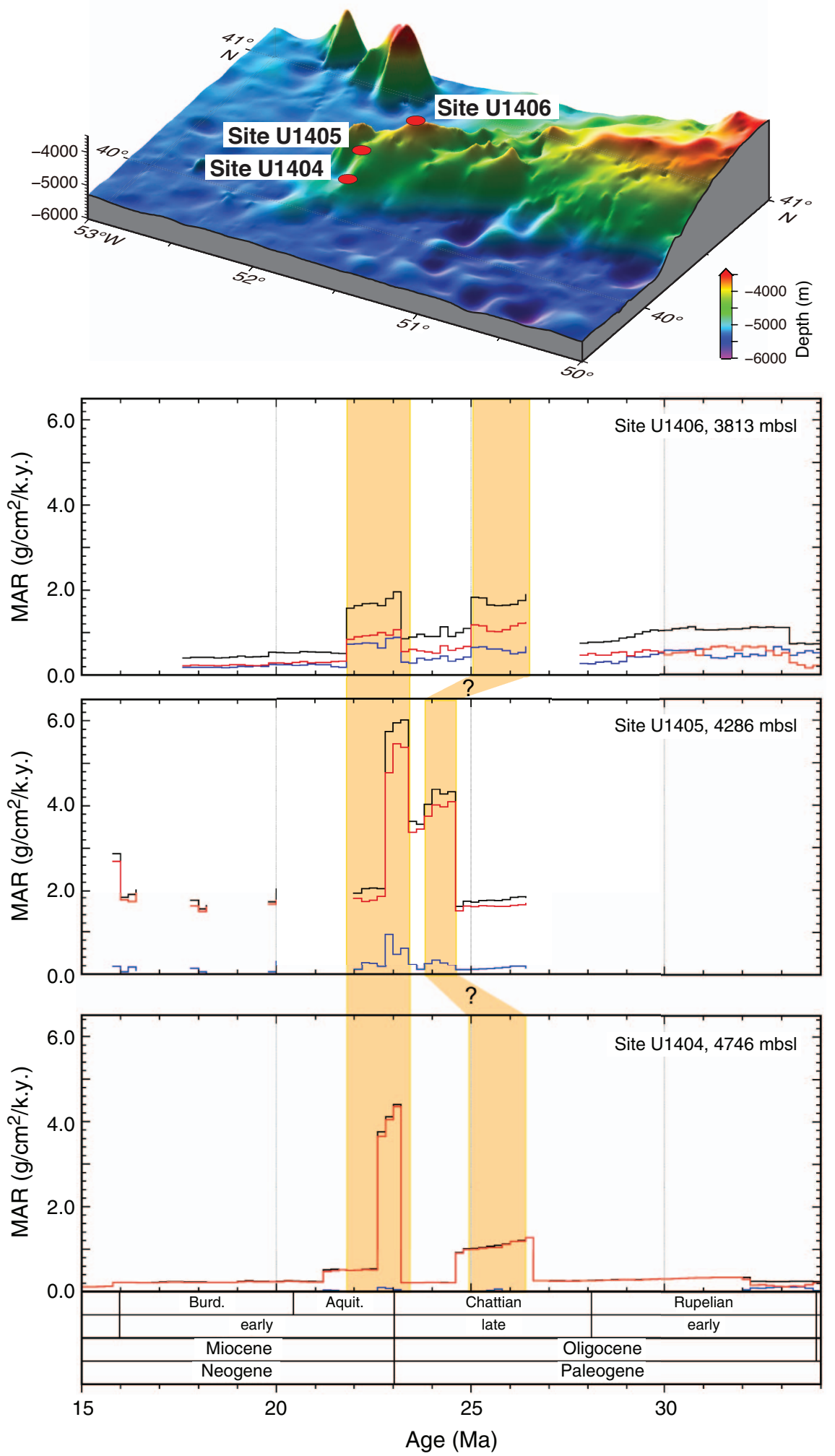
Figure F56. Mass accumulation rate (MAR) for Paleocene-Eocene sequences on the edges of drifts on the Southeast Newfoundland Ridge, Sites U1407-U1410. Black lines = total MAR, blue lines = carbonate accumulation rates, red lines = noncarbonate accumulation rates. Extreme value close to early/middle Eocene boundary is likely artifact of age model associated with underlying unconformity.
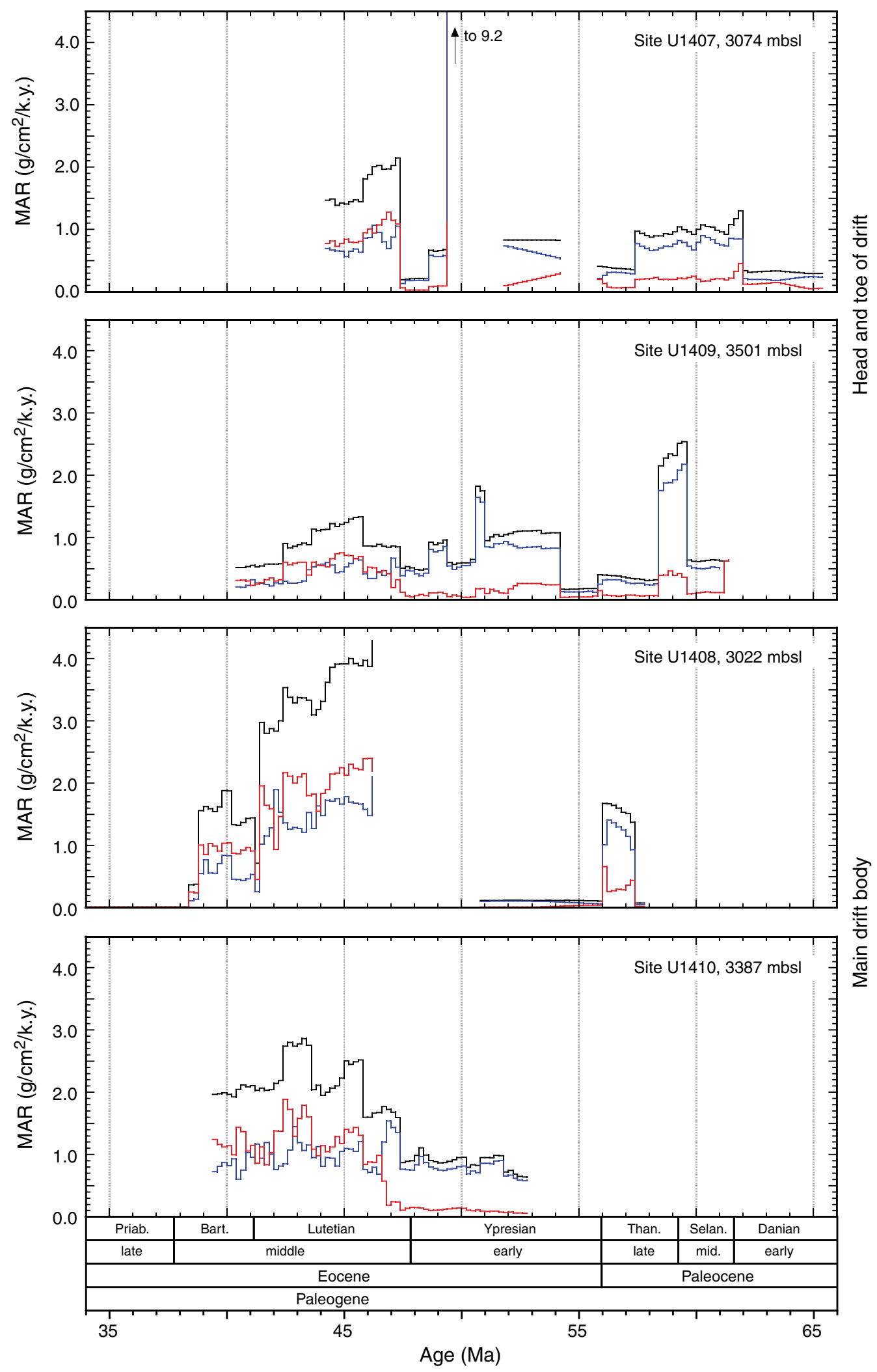


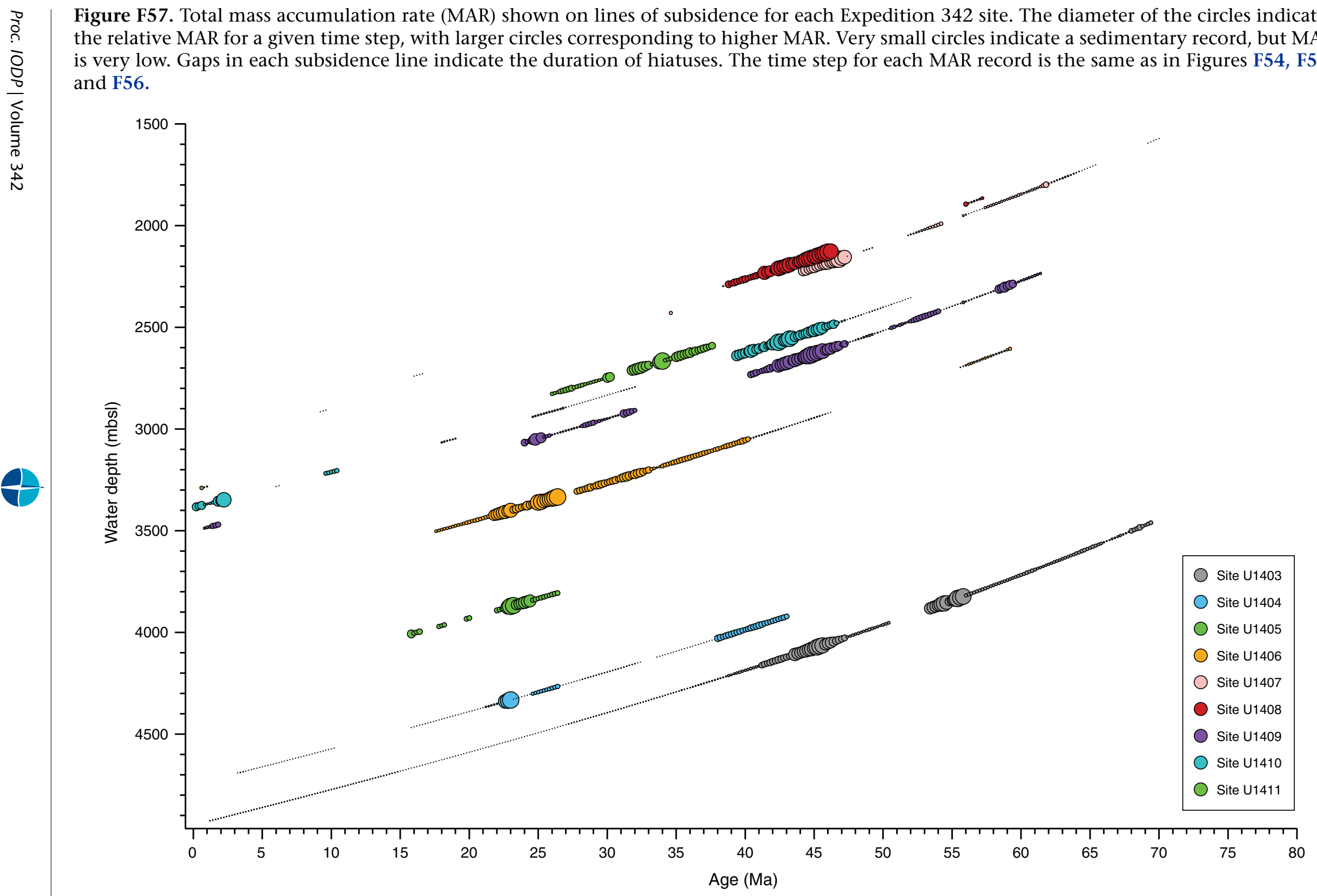


Figure F58. Calcareous nannofossil and planktonic foraminifer presence across the Oligocene-Miocene interval, Sites U1404-U1406. Solid blue lines = Braarudosphaera beds in Hole U1405A, dashed blue line = Braarudosphaera beds in Holes U1405B and U1405C.

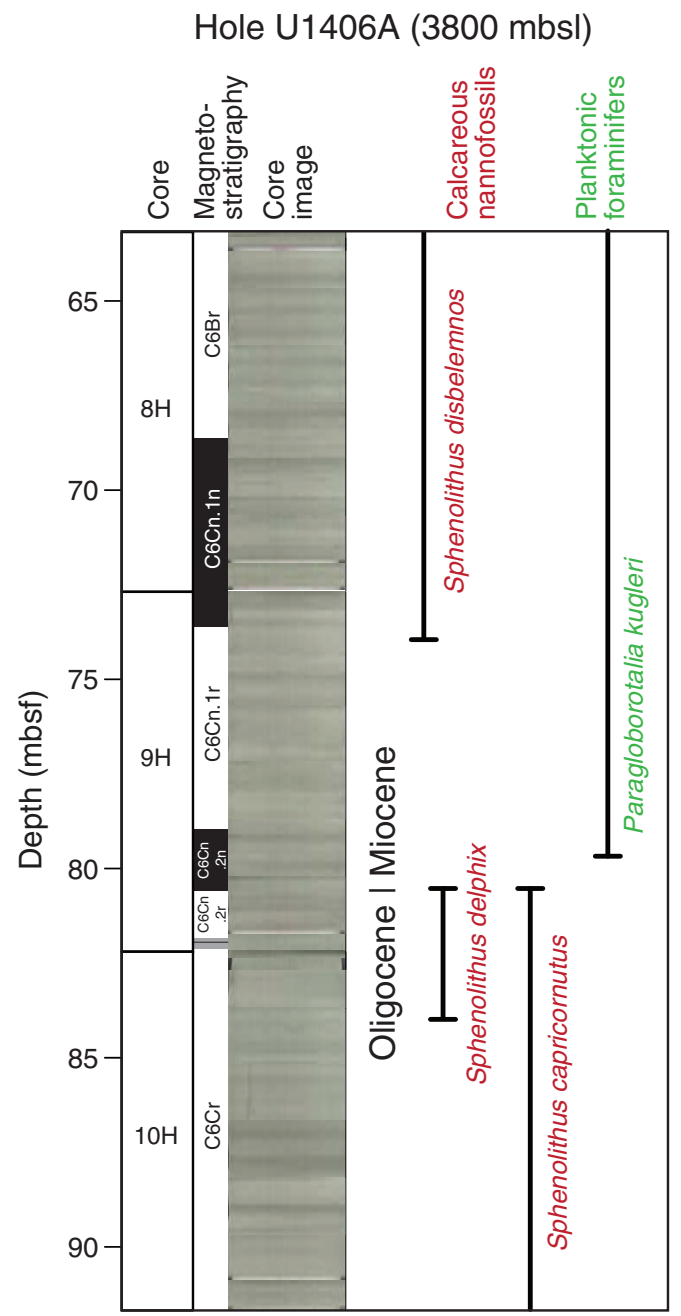

$40^{\circ} 21^{\prime} \mathrm{N}, 51^{\circ} 39^{\prime} \mathrm{W}$
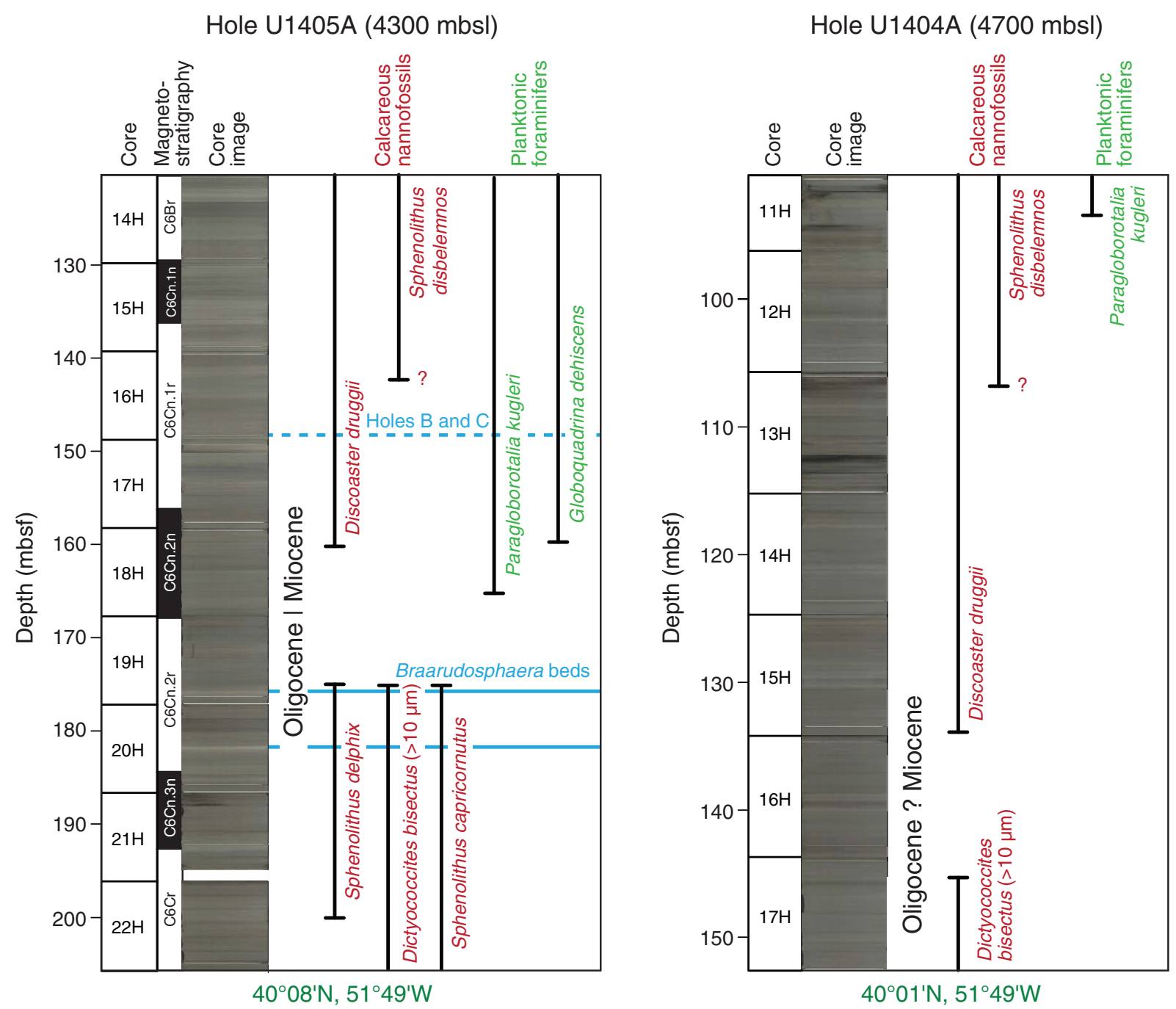
Figure F59. Calcareous nannofossil and planktonic foraminifer presence across the Oligocene-Miocene interval at Site U1405 and stable isotope and biostratigraphies from the Ceara Rise ODP Sites 926 and 929 and the Agulhas Ridge ODP Site 1090 (redrawn after Pälike et al., $2006 a$ ). Mi1 = Miocene Isotope Event 1.

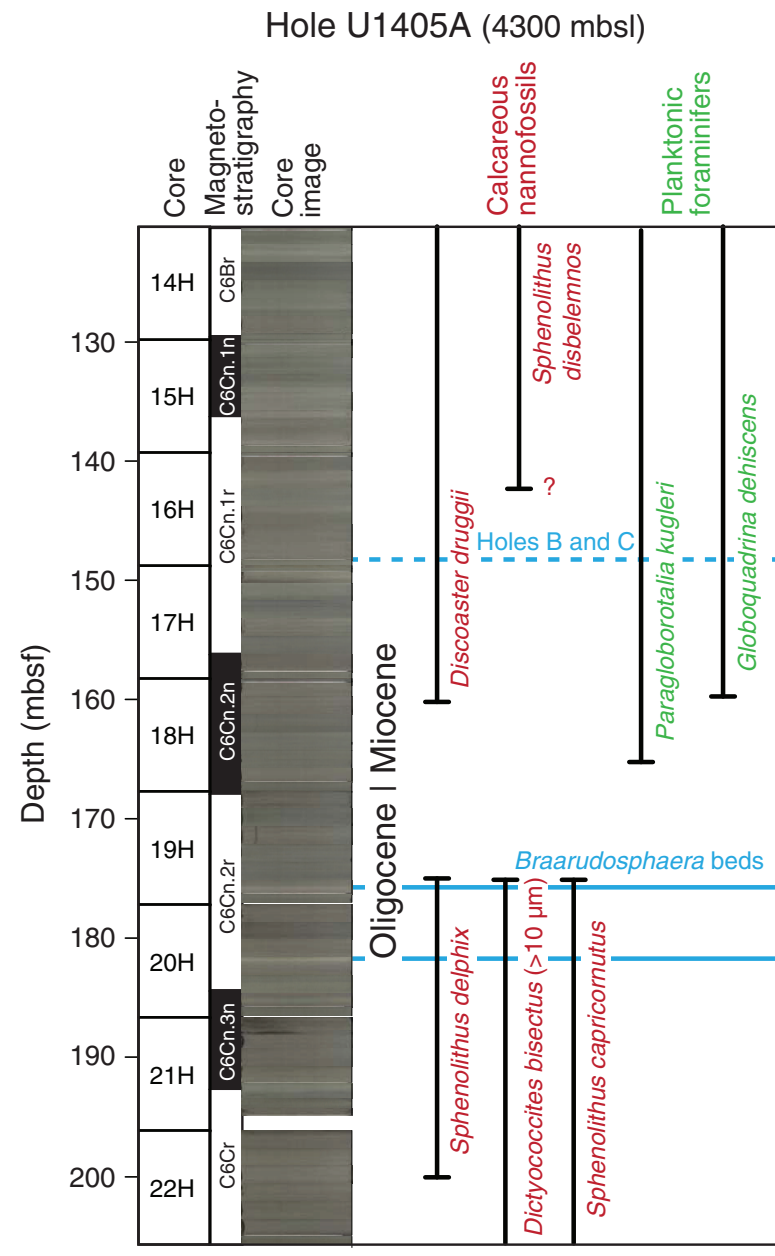

$40^{\circ} 08^{\prime} \mathrm{N}, 51^{\circ} 49^{\prime} \mathrm{W}$

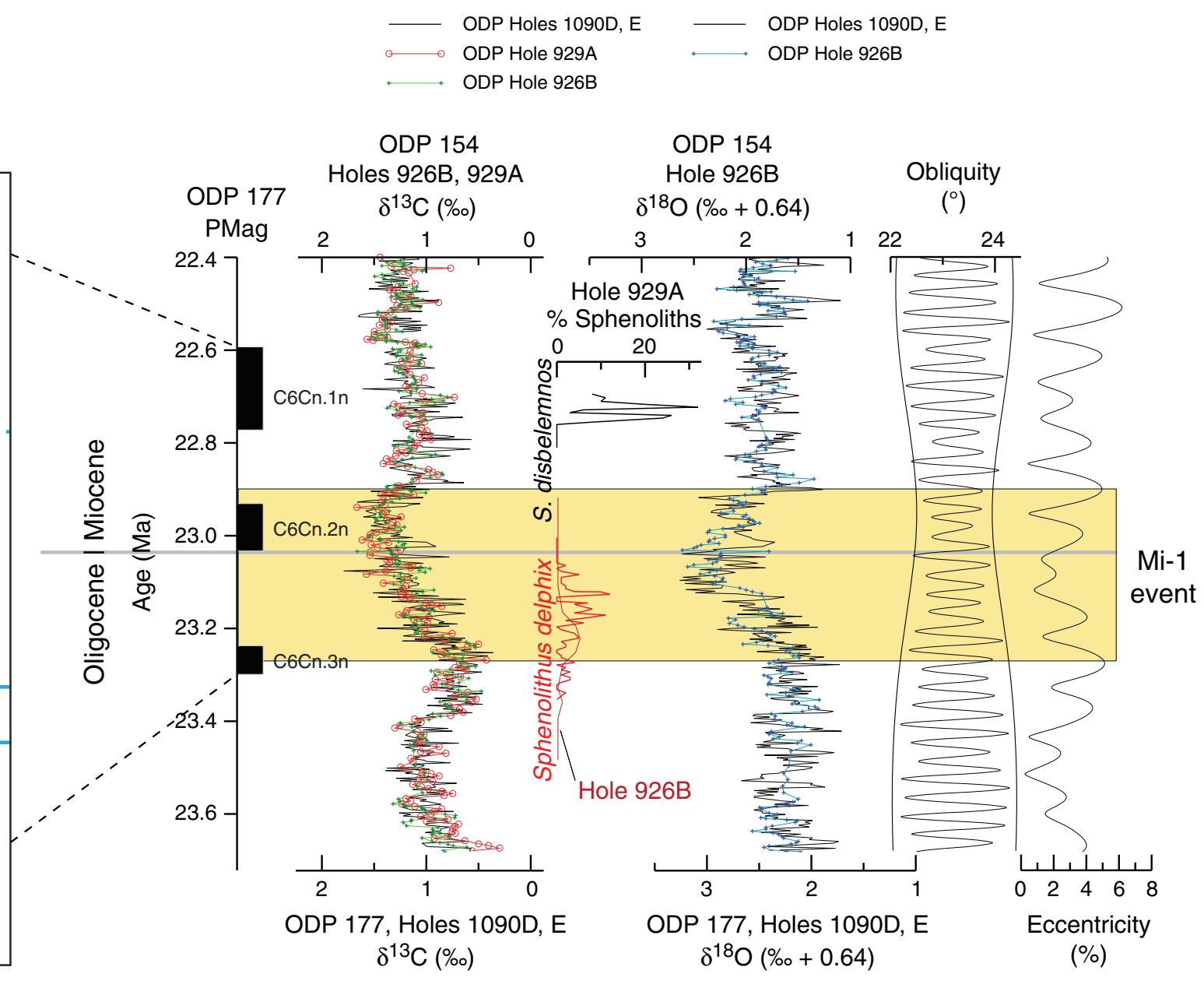


Figure F60. Lithologic expression of the Eocene-Oligocene transition, Sites U1404, U1406, and U1411. Calcium carbonate content and brightness $\left(\mathrm{L}^{*}\right)$ derived from color reflectance measurements. Yellow area indicates the stratigraphic interval between chron boundaries C15n/C13r (34.999 Ma; Gradstein et al., 2012) and C13n/C12r (33.157 Ma; Gradstein et al., 2012) between sites; where not unequivocally defined (gray shading), midpoints were used.

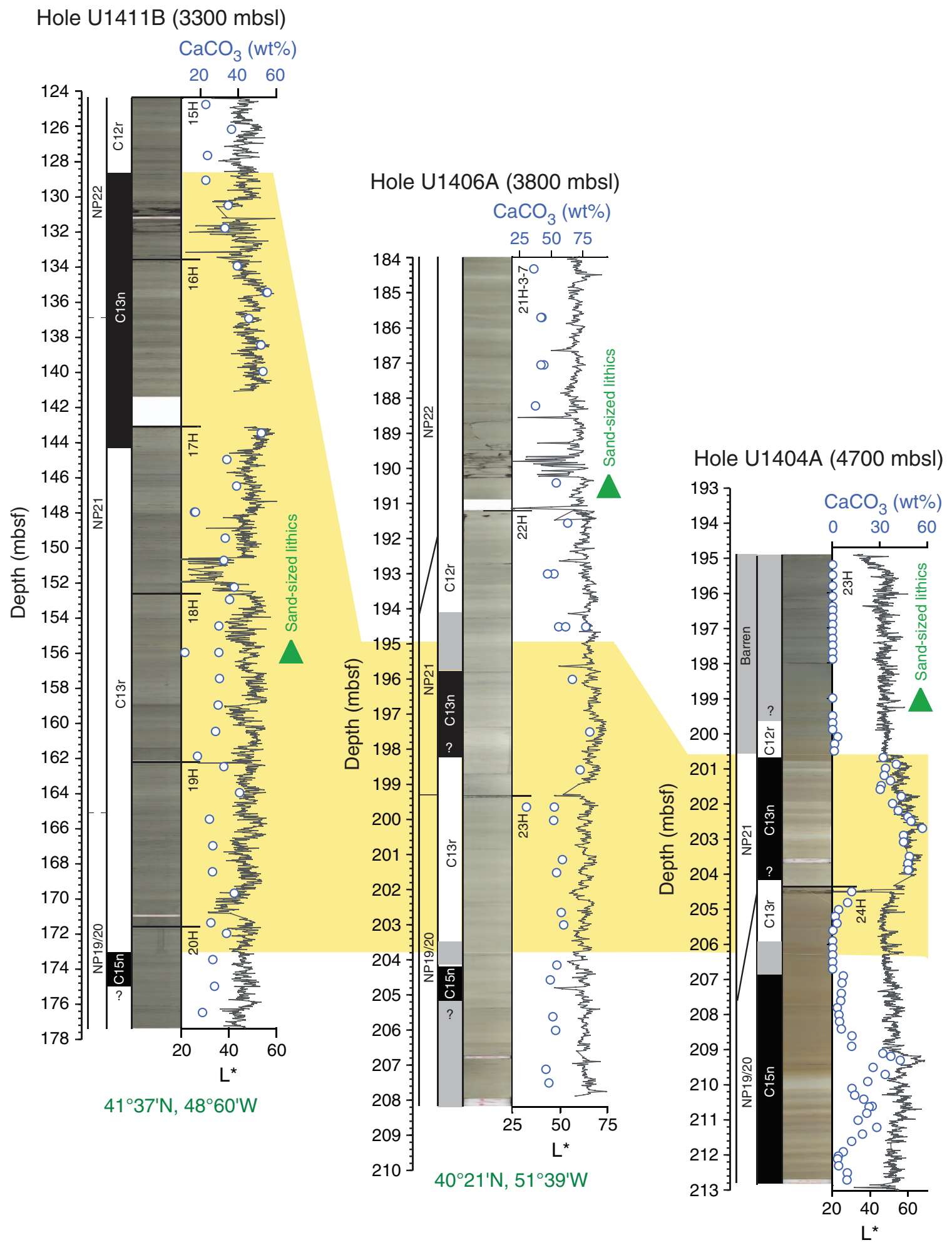

$40^{\circ} 01^{\prime} \mathrm{N}, 51^{\circ} 49^{\prime} \mathrm{W}$ 
Figure F61. Middle Eocene Climate Optimum (MECO), Hole U1408A. Significant changes in calcareous nannofossil taxa are associated with the dominance of infaunal benthic foraminifers and the presence of the planktonic foraminifer Orbulinoides beckmanni. Gray area highlights the perturbation in calcareous microfossil assemblages during the MECO.
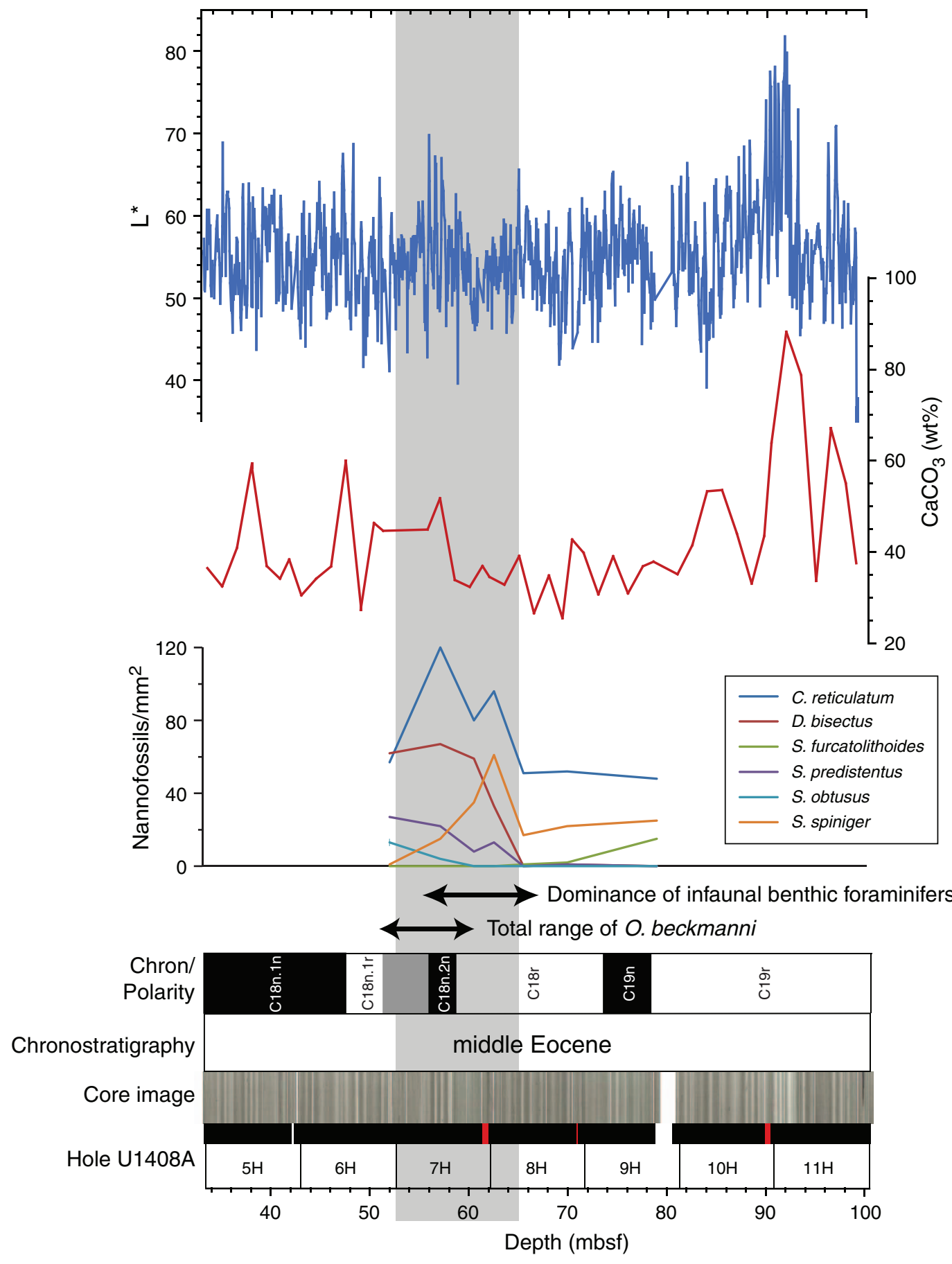
Figure F62. Magnetic susceptibility and calcium carbonate records across the early-middle Eocene transition at Sites U1403 (gray), U1407 (pink), U1409 (purple), and U1410 (blue). Magnetic susceptibility records (solid lines) are from the preliminary shipboard spliced interval at each site, whereas carbonate data (dashed lines) are from Hole A of each site. Chron boundaries are identified from Hole A of each site and converted to the preliminary CCSF depth scale.
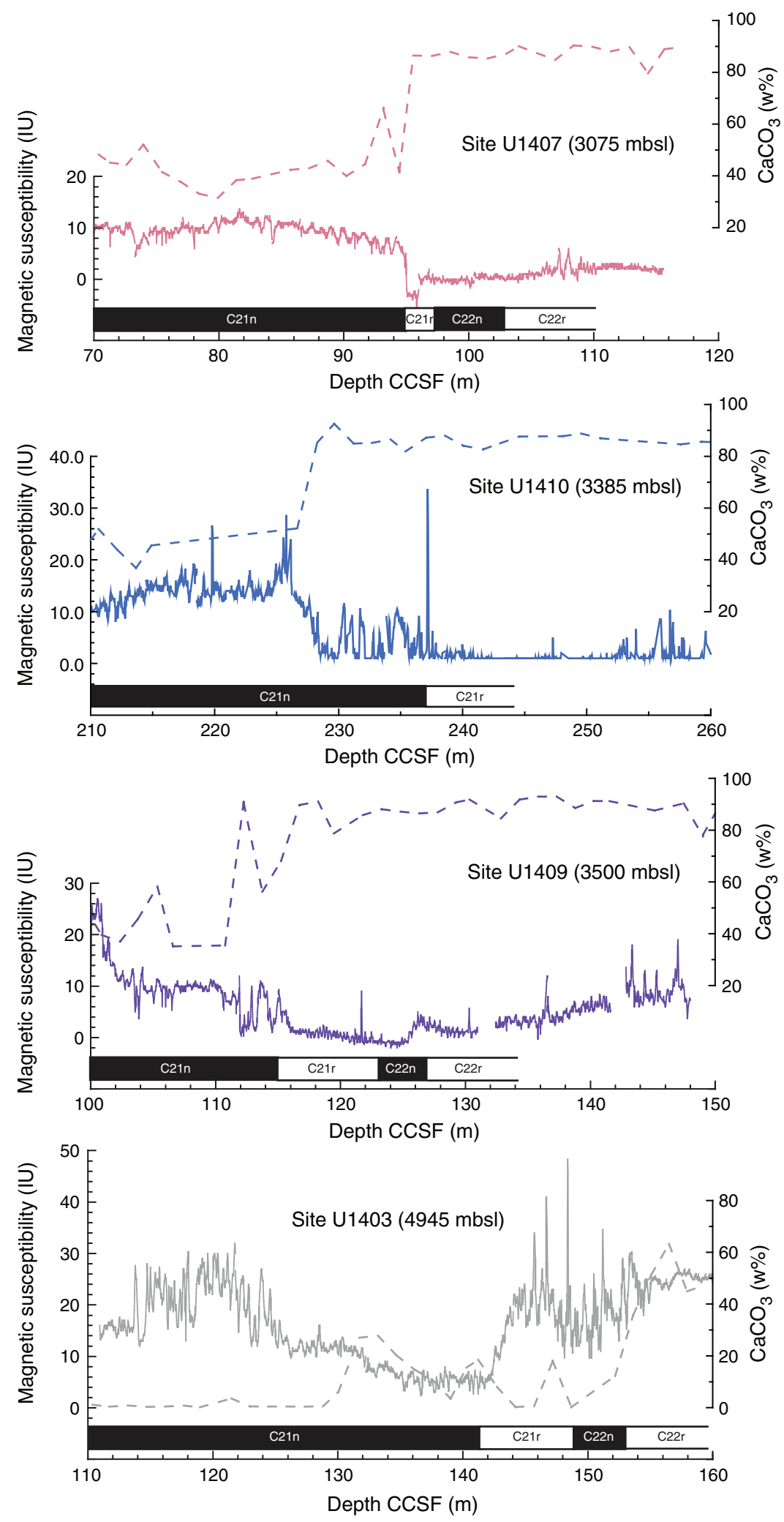
Figure F63. Comparison of core image and magnetic susceptibility, Core 342-U1409B-16X. The core catcher of Core 16X (not shown) contains nannofossil Zone NP11. Based on correlation with Hole U1409A, the rest of the core contains nannofossil Zone NP12. This core shows typical lithology for early Eocene cores from Site U1409, with a series of dark, clay-rich layers roughly corresponding to peaks in magnetic susceptibility. These intervals may be hyperthermal events.

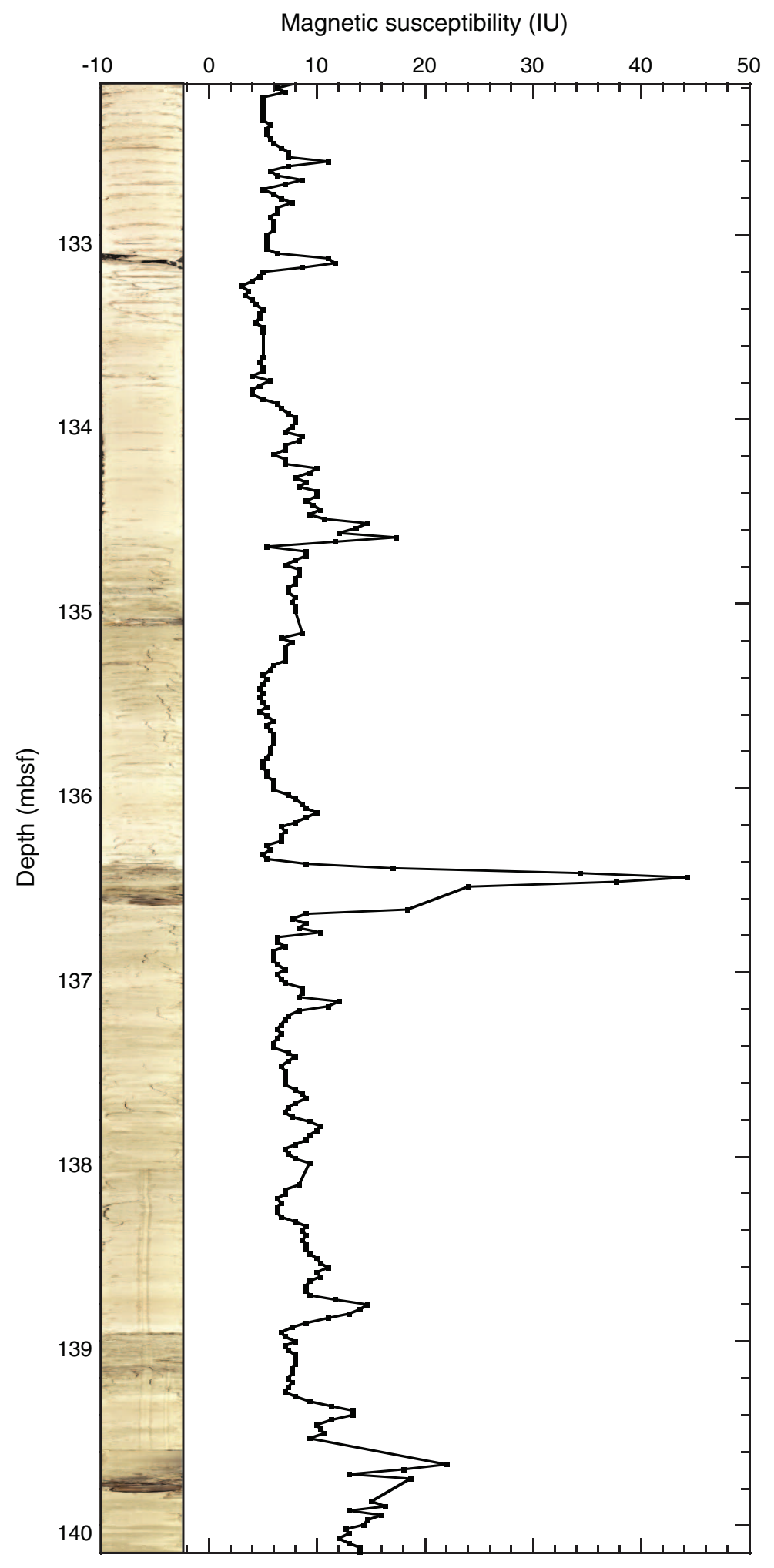


Figure F64. Lithologic expression of the Paleocene/Eocene boundary, Holes U1403A, U1408A, and U1409B. Carbonate content was not measured at high resolution at Site U1408. Lithology is based on macroscopic visual core description, smear slide and thin section analysis, X-ray diffractometry, and carbonate content.

Hole U1408A (3022 mbsl)

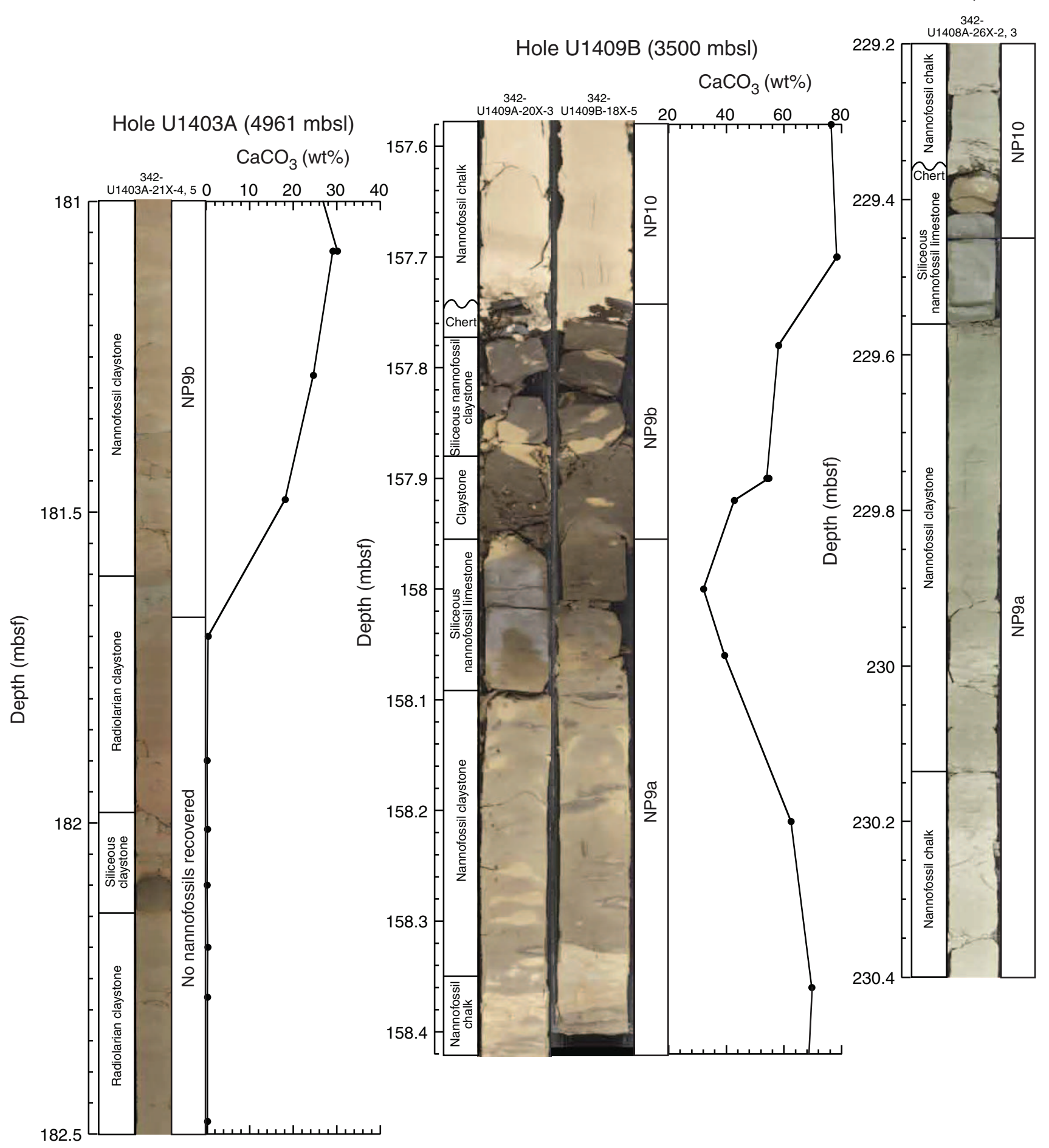


Figure F65. Lithostratigraphy, global events, and benthic foraminiferal isotope records of the Paleocene at ODP Site 1209 (Westerhold et al., 2011 ; central Pacific compared to Expedition 342 records of the middle Paleocene). Age model follows Option 1 of Westerhold et al. (2008). Cored lithologies are shown for Sites U1403 and U1407, covering the Danian-Selandian interval (yellow). CN $=$ calcareous nannofossil, NF $=$ nannofossil, $\mathrm{VPDB}=$ Vienna Peedee belemnite. PETM = Paleocene/Eocene Thermal Maximum, ETM1 = Eocene Thermal Maximum 1, K/Pg = Cretaceous/ Paleogene boundary. A, B. Representative lithologies within nannofossil Zone NP4.

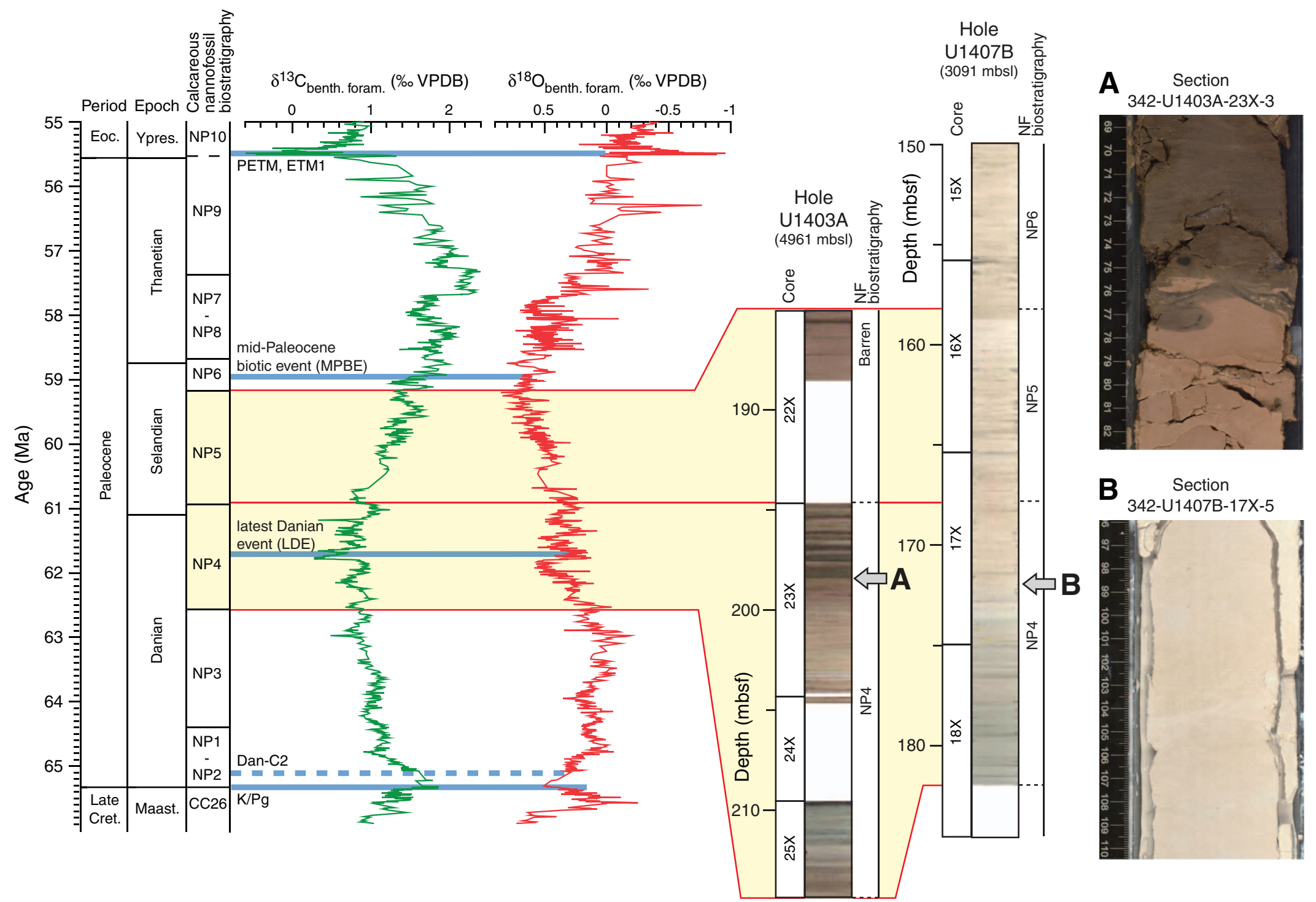


Figure F66. Cretaceous/Paleogene boundary (K/Pg) at J-Anomaly Ridge Site U1403. The K/Pg boundary is set at the base of an $\sim 1 \mathrm{~cm}$ thick graded spherule layer in Holes U1403A and U1403B. The spherule layer is underlain by diverse late Cretaceous nannoplankton assemblages (Zone UC20D) and overlain by abundant calcispheres with early Danian nannoplankton (Zone NP1). The close-up image of the K-Pg boundary in Hole U1403B shows the detailed stratigraphy of the boundary, including an apparently unbioturbated fine, whitegray layer $<0.5 \mathrm{~cm}$ thick underlying the $\sim 0.5 \mathrm{~cm}$ thick bed of normally graded green sand- to silt-sized impact spherules. A light greenish gray chalk $(\sim 0.5 \mathrm{~cm}$ thick) with abundant calcispheres and early Paleocene biomarkers sits immediately above the graded spherule bed.

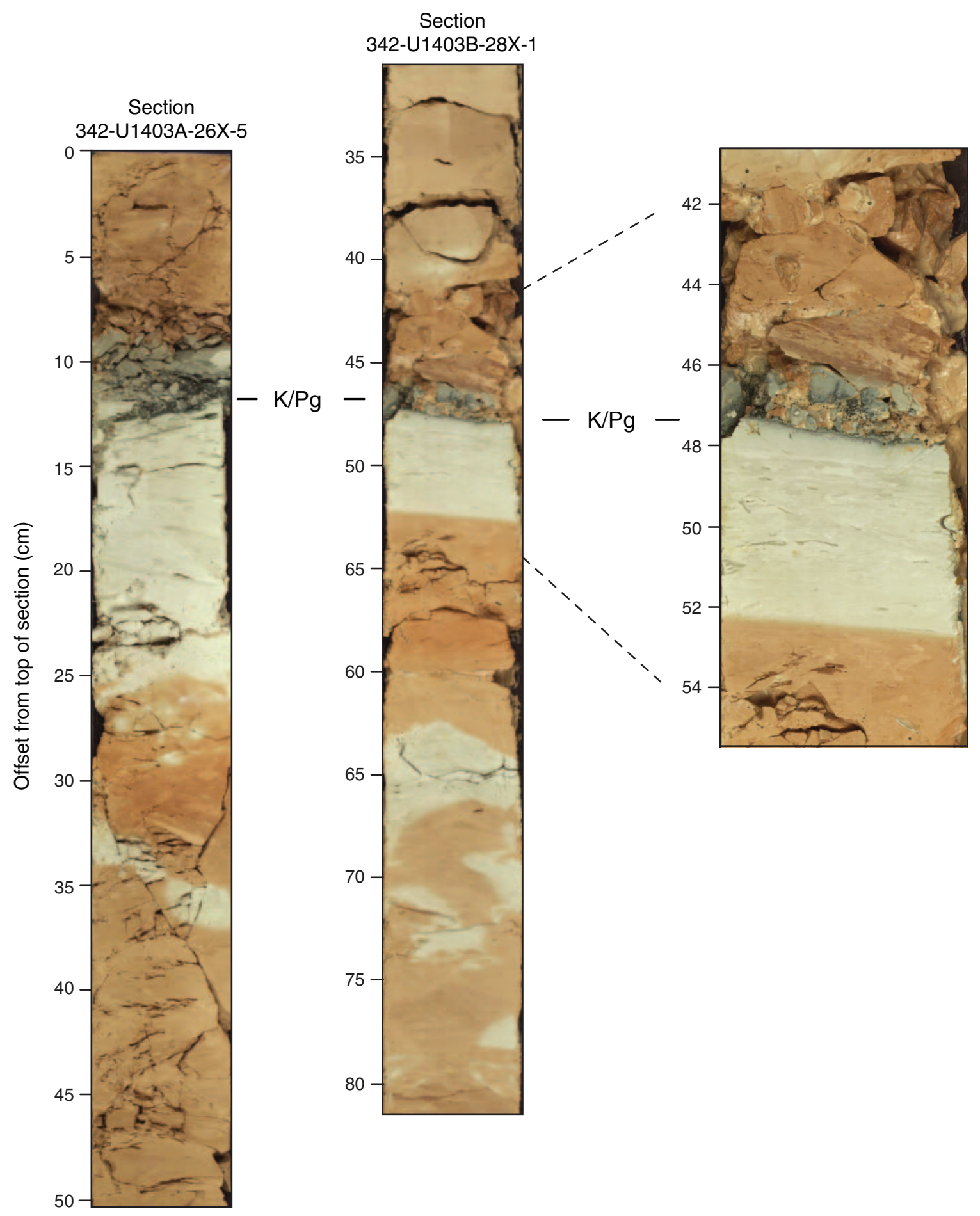


Figure F67. Cretaceous/Paleogene $(\mathrm{K} / \mathrm{Pg})$ boundary sections showing a range of spherule bed thickness. Spherule bed thickness ranges from $>8 \mathrm{~cm}$ thick at sites proximal to the impact (e.g., Caribbean ODP Site 1001) to not observed in very distal sites with bioturbation (Shatsky Rise ODP Site 1209).

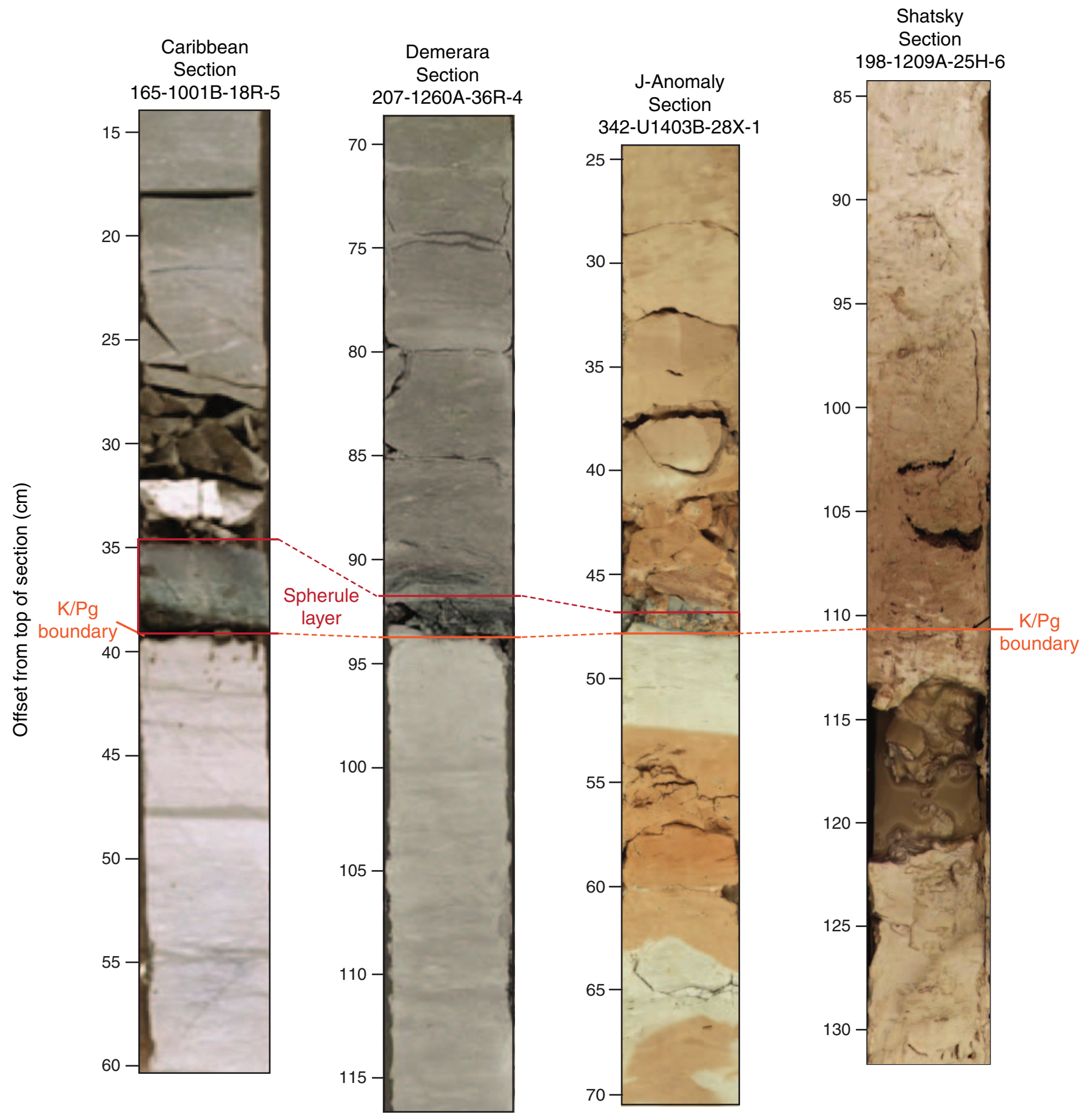


Figure F68. Stratigraphic logs, Site U1407. Interval includes the late Cenomanian through early Turonian. Logs have a stylized weathering profile that denotes the relative resistance of chalks to the more friable black shales and claystones. TOC $=$ total organic carbon.

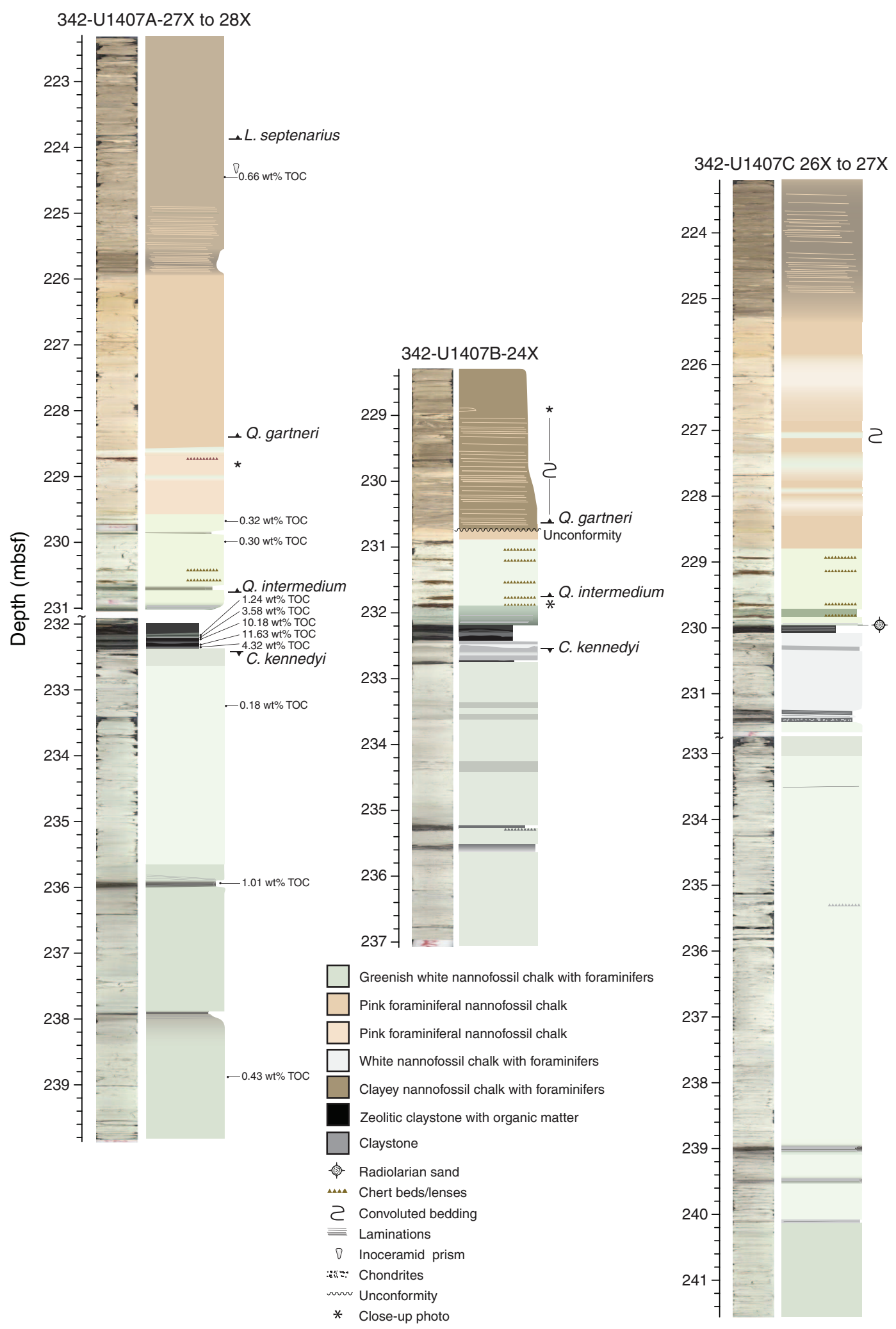


Figure F69. Ocean Anoxic Event 2 black shale horizons, Holes U1407A-U1407C. Gaps in Hole U1407A are the result of coring disturbance.

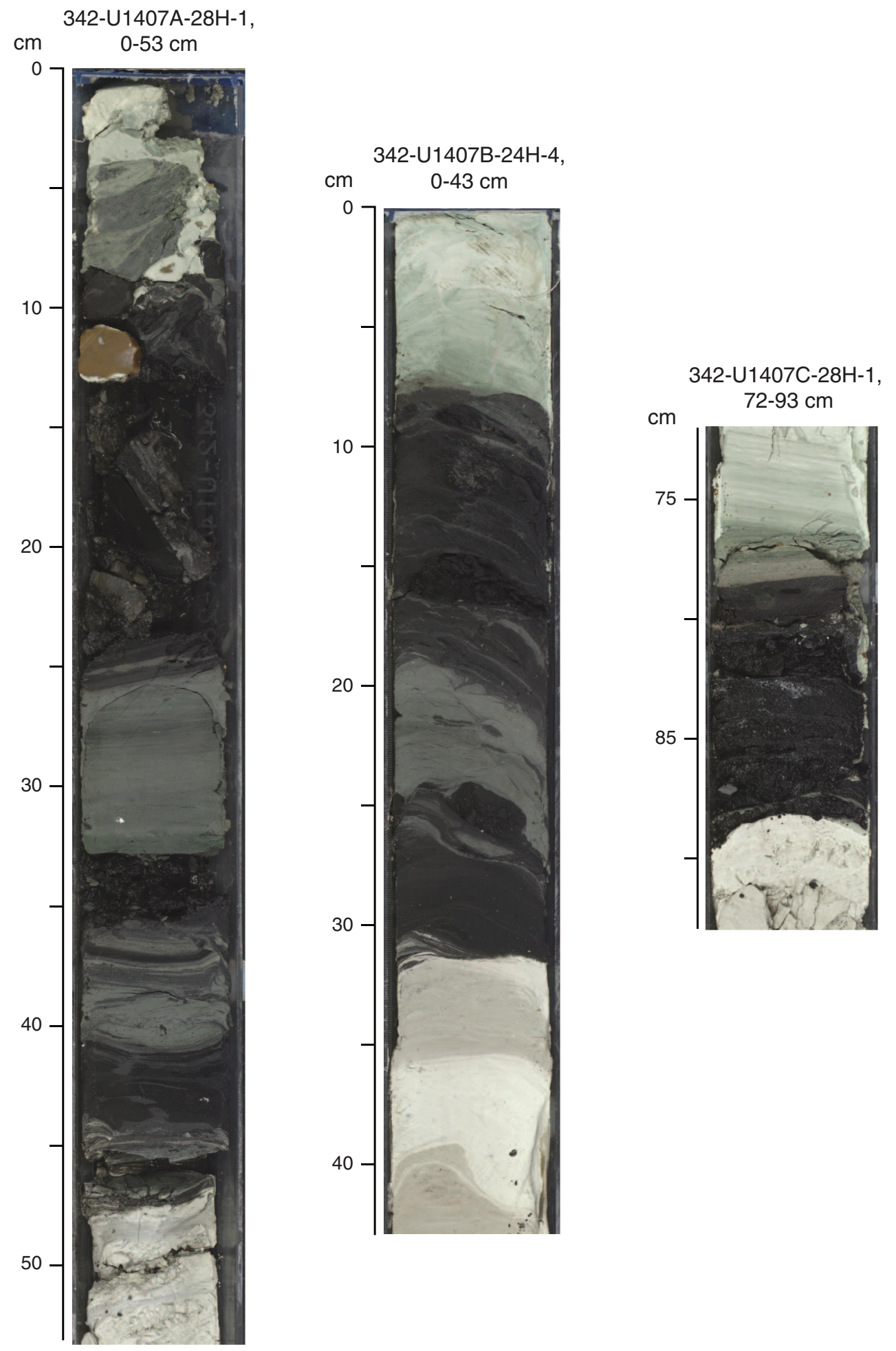


Figure F70. Characteristic lithologies from the Oceanic Anoxic Event (OAE) 2 interval, Holes U1407A and U1407B. A. Example of a preblack-band laminated claystone with well-developed Chondrites burrowing at the top. The wedge shape of this bed is the result of core rotation during extended core barrel drilling. B. Example of reddish brown chert with mottles accompanied by significant magnetic susceptibility peaks. Surrounding lithologies are nannofossil chalk with clay (light green below chert) and nannofossil chalk (greenish white above chert). C. Example of middle Turonian laminated clayey nannofossil chalks with well-preserved slumpinduced overturning. D. Red radiolarian chert hosted in pinkish white nannofossil chalk overlying the OAE interval. E. Laminated nannofossil claystones with radiolarians that directly overlie the black shales.

A

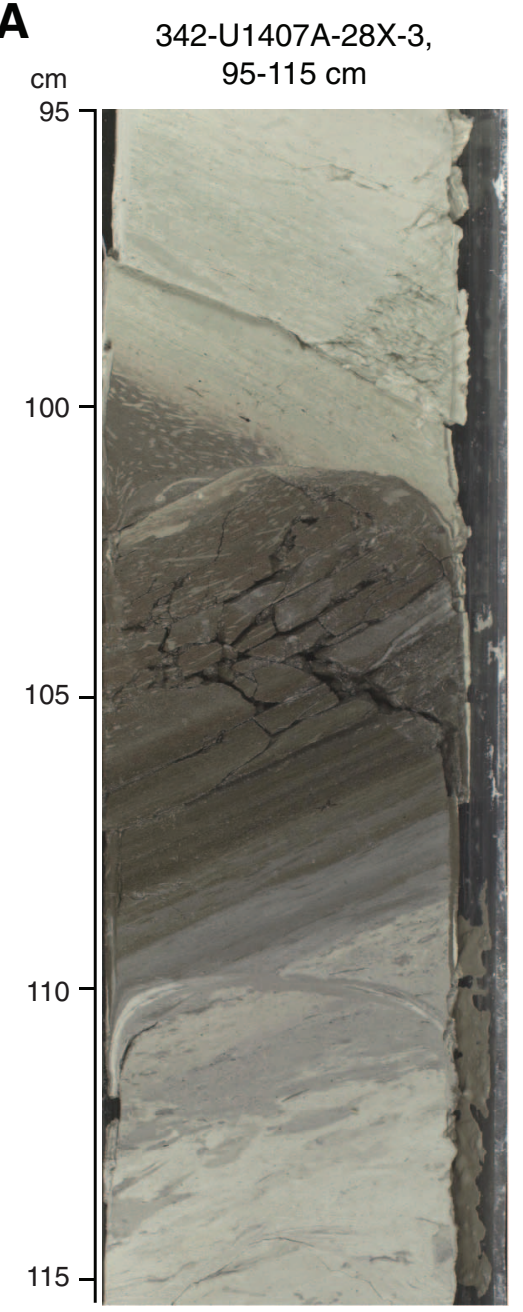

B
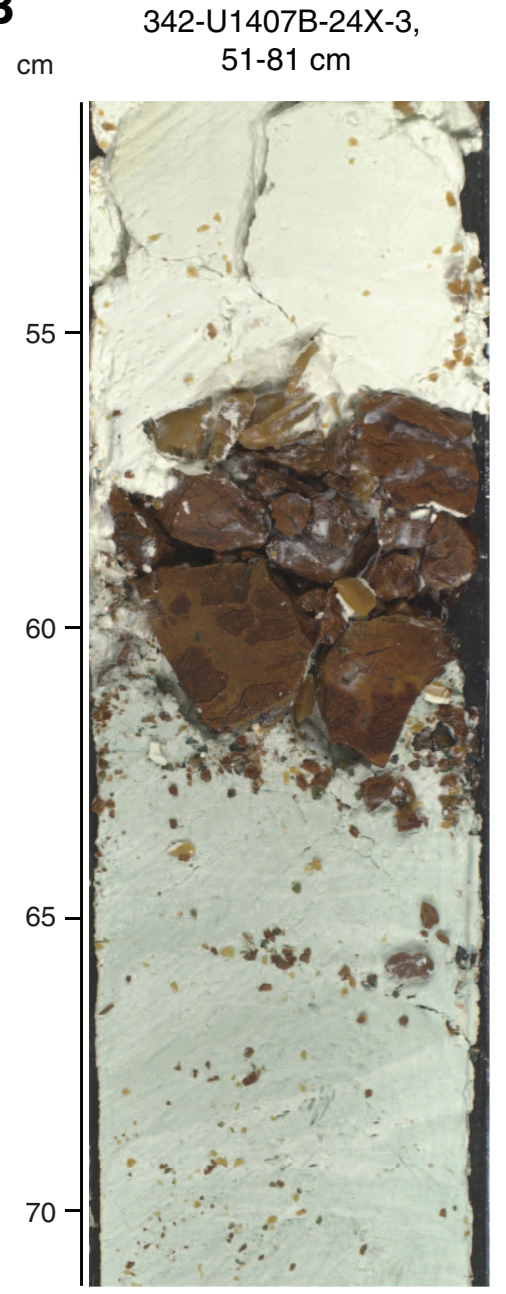

C $\mathrm{cm}$ 342-U1407B-24X-1, $62-66 \mathrm{~cm}$

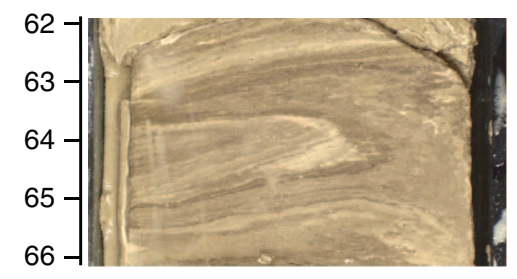

D
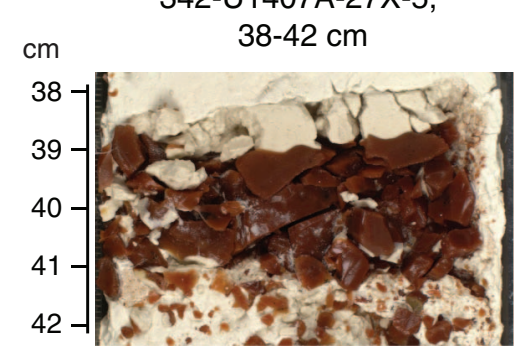

E

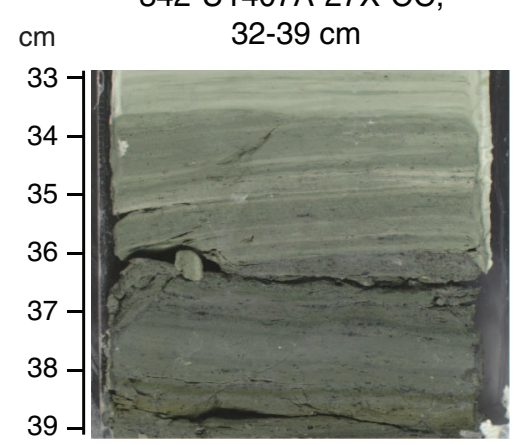


Figure F71. Shallow-marine carbonate sediment contents, Hole U1407A. A. Mixed carbonate-clastic grainstone that has been lightly dolomitized and heavily cemented with iron manganese crusts (Sample 342-U1407A-31XCC, 17-18 cm). B. Pel-bio-micrite (Folk, 1959) (Sample 342-U1407A-35X-CC). C. Mollusk mold in limestone (Sample 342-U1407A-35X-CC). D. Mold of scleractinian coral fragment (Sample 342-U1407A-35X-CC). E. Orbitolina benthic foraminifers (Sample 342-U1407A-33X-CC). F. External mold of high-spired gastropod in limestone.
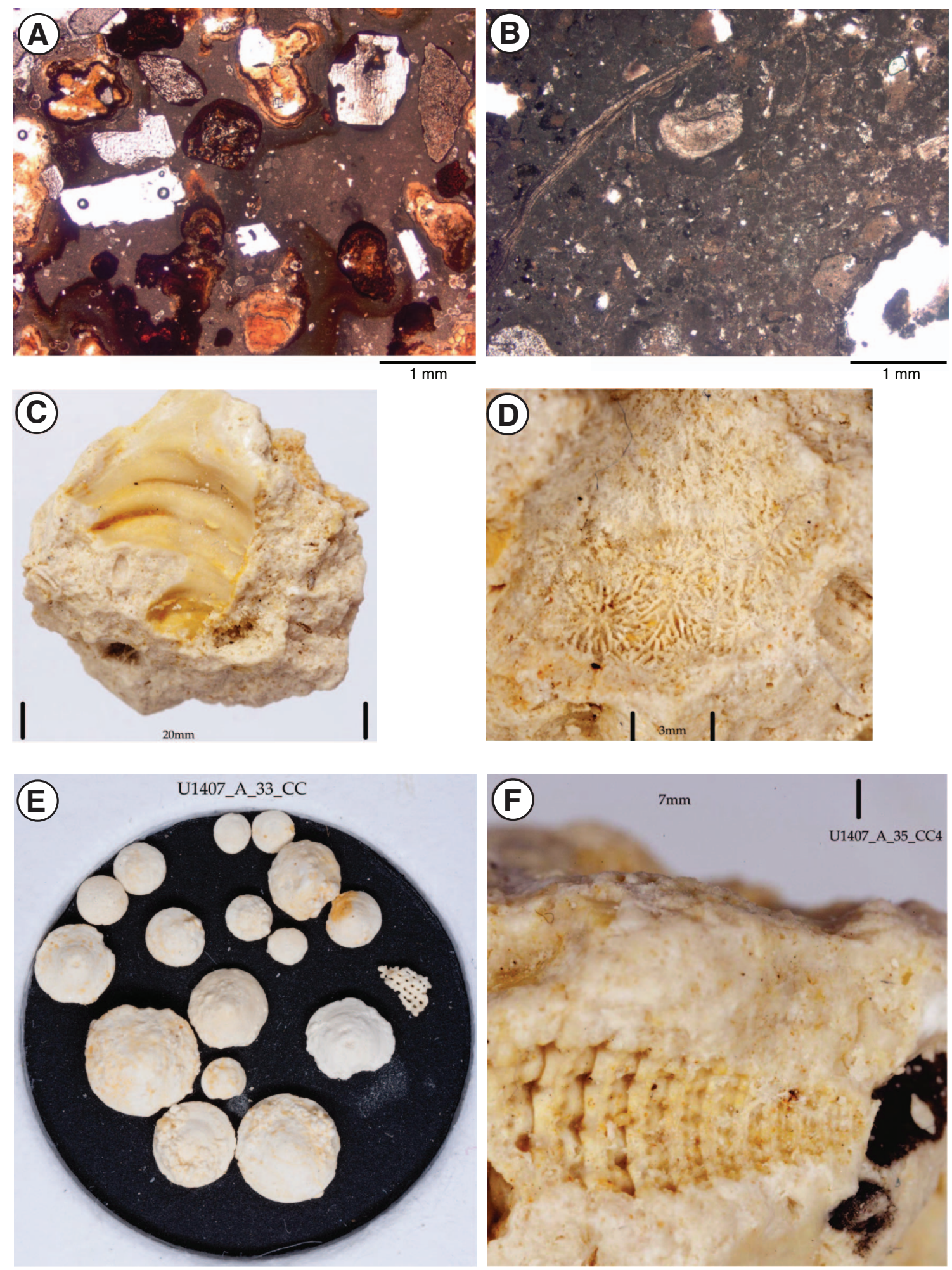
Figure F72. Motion Decoupled Hydraulic Delivery System (MDHDS) Deployment 2 pressure vs. time profile, Site U1402. The MDHDS was deployed at $745 \mathrm{~m}$ DRF. Time elapsed is from the moment the penetrometer is driven into the formation. As the latch releases on the MDHDS at 0 $\mathrm{s}$, the tip of the temperature-dual-pressure probe (T2P) is driven into the formation by its own mass (1); the T2P is driven farther into the formation as the MDHDS is pressured up a second time causing the tip and shaft pressure to spike from 0 to $60 \mathrm{~s}$ (2). Circulation pumps are then turned off (3), simultaneously causing a minor decrease in pressure and reducing measurement noise substantially at $60 \mathrm{~s}$. The pressure dissipates as expected with the exception of a brief increase in pressure (and acceleration) caused by the circulation pumps turning on momentarily at 2200 seconds (4).

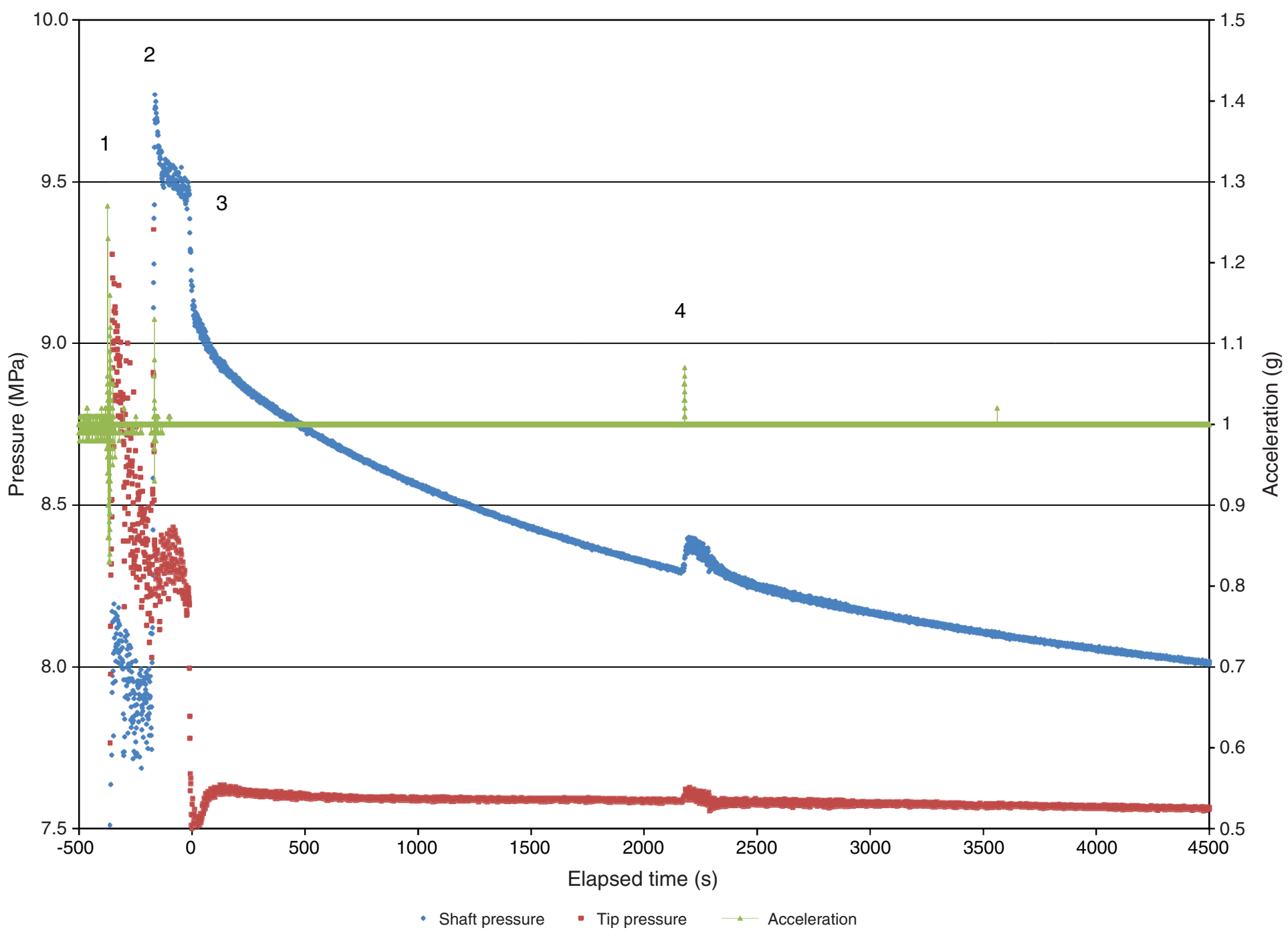


Figure F73. Predictions of in situ pore pressure from temperature-dual-pressure probe sensors as compared to the hydrostatic and lithostatic pressures, Expedition 342. Inset plot shows pressure in the shaft (blue line) and tip (red line) measured against inverse time. The intercept of these data is often used to estimate in situ pressure. The intercepts for the shaft and tip is 7.70 and $7.55 \mathrm{MPa}$, respectively. The main plot illustrates the estimated in situ pressure on a pressure depth plot. The in situ pressure is slightly above the hydrostatic pressure at this depth.

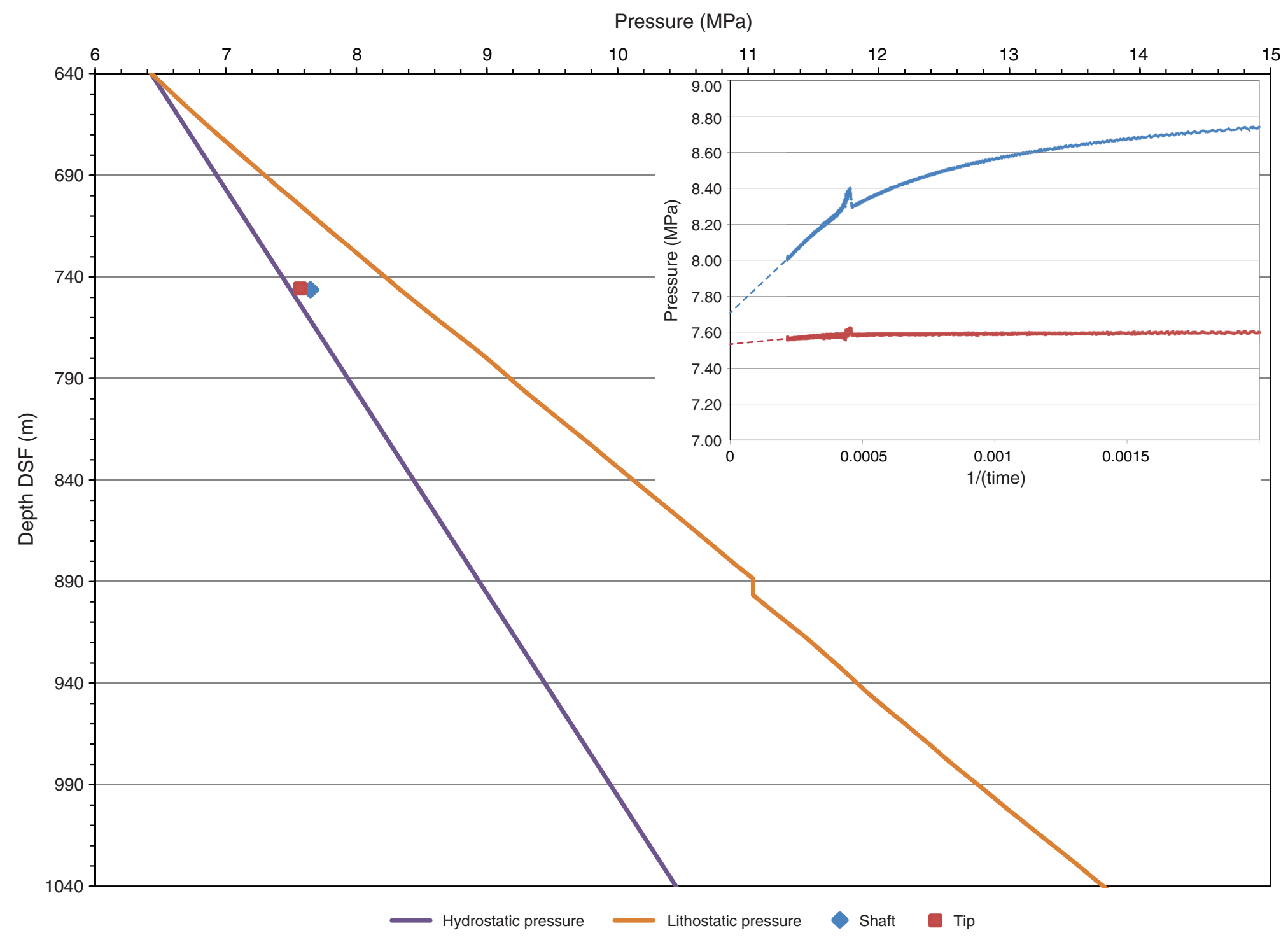


Table T1. General and site-specific lithostratigraphic units, Expedition 342.

\begin{tabular}{|c|c|c|c|c|c|c|c|c|c|c|}
\hline \multirow{2}{*}{$\begin{array}{c}\text { General } \\
\text { unit }\end{array}$} & \multirow[b]{2}{*}{ Description } & \multicolumn{9}{|c|}{ Site-specific unit/subunit } \\
\hline & & U1403 & U1404 & U1405 & U1406 & U1407 & U1408 & U1409 & U1410 & U1411 \\
\hline A & Pleistocene clay, foraminiferal ooze, ice-rafted debris & I & $\mathrm{I}$ & I & I & I & I & I, II & I & I \\
\hline B & early Miocene-Oligocene clay, silty clay (condensed) & II & Ila & & & ॥ & II & II & ॥ & \\
\hline $\mathrm{C}$ & Miocene-middle Eocene nannofossil clay, nannofossil ooze & III & IIlb, III, IV & II & $\mathrm{II}, \mathrm{III}$ & III & III & III, IVa & III & II, III \\
\hline $\mathrm{D}$ & early Eocene-Campanian nannofossil ooze/chalk, chert, biosiliceous ooze & $\mathrm{IV}, \mathrm{V}$ & & & IV & IV, Va & IV & $\mathrm{IVb}, \mathrm{IVc}$ & IV & \\
\hline $\mathrm{E}$ & Santonian-Albian nannofossil chalk, claystone & & & & & $\mathrm{Va}, \mathrm{Vb}$ & & & & \\
\hline $\mathrm{F}$ & Albian (or older) shallow-marine carbonate & & & & & $\mathrm{VI}$ & & & & \\
\hline
\end{tabular}

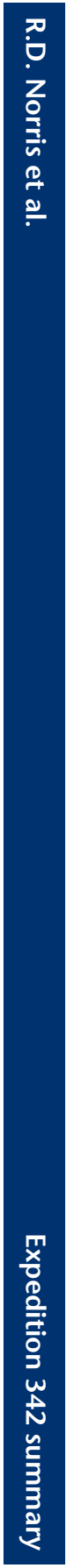


Table T2. Coring summary, Expedition 342.

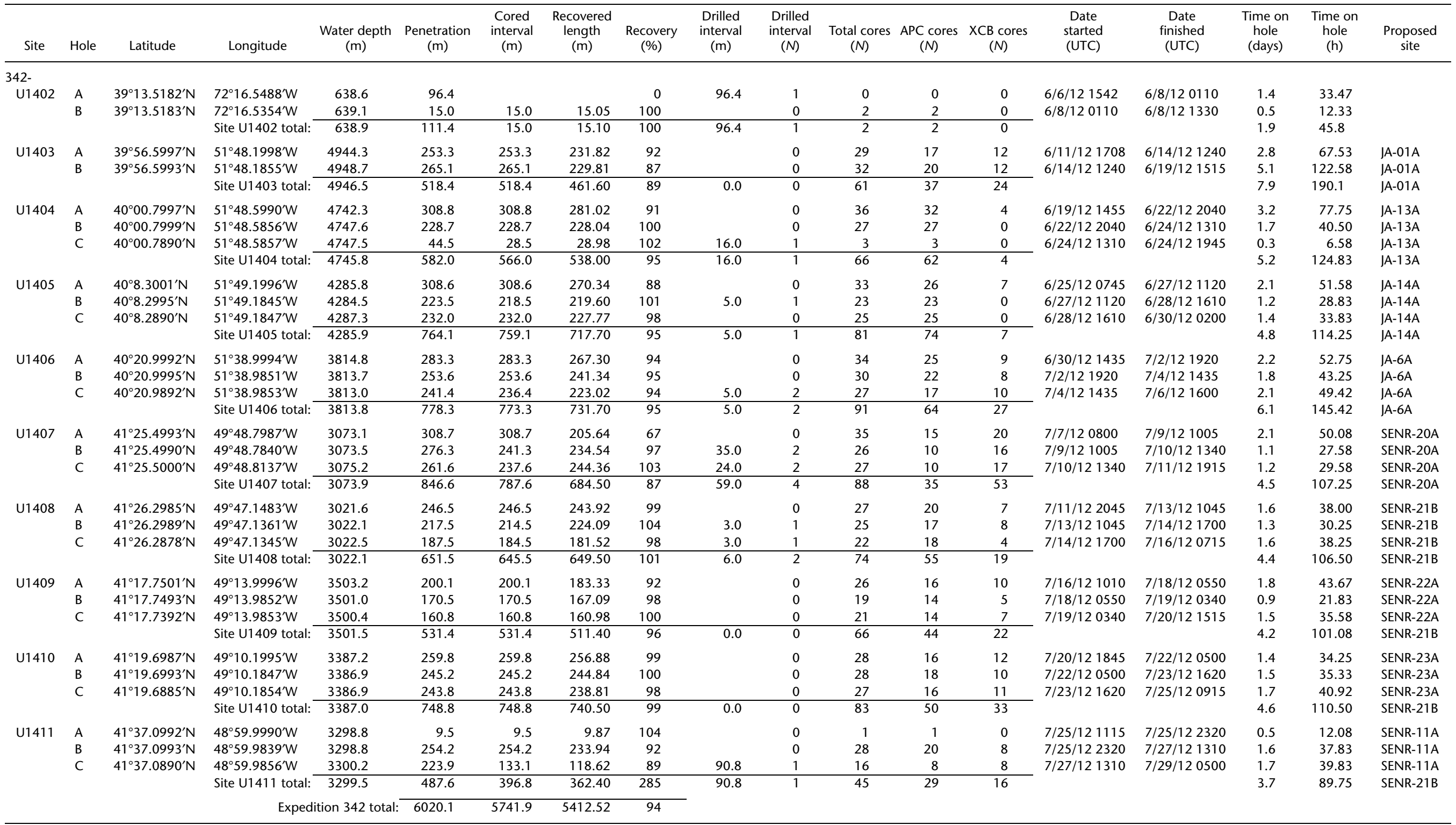

$\mathrm{APC}=$ advanced piston corer, $\mathrm{XCB}=$ extended core barrel. 